Florida International University FIU Digital Commons

$11-9-2012$

\title{
Not Getting By: Poverty Management and Homelessness in Miami
}

Karen M. Mahar

Florida International University, karenmahar@gmail.com

DOI: $10.25148 /$ etd.FI12120502

Follow this and additional works at: https://digitalcommons.fiu.edu/etd

\section{Recommended Citation}

Mahar, Karen M., "Not Getting By: Poverty Management and Homelessness in Miami" (2012). FIU Electronic Theses and Dissertations. 772.

https://digitalcommons.fiu.edu/etd/772

This work is brought to you for free and open access by the University Graduate School at FIU Digital Commons. It has been accepted for inclusion in FIU Electronic Theses and Dissertations by an authorized administrator of FIU Digital Commons. For more information, please contact dcc@fiu.edu. 


\title{
FLORIDA INTERNATIONAL UNIVERSITY
}

Miami, Florida

\section{NOT GETTING BY: \\ POVERTY MANAGEMENT AND HOMELESSNESS IN MIAMI}

\author{
A dissertation submitted in partial fulfillment of the \\ requirements for the degree of \\ DOCTOR OF PHILOSOPHY \\ in \\ COMPARATIVE SOCIOLOGY \\ by
}

Karen M. Mahar

2012 
To: Dean Kenneth G. Furton

College of Arts and Sciences

This dissertation, written by Karen M. Mahar, and entitled Not Getting By: Poverty Management and Homelessness in Miami, having been approved in respect to style and intellectual content, is referred to you for judgment.

We have read this dissertation and recommend that it be approved.

Guillermo Grenier

Matthew Marr

Patricia Price

James Wright

Alex Stepick, Major Professor

Date of Defense: November 9, 2012

The dissertation of Karen M. Mahar is approved.

Dean Kenneth G. Furton

College of Arts and Sciences

Dean Lakshmi N. Reddi

University Graduate School

Florida International University, 2012 


\section{DEDICATION}

I dedicate this dissertation to Paul R. Ahr, whose mentorship, wisdom and never ending encouragement started me on this journey, and whose constant support ensured I would see it through. 


\section{ACKNOWLEDGMENTS}

I am blessed to have had so many wonderful people provide help and support over the past several years. It has been an honor to work with the brilliant individuals who gave their time and wisdom to serve on my committee, including especially my advisor, Alex Stepick, who provided guidance no matter where in the world he was. And to my other committee members, Guillermo Grenier, Matthew Marr, Patricia Price, and James Wright, I owe a debt of gratitude for their feedback, insights, and encouragement.

I will forever be indebted to the Camillus House Board of Directors, and my boss and mentor, Paul R. Ahr, for creating the Camillus House Scholars Program and giving me the honor of being its first Fellow. They ensured that I would have the resources necessary to embark on this journey, and helped me at every step along the way. Everybody should get to work at such a wonderful place! I am also grateful to the incredibly dedicated and talented staff at Camillus House, nearly all of whom have lent a hand at some point. Special thanks are due to Lesly Borges and Clifford Homme for their unwavering commitment to helping me recruit the men who participated in the study, no matter how many times I asked for more, as well as to Kathy Garcia, Fred Mims, and Kenneth King. I know that I work with the best staff in the world, and give a special shout out to LeTania Severe for all of her help with the data and all those late night emails; to Eddie Gloria for coming along on so many interviews and translating hours of conversations; to Marti Yeager for doing whatever needed to be done; and to intern Karina Ruiz for transcribing all the interviews.

My study could never have been completed without the help of the many organizations working to end homelessness in Miami, including Citrus Health Network, 
Carrfour Supportive Housing, Chapman Partnership, the City of Miami Homeless Assistance Program, and the City of Miami Beach Office of Homelessness. While the staff at each of these agencies went above and beyond to recruit subjects and answer questions, I owe a special thanks to Carmen Gomez-Abreu, who never hesitated to help me find yet one more individual to interview. The staff at the Miami-Dade County Homeless Trust have also been a great source of assistance, and I am particularly grateful to David Raymond, who always took my calls and asked how he could help.

I cannot give enough thanks to the 55 men who shared their stories for this study, allowing me into their homes to take pictures and videos and ask personal questions. Their stories will stay with me forever, and I hope their willingness to share the intimate details of their lives will help make our world a better place.

Finally, I give special thanks to my best friend, Mikey Fitch, for putting up with all the ups and downs and giving me encouragement when I needed it most, and to my parents, who raised me to care about those who don't have as much as I do. 
ABSTRACT OF THE DISSERTATION

NOT GETTING BY: POVERTY MANAGEMENT AND HOMELESSNESS IN MIAMI

by

\author{
Karen M. Mahar \\ Florida International University, 2012 \\ Miami, Florida \\ Professor Alex Stepick, Major Professor
}

Urban inequality has emerged as one of the dominant themes of modern life and globalization. More than three million people experienced homelessness in the United States last year; in Miami-Dade, more than 15,000 individuals were homeless. Surviving extreme poverty, and exiting or avoiding homelessness, involves negotiating a complex mix of public and private assistance. However, a range of factors influence what types of help are available and how they can be accessed. Frequently, larger social structures determine which resource are available, leaving many choices entirely out of the individual's control. For single men, who are ineligible for many benefits, homelessness can be difficult to avoid and even harder to exit. My study seeks to better understand how adult, minority men living in extreme poverty in Miami-Dade negotiate their daily survival. Specific research questions address: Do black and Hispanic men who are homeless or at risk of homelessness have different personal characteristics and different experiences in avoiding or exiting homelessness? How does Miami’s response to extreme poverty/homelessness, including availability of public benefits and public and private service organizations, either maximize or constrain the choices available to this population? And, what is the actual experience of single, adult men who are homeless or 
at risk of homelessness, in negotiating their daily survival? A mixed methods approach combines quantitative survey data from 7,605 homeless men, with qualitative data from 54 semi-structured interviews incorporating the visual ethnography techniques of Photo Elicitation Interviewing. Results show the differences experienced by black and Hispanic men who are poor and homeless in Miami. Findings also highlight how the community's official and unofficial responses to homelessness intersect with the actual experiences of the persons targeted by the policies and programs, challenging pre-conceived notions regarding the lives of persons living in extreme poverty. It adds to the existing body of literature by focusing on the urban Miami context, emphasizing disparities amongst racial and ethnic groups. Findings are intended to provide an empirically grounded thesis that humanizes the subjects and illuminates their personal experiences, helping to inform public policy around the needs of extremely poor populations. 


\section{TABLE OF CONTENTS}

CHAPTER

PAGE

CHAPTER 1: BECOMING HOMELESS IN A MODERN WORLD ............................. 1

CHAPTER 2: LITERATURE ARGUMENT AND THEORETICAL PERSPECTIVE.... 8

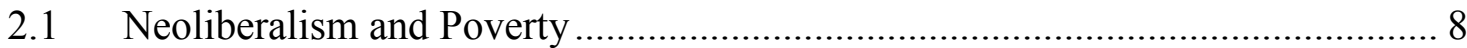

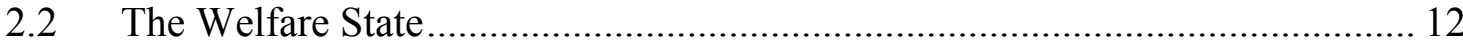

2.3 Poverty Management and Negotiating Poverty .............................................. 18

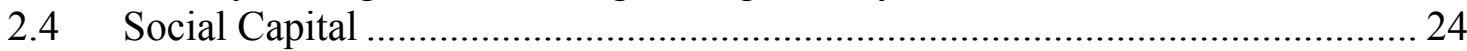

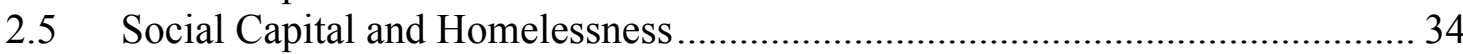

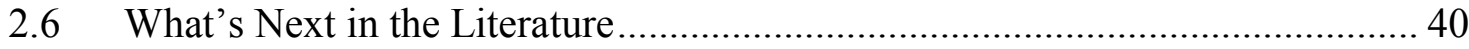

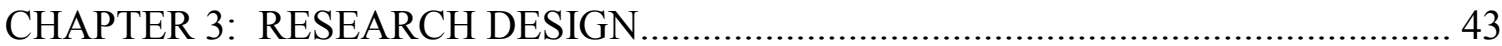

3.1 Operationalizing the Hypotheses ................................................................... 45

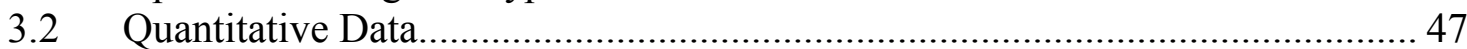

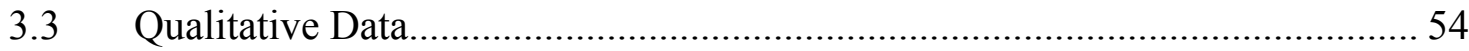

3.4 Examining the Homelessness Services Delivery System ............................. 71

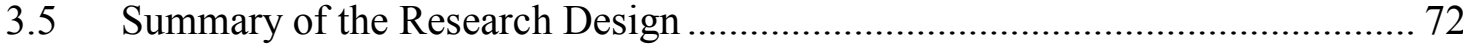

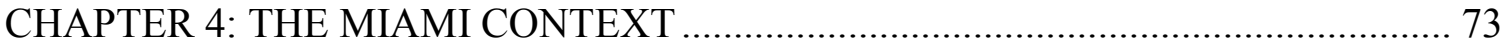

4.1 Poverty and Housing Trends in Miami ........................................................ 75

4.2 Welfare Benefits in Miami ......................................................................... 85

4.3 Miami's Response to Homelessness .................................................... 87

4.4 Establishment of Miami's Homelessness Services System .......................... 103

4.5 Summarizing the Response .................................................................. 105

CHAPTER 5: CONTEMPORARY HOMELESSNESS IN MIAMI ........................... 107

5.1 Overview of Miami-Dade Homeless Population .............................................. 108

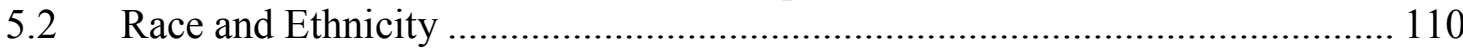

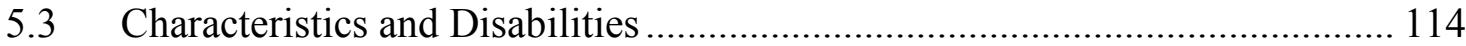

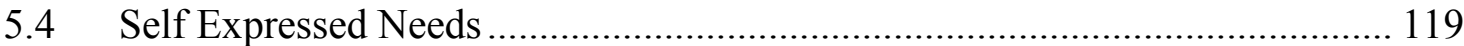

5.5 Spatial Distribution by Race/ Ethnicity................................................... 123

5.6 Program and Housing Outcomes................................................................ 137

CHATER 6: EARNED INCOME AND BENEFITS …............................................. 142

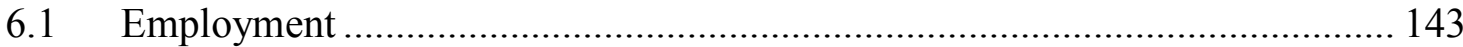

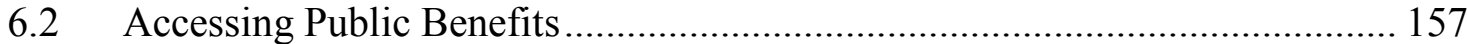

6.3 Health Care Benefits .............................................................................. 176

6.4 Food Security ............................................................................................ 187

6.5 Summary of Findings on Income and Benefits ........................................... 191

CHAPTER 7: SOCIAL CAPITAL AND PRIVATE RESOURCES ........................... 195

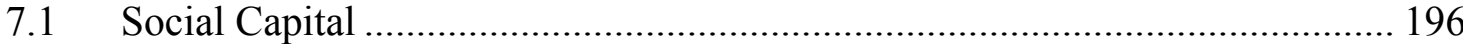

7.2 Private Agencies........................................................................................ 206 
7.3 Summary of Social Capital and Resources Findings .................................... 211

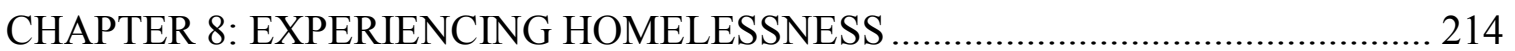

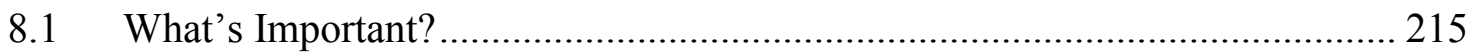

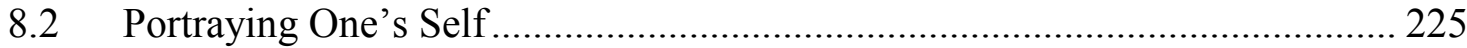

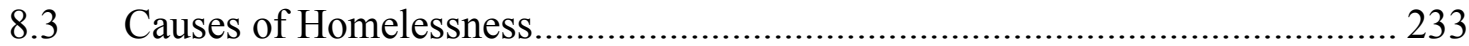

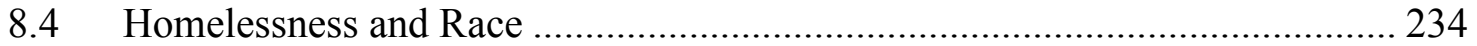

8.5 Summary of Findings on Perceptions ........................................................ 236

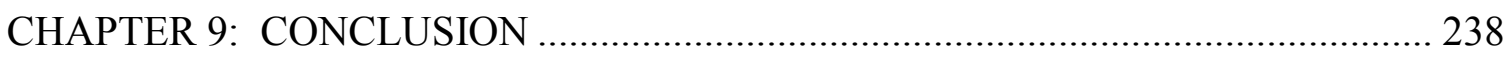

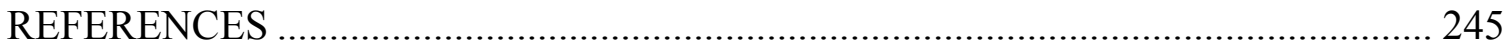

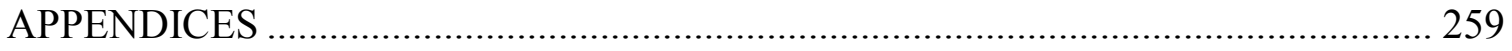

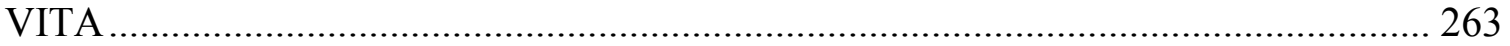




\section{LIST OF TABLES}

TABLE

PAGE

Table 1: Comparison of Race and Ethnicity in Data Sets.............................................. 52

Table 2: Repeat entries into homeless system for homeless males in Miami-Dade....... 109

Table 3: Racial/Ethnic Make Up of Miami-Dade Population Compared to Local and National Homeless Population ......................................................................... 112

Table 4: Age Distribution of Homeless Men in Miami-Dade ........................................ 114

Table 5: Veteran Status amongst Homeless Males in Miami, by Race/Ethnicity .......... 115

Table 6: Prevalence of Disabilties Amongst Miami-Dade Homeless Males, by

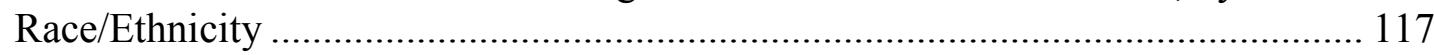

Table 7: Services Needs Expressed by Homeless Men in Miami-Dade.......................... 120

Table 8: Racial/Ethnic Make-Up of Homeless Males Served by Provider/Agency ....... 125

Table 9: Homeless Men's Destination Upon Exiting Emergency Shelter ....................... 138

Table 10: Homeless Men's Reasons for Leaving Programs in Miami-Dade ................... 140

Table 11: Earned Income Amongst Homeless Men in Miami-Dade.............................. 144

Table 12: Comments on Employment Opportunity for Criminal Backgrounds............. 152

Table 13: \% of Homeless Men Receiving Public Benefits in Miami-Dade, by Race/Ethnicity

Table 14: \% of Homeless and At-Risk Male Interviewees Receiving Benefits ............. 161

Table 15: Interview Comments Regarding SSI/SSDI Benefits ...................................... 167

Table 16: Photo Contents of Homeless Men Living on Streets.................................... 217

Table 17: Photo contents, Formerly Homeless Men........................................................ 218

Table 18: Photos Content, Men at Risk of Homelessness ........................................... 219

Table 19: Hispanic Interviewees Comments re Life on Street ...................................... 228

Table 20: Black Interviewees, Comments re Life on Street ......................................... 228

Table 21: Formerly Homeless Men, Comments re Fear of Going Back ........................ 231 
Table 22: Interviewees Comments re Homelessness and Race 


\section{LIST OF FIGURES}

FIGURE

PAGE

Figure 1: 2011 Unemployment Rates for Miami-Dade vs US, by Race/Ethnicity........... 78

Figure 2: (photo) Under the 395 overpass, downtown Miami........................................... 95

Figure 3: Racial/Ethnic Make-Up of Miami-Dade Homeless Population Compared to General Population 113

Figure 4: Disabilities Prevalence Amongst Homeless Men in Non-Permanent Housing Programs in Miami-Dade 118

Figure 5: Disability Prevalence Amongst Homeless Men in Permanent Housing Programs in Miami-Dade. 118

Figure 6: Expressed Needs for Healthcare, Drug/Alcohol Treatment and Mental Health Treatment 121

Figure 7: Expressed Needs for Jobs, Training, Education and Benefits 121

Figure 8: Racial/Ethnic Population Served by Agency, Over Census Tract Race/Ethnicity 126

Figure 9: Last Address of Homeless Men in Miami-Dade, by Race/Ethnicity ... 128

Figure 10: Addresses of Formerly Homeless / At-Risk Interviewees, by Race/Ethnicity 130

Figure 11: Addresses of Formerly Homeless / At-Risk Interviewees, by Race/Ethnicity (Neighborhood Close-Up) 131

Figure 12: (photo) Luis, in East Little Havana, in front of the stadium 134

Figure 13: (photo) Jimmy's view of the water .......................................................... 135

Figure 14: (photo) Larry and the two views of his apartment ......................................... 136

Figure 15: \% of Homeless Men Reporting Earned Income, by Race/Ethnicity ............ 145

Figure 16: (photo) Larry, selling coconuts on Ocean Drive ........................................... 147

Figure 17: (photo): Willie, panhandling in downtown Miami......................................... 148

Figure 18: \% of Homeless Interviewees with Criminal Backgrounds, by Race/Ethnicity 
Figure 19: Education Level of Homeless and At-Risk Interviewees

Figure 20: Andre, in private apartment living room

Figure 21: \% Homeless Men in Miami-Dade in Permanent Housing Receiving Public

Benefits, by Race/Ethnicity 160

Figure 22: \% Homeless Men in Miami-Dade in Emergency/ Transitional Program

Receiving Public Benefits, by Race/Ethnicity 160

Figure 23: \% of Homeless / At-Risk Males Receiving Benefits, within Race/Ethnicity

Figure 24: Disabilities Prevalence Amongst Homeless /At-Risk Male Interviewees .... 163

Figure 25: Jackie, with key to his own apartment in Wynwood.................................. 170

Figure 26: James, on sidewalk in front of Overtown apartment................................ 171

Figure 27: Photograph - Hector, inside apartment with fan..................................... 173

Figure 28: Jose, under bridge where he sleeps on Miami River ................................ 175

Figure 29: (Photo) Horacio, with the bills he manages to cover ................................ 179

Figure 30: (photo) James, in his efficiency with his walker ..................................... 179

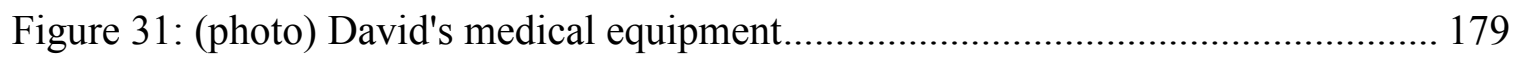

Figure 32: (Photo) Alberto, in apartment and with old business equipment ................ 181

Figure 33: (Photo) Steven, outside in park ........................................................... 183

Figure 34: (Photo) James, outside shelter with his cane and medical documents .......... 186

Figure 35: (photo) Jerome, on his couch after a day's work ........................................ 191

Figure 36: Access to Social Capital, by Race/Ethnicity ........................................... 197

Figure 37: (photo) Osvaldo, under Metro station in downtown Miami......................... 199

Figure 38: Access to Social Capital, by Housing Status.......................................... 200

Figure 39: (photo) Larry in his old neighborhood in Overtown ................................. 203

Figure 40: (photo) Paul cooking in his new kitchen .................................................. 204

Figure 41: (photo) Herman and his favorite agency staff member ............................. 206 
Figure 42: (photo) Overhang where Heriberto seeks shelter from rain

Figure 43: (photo) Jimmy in abandoned building and empty lot................................. 221

Figure 44: (photo) Richard, in one of many spots he's slept on the beach .................... 221

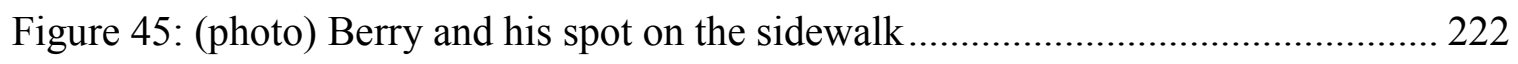

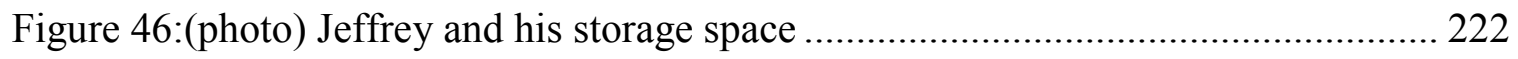

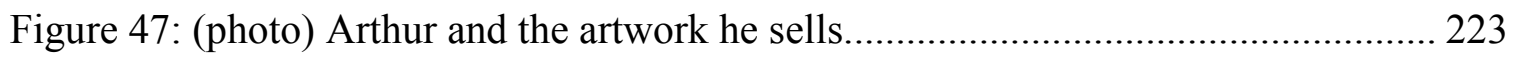

Figure 48:(photo) Jorge, in small bedroom with belongings .................................... 224

Figure 49: \% of Homeless/At-Risk Men Smiling in their Photos ............................... 226

Figure 50: \% of Homeless/At-Risk Men Smiling in Photos, by Housing Status .......... 227

Figure 51: (photo) Wilbur on downtown streets.................................................. 230

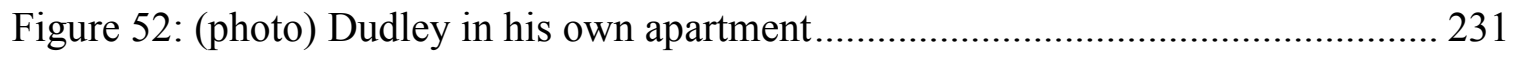

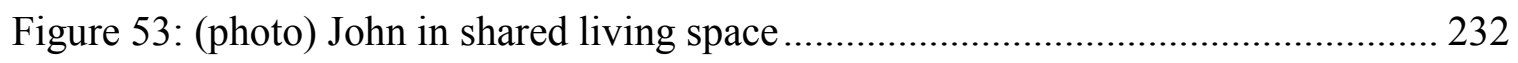

Figure 54: Interviewees Perceptions of Causes of Homelessness .............................. 234 


\section{LIST OF ABBREVIATIONS and ACRONYMS}

GIS: $\quad$ Geographic Information System

HMIS: Homelessness Management Information System

HUD: $\quad$ Housing and Urban Development

PEI: $\quad$ Photo Elicitation Interview

PIT: $\quad$ Point-in-Time (Survey)

SNAP: $\quad$ Supplemental Nutrition Assistance Program

SSI/SSDI: Social Security Income / Social Security Disability Income

TANF: $\quad$ Temporary Assistance to Needy Families 


\section{1: BECOMING HOMELESS IN A MODERN WORLD}

Urban inequality has emerged as one of the dominant themes of modern life and globalization. More than three million people in the United States experience homelessness each year (National Law Center on Poverty and Homelessness 2012); millions more go to bed housed, but unsure of how they will pay next month's rent or put food on the table. In Miami-Dade County alone, 15,077 unduplicated individuals were served by homelessness provider agencies in 2011, including 11,808 adults (Miami-Dade County Homeless Trust 2012b). A wide body of research has found the primary causes of homelessness to be chronic, extreme poverty and a lack of affordable housing (Burt, Aron, and Lee 2001; Hopper 2003; Koegel 2004; Wright 2009), and both of these problems are widespread in Miami-Dade.

Approximately $14 \%$ of the county's population lives in poverty with incomes below the federal poverty level; $7 \%$ live in extreme poverty with incomes below $50 \%$ of the poverty level, leaving a significant portion the county particularly vulnerable to economic and housing hardships (Ruggles et al. 2007). For these persons, staying out of homelessness involves negotiating a complex mix of potential safety net resources that includes public benefits, private assistance, community programs, and personal networks. The manner in which these resources are accessed and utilized is constrained by whether such resources exist actually exist in a specific community, the systems through which they are made available, and the individual's capacity to tap into them.

The implementation of neo-liberal policies in the United States has included massive welfare reforms, further privatization of health care, and defunding of community services, against a backdrop of widespread calls for the lowest-income 
persons to assume more personal responsibility for their lives (Burt and Smith Nightingale 2010; Fox Piven 2002; Newman and Massengill 2006; Wacquant 2009). One trend in responding to the persistence of poverty has been one of "poverty management" whereby the state attempts to provide poor populations with a minimal level of assistance to survive, but not exit, poverty (DeVerteuil 2006). Poverty management, which frequently includes bureaucratic agencies with cumbersome compliance requirements, strict eligibility criteria, and time restrictions, along with laws and regulations designed to manage and control how and where extremely poor and homeless persons are seen, is viewed by some as the state-sanction method for containing the problem of poverty without having to actually address it (DeVerteuil 2009; Harvey 2005; Wacquant 2008).

The intersection of poverty and homelessness is complex. Say the word "homeless" and most Americans picture that cadre of bedraggled people who sleep on the sidewalks and park benches, in the doorways and alleys, and in the bus stations and emergency shelters all across the country. It is an image that conjures both sympathy and distancing at the same time. Yet, homelessness has been, and continues to be, conceptualized with many different meanings. For some, homelessness is quite simply the condition of persons relegated to living on streets and other places not intended for human habitation. It is a physical and literal condition best addressed through efforts to get a specific group of people into housing. But homelessness can also be conceptualized within a much broader framework, as the most visible symptom of extreme poverty. In this view, people who are homeless are experiencing one of the harshest conditions of extreme poverty; they are not a distinct category of persons, but rather are members of the larger class of persons living in extreme poverty (Blau 1992; Hopper 2003; Liebow 
1993; Wright 2009; Wright 1997). Homelessness in this sense is far more difficult to address.

A number of homelessness scholars have described the association between the structural loss of housing and the personal loss of shelter as akin to a children's game of musical chairs, in which there are not enough chairs for all of the players (Hopper 2003; Koegel, Burnam, and Baumohl 1996; McChesney 1990). When the music stops, somebody will not have a seat. At first, the least physically adept players are the ones to drop out. By the end, more subtle tricks of timing and coordination decide the winners. For persons living in poverty in the United States, the chairs are housing units, and the losers are those least able to compete for jobs and housing. The problem is not that some players are less adept, but that there are not enough chairs.

Taking the musical chairs analogy a step farther, homelessness in the U.S. can be framed as a form of abeyance, with expendable people warehoused on the margins of society (Hopper 2003). With the demand for housing far exceeding the available supply, some people will be forced into homelessness and into the public shelter system-held in abeyance - for some time. Here again, homeless people are not a specific set of individuals with unique characteristics, but rather they are a subset of the marginalized who lost their access to housing. They are the ones held in abeyance, the ones without a chair when the music stopped. In Miami-Dade, an entire subpopulation of individuals is stuck inside this game of musical chairs, living in extreme poverty and moving in and out of homelessness over time, struggling to maintain a decent standard of living with some sort of stable housing. 
My dissertation explored the daily lived experience of adult, single men in extreme poverty in Miami-Dade County, within a larger context of neoliberal policy and poverty management. The experience of minority males differs from that of the rest of population, as evidenced by the wide disparities in the likelihood of blacks to become homeless. Blacks constitute $17.6 \%$ of the county's overall population and $29.7 \%$ of the population living in extreme poverty (US Census Bureau 2012), yet constitute $54.6 \%$ of the homeless population (Miami-Dade County Homeless Trust 2012b). On the other hand, Hispanics comprise nearly $60 \%$ of the county's overall population and $50.6 \%$ of those living in extreme poverty, but only $30 \%$ of the homeless population. Whites are $21 \%$ of the county population but only $15 \%$ of the homeless population. Thus, it is clear that the safety net for blacks in Miami is not functioning as well as it does for other racial and ethnic groups.

Specific research questions I will address are: (1) In Miami-Dade County, do black and Hispanic men who are homeless or at risk of homelessness have different personal characteristics and different experiences in avoiding and/or exiting homelessness? (2) How does Miami’s response to extreme poverty/homelessness, including availability of public benefits and the presence of public and private helping organizations, either maximize or constrain the choices available to this population? What is the experience of single, adult men living in extreme poverty in Miami-Dade, who are homeless or at risk of homelessness, in negotiating their daily survival?

To answer these questions I utilize a mixed methods approach incorporating quantitative and qualitative analysis, along with visual ethnography techniques. Statistical analysis of more than 7,500 records of homeless men served in Miami-Dade County over 
an 18-month period is used to provide a broad overview of the target population. Then, 54 semi-structured one-on-one interviews with black and Hispanic males explore the meaning and details behind the numbers. Finally, Photo Elicitation Interviewing (PEI) is utilized to incorporate the viewpoint of the subjects, bringing in their own perspective on what is important in their efforts to negotiate poverty and homelessness on a daily basis.

In the following chapter I will review the literature and provide the theoretical background for the rest of the dissertation. The trends associated with neoliberal policies will be traced down to local levels, examining the impact on housing and labor markets, along with welfare reform. I will also discuss responses to the negative side of neoliberalism, including poverty management, social capital, and the development of service delivery systems. In the third chapter I will discuss the research design and methods. The fourth chapter will examine how the trends and policies from the previous section have manifested in Miami, emphasizing effects on affordable housing, labor market, and welfare benefits. I will also review how Miami has responded to its contemporary problem of homelessness, beginning in the late 1980s through the present time. The fifth chapter looks at homelessness in Miami from a broad perspective, utilizing countywide data to explore how single, minority men move through the current homelessness services delivery system. The sixth chapter examines the issue from a more micro level, utilizing interview data to gain a better understanding of the experience of minority men in trying to attain income and benefits in order to avoid or exit homelessness. The seventh chapter utilizes the same interviews to further explore how the men utilize social capital and other private resources. The eight chapter focuses on the voice of the subjects themselves, highlighting their interviews and the photographs they 
choose to depict what it is like to experience poverty and homelessness in Miami. Throughout these chapters, I will focus on the similarities and differences between the experiences of blacks and Hispanics. Finally, in the conclusion, I will discuss the implications for public policy and how we perceive the effects of neoliberal policies that are created at a high levels, but manifested and felt at individual levels.

It is important to note that while I use the term "minority" to describe blacks and Hispanics, it is actually white non-Hispanics who are the minority group in Miami, while Hispanics are the majority population in Miami. I use the term minority throughout this study referring to their representation in the overall national population. In referring to blacks and Hispanics as minorities, I am interested in embedding this dissertation within the body of literature which incorporates race and ethnicity in the study of inequality. Thus, I categorize blacks and Hispanics as minorities in spite of their numerical representation within the local population, focusing instead on the socio-economic status, characteristics, and, importantly, access to resources and power that are shared with other minority groups at a national level.

The results from my study highlight how Miami-Dade's official and unofficial response to homelessness intersects with the daily lived experience of the persons targeted by the policies and programs. It is intended to help challenge pre-conceived notions regarding the lives of persons living in extreme poverty. Additionally, it adds to the existing body of literature regarding the intersection of public policy and efforts to avoid homelessness, focusing in particular on disparities amongst racial and ethnic groups in Miami. It examines how resources are accessed specifically within MiamiDade County and its systems for responding to homelessness, with implications for other 
globalizing, urban centers. The findings combining quantitative data, qualitative interview data, and visual ethnography provide empirical evidence while humanizing the subjects and illuminating their daily experiences, helping to inform public policy around the needs of extremely poor populations. 


\section{CHAPTER 2: LITERATURE ARGUMENT AND THEORETICAL PERSPECTIVE}

The emergence of homelessness in its contemporary form beginning in the late 1970s and early 1980s can be explained within a framework that takes a neo-Marxist and/or critical perspective toward the manifestation of neoliberal policies over the past several decades (Harvey 2005; Smith 1996; Wright 2009). The impact of neoliberal financial policies on labor and housing markets has been substantial, with devastating results for lower income populations. Millions of Americans have been made vulnerable to cycles of deprivation, living at daily risk of homelessness. At the same time, neoliberalism's emphasis on "personal responsibility" led to massive welfare reforms, including reductions of benefits, cuts for social services funding, and increased privatization of health care and services (Bowie, Stepick, and Stepick 2000; Fox Piven 2002; Goode and Maskovsky 2001; Morgen and Maskovsky 2003; Wolch and Dear 1993). These theoretical perspectives provide a backdrop for examining the implementation of neoliberal policies, while the large body of contemporary empirical research on poverty and homelessness provides substantial opportunity for analyzing the intersection of such policies with the daily, lived experienced of the urban poor and linkages to homelessness. Additionally, the literature can provide insights into the implications for black and Hispanic adult men, who must contend with exclusion from portions of the safety net coupled with the difficulties inherent with being members of racial and ethnic minority groups.

\subsection{Neoliberalism and Poverty}

In recent decades, "neoliberal" trends and policies associated with globalization have become the dominant philosophy in the U.S. and capitalist western world, aimed at 
creating the most advantageous environment for the continued expansion of capitalism (Agnew 2005; Ferguson 2006; Glyn 2006; Harvey 2005; Sassen 2006; Sklair 2001). For purposes here, I consider neoliberalism as a set of economic and political policies that seek to minimize the role of the state and to maximize the role of the private business sector. Neoliberal policies influencing financial, labor, and housing markets are intricately linked to local urbanization processes from both spatial and socio-economic perspectives, and the inequality perpetuated by macro forces at international levels is reproduced at micro levels in the urban centers across the U.S. Thus, one of the results of the adoption of neoliberal trends and policies over the past decades has been the entrenchment of class inequality and extreme poverty for an alarming segment of the population. These inequalities are seen in particular in the effects on housing and labor, as discussed below. The results are manifested in conditions of extreme poverty and homelessness.

The ideologies of deregulation, privatization, and reliance on free-markets led to the institutionalization of the belief in private markets' ability to meet the housing needs of persons at all income levels, ensuring provision of housing to everyone. Yet, in practice, a variety of factors converged to make housing increasingly unaffordable for many Americans. Inflation and increasing poverty put housing costs out of reach for many; affordable housing itself became more difficult to attain as a result of conditions that encouraged gentrification, speculation, and an emphasis on housing as a profit-driven investment; and national housing policies decreased funding and supports for low-income housing (Blau 1992; Hartman 2000; Koegel, Burnam, and Baumohl 1996; Lyon-Callo 2004; Timmer, Eitzen, and Talley 1994; Wright, Rubin, and Devine 1998). Put more 
simply, the cost of housing in the U.S. rose more quickly than incomes. From 1970 to 2000 , real income rose by $7 \%$ while the cost of a home rose by $28 \%$. For the poorest onefifth of households, real income decreased by $4 \%$, while rental costs rose $18 \%$ (Hartman 2000). By 2010, three fourths of Extremely Low Income renter households, defined as those with incomes at $30 \%$ or less than the Area Median Income, were spending the majority of their income on rent and utilities, leaving them with little money left for other necessities such as food, medicine, transportation, and childcare. These are the households that are most vulnerable to becoming homeless if their incomes go down or they have unexpected expenses (Bolton 2012).

Post-industrial developments transformed the U.S. labor market in 1960s and 70s. New global financial initiatives focused on controlling currency valuations and inflation and limiting budget deficits more than on lowering unemployment. Corporations led the charge to decrease government regulation and intervention, and to cut unemployment benefits, employee protections, and minimum wages (Blau 1992; Glyn 2006). Manufacturing began moving to countries with less expensive labor costs, leading to deindustrialization and closing of factories across the country. The Age of Fordism, where lower-skilled workers could still earn a decent living working through factory work with the support of unions, came to an end (Blau 1992; Glyn 2006). Cities transformed into centers of information processing, with an expansion of the servicesector economy. Thus, the demand for poorly educated labor declined substantially, driving lower-skilled workers, and particularly minorities, into low-wage service industry sector jobs (Blau 1992; Castells 2002; Hartman 2000; Kasarda 1993; Morgen and Maskovsky 2003; Susser 1996; Wilson 1996; Wolch and Dear 1993; Wright 2009). 
Neoliberalism's emphasis on individualism, personal responsibility, and deregulation, easily translated into a philosophy that stripped the state, and society, of its duty to provide for the welfare of its citizens. Neoliberal policies reinforce a conceptualization of individuals as rational economic actors, who are expected to preserve their own security and take responsibility for their own future. People and communities become "responsibilized," expected to assume responsibility for themselves and avoid reliance upon the state (Herbert and Brown 2006). Poor and marginalized populations are treated as derelicts and criminals, rather than as victims of larger economic forces, thereby downplaying the need for the state to provide welfare functions (Wright and Devine 1993).

A neoliberal perspective, however, is not new; it simply dovetails nicely with a long-held attitude towards the poor. For centuries, the societal response to poverty and homelessness has been guided by the idea of the "deserving" versus the "undeserving poor." Under this philosophy, individuals who are poor and/or homeless as a result of large-scale forces beyond their control are deemed worthy of assistance, but those struggling as a result of personal characteristics and/or their own actions are deemed unworthy (Morgen and Maskovsky 2003; Wright 1993). Societal attitudes in this regard were codified as far back as 1601 when England's Elizabethan Poor Law placed responsibility squarely on the individual by establishing work requirements for the ablebodied. Refusing to work was punishable by imprisonment. Adopting Poor Law philosophies, Americans made poverty and homelessness, along with the workhouses and shelters meant to address the problems, the province of welfare departments, rather than housing departments, thereby firmly establishing the phenomena as a social work 
problem to be fixed through individual counseling rather than with more housing. The belief that persons who were poor and/or homeless were in some way responsible for their predicament infused this response.

Good and Maskovsky's (2001) New Poverty Studies, a compilation of studies and essays from a wide range of scholars, examines what they describe as a new war against the poor accompanying the rise of the New Economy. Contesting conventional wisdom that poverty persists because of the pathology, social isolation and so-called welfare state "dependency" of the poor, they promote the role of neoliberal reforms in increasing inequality. They argue that this new poverty is the result of the intertwining of increased economic polarization, political demobilization, and market triumphalism, resulting in a "mode of governance, economy, and politics in which the poor are not so much vilified as they are marginalized or erased by the institutional and ideological aspects of work, social welfare, and politics that are dominant under neoliberalism" (Goode and Maskovsky 2001:10).

\subsection{The Welfare State}

\section{Role of the Welfare State}

Most industrialized nations are some form of a "welfare state," as they contain provisions for the state to play a central role in the delivery of services and benefits to meet basic needs, thereby helping to manage the risks faced by people over the course of their lives, including sickness, disability, job loss, and old age (Giddens 2001). The New Deal and Great Society initiatives put in place a range of social welfare programs and supports that had succeeded in raising millions of Americans out of poverty. However, within the U.S., the adoption of neoliberal principles beginning in the 1970s led to 
massive welfare reforms and a lessening of the social safety net, including reductions of benefits, cuts for social services funding, and privatization of health care and services (Bowie, Stepick, and Stepick 2000; Fox Piven 2002; Goode and Maskovsky 2001; Morgen and Maskovsky 2003; Wolch and Dear 1993). The following section explores the philosophies behind social welfare and the responsibility of the state versus the individual, along with its implementation in recent history.

The purpose of the welfare state can be examined within multiple frameworks. Marxists see welfare as necessary for sustaining the capitalist system. Functionalists see it as helping to integrate society in an orderly fashion under the conditions of advanced industrialism. As touched on above, neoliberals believe the role of the state should be limited to safeguarding the free market and providing a minimum level of security against poverty. The classic Keynesian argument views the welfare-state as an effective strategy for achieving long-term economic growth, avoiding capitalist boom-and-bust business cycles, and managing class antagonism. Building upon the Keynesian viewpoint regarding welfare's role in providing a stable base from which capitalism can flourish, Harvey (2005) describes it in the context of "embedded liberalism," a form of politicaleconomic organization where the market and corporate activities are surrounded by (embedded within) social and political constraints and a regulatory environment that could restrain capitalism but could also pave the way for an improved economic and industrial strategy. Capitalism is still embraced, but within a system that also looks out for the living standards of the citizenry. The Keynesian philosophy and concept of embedded liberalism worked well in the 1950s and 1960s. However, as described above, 
neoliberal reforms focused on disembedding capitalism from these constraints facilitated a receding of the social safety net.

Esping-Anderson's (1990) influential categorization of the forms of welfare states distinguishes three major types: a) the Social Democratic (or Marxist) model, which seeks to create a system of equality and socialism that also provides political power to working classes; b) the Conservative/Corporatist model, which sees a more authoritative state as most capable of meeting citizens' needs; and c) the Laissez-Faire Liberal (Neoliberal) model, which argues that only a free market will abolish class and inequality. In my dissertation, I address the Neoliberal model, which is the one that guides U.S. welfare policy. Esping-Anderson is particularly interested in the causal factors behind welfare-state development, suggesting three primary factors that determine how a specific welfare regime will develop: the nature of class mobilization, classpolitical coalition structures, and the historical legacy of regime institutionalization. He argues that in theorizing the welfare state, it is more important to focus on its functions and the integrations between public and private sectors, rather than on social programs themselves. In this framework, social stratification, de-commoditization of labor, and employment are keys to a welfare state's identity. In discussing the neoliberal model, he argues that while neoliberalism's proponents claim that only a free market will abolish inequality and that state intervention only strengthens issues of class, the reality is much different. Specifically, the neoliberal capitalist system has commoditized labor so strongly that it has become impossible for workers to survive outside of the market system. Esping-Anderson writes that they are thus stripped of one of their most basic 
social rights - the degree to which they are permitted to make a living independent of market forces:

It is as markets become universal and hegemonic that the welfare of individuals comes to depend entirely on the cash nexus. Stripping society of the institutional layers that guaranteed social reproduction outside the labor contract meant that people were commoditized. In turn, the introduction of modern social rights implies a loosening of pure commodity status. De-commoditization occurs when a service is rendered as a matter of right, and when a person can maintain a livelihood without reliance on the market. (P. 21)

Because the neoliberal regime is so reliant on market forces, the state does not want to intervene unless market or familial institutions fail. Social assistance is meanstested, and social welfare recipients are punished and stigmatized. Benefits tend to be small, as welfare as viewed as contributing to, rather than diminishing, poverty, unemployment and laziness. Esping-Anderson, writing in 1990 prior to major welfare reform in the US, was clearly quite prescient about what was to come. Indeed, these phenomena are manifested extensively in the lives of the homeless men interviewed in this study.

\section{Welfare Reform}

Much of the current era of welfare reforms was sparked during the 1976 presidential campaign of Ronald Reagan. A national debate about welfare programs was launched when, at campaign stops, Reagan began telling the story of the so-called "Chicago Welfare Queen:"

She has eighty names, thirty addresses, twelve Social Security cards and is collecting veteran's benefits on four non-existing deceased husbands. And she is collecting social security on her cards. She's got Medicaid, getting food stamps, and she is collecting welfare under each of her names. Her tax-free cash income is over $\$ 150,000$. (Quoted in New York Times 1976:51) 
Although journalists' fact checking found that the Welfare Queen as described did not actually exist, the public was outraged. Welfare reform took a prominent role in Reagan's campaign and administration, and stereotypes of poor, single women with children turned welfare recipients into scapegoats as the public searched for someone to blame for all of society's ills (Bowie, Stepick, and Stepick 2000; Wright 1993). A nationwide hegemonic discourse, which included a significant amount of literature from mainstream sources portraying welfare reform as positive, basically blamed the victim and largely dismissed the reality of welfare provision in the U.S. (Morgen and Maskovsky 2003). The anti-welfare mood of the county culminated with the Clinton administration's passage of the Personal Responsibility and Work Opportunity Reconciliation Act (PRWORA), commonly referred to as the current era of "welfare reform" (1996).

The welfare reform of PRWORA engendered a process of devolution, whereby responsibility for safety nets was passed down from the federal to state governments, and sometimes further down to local levels. The Aid to Families with Dependent Children (AFDC) program was replaced by a new program, Temporary Assistance to Needy Families (TANF). The TANF program defederalized public assistance, giving more control to state governments while also providing less funding. While a few states supplemented these reduced benefits, most did not; many created even stricter requirements than those imposed at the federal level. Changes to this most basic component of the social safety net were significant, with key points including mandating five-year maximum time limits for receiving cash assistance, establishing strict work requirements for recipients, and tightening eligibility criteria. 
Proponents of welfare reform point to the declining welfare roles as evidence of its success. Their reports tend to focus on indicators regarding the numbers of persons who left welfare, rather than the outcomes for those individuals who left welfare. The U.S. Department of Health and Human Services' 2008 Annual Report to Congress on welfare dependence declared that there were 2.59 million fewer Americans dependent on welfare in 2005 compared with 1996, without any mention of what became of those 2.59 million households (Crouse, Hauan, and Waters Rogers 2008). The report also highlighted that the percentage of individuals receiving TANF case assistance fell from 5.4 percent to 1.6 percent between 1993 and 2006, with the average lengths of spells receiving TANF also seeing significant declines. Again, the report did not go into any detail regarding the fact that lengths of time on TANF would have to be reduced given the legislated time-limits, even when families would be left in poverty without it.

A more in-depth analysis reveals that people left the welfare rolls but did not leave poverty (Danziger 2010; Morgen and Maskovsky 2003). In some cases, families simply timed out of their eligibility periods. In other cases, the new welfare rules were so complicated and punitive that many struggling families could no longer get the help they needed. With PRWORA came the establishment of bureaucratic institutions which offer assistance coupled with complex paperwork, time, and compliance requirements that necessitate an extraordinary effort on the part of recipients. Food stamps are cut when a form is misfiled; Section 8 rental assistance is retracted when an appointment is missed, sending the recipient back to waiting lists five years plus long. The determination of who qualifies for Medicaid, housing subsidies, food stamps and other benefits is driven by social constructions of need and an underlying discourse built upon the concept of the 
deserving versus undeserving poor. In most parts of the country poor, unemployed individuals not raising minor children are no longer eligible for any cash assistance outside of unemployment benefits, limited one-time rental assistance, or, if they qualify, social security disability (Fox Piven 2002). The result is that vast numbers of lowincome, struggling individuals who would otherwise be considered eligible for (and “worthy of”) public assistance are denied help due through purely bureaucratic means.

\subsection{Poverty Management and Negotiating Poverty}

\section{Poverty Management}

Today's public policies have now come to resemble a perspective of "poverty management." Poverty management represents the organized responses by elites and/or the state to contain potentially disruptive populations through a managerial and somewhat ambivalent response, rather than the narrower revanchism framework (DeVerteuil 2009) employed by some. DeVerteuil (2006) points to the existence and continued expansion of homeless shelters and social services agencies, supported by private and public agencies alike, as evidence of a societal response to homelessness that does not fit into neat anti-neoliberal framework blaming globalization for homelessness. The poverty management viewpoint is far more nuanced than Smith's (1996) "revanchist city," where gentrification is used as a weapon of revenge against the poor who are blamed for society's ills, and Mitchell's (2003) “post-justice city," where cities attempt to end homelessness by annihilating the poor and homeless from public space. The geographies of homelessness in today's urban centers are increasingly varied and complex, with the experience of homelessness greatly influenced by the presence and actions of local authorities, governmental bodies, community leaders, and local residents. Numerous 
studies have documented that a particularly important factor in determining the success of services for poor and homeless populations is the presence of well-connected social service agencies (Small, Jacobs, and Massengill 2008; Small 2009; Wolch and Dear 1993).

An important component of poverty management is the role of the state in creating bureaucratic systems and in determining who is poor, who is homeless, and who qualifies for assistance (Newman and Massengill 2006). The categorization of individuals who are homeless into specific, carefully designed subgroups is an important element of poverty management policies. To begin with, homelessness is not easy to define. In some definitions it is simply the condition of persons relegated to living on streets and other places not intended for human habitation. That makes it a physical and literal condition best addressed through efforts to get a specific group of people into housing. But homelessness can also be conceptualized within a much broader framework, as the most visible symptom of extreme poverty. In this view, people who are homeless are experiencing one of the harshest conditions of extreme poverty; they are not a distinct category of persons, but rather are members of the larger class of persons living in extreme poverty (Blau 1992; Hopper 2003; Liebow 1993; Wright 2009; Wright 1997). The vast number of households struggling with extreme poverty is a much less manageable problem than persons living on streets. Thus, the narrow defining of who qualifies for services is an important component of poverty management. Negotiating Poverty

The daily lived experience of households living at or below the poverty level is typically a far cry from the hegemonic view portrayed in the media and by politicians of a 
class of people characterized by laziness and dependency on the state. Bowie, Stepick and Stepick (2000) examined the disconnect between the negative stereotypes of poor, single women with children that provided the impetus for welfare reform and the actual lived experiences of 20 welfare-reliant women in Miami struggling with the transitions under PRWORA. They found that the women in their study aspired to gain independence and achieve the American dream, just as the rest of mainstream society, even while they were trapped into cycles of poverty and deprivation, writing that, "There seems to be a chasm of biblical proportions between the theory and spirit of welfare reform, and the practical, day-to-day realistic opportunities for these women to overcome the obstacles to real self-sufficiency" (p. 48).

One of the most consistent and basic findings of researchers studying poverty and welfare has been the failure of low-wage employment as a strategy to escape poverty or attain self-sufficiency (Newman and Massengill 2006). Entry level jobs where persons with low educational and training credentials can gain employment are typically lowwage, part-time, and/or short-term. The costs for exiting welfare into the job market can be substantial for poor, single parent families who must now cover transportation, child care, and other costs that can exceed whatever increase in income was achieved by going to work. Journalist Barbara Ehrenreich brought renewed attention to the extreme difficulties of surviving on low-wage jobs in her influential book Nickel and Dimed: On Not Getting By in America (2001). Ehrenreich spent a full year working in low-wage jobs, as a waitress, maid, nursing home aide, and Wal-Mart employee. She found that the jobs themselves were both mentally and physically exhausting, and that none were truly "low-skilled." She worked in multiple cities, and would not have been able to survive 
working just 40 hours a week in any of them. No matter how hard she worked, wages were simply too low for the high costs of housing. While she was, of course, able to move on at the end of her field research, the low-wage workers with whom she had worked side-by-side did not seem likely to escape their circumstances, because of a lack of information, opportunities, contacts, and supports. Ehrenreich was particularly concerned with the fraying of the social contract that promised a decent standard of living to anyone willing to work for it:

But when we have full or nearly full employment, when jobs are available to any job seeker who can get to them, then the problem goes deeper and begins to cut into that web of expectations that make up the "social contract." According to a recent poll conducted by Jobs for the Future, a Boston-based employment research firm, 94 percent of Americans agree that "people who work full-time should be able to earn enough to keep their families out of poverty." I grew up hearing over and over, to the point of tedium, that "hard work" was the secret of success: "Work hard and you'll get ahead" or "It's hard work that got us where we are." No one ever said that you could work hard - harder than you ever thought possible - and still find yourself sinking deeper into poverty and debt. (P. 220)

While low-wage jobs have been shown to have little impact on lifting people out of poverty, it is even more difficult to survive solely on welfare benefits. In a landmark study, Edin and Lein (1997) interviewed 379 low-income female-headed families in four cities, with approximately half of the sample relying on welfare benefits and half deriving their primary income from employment. They found that for the families reliant on welfare, approximately $3 / 5$ of their monthly expenses were covered through public assistance, compared to $2 / 3$ being covered by income for working mothers. None of the four cities provided enough welfare benefits to cover basic monthly expenses, so all but one of the 379 mothers were supplementing their income with other strategies, including work in the formal, informal or underground economy, cash assistance from family or 
friends, and donations from charities or other agencies. However, they also noted significant variations in the amount of assistance provided from city to city, with the differences having large, material effects on how much hardship was experienced depending on where they lived. Other researchers have similarly documented the inadequacy of welfare supports for meeting basic family needs (Bowie, Stepick, and Stepick 2000; Burt and Smith Nightingale 2010; Morgen and Maskovsky 2003).

Much of this literature discussed in the previous paragraphs has focused on women and families, rather than single men, leaving opportunity for new research in this area. While the men interviewed for this study express experiencing many of the same issues described in literature on welfare reform and the lived experience of poverty, including difficulty finding adequate employment and reduced eligibility for public benefits, they are frequently overlooked in favor of research focused on women and children.

\section{Socio-Spatial Effects}

Socio-spatial factors also play an important role in affecting how one negotiates daily survival while struggling with extreme poverty. A plethora of "neighborhood effects" literature examines how growing up and living in neighborhoods characterized by extreme poverty, crime, and poor educational attainment influences life outcomes and opportunities for residents (Barnes 2005; Newman and Massengill 2006; Small, Jacobs, and Massengill 2008). As poverty develops in neighborhoods, it can become entrenched for generations, with many people not able to make it out. Growing up in poverty influences a person's ability to achieve positive outcomes later in life, even if they are able to move out to a better neighborhood (Sampson 2008). 
The effect of being poor is compounded by having to live in poor urban areas. Research shows that the presence or lack of resources and assets in poor communities influences the ability of residents to improve the quality of their lives (Moser 1998; Saergert, Thompson, and Warren 2001; Wolch and Dear 1993). Living in poor neighborhoods provides less access to opportunities to gain income from informal and unreported work, and persons living in poor neighborhoods report receiving less cashassistance from family and friends (Edin and Lein 1997; Wacquant and Wilson 1989). Additionally, the cost differential for living expenses is significant based upon where people can afford to live. Studies have found that grocery prices were most expensive in poor, urban centers, growing less and less expensive as one travels outward toward white suburbs (Barnes 2005). Without a car, living in neighborhoods located away from jobs requires using public transportation to get to and from work, adding hours of commuting time onto already long days and leaving children longer in day care. A bus that is late too often can lead to probation or even firing from a job. Daily occurrences that can be mere inconveniences for persons with the means to deal with them become major emergencies for persons with few resources. Indeed, it would appear that simply living in a poor neighborhood exacerbates the existing difficulties of struggling with poverty, making it even harder to transition into the middle class.

While the root causes of homelessness are largely traced back to the larger societal forces discussed above, the individual experience of poverty and homelessness is examined through other frameworks. For individuals who are made vulnerable to becoming homelessness through a range of social forces beyond their control, it is often individual access to safety net supports that can make the difference in staying housed 
versus becoming homeless. In the following section I discuss the important role of social capital in mitigating the effects of poverty and homelessness.

\subsection{Social Capital}

Research shows that social capital in particular can help mitigate, or in some cases contribute to, homelessness. The term "social capital" itself has been used quite broadly to refer to anything from social networks to the level of trust in an entire community. However, for purposes here, I start with Bourdieu's (1986) definition:

Social capital is the aggregate of the actual or potential resources which are linked to possession of a durable network of more or less institutionalized relationships of mutual acquaintance and recognition or in other words, to membership in a group - which provides each of its members with the backing of the collectivity-owned capital, a "credential" which entitles them to credit, in the various senses of the word. (P. 248)

For persons who do become homeless, social capital can affect one's ability to transition back into a stable and housed living situation (Bassuk and Rosenberg 1988; Bassuk et al. 1997; Eyrich, Pollio, and North 2003; Hawkins and Abrams 2007; Hopper 2003; Irwin et al. 2008; National Health Care for the Homeless Council 2003; Rossi 1989; Shinn, Knickman, and Weitzman 1991; Wright 2009; Zugazaga 2008). Most people who find themselves near homelessness can turn to family and friends for help. In general, though, for a variety of reasons, homeless people lack this resource (Wright, Rubin, and Devine 1998). As Wright notes, "In a very deep sense, to be homeless is to be without family or friends that can be relied upon in times of crisis or need," (2009:87). Whether it is cash assistance, help with groceries, shared child care, a job referral, a couch to stay on, or intangible supports of friendship, guidance, and moral support, temporary or ongoing assistance can be the last line of defense to keep people out of 
homelessness. One of the major differentiating characteristics between low-income persons who are housed and versus those who are homeless is the lack of a supportive social network (Bassuk et al. 1997; Rossi 1989; Wood et al. 1990; Wright 2009).

Social capital does much more than serve as a buffer between poverty and homelessness, though. It plays a central role in helping persons attain access to resources that could actually lift them out of poverty and facilitate social mobility. It also plays an important role in social and economic stratification, and has implications for how individuals can, or cannot, exercise agency and attain or utilize power in their day-to-day lives. In this section I will provide a brief overview of social capital theories, including its application to poverty and homelessness.

\section{Social Capital Theory:}

While the term social capital first came into vogue in the 1970s, the idea that social relationships and community integration are integral to sociological understanding is not new. Durkheim, Marx, Simmel, and Weber all acknowledged the power of social relations and group life in one way or another. "In this sense, the term social capital simply recaptures an insight present since the very beginning of the discipline," (Portes 1998:2). Bourdieu was one of the first scholars to discuss social capital in its contemporary usage (Bourdieu 1977; Bourdieu 1986). Defining capital as “....accumulated labor (in its materialized form or its 'incorporated," embodied form) which, when appropriated on a private, i.e. exclusive, basis by agents or groups of agents, enable them to appropriate social energy in the form of reified or living labor," (1986:241), Bourdieu focuses on three specific forms which capital can take: economic, cultural, and social. His argument that capital can take forms outside of the usual 
economic form, and that capital is fungible, was particularly instructive in the development of current theories of social capital.

While Bordieu had laid the foundation for social capital as a sociological framework, it was James Coleman writing in the 1980s who brought the concept into the mainstream. His examination of social capital is driven in large part by his interest in incorporating elements of rational choice theory while also introducing social structure into the rational action paradigm $(1988 ; 1990)$. He uses social capital as a conceptual tool for combining both components of the two primary streams of thought on actors: 1) the sociological viewpoint that the actor is socialized and action governed by norms, rules, and obligations, and 2) the neo-classical economic viewpoint that the actor has wholly self-interested goals independently arrived at, with a focus on maximizing utility. Coleman (1988) defines social capital by its function:

It is not a single entity but a variety of different entities, with two elements in common: they all consist of some aspect of social structures, and they facilitate certain actions of actors-whether persons or corporate actors-within the structure. Like other forms of capital, social capital is productive, making possible the achievement of certain ends that in its absence would not be possible. Like physical capital and human capital, social capital is not completely fungible but may be specific to certain activities. A given form of social capital that is valuable in facilitating certain actions may be useless or even harmful for others. (P. 98)

Coleman's conceptualization, like Bourdieu's, is concerned with power. He describes social capital in a context that is focused on the degree of control one has over events in which one has an interest, but in which another subject has direct or indirect control, mediated by a wider circle of relations. It is this beneficial network of relationships that can be converted into economic capital. He gives the example of wholesale diamond markets, where merchants are able to freely pass extremely valuable 
diamonds back and forth without insurance or formal agreements, because of the personal relationships and trust developed amongst themselves. Of particular relevance to studies of poverty is how he theorized social capital in a way that illuminated the processes and experiences of non-elite groups, arguing that those living in marginalized communities or who were members of the working class could also benefit from its possession.

Economist Glenn Loury (1977) is another pioneer in using the idea of social capital, having incorporated the term into his critique of neo-classical theories of racial income inequality. Coming from an economic viewpoint, he argued that racial disparities would not be reduced by affirmative action programs, because blacks still lacked the social capital necessary to succeed in the labor market. Specifically, the poverty inherited from poor parents limits a child's access and opportunities, resulting in poor connections to employment opportunities.

The policy recommendations Loury derived from his conclusions regarding the responsibility for addressing poverty were quite controversial. On the one hand, he argued that the legacy of slavery and historical discrimination had engendered the current situation where blacks lacked social capital necessary to succeed. On the other hand, he also argued that the remedy was not affirmative action, but rather was for the black community to confront its own problems of drug use, out-of-wedlock childbirths, and violence rampant in the inner cities. He posited that with racism embedded within the fabric of society, it was up to the black community to address the "enemy within." His conservative viewpoint was not popular with more liberal sociologists and activists, or within much of the black community. Loury did not deny the importance of social capital and its central role in perpetuating racial income inequality; his differences with other 
scholars in the field fell mainly within the conclusions he drew regarding who was responsible for addressing the inequality. However, his work in applying an economic analysis to the benefits of membership in a group, and the ramifications of inherited social stratification, furthered the development of social capital as a theoretical tool. Policy arguments aside, his work makes an important contribution to examining poverty and homelessness by focusing on how social capital interacts with class stratification and inequality.

\section{Strong Ties and Weak Ties}

The relationship between social capital, social networks, and access to employment is a central theme in the literature, and provides one of the clearest connections between social capital as an abstract theory and its usefulness in explaining some reasons for entrenched poverty and risk of homelessness. Mark Granovetter's (1973) seminal economic sociology work on social networks and information channels made a significant contribution through his idea of "strong" versus "weak" ties. The strength of a tie is a combination of the amount of time, the emotional intensity, the intimacy (mutual confiding), and reciprocal services which characterize the tie. A new emphasis on weak ties, or those with persons outside of one's close network, would offer an avenue for examining how relations between groups could facilitate greater mobility and opportunity. Weak ties serve as "bridges" to other networks, proving invaluable in widening ones circle and knowledge base. Lin, Walter, and Vaughn (1981) found that job seekers' use of weak ties, along with personal resources including family background, educational, and occupational achievement, has a significant effect on their ability to 
reach a contact of high status. Additionally, the contact's status has a strong and direct effect on the prestige of the attained job.

The importance of weak ties in economic mobility has been shown to vary in importance with some subpopulations. Portes and Zhou (1992) studied the role of social capital in recent immigrant communities, finding that social capital was instrumental in improving the economic mobility for some immigrant and minority groups, including in particular those living in ethnic enclave neighborhoods. However, the social capital attributes that facilitated economic mobility were the establishment of a bounded solidarity within the group, along with enforceable trust. Thus, it was not weak ties to outsiders that promoted economic mobility, but rather strong inter-group support and ties that made group members successful. They also noted that one of the contributing factors to successful entrepreneurship was close proximity to another minority group that lacked a strong entrepreneurial presence, thereby providing an opportunity for fulfilling an unmet need or niche. I discuss additional literature exploring the nuances of weak ties in minority populations in the next section regarding community social capital.

Woolcock (2001) suggests that the range of outcomes that can be attributed to social capital are comprised of different combinations of three dimensions of social capital: bonding, bridging, and linking. Bonding social capital (i.e., strong ties) are the ties between people in similar situations, such as immediate family, close friends, and neighbors; Bridging social capital (weak ties) encompasses more distant ties of like persons, such as loose friendships and workmates; and linking social capital reaches out to unlike people in dissimilar situations, enabling members to leverage a far wider range of resources than are available in the community (Woolcock 2001). 


\section{Negative Social Capital}

Much of the literature reviewed thus far has suggested that social capital in some way stands for the ability of actors to secure benefits by virtue of membership in social networks and structures. However, it should also be noted that social capital can bring negative consequences. Portes (1998) describes four categories of negative consequences:

1) the exclusion of outsiders; 2) excess claims on group members (for example, a successful business in a high-solidarity community may generate free-riders); 3) restrictions on individual freedoms in the name of community solidarity; and 4) downward leveling norms. Social capital has both benefits and costs, and groups can possess too much or too little in terms of the amount required for optimal economic exchange (Woolcock 2001). Additionally, sources of social capital can change over time. The potential negative consequences of social capital are particularly relevant in studies of poverty and homelessness, both from an individual and community level. Strong ties and requirements of reciprocity with problematic family members can have dire consequences for ability to escape poverty, as individuals trying to meet family expectations can end up giving time, money, and emotional support to persons with drug histories or criminal backgrounds. To a lesser degree, persons living in poverty may be unable to save money because they are responsible for helping their equally poor relatives. The effect of norms, expectations, and emotional support can also play a big role in preventing persons who are homeless from exiting poverty, as they become accustomed to life on the streets and do not want to leave their peer network. 


\section{Community Social Capital}

Scholars have also examined social capital at community level, equating it in a sense with "civic virtue." Most prominent in this arena is Robert Putnam, whose Bowling Alone: The Collapse and Revival of American Community (2000) brought the idea of social capital as a community trait to the attention of mainstream media. Putnam (2000) expanded on the ideas of bridging and bonding capital, arguing that bridging capital, where individuals form relationships with persons different from themselves, is essential for creating peaceful, democratic societies in a diverse and multi-ethnic country. He argues that civic life in the U.S. is in decline, with serious negative consequences, and that such decline is tied to decreases in levels of both bonding and bridging capital. Critics of Putnam (Fischer 2010; Portes 1998; Skocpol 2003) have suggested that his theorization is tautological, and questioned his definition of civic virtue and his units of measurement, suggesting that perhaps social connections have not declined nearly as much as he posits. In spite of the criticism, however, Putnam's work in embedding social capital as a community trait has generated a raft of research refining his concept, and in particular applying it to attempts to strengthen communities and alleviate poverty in neighborhoods and even entire developing countries.

Carol Stack's landmark ethnography on a poor, African-American neighborhood, All Our Kin (1974) provided one of the earliest sociological examinations of the functioning of social networks in poor communities. Stack spent three years in 1968 living with her subjects, studying the support systems formed by family and friends when coping with poverty. She found that contrary to popular belief, the families she studied were not unstable or disorganized, but rather formed strong, complex, life-long support 
networks that allowed them to survive by sharing both in-kind and cash resources.

Subsequent research has presented similar findings regarding the strength and importance of social support systems for poor families (Edin and Lein 1997; Malson 1983; Shinn, Knickman, and Weitzman 1991). Participation in mutual aid systems includes shared child care, economic assistance including monetary and domestic living arrangements, and psychological well being. In Malson's (1983) review of literature on black family support systems, he asserts that, "The most important function of social-support systems may be to provide someone to rely on, to listen and offer advice about problems and concerns," (p. 46).

Stack, however, also noted the negative consequences associated with networks based on obligation, reciprocity, and gratitude. In particular, kinship obligations frequently hindered the ability of women to move out of the neighborhood. Others have noted that poverty itself is a severe stressor with significant implications regarding potential sources of support. Belle (1983) notes that:

While the positive impact of supportive social ties has thus been well documented, there is also evidence that not all social ties provide social support. Furthermore, there are often costs associated with maintaining membership in a social network composed of family members, friends, and others with whom regular contact is maintained. (P. 91).... Thus, a social network does not automatically constitute a social support network to its members. (P. 93)

Other contemporary researchers have questioned whether the reciprocity documented by Stack is actually present, positing that what many recipients perceive as reciprocity is actually a one-way street (Nelson 2000; Roschelle 1997). Smith suggests that poor African Americans do not lack social ties so much as that limited trust affects their ability to activate those ties (Smith 2005; Smith 2007). 
The potential for social capital to combat poverty in distressed communities (Carpiano 2006; Gittell and Vidal 1998; Saergert, Thompson, and Warren 2001) has lead some call for increased efforts in this area, asserting that poverty is NOT the result of weak social capital in a community, but rather is the result of lack of resources. Thus, as also discussed by Portes, social capital should not be confused with the resources themselves, but rather the ability to access and use those resources.

The actual process by which the social capital of community can benefit its residents is complex, with recent research examining the role of community organizations and staff members addressing more of the nuances of weak and strong ties (Briggs 1998; Marr 2012; Small 2009). These in-depth studies of how poor community residents make use of social capital suggest that the whole concept of strong versus weak ties creates false dichotomies, with many ties being hybrid forms that actually serve both functions. Organizational ties in particular can serve hybrid functions, helping to mobilize affective resources, rather than serving as simple instrumental bridges (Marr 2012). Small (2009) asserts that it is institutional conditions that make the biggest difference in how social networks of poor individuals are altered, and that it is not the connections people make, but rather the context in which they are made (which they frequently do not control) that matters. The influence of community and organizational social capital on access to services for persons who are homeless is significant. Rosenheck et al. (2001) conducted a major, multi-year study at 18 different sites serving persons who were homeless and mentally ill, finding a significant association between the level of systems integration, social capital, and probability of exiting homelessness. 
The culture of service provision within an organization also influences how much social capital can play a role in improving circumstances for clients. Marr (2010) examined how specific organizational conditions affect the development of client-staff trust in transitional housing programs for persons who are homeless, which plays an important role in determining how well clients were able to access and benefit from social capital. Comparing organizational ties and fields in agencies operating in Tokyo and Los Angeles, Marr found that external constraints, including from local culture and spatial politics, have a significant impact on program culture. The program culture, in turn, helps determine the level of trust clients have with their case worker, which becomes particularly important for the development of weak and strong ties that are so influential on helping persons transition out of homelessness. Lockhart (2005) compared the implementation of poverty-to-work programs amongst several types of agencies, finding that the development of social capital was entirely dependent upon which agency a client walked into. The implications for the men interviewed in this study are significant, as shown by the propensity for individuals to enter agencies located in their own geographic area, as well as for them to the rely heavily on the relationship developed with specific staff members at those agencies.

\subsection{Social Capital and Homelessness}

Social capital can help contribute to, or mitigate, homelessness (Bassuk and Rosenberg 1988; Bassuk et al. 1997; Eyrich, Pollio, and North 2003; Hawkins and Abrams 2007; Hopper 2003; Irwin et al. 2008; National Health Care for the Homeless Council 2003; Rossi 1989; Shinn, Knickman, and Weitzman 1991; Wright 2009; Zugazaga 2008). In this section I examine the literature which focuses specifically on 
social capital and homelessness, including research on the role of social and kinship networks in preventing homelessness; the phenomenon of people "using up" their social capital; and the function of social networks and capital for persons once they become homeless.

\section{Social Networks as Buffers}

The importance of helpful social networks is well documented. Many studies comparing low-income housed persons with persons who were homeless have found that lack of a supportive social network is a notable differentiating characteristic for homeless persons (Bassuk et al. 1997; Wood et al. 1990; Wright 2009). Rossi (1989), drawing upon extensive amounts of data collected over several years in Chicago, stressed the importance of social networks, and in particular connections to kin, in serving as the firstline buffer in times of trouble, allowing the sharing of a household to cushion against abrupt and drastic downward spirals in fortune. He found that fewer than half $(48 \%)$ of those who were homeless reported having friends they could count on.

The perceived ability to count on contacts for material help is essential, as studies which found no difference in the actual size of networks for homeless versus housed persons still found that homeless persons were less likely to believe these network members could provide help with something such as housing (Toohey, Shinn, and Weitzman 2004). Thus, the perception of the networks utility was more important than the actual potential utility, since homeless persons simply did not attempt to access that source of social capital. Smith similarly found that amongst poor African Americans, limited trust, rather than lack of resources, was the inhibiting factor in preventing activation of social networks (Smith 2005; Smith 2007). 
Living alone has been associated with greater risk of homelessness. Sosin, Colson, and Grossman's (1988) influential survey of 535 homeless persons in Chicago claimed that the distinguishing characteristic of homeless persons was that they tend to live alone when they do have a residence. Rates of homelessness have been shown to be higher in metropolitan areas with higher percentages of single-person households (Lee, Price-Spratlen, and Kanan 2003). Rossi (1989)found that one of the most dramatic contrasts between persons who were homeless versus those who stayed housed was marital status, with $92-95 \%$ of homeless clients in his Chicago not married; also, lack of nearby family was one of biggest predictors of poor persons becoming homeless. The importance of general geographic proximity to potential sources of help is also supported by studies documenting that for low-income households, being new to an area is a predictor of increased risk of homelessness (Bassuk et al. 1997; Stainbrook and Hornik 2006), suggesting that lack of access to nearby social and kinship networks removes an important safety net in times of trouble.

\section{Wearing Out Your Welcome}

Most homeless persons are not completely isolated, commonly reporting having contact with friends and family. However, these contacts were not seen as resources that could be drawn upon for support. In many cases, this can be attributed to having already drawn upon as much support as could be offered (Wright 2009). Quite simply, many individuals and families simply wear out their welcome.

Loss of social supports pushes persons closer to homelessness, while at the same time, the behaviors associated with homelessness push loved ones farther away. Evidence has shown that the average life of tolerance and help for poor families to care for an 
impoverished family member is four years (Rossi 1989). Once a family’s patience and capacity for help is stretched to the limit, the individual may be forced into other friends' homes, flophouses, hotels, and eventually shelters and streets. Hawkins and Abrams' (Hawkins and Abrams 2007) study of the social networks of homeless persons suffering from co-occurring disorders of mental illness and addiction found that study participants had small networks to begin with, made more complicated by years of relationships strained by drugs, acting out, and continued need, so that the "pushes and pulls are hard to disentangle" (pg. 2037).

Living in doubled-up or overcrowded housing frequently precipitates homelessness (Danseco and Holden 1998; Rossi 1989; Shinn, Baumohl, and Hopper 2001), further suggesting that the road to homelessness is paved with a slow burning through of one's social capital. A comparative study of 495 housed and homeless families found that while homeless families had experienced higher rates of disruption in social relationships, they were actually more likely than housed families to have had recent contacts with friends and family. However, they were also less likely to consider those contacts to be sources of help, and more than three fourths had already stayed with members of their support networks in past year, suggesting they had used up their social capital (Shinn, Knickman, and Weitzman 1991).

\section{Social Networks, Survival, and Exiting from Homelessness}

Even after becoming homeless, most individuals and families do still maintain some sort of social networks, whether pre-existing friendship and kinship networks or newly formed associations. The results can go both ways, as impoverished support networks can contribute to continued homelessness (Morrell-Bellai, Goering, and 
Boydell 2000; Pippert 2007; Wright 2009), while exits from homelessness can be improved with positive social affiliation (Ravenhill 2008; Zlotnick, Tam, and Robertson 2003). Marr's study of single transitional housing users in Los Angeles found that given the environment of neoliberalized labor and housing markets and the associated lack of job opportunities, it was social ties that facilitated exiting homelessness (2012). Eyrich, Pollio and North (2003) found that longer-term homelessness was associated with smaller family support networks and unreliable family and friends, although the actual size of friend networks remained the same throughout duration of homelessness.

Some researchers posit that a distinct "culture of homelessness" serves to further isolate persons living on the streets from the rest of society (Ravenhill 2008). They describe a lifestyle associated with long-term homelessness that is a lifestyle devastated by disaffiliation and social distance, often reflecting a life-time of transience and impulsiveness which drags the person down over time (Grunberg 1998). Note that other researchers reject the idea of a culture of homeless, attributing behaviors associated with the perceived "culture" as being necessary reactions to surviving on the streets while being excluded from society, but stopping short of forming a distinct culture unto themselves (Hopper 2003).

Substance abusers in particular may experience particularly negative effects from social networks, deriving from overall poor access to supports (Zlotnick, Tam, and Robertson 2003), and the harmful nature of the networks themselves (Hartwell 2003; Tyler and Johnson 2006). On the other hand, new social networks formed amongst homeless persons can also provide substantial benefits. In his ethnographic study of the lives of women in homeless shelters, Liebow (1993) described how amidst all of the 
difficulties and indignities associated with living in an emergency shelter, the socialization with others in similar circumstances proved to be a great benefit for the women: "Shelters also serve as a home base for women who have no homes, and provide a pool of persons from which they may choose acquaintances, associates, comrades, and friends" (p. 4). However, Snow and Anderson's (1987; 1993) extensive study of homeless street people in Austin, Texas described a complex social structure of life on the street, where social relationships were quick to form yet remained at a superficial and unstable level. On the one hand, the easy formation of friendships provides one of the only sources of social validation, allows for sharing of information, and offers opportunity to pool whatever limited resources they have. On the other hand, deep relationships were inhibited by the individuals' transience and mobility, varying degrees of willingness to trust, and reluctance for emotional intimacy. Snow and Anderson (1993) posit that the superficial social relationships formed on the street serve as "weak ties" offering significant survival value in an otherwise resource-depleted environment. The formation of adaptive and fleeting friendships that can expand subsistence opportunities are evidence of highly functional adaptations to survival on the street. The small social networks of persons living on the streets described by the men interviewed for this study seemed to serve this exact purpose.

Molina-Jackson has conducted more recent research in Los Angeles that provides a particularly relevant and interesting comparison to Miami (Molina-Jackson 2008). He observed how black and Hispanic homeless men initiate, participate in, and maintain social networks and how these networks function, finding that homeless men are active, rational, and competent actors engaged in negotiating their social world, with members 
relying on social networks composed of a hierarchy of casual and intimate affiliations. His specific findings regarding how the networks of Americanized Latinos and African Americans facilitate their integration into a subculture of street life were similar to findings of my study; however, his other findings that the networks of recent-immigrant Latinos revolve around their struggles to find work, avoid deportation, and enlist the support of paisanos differed from my own findings. This suggests opportunity for exploration of the differences in how Hispanics utilize social capital in Los Angeles versus Miami, posing the question of why there are differences and what that means for linkages between race/ethnicity, social capital, and place.

\subsection{What's Next in the Literature}

The literature on homelessness encompasses an incredibly wide swath. From broad perspectives on globalization and neoliberalism, to more localized issues related to housing and labor markets, much of the literature is focused on the structural causes of homelessness. Over the course of the past three decades of homelessness research, there is now much consensus that the primary causes of homelessness are a lack of affordable housing and extreme poverty.

Additional literature examines how these structural changes have intersected with the role of the welfare state, welfare reform, and the daily negotiation of poverty. The importance of social capital in mitigating or contributing to, poverty and homelessness is also important in examining how individuals contend with surviving poverty. Social capital itself covers a wide range of ideas, including how social capital functions overall, the roles of weak and strong ties, along with bridging, bonding, and linking social capital, and utilizing social networks as buffers. 
While a great deal has been written about homelessness, its causes, and its potential solutions, there is room for expansion in some areas. In particular, there has been little research on homelessness conducted specifically in Miami, which, as a new global city, offers opportunity for others to learn from its experiences. Several factors make Miami an interesting learning laboratory for studying the intersection of neoliberal policy, poverty, homelessness and race. On the one hand, Miami is situated with the State of Florida, which provides some of the lowest levels of public benefits in the country, with single men ineligible for many forms of assistance. On the other hand, the local Miami community has developed a homelessness system that is considered one of the most progressive and effective systems in the country (Donley and Wright 2009; MiamiDade County Homeless Trust 2012a). Additionally, Miami’s demographics with a majority minority population provide ample opportunity for examining disparities between blacks and Hispanics, exploring the nuances of how and why these racial and ethnic groups experience homelessness differently. While studies focusing on race, ethnicity and homelessness have been conducted in other U.S. cities, they have not been done in Miami. Thus, research examining the intersection of race, ethnicity, poverty and homelessness in Miami opens the door to comparisons with other major urban centers where similar research has been ongoing, including Los Angeles and New York. Similarities and differences between the cities may have implications for public policy across the country.

Finally, the methods I utilize are themselves a contribution to the literature. The visual ethnography techniques of Photo Elicitation Interviewing, described in detail in the Research Design chapter, go farther than most studies in offering the subjects opportunity 
to participate in how they are portrayed in the study. The manner in which I utilize PEI transforms the photography into data collection, data analysis, and data itself, all at the same time. The success of this technique in both engaging and portraying subjects suggests further applications for studying marginalized populations while giving them a voice in how the findings are developed and used. 


\section{CHAPTER 3: RESEARCH DESIGN}

My study employs a mixed methods research design in order to better understand the daily lived experience of black and Hispanic men who are homeless or at risk of homelessness in Miami-Dade County, within a larger context of neoliberal policy and poverty management. Specific research questions addressed: (1) In Miami-Dade County, do black and Hispanic men who are homeless or at risk of homelessness have different personal characteristics and different experiences in avoiding and/or exiting homelessness? (2) How does Miami’s response to extreme poverty/homelessness, including availability of public benefits and the presence of public and private helping organizations, either maximize or constrain the choices available to this population? What is the experience of single, adult men living in extreme poverty in Miami-Dade, who are homeless or at risk of homelessness, in negotiating their daily survival? Specific hypotheses were developed and tested for each question, as described in more detail below.

The mixed methods approach incorporated four means of analysis: (1) Quantitative data from approximately 9,000 records of homeless men (7,605 unduplicated individuals) receiving services in Miami-Dade County's continuum of care over an 18-month period was analyzed utilizing SPSS statistical software; (2) Qualitative data from 54 video-taped semi-structured interviews was analyzed utilizing MaxQDA software; (3) Photo-Elicitation Interviews (PEI) conducted with a subset of the semistructured interviews were analyzed utilizing visual ethnography techniques; and (4) GIS mapping was conducted incorporating census data with the collected data. Combining these methods provided a means to paint an accurate overall picture of the target 
population's current situation, focusing in particular on racial and ethnic disparities, while using interviews to explore meaning behind the data. Further, incorporation of PEI provided a means for subjects to insert their own voice and perspective into the project, while also visually illuminating the daily lived experience of the target population. Thus, the question of how policies shape the choices and outcomes for poor and homeless minority men is examined from macro and micro levels.

Of note is that the researcher has worked in administrative positions with one of the largest nonprofit agencies working with persons who are homeless in Miami-Dade County for 19 years. The researcher's connections to the provider community facilitated a high level of access to data, assistance recruiting subjects, and feedback from individuals and leaders working within the system. However, the potential for bias because of the researcher's involvement in the delivery system is noted. When interviewing subjects, the researcher described herself as affiliated with the university, rather than the nonprofit organization, so that subjects did not feel inhibited about critiquing the service delivery system. While the researcher disclosed the relationship with the nonprofit agency if it came up, few subjects expressed any concerns in that area. In an effort to reduce bias that might be introduced as a result of having been involved in the planning and development of various programs, services, and policies in the area, the researcher referred to historical documentation and meeting minutes rather than memory in writing the background sections. Additionally, the researcher conducted many informal interviews with staff and leaders at both public and private agencies in order to confirm information. 
Ongoing participant observation of systems-level activities was conducted via the researcher's attendance at, and sometimes direct involvement with, various planning boards at the county and state levels. The history of the development of the homelessness services delivery system in Miami-Dade is provided through historical documents and articles, as well as the researcher's direct observation over the past 19 years as someone working within the system.

\subsection{Operationalizing the Hypotheses}

Research Question 1 asked: In Miami-Dade County, do black and Hispanic men who are homeless or at risk of homelessness have different personal characteristics and different experiences in avoiding and/or exiting homelessness? The following hypotheses were designed to answer the first question.

- In Miami-Dade County, blacks are at no greater risk of becoming literally homeless than are Hispanics, whether controlling for income level or not.

- The characteristics and needs of single men who are homeless in MiamiDade do not differ among race/ethnic groups.

- Single men exiting homeless programs in Miami-Dade County go to similar destinations when broken down by race/ethnicity.

- The spatial distribution of different racial/ethnic groups amongst Miami's poor and homeless populations, along with the geographic location of homeless programs, does not influence how different racial and ethnic groups access formal assistance.

- Black and Hispanic men who are homeless do not express different desires for the type of help they believe they need.

- Single men exiting homeless program in Miami-Dade County have similar outcomes regarding successful/non-successful program completion when broken down by race/ethnicity

These hypotheses were examined primarily through statistical analysis of records of men who had received services in emergency, transitional, or permanent housing 
programs in Miami-Dade County's services delivery network. The data set is described further below. Specific variables included race, ethnicity, age, living situation prior to becoming homeless, type and location of programs utilized, duration of homelessness, reason for exiting homeless programs, and destination upon leaving the program.

Additional variables regarding disabilities, income sources, and benefit sources were also utilized. Homeless data was compared with local census data, and national homeless data.

Research Question 2 asked: How does Miami's response to extreme poverty and homelessness, including availability of public benefits and the presence of public and private helping organizations, either maximize or constrain the choices available to this population? The following hypotheses were designed to answer the second question:

- The formal system of care for homeless men in Miami-Dade is constrained by state and federal regulations regarding benefits, eligibility criteria, and program requirements.

- Utilization of public benefits does not differ between blacks and Hispanics, including: (i) efforts to apply for benefits; and (ii) success in qualifying for the benefits.

- Men who are homeless or at risk of homelessness sometimes fail to access benefits for which they would qualify because of bureaucratic barriers, with differences between racial/ethnic groups.

These were examined primarily utilizing data collected during semi-structured interviews with men who were currently homeless; formerly homeless; and/or at risk of homelessness. The methodology for these interviews is described more below. Specific variables utilized included receipt of public benefits including Supplemental Nutrition Assistance Program (SNAP), Social Security Income/Social Security Disability Income (SSI/SSDI), Medicaid/Medicare, Section 8 or other housing assistance, Veterans Administration (VA) benefits; as well as reasons for not receiving benefits, and reasons 
for not applying for benefits. Additional variables examined participation in local homeless programs, and utilization of private charities. These were examined against the backdrop of federal, state, and local regulations regarding availability of benefits and eligibility criteria.

Research Question 3 asked: What is the experience of single, adult men living in extreme poverty in Miami-Dade, who are homeless or at risk of homelessness, in negotiating their daily survival? The following hypotheses were designed to answer the third question:

- $\quad$ Single men who are homeless or at risk of homelessness rely on social capital, including access to friends or family who can provide help, to replace the lack of access to public benefits, with differences between blacks and Hispanics.

- Single men who are homeless do not have access to adequate programs and services necessary to help them exit homelessness.

- Black and Hispanic men who are homeless or at risk of homelessness do not express different opinions regarding how they believe they are treated by others and provided access to helpful resources.

- Black and Hispanic men who are homeless do not express different opinions regarding the experience of being poor and homeless.

These were examined utilizing data from the same semi-structured interviews, while also incorporating more personal opinions as shown through the PEIs, described more below.

\subsection{Quantitative Data}

Quantitative Data - Homelessness Information Management System (HMIS)

An extensive amount of quantitative data regarding the demographics, characteristics, and pathways through the Miami-Dade homelessness system was 
analyzed, including the records of 7,605 adult men. The data was drawn from the County's Homelessness Management Information System (HMIS), a countywide, webbased database utilized by all 27 homelessness service delivery agencies funded through the Miami-Dade County Homeless Trust, which serves as the centralized coordinating and planning entity for homelessness in the county. The HMIS system contains records of every individual who receives any service at a homeless provider agency. A unique ID is created for each individual, and when an individual moves from one agency to the next, his/her record should follow them, keeping the same ID number. In 2011, 15,077 unduplicated individuals were recorded in the system, including 11,808 adults. Another 1,911 households who received homelessness prevention services in the form of rental assistance were not included in the data set at all.

While individual client-level data can only be seen by each individual direct service provider, to ensure privacy and confidentiality, the data could still be made available from the county by removing names and birthdates that might identify an individual. The client ID numbers are system-generated, and are not related to social security numbers. Because the HMIS system is county owned, the records fall under public records and can thus be made available as long as no personal identifying information is included.

In order to extract the data from the county's system, the researcher designed a report template utilizing the system's Advanced Reporting Tool (ART), which facilitates design of customized reports. The report template would extract all of the data meeting established criteria, and export it to an Excel sheet. The template was provided to the county, whose staff ran the report incorporating data from the entire countywide system. 
The criteria selected data for all single, adult men who were served by a county homelessness agency during the 18-month period from July 1, 2010 through December 2011. The original time period of Year 2011 alone was extended by the additional six months after it became apparent that one year was not long enough to capture much movement through the system - the men were staying in many programs for longer periods of time and often did not exit a single program over the course of a year. The resulting data provided 7,605 unduplicated records.

\section{Limitations of the Data}

While the HMIS data presents a large amount of data covering an 18-month period, it presents some limitations. The data stream is entered by caseworkers at some 27 different provider agencies. In many cases the data are meticulously entered by welltrained staff; in other cases the data are entered with less attention to detail. Some providers frequently chose "other" as a choice, and then answered free-form notes of explanation. In those cases, the researcher was able to convert many of the free-form notes into answers that could be categorized along with the answers from other providers. In some cases, basic data were entered, but details regarding disabilities, income and noncash benefits was left blank. It was clear when these questions were skipped, rather than leaving blanks when "no" was the answer, because answer options include "no income" or "no non-cash benefits." If all of the options were blank, these records were marked as incomplete for those areas of questions. These records were still included in analysis regarding race/ethnicity and program success; however, they were noted as missing for analysis regarding the presence of disabilities and income. One provider in particular left much of this info blank, leaving room for some bias if this provider was seeing one 
particular type of client. However, the racial/ethnic breakdown of clients seen by this client was not significantly skewed.

The data may have had more duplications than indicated by the unique client IDs. The system is supposed to work such that when a provider refers a client to another agency, the referral is made electronically and the record, and ID number, follows the client. Thus, the same client ID will show entry and exit from various programs, therefore having multiple records, but with capacity to de-duplicate the records if needed on the basis of Client ID. However, anecdotal evidence suggests that some providers sometimes skip the electronic referral method, and the new agency creates a new record and new ID. While the Homeless Trust attempts to monitor and correct these instances, it can be assumed that some unknown duplications of clients exist.

Finally, not every agency and/or program that provides services to persons who are homeless in Miami-Dade County is funded by the Homeless Trust and thus required to enter client data into the HMIS system. While the vast majority of emergency, transitional, and permanent housing providers do participate in the system (even for those programs not actually funded by the Homeless Trust), a few agencies/programs do not enter their clients' data. Therefore, if a subject was participating in one of those programs for any length of time, they would not show up in the data for that time period.

\section{Quantitative Data - Miami-Dade County Point-in-Time Survey}

Additional countywide data was utilized primarily to cross-check the HMIS data, and to provide information regarding the needs expressed by the target population. The Homeless Trust collects data, in addition to the HMIS data described above, through an annual Point-in-Time Census and Survey (PIT) mandated by US Housing and Urban 
Development. As indicated by its name, the PIT counts individuals who are homeless in the county on one particular day. Coordinated by the Homeless Trust each January, the census is an actual head-count conducted overnight, counting those individuals who are seen sleeping in places not meant for habitation, along with those staying in shelters or non-permanent housing programs.

The following day, a survey is administered to a large sample of those persons living on the streets, in shelters, and in emergency or transitional housing programs. Both individuals and families are included. The Homeless Trust does not utilize a defined sampling methodology for the PIT surveys. Rather, every agency and outreach team who are part of the Trust's network are instructed to survey as many of their clients/residents as they can during the one day period, covering persons who are living on the streets, in shelters, or transitional programs. The Trust estimates that approximately one third of Miami's homeless population completes the survey. Surveys are administered by staff and volunteers working for participating agencies, but clients are allowed to provide their own answers, so that surveys capture their own expressed needs, rather than diagnoses or assumptions made by case managers or other staff members. The four-page surveys are then entered into an Excel sheet, which does not include personal identifying information. The Excel sheet containing all of the raw data was provided to the researcher, from the Homeless Trust, along with the HMIS data. As with the HMIS data, these data are limited by the reliability of those persons doing the data entry. Additionally, bias may be introduced by the sampling method, as some staff or outreach workers may be inclined to select individuals who are more compliant and easier to interview. 
The PIT data, collected in January 2012, included 1,537 records. Selecting only the single men resulted in 882 unduplicated records; of those, 857 had complete information on race and ethnicity. These were imported into SPSS for analysis. The racial and ethnic breakdown of men in this sample was close to the racial and ethnic breakdown of records in the HMIS data. Table 1 shows the comparison:

\section{Table 1: Comparison of Race and Ethnicity in Data Sets}

\begin{tabular}{|c|c|c|c|c|}
\hline & Black & Hispanic & White & Total $\mathrm{n}$ \\
\hline HMIS Data & $54.6 \%$ & $29.9 \%$ & $15 . \%$ & 7605 \\
\hline PIT Surveys & $57.4 \%$ & $28 \%$ & $11.4 \%$ & 857 \\
\hline
\end{tabular}

\section{Quantitative Data Analysis}

The HMIS data were provided via four separate Excel spreadsheets. These were imported into SPSS for cleaning, and were then combined into one worksheet for analysis. Sheet One, which became the primary worksheet to which the others were appended, included variables for race, ethnicity, prior zip code, prior living situation, program served in, entry and exit dates into the program, reason for leaving, and destination upon leaving. Many individuals had multiple records, as they had moved from program to program.

Sheet Two included information on disabilities, including presence of a substance abuse problem, mental illness, physical or medical disability, or co-occurring disorders. Various medical conditions, including HIV/AIDS, were combined into one category for "physical/medical” disability. A dummy variable was created for each disability type, indicating presence or non-presence of that specific disability, and then appended to Sheet One by matching client IDs. 
Sheet Three included information on Non-Cash Income and Sheet Four included Cash Income. Again, some answers were collapsed into one. For example, retirement benefits and pension retirements were combined; various veterans' benefits were combined; Medicaid and Medicare were combined. These variables for Source of NonCash Income and Source of Income were also transformed into multiple dummy variables indicating the presence or lack of presence of that source of income. These variables were then appended to the main data sheet via matching of Client IDs.

The HMIS system records one entry for race, and a separate entry for ethnicity. In order to analyze the data according to a breakdown of black; white Hispanic, and white non-Hispanic, the race and ethnicity variables were combined. Persons of "other" race/ethnicity were not included. Missing and "other" data represented less than $1 \%$ of total data. Persons who were Hispanic of any race were coded as Hispanic. The PIT data were similarly recoded to combine the race and ethnicity variables.

Data were then analyzed primarily through cross-tabulations, using Pearson ChiSquare measures to test for validity. Several types of cross-tabs were produced, focusing in particular on comparisons between the different categories for race and ethnicity (Black; White Hispanic; and White Non-Hispanic).

Quantitative Analysis - Geographic Information System (GIS)

Data were also examined utilizing ARC Geographic Information System (GIS) to illustrate the distribution of subjects and programs by zip code and racial/ethnic groups. Data regarding the race and ethnicity of individual clients served, along with aggregated race/ethnicity information by program, were exported from SPSS into GIS, where it was laid over County maps showing racial/ethnic groups by census tract, drawn from the US 
Census. While GIS was utilized to provide a visual depiction of disparities, similar data were also analyzed in SPSS via crosstabs in order to test for significance in the apparent disparities.

\subsection{Qualitative Data}

Qualitative data were collected through one-on-one interviews that included semistructured questions along with Photo-Elicitation Interview (PEI) techniques, described in detail below. Nearly all interviews were also recorded on video, with permission of the subjects. Given the vulnerable nature of the target population, particular attention was paid to respecting the wishes of subjects regarding topics they did not want to discuss or photos they did not want to take. However, as noted in the following section, subjects actually reported a deep appreciation for being included in the project and being given the opportunity to share their own stories.

\section{Categorizing the Subjects}

A total of 55 adult males were recruited for the interviews. One interview was discarded after it was determined that he had been an improper referral in that he was not Hispanic, as the referring caseworker had misunderstood. The 54 interviews were stratified into three subgroups, each including black and Hispanic individuals. Since the primary focus of this study is black males, and because black males are overrepresented in the general homeless population, groups were weighted toward blacks, including approximately 12 blacks and 8 Hispanics. White Non-Hispanics were not interviewed, since they represent such a small portion of the overall homeless population in the area, at $15 \%$, any statistical analysis incorporating these interviews would require a larger number of interviews in order to ensure statistical significance. Data on white non- 
Hispanic males were included in the quantitative data from the HMIS and PIT data sets, so an overall picture of their presence in the system is included. However, my study is specifically interested in how minority men negotiate systems in Miami and thus interviews were limited to blacks and Hispanics.

Subgroups of interviewees were supposed to include:

- Currently Homeless (living on the streets)

- $\quad$ Formerly Homeless (and now living in supported or independent housing)

- At-Risk of Homelessness (in immediate danger of eviction or otherwise becoming homeless)

However, during the course of the nine-months of interviews, it became apparent that the divisions among the three subgroups were not as clear cut as envisioned at the onset of the study. Subjects were moving in and out of the different groups over the course of data collection; many qualified for several groups at the same time. For example, people who were living on the streets when the researcher set up the interview would be housed by the time the interview actually took place. Individuals who were formerly homeless turned out to be still at-risk-of-homelessness, expressing during the interview that their greatest fear was losing the apartment they had just attained. Individuals who had been doing well when they first exited homelessness and since lost their jobs and were at risk again; several had indeed become homeless again by the time the researcher followed up months later. Individuals who were at-risk of homelessness turned out to have experienced homelessness before, and/or would have lost their apartment when the researcher checked in with them months later. 
While this made it difficult to keep subjects neatly categorized into the three groups, it supports the theory that homeless persons are not a distinct category of persons unto themselves, but rather a visible subset of the larger group of persons at risk living in extreme poverty. A number of researchers suggest reframing the issue: given the vast numbers of persons living in extreme poverty in the U.S., the question should not be why people are homeless, but why more people are not homeless (Hopper 2003; Wright 2009). Hopper posits that a more realistic approach to understanding and ending homelessness would direct attention toward the "displacement that doesn't happen" by measuring how the alternatives to homelessness function in allowing poor households to survive on their own (Hopper 2003).

The transitional nature of homelessness is further supported by HMIS and PIT data described above. HMIS showed that 5,359 individual males were homeless in Miami-Dade in 2011; but the PIT count found only 897 individual males. Yet, it is the PIT figure most commonly quoted as representing the number of persons who are homeless, at both county and national levels.

By counting only the number of persons who are literally homeless on any given night, which also requires excluding persons living in hotels, sleeping temporarily on couches doubled up with friends, or other situations whereby the person clearly does not have a stable, permanent place to live, the PIT surveys succeed in portraying a picture of a neatly contained homeless population which only needs housing in order to become "non-homeless." However, in Miami-Dade the actual number of males who are homeless over a year is nearly six times that of the PIT count (Miami-Dade County Homeless Trust 2012b; Severe 2012). 
The movement of persons in and out of homelessness was clearly evident in attempts to organize data collection into the three distinct categories of persons who were either homeless, formerly homeless, or at risk of homelessness. To resolve the issue, data were categorized three ways, depending upon the issue for analysis. First, the three categories were maintained as is, placing individuals into the group where they had been at the time of the initial interview. In cases where they fell into both groups at time of interview (i.e., both formerly and at-risk), they were placed into the category from where the referral had come. For example, if a case worker referred the subject as "at-risk," but during the interview it was discovered that they were also formerly homeless, they were kept them in the "at-risk" category. Second, in some cases the data were analyzed with both the formerly homeless and at-risk categories combined, into one category of "housed." Third, in some cases the data were analyzed with persons who had ever experienced homeless categorized as "formerly homeless," which required moving some subjects from the at-risk category to the formerly homeless category. The third categorization methodology was utilized when the more important factor was whether they had ever experienced being homeless at any time, rather than their current status.

\section{Recruitment Sources:}

Subjects were recruited from a variety of sources, all being providers of services to persons who are homeless in Miami-Dade County. Some agencies in Miami tend to attract different types of clients, through self-selection amongst clients themselves and in response to the types of services offered. Thus, in order to avoid bias introduced by interviewing subjects associated with only one agency, a range of agencies and programs were included. These included: 


\section{- Persons Living on Streets:}

Persons who were still living on the streets, or other places not intended for human habitation, were recruited from four sources. First, the Camillus House Day Center is a daily, drop-in program offering basic services such as meals, showers, and clothing, along with general engagement activities. Nearly every person on the streets within the downtown area visits this program for services, including to receive their mail. When recruiting clients, the researcher would alert the program manager that she would visit the program at a designated time that same day. The program manager would then ask for interested parties from the pool of persons sitting in activity or waiting rooms. The opportunity to participate in an interview was largely viewed as an interesting diversion from the usual daily routine and there was no shortage of volunteers. Thus, the researcher was able to include subjects who simply happened to be on site at the time, and had not been selectively pre-chosen for a specific reason, thereby helping to reduce the introduction of bias into the sampling. Some of these interviews were conducted onsite at the Day Center, located within the larger shelter and services operation. Others were conducted by walking to wherever the subject slept at night, which included sidewalks, under MetroRail stations, on the beach, under bridges, in parking lots, parks, and in front of buildings with overhangs. Each subject identified a specific space they considered their sleeping spot.

Additional persons who were currently homeless were recruited with the assistance of three separate outreach teams. The City of Miami Homeless Assistance Program conducts street outreach 24 hours a day, 7 days a week, to identify and place individuals into shelters or other appropriate programs, covering the geographic area of 
the entire county exclusive of Miami Beach. The City of Miami Beach Outreach Team provides the same activities within the jurisdiction of City of Miami Beach city limits. The Citrus Health Network Chronic Outreach Team also conducts street outreach countywide, with a specific focus on persons who are chronically homeless and more difficult to engage. All of these outreach workers have developed extensive relationships with nearly every person living on the streets. They would present the study opportunity to individuals they encountered during their daily routine, and then coordinate with the researcher to set up times and places to meet. The outreach worker then accompanied the researcher to meet the subject at the arranged time and place. Even when appointments were set up days in advance, the subjects were always ready and waiting at the agreed upon spot at the correct time.

\section{- Persons Formerly Homeless:}

Persons who were formerly homeless included two subgroups: persons who had moved on into independent living in the community, and persons who were now living in permanent, service-supported and/or subsidized housing programs. Individuals now living in the community were recruited via referrals from their former case worker at whichever agency had originally helped them transition to permanent housing. The group of persons living in the community included persons placed from both emergency and transitional housing programs operated by a range of agencies. Some had transitioned from homelessness as recently as one month prior; for some it had been many years. Interestingly, several of these subjects claimed to be living completely independently, in spite of the interview revealing that they were receiving a HUD Section 8 housing subsidy. In Miami-Dade County, the Section 8 housing voucher system is operated 
separately from the homelessness system, and thus is not treated as a "homeless" support program. Persons who are homeless do not receive any priority in gaining access to the subsidy, which has a years-long waiting list. Because the Section 8 program was not a "homeless" program and did not include services, interviewees considered themselves to be completely independent.

Persons living in supported housing situations were recruited from multiple agencies and programs, including the three largest providers of supported housing in the county. The types of facilities in which subjects lived included older buildings with small efficiencies; new buildings with one-bedroom apartments; and projects with individual apartments rented in regular apartment buildings.

\section{- Persons at risk of Homelessness:}

Persons at risk of homelessness were recruited from the pool of persons who had called the County's Homelessness Prevention Hotline, which offers, amongst other things, temporary cash assistance to qualifying persons who are about to be evicted. The percentages of callers who were single men was lower than anticipated. According to the HelpLine Administrator, for the period January 2012 through September 2012, single males represented only 1,606 out of 10,213 (15.7\%) of callers (Lesly Borges October 2012). The low number of single male callers was puzzling, as single men were equally eligible for this resource; anecdotal evidence indicated that they were simply selfselecting out of the process because they assumed they would not be eligible due to their status as a single male. However, it was still possible to recruit enough subjects through this source, as well as through word of mouth. 
Finally, subjects were recruited for all categories through snowballing techniques, with subjects referring other subjects. Recruiting new subjects through the assistance of current subjects was particularly helpful for engaging individuals who were hidden from view and not engaged in any programs or services. Because they did not participate in local programs, the newly recruited subjects could not have been reached through any agency, and the assistance of the street "gatekeepers" was helpful.

At the same time, the researcher was also repeatedly warned by subjects to avoid certain groups of persons living in encampments around the downtown area. On multiple occasions, subjects described these other groups as dangerous, hostile to outsiders, and full of criminal elements. Subjects were themselves afraid of these groups. The exclusion of these individuals from the study may introduce some bias, as they are specifically not engaged in the regular homelessness delivery system and there is no way to verify where they attain resources to survive. However, the study's subjects point to criminal activity as their method of survival.

\section{Recruitment Procedures:}

Referrals were made through case workers and outreach workers at each agency. They were supplied with a statement regarding the recruitment criteria, purpose of study, and provision of client incentives. When they identified an appropriate candidate, they would assess interest in the study, and then provide the subject's phone number to the researcher to call to set up the appointment. However, many subjects didn't have phones, particularly those living on the streets, which required sending messages through outreach workers to set up meeting points at specific times. While this sometimes took days, or even weeks, to accomplish, the ultimate show-up rate was $100 \%$. 
Subjects were offered two levels of cash incentives for participation: \$15 for doing just the semi-structured interview; or $\$ 50$ for doing the interview and the PEI component. The amount of $\$ 50$ was chosen because subjects were being asked to share intimate details of their lives through the photographs, and were granting permission for the images to be used in any way, including public forums if the research were published or shared on the Internet. Thus, fair compensation was required. However, no more than $\$ 50$ was provided, to avoid moving into the territory of possible coercion. Cash was utilized, rather than gift certificates, as that is far more useful to someone living on the streets with limited ability to reach specific stores and no ability to store many types of purchases.

Subjects were given a choice regarding whether they wanted to do the photographs, and $85 \%$ said yes. They were also given a choice as to whether they wanted to appear in the photos themselves, or just depict parts of their life, and they were allowed to request deletion of any photo they did not like. Nobody requested deletion of any photos.

Case workers helping with recruitment reported having few problems finding participants. Subjects expressed multiple reasons for wanting to participate, beyond receiving the $\$ 50$ cash incentive. Nearly every subject expressed gratitude that somebody wanted to hear his story. They wanted their stories made public, in hopes of dispelling myths about the way they lived and the way they earned and spent their income. Even after being told they would receive no direct benefit beyond the cash incentive, they were eager to do something that might lead to help for others like them. In addition, many stated they wanted to do the interview because their current or former case worker had 
asked them to, and they were happy to be able to do something to "give back" to a system that helped them. For persons living on the streets, the interviews also presented an opportunity to do something interesting for the day.

Another motivation expressed by many was an effort to actually build their own social capital by engaging with the researcher, who was known primarily as being associated with the university, rather than with the Camillus House agency, and therefore could be somebody who might have resources the agencies did not. One subject summed up this thought process by saying, "I agreed to talk to you because I heard you were from the university and I thought you might know somebody who could help me with immigration." When asked why he didn’t ask his own case worker for help, he replied “They've done all they can; I need somebody new who knows different people."

Of note is that not a single subject asked the interview for material items. Nobody requested cash, food, clothing or other physical items. They wanted resources that would help them help themselves - help getting a job interview; a connection at immigration; assistance getting on waiting lists for new housing projects.

Thus the very act of conducting the interview altered each respondent's own use of social capital. They were very aware that one of the most direct ways out of their situation was to gain access to someone outside of their usual circle, someone with access to "new people," and jobs. They were seeking out those "weak ties" and "bridging social capital" theorized in the social capital literature. Subjects called the researcher after the interview to inquire about job leads. One subject asked for help getting on a waiting list for new teeth, since his pair of dentures had been stolen from his backpack while he slept on the sidewalk. Notably, his attempts to attain new teeth by reaching out to a new 
connection were successful, as the researcher was able to get him on a waiting list for new, no-cost dentures. In this case, it was individual social capital that succeeded where the system had failed. While great news for this subject, though, it did nothing to address the underlying systemic problem of a man having no means to attain something as a basic as a set of teeth.

The very act of conducting fieldwork changed the nature of what was being studied, as the researcher's presence and follow-up had potential to alter the system. The potential for unintended consequences resulting from the researcher's engagement with the subjects was made evident when, after interviewing approximately half of the 55 individuals, the majority of subjects were answering that they did not qualify for the benefit of a SafeLink phone. These cell phones are supposed to be provided by the State to persons who are homeless, with limited minutes, so that they can conduct job searches and stay in touch with family. Yet persons living on the street kept reporting having been denied a phone, or having not applied because they knew they wouldn't qualify. Upon further investigation, the researcher learned that while the State of Florida was required to provide the phones, they also required an address, and allowed only one phone per address. Since nearly everybody living on the streets of Miami uses Camillus House as its address, only one person out of the thousands registered there could receive the SafeLink phone. Whether deliberate or not, this administrative rule effectively cancelled out the benefit supposedly intended by the SafeLink program. The researcher reported the situation to a local legal services agency, who agreed to take this up as a case to get that administrative rule changed. This created a dilemma for the remaining data collection, because if the rule were changed halfway through the data collection, the results would 
be seriously altered and the disparity wouldn't show up at all. On the other hand, the lives of the subjects certainly trumped any personal research. At the end, though, it had no effect, as the legal case was nowhere near completion by the time data collection was finished.

Settings:

The majority of interviews were conducted at the location where the subject slept at night. Thus, interviews took place under bridges, on sidewalks, inside and outside of shelters, in parks, in abandoned lots, on the beach, on jetties, and in abandoned buildings. For persons who were housed in the community, interviews took place in a variety of dwellings, ranging from nice houses in the suburbs and regular apartments in average looking buildings, to trailer parks, crowded one-room units, and sub-standard apartments in dangerous neighborhoods. In a few cases, subjects chose to be interviewed at the Camillus House shelter rather than their own home, indicating fear about being interviewed in their own home. They stated that it would be dangerous for them, not for the interviewer, to be seen by their neighbors bringing in a "white outsider." They were concerned that they'd be accused of working with the police. One formerly homeless individual who had completed a drug treatment program explained,

"When I got clean, I still couldn't afford to move anywhere except back to the old neighborhood. Nobody there really trusts me now because I'm clean, you know, I don't use with them anymore. If they see me with some white person carrying a camera, they'll think I turned narc. They'll think you police or FBI or something. I won't be able to stay there no more."

In several other cases, the subjects allowed the interviews to take place in their home, but subsequently went door to door in their building, with the researcher, to make introductions and explain that the researcher was a student from the local university, and 
not part of any authority. In one case, a subject who had wanted video and photos taken by the storage unit where he kept his belongings brought the researcher to the manager's office, asking that the researcher explain her student status and purpose of the study. The facility had not had elevator service for months, and the subject had to walk up 7 flights of stairs to get to his belongings. He was afraid the manager would ban him entirely if he thought the researcher was with a news team there to do an expose on the substandard conditions provided to paying customers. The subject was not concerned about getting the substandard conditions fixed; only that he not be thrown out. In all of these cases, the subjects also needed the researcher to provide the explanation directly, as they did not believe their own word would be accepted.

In some cases the subjects were indeed worried about the safety of the researcher. Many subjects who lived in apartments were waiting outside, greeting the researcher in the parking lot or front gate, expressing fear that the researcher's race and camera equipment would make her an immediate target. One subject warned, "By the time you park, word's gone through the whole block and they're watching to see what you do." As an extra precaution, the researcher did not attend interviews conducted in person's apartments alone, bringing either a research assistant or outreach worker along. Outreach teams who helped arrange interviews with persons on the streets typically remained in the vicinity while the interview was conducted, keeping an eye out for others who might be eyeing the equipment or overall situation. On occasions when conducting interviews with subjects on the streets, other persons who were homeless came along during the interview, acting as "gate keepers" for entering areas under bridges or homeless encampments. 


\section{Semi-Structured Interviews}

The interviews themselves lasted approximately 45-60 minutes. Questions were broken into five categories, covering Life Stories and Surviving Homelessness; Basic Demographics and Characteristics; Public Benefits; Access to Social Capital; and Income Sources. The Survey Instrument is included in the Appendices. Interviews followed the general format of the survey instrument, although questions were not always asked in the same order as subjects gave lengthy answers that sometimes covered multiple subjects. Probing questions were asked as follow-up. While offered the opportunity to decline to discuss any topic, few subjects declined to answer any questions. Sometimes they had to be reminded not to go into detail regarding current illegal activity while the video camera was running. This willingness to share virtually any information seemed to come from two sources: First, persons who are homeless have typically been served in multiple programs, so most of the subjects had been through countless "intake" interviews conducted every time they enter a program. They have been normalized to having complete strangers ask intimate questions about mental health status, medical problems, histories of drug or alcohol use, criminal backgrounds, and their life histories. Second, they did not feel they had much to lose by giving honest answers - they were already sleeping on the street and had little privacy, or dignity, left to protect. Persons who were at risk of homelessness, but not yet homeless, were more likely to give guarded answers or decline to be in photographs.

The one area where some subjects did change the subject was regarding relationships with family. When asked why they no longer maintained relationships with family members, or why they did not turn to family for help, some subjects stated they 
wouldn't discuss it, or became too emotional to talk about it. Some, brought to tears, asked that the interview move on to something else.

I conducted every interview. In cases where the subject did not speak any English, a translator participated. Interviews were recorded on a video camera; in cases where the subject did not wish to be videotaped (8/54 interviews), only the audio portion was utilized.

\section{Photo Elicitation Interviews}

At the completion of the interview questions, subjects were asked if they wanted to participate in the Photo Elicitation Interview (PEI) component. The PEI methodology I utilized was actually a hybrid between formal PEI, where subjects are shown photos and asked questions about what they see, and "photo voice" where subjects are given cameras and asked to photograph their own environment, on their own, over a period of time (Wang and Burris 1994). In this case, PEI was modified so that interviewees also help select the pictures that were taken, in collaboration with the researcher. However, unlike Photo Voice, the researcher still took the pictures during the interview. Utilizing PEI can be particularly effective when interviewing individuals about personal subjects, as the informal nature of the interaction can help to quickly break down barriers and invite open expression (Banks 2001; Collier and Collier 1986; Collier 2003; Harper 1989a). The photos are not used strictly as a form of documentation, but rather are used to evoke comments, memories, and discussion in conjunction with a semi-structured interview, setting off a chain reaction of new thoughts (Banks 2001) as the subject engages in the photography process. It is more useful when the subject understands the purpose and intended use for the photos, as they are able to provide more direction in determining 
what best depicts their own perspective. The process of choosing what to photograph can be more important than the photo itself (Clark-Ibanez 2007).

The pictures were taken on a digital camera and thus the results could be immediately shared with the subject, who was asked to explain why the photo was chosen and what it meant. As would be predicted by PEI theory, the act of describing the photos brought out new information and perspectives that did not come out of the regular interviews. Given control over how to express what was important to them, and what depicted their own lives, subjects brought up points that would otherwise have been lost, focusing on things that represented the hardships in their lives, as well as sources of pride.

In order to ensure subjects didn't feel coerced into the photography, they were again asked to consent prior to beginning that portion of the interview. The vast majority $(85 \%)$ of subjects wanted to participate in the photography. Persons living on the streets rarely expressed any concern about anything being photographed. As one subject explained, "I sleep on the sidewalk and am kicked awake every morning by a cop telling me to move. I live in public. I have no privacy. Your photographs don't bother me one bit." Analyzing the Semi-Structured Interviews

Interview recordings were uploaded to a video editing system (Final Cut Pro), and the audio portions were compressed into avi files and sent to a research assistant for transcribing. Interviews that had been conducted in Spanish included transcriptions of the English and Spanish words, along with a secondary translation of the Spanish portions so as to capture the exact words in cases where the translator may have paraphrased. 
The transcriptions were then coded utilizing MaxQDA qualitative analysis software, utilizing several methods. Specific categorical variables were created to capture specific pieces of information such as race/ethnicity, duration of time spent on the streets, receipt of various benefits, ability to ask family or friends to help, and current housing status. Transcripts were then coded for answers regarding specific areas such as life on the streets, feeling about race and ethnicity, utilization of social capital, daily activities, perceptions of causes and solutions to homelessness, and desire for income or benefits. Additionally, transcripts were coded for emotions, including when subjects expressed pride, embarrassment, resentment, happiness, contentment, hope and others.

The categorical variables were utilized to create cross tabulation tables, utilizing the Pearson Chi-Square tests of significance. The variables could also be used separate the other coded areas, focusing in particular on differences in answers given between blacks and Hispanics. Answers on various topics were analyzed in matrixes that compared responses between the racial and ethnic groups.

The PEI data was analyzed based upon the content of the photos as well as the manner in which subjects chose to portray themselves. Photos were coded according to whether the subject has chosen to smile or not, assuming that because the subjects were posing themselves for the photo, their facial expression was symbolic of how they wanted to present their situation to the world. Data from the photos were then utilized in cross tabulation analysis in comparison with race and ethnicity, as well as housing status. The content of photos was grouped into categories to determine which themes emerged as important to the subjects overall, and was used to supplement the content of individual interviews. 


\subsection{Examining the Homelessness Services Delivery System}

The background information provided regarding the development and operations of the homelessness services delivery system in Miami-Dade County was accessed in large part through the researcher's own involvement, having worked in the system for the past 19 years. The researcher is employed by the largest provider of homelessness services (Camillus House) in the area, and was a board member with the Miami-Dade County Homeless Trust for 9 years and with the Miami Coalition for the Homeless for 3 years. Thus, the researcher was actually present at many of the systems-level homelessness policy development meetings taking place over the past decade and a half. Further, the researcher personally knows the community leaders and stakeholders in the field, and thus has easy access to verifying information or inquiring about historical events in the field.

The researcher's own experiences were supplemented and cross-checked through review of meeting minutes from Miami-Dade County Homeless Trust Board meetings, newspaper articles, and other articles and books regarding the local community. Additionally, informal interviews with the individuals who had helped shape the system over the past 20 years were conducted via daily interactions or phone calls.

While the researcher's personal history of employment with Camillus House and leadership roles with the Homeless Trust does open up opportunities for introduction of bias, it also provides for outstanding access to the service delivery system and to subject recruitment. Every private agency that was asked to provide assistance, by answering questions and/or recruiting subjects, readily agreed. Miami-Dade County, the City of Miami, and the City of Miami Beach all assigned staff to assist with various aspects of 
data collection. The only request from every participating entity was that the results be presented to themselves and the community, so that any relevant findings could be used to improve the delivery system and the lives of the adult, minority men who were the subject of the study. Nobody asked that they be allowed to preview or comment on findings before they were finalized.

\subsection{Summary of the Research Design}

Understanding the intersection of public policy and homelessness is a complex issue. In order to gain a more comprehensive view of the problem, the study was designed employing a mixed methods approach. Analyzing the countywide data sets is intended to provide the broad overview of how minority men are moving through the system, illuminating any clear disparities in program utilization or outcomes between blacks and Hispanics. The semi-structured interviews provide more detail and texture to the data, offering insights into what the numbers mean and possible explanations for disparities. Finally, the PEI component ensures that the voice of the subjects themselves is included. Ultimately, the study results should help to dispel myths about the choices made by homeless men, and to inform the future development of public policy. 


\section{CHAPTER 4: THE MIAMI CONTEXT}

"This is the tourist city right here, but don't forget, this used to be the ghetto, this was the ghetto long, long time ago, until somebody start making this the rich and famous. This was the slums like you say Downtown, this used to be Downtown. This was the little shacks, the little tents, used to be right here. Until everybody just start building it up and everything."

- Richard (homeless in Miami 22 yrs)

By the late 1980s, Miami had an estimated 8,000-10,000 people living on the streets, in parks, and in enormous encampments under the long bridges formed by expressways in the downtown area (Miami Coalition for the Homeless 1987). Families with children lived in cars, or hidden from view inside tent cities. The city was embroiled in a class action lawsuit brought as a result of way in which police officers were responding to the situation, with methods ultimately deemed to be arbitrary, unfair, and unconstitutional (Atkins, Senior US District Judge 1992). As one community leader recalls, "None of us really knew what to do, we just knew we had a big problem and we had to do something."

How did Miami get here? The story of homelessness in Miami is in many ways a direct reflection of the unique history of the city itself. In this Chapter I will discuss how the same social and economic trends that have shaped Miami's development have also shaped its problems with poverty and housing inequality. I will begin by examining how the housing and labor trends manifested in Miami's real estate market, construction industry, and low-wage tourism industry are linked to a lack of affordable housing and poor employment. I will then discuss how Florida's interpretation of welfare reform policies has impacted the social safety net at the local level. The results have placed a large percentage of Miami's population in poverty and at risk of homelessness. 
Responses to homelessness are specific to time and place, with the actions of people who inhabit the city having a significant impact on the context in which people living in extreme poverty move about on a daily basis. I will conclude this chapter by reviewing how Miami's contemporary response to the homelessness problem that exploded with those tent cities in the 1980s began with a mix of motivations, from the civic to the humanitarian to the punitive, culminating in today's homelessness delivery system. Miami provides an excellent example of how complex, nuanced, and even contradictory the responses to homelessness actually are. Here, the public and private sectors are intertwined not only in the creation of homelessness, but also in the solutions to homelessness.

Miami's multi-faceted relationship with poverty and homelessness can be examined within overlapping theoretical frameworks, with the forces of globalization and neoliberalism discussed in a previous chapter clearly evident in both positive and negative ways. Miami offers a glimpse of what may lie in the future for many urban centers. Even as a relatively small city population-wise, Miami has managed to establish its place as a truly "Global City". As one of the original sociologists to use the term "global city" (Sassen and Portes 1993), Sassia Sasken recently explained in an interview why she considers Miami to be the perfect example of a new global city:

"And then there's Miami. Never an old-world city, today Miami is certainly a global city -- why? It's quite surprising. Where did its diversity and complexity come from? Let's go back to the history. Before the 1990s, Miami was sort of a dreadful little spot, frankly. There was lots of domestic tourism; it was cheap; it was rundown; it was seen as dominated by the Cubans. But several important things happened. One was the infrastructure of international trade that the Cubans in Miami developed. There was also real estate development, often spurred by wealthy individuals from South America. All this coincided with the opening of Latin America. In the 1990s and early 2000s, firms from all over the world -- the Taiwanese, Italians, Korean, French, all over -- set up regional headquarters in 
Miami. In the 1990s, there was also deregulation, so Miami becomes the banking center for Central America. Then the art circuit, the designers' circuit, and other things began to come into the city. Large international corporations began to locate branches there, forging a strong bridge with Europe that doesn't run through New York. That mix of cultures -- in such a concentrated space, and covering so many different sectors -- created remarkable diversity and complexity. Of course, the Miami case is rather exceptional" (Larson 2010).

Thus, Miami manifests macro forces at a micro level. As discussed in the rest of this chapter, the development of its safety net for persons who are poor and homeless demonstrates the complexity of local-level responses to global forces. No single theory explains Miami's homelessness system; rather, it is a tangled web of policies and attitudes that are at once punitive and compassionate; conservative and liberal; destructive and constructive. And, it is thoroughly embedded in the character of Miami.

\subsection{Poverty and Housing Trends in Miami}

Homelessness is rooted in large-scale structural problems that begin at national and even global levels, engendering and reproducing inequalities at local and individual levels. In the U.S., these can be grouped into two primary categories: chronic poverty and inadequate housing supply. Each of these issues can be seen at work in Miami.

\section{Income and Employment}

Miami is by most accounts a growing cosmopolitan city, ranked highly on the Global City Index (FP Magazine 2010) for its business activity, human capital, diversity, information exchange, cultural experience, and political engagement. It was also just ranked the \#1 Most Miserable City by Forbes Magazine (Badenhausen 2012):

Miami is a playground for the rich and famous. Celebrities flock to parties at South Beach clubs and then return to their $\$ 10$ million mansions in Miami Beach and Key Biscayne. It's a leading city in culture, finance and international trade. But away from the glitz and glamour, many ordinary Miamians are struggling. A crippling housing crisis has cost multitudes of residents their homes and jobs. The metro 
area has one of the highest violent crime rates in the country and workers face lengthy daily commutes. Add it all up and Miami takes the top spot in our ranking of America's Most Miserable Cities.

The real estate boom and bust has had a particularly significant impact on Miami's economy. From 2002-2007, the biggest growth industry was real estate, which generated $45 \%$ of all economic growth in the area (Cruz 2012). The construction industry, one of the major employers for the entire county, was the hardest hit industry during the recent recession, losing $41.2 \%$ employment from 2007 to 2010 (Eisenhauer and Sanchez 2011).

The area's standing as an international tourism destination serves as an important economic engine, but a heavy reliance on the tourism industry and its attendant low-wage service jobs has given Miami one of America's lowest household median incomes $(\$ 33,000)$ and the country's highest proportion of renters and homeowners who spend $30 \%$ or more of their pay on housing (Padgett 2006). Also of significance is the increasing gap between top and bottom wage earners over the past three decades. From 1979-2010 the wages of those in the bottom $20 \%$ grew $13.8 \%$, while the wages of those in the top $20 \%$ grew by $31.6 \%$ (Eisenhauer and Sanchez 2011). Note that this refers to earned wages, and not to overall income, where disparities are much greater.

Blacks have fared particularly poorly in Miami's labor market. Over the past three decades, unemployment rates for blacks in Florida have consistently been higher than in the nation as a whole, and also significantly higher than for Hispanics or whites. During the recession of the 1980s, the unemployment rate for blacks reached $16.4 \%$, compared to just 6.5\% for whites (Opurum and Eisenhauer 2009). 
In 2011, as the unemployment rate began to come down overall in Miami-Dade, it did not for blacks. As shown Figure 1, while the total unemployment rate for MiamiDade County was $9.8 \%$, compared to $8.2 \%$ for the rest of the country, the rate for Hispanics and white non-Hispanics was actually lower in Miami-Dade than in the rest of the country (Cruz 2012). With an alarmingly high unemployment rate of $16.1 \%$, MiamiDade blacks are significantly higher than their local counterparts, as well as blacks at a national level.

These figures do not take into account the hidden unemployment and “underemployment" rates, which would offer an even drearier picture. Underemployment would include persons no longer listed amongst the unemployed because they have given up looking, as well as persons who are employed but at levels below what they actually desire, such as part-time or contracted workers. Underemployment tends to disproportionately affect service sector and related industries, which rely on part-time and seasonal workers. With many minorities employed in these types of jobs, the underemployment rate is significant. Indeed, a common thread found in many of the interviews discussed in the following chapters was problems with "underemployment," with subjects indicating that they were employed, but with reduced hours, sporadic event work, or other problems keeping their employment income too low to survive. 
Figure 1: 2011 Unemployment Rates for Miami-Dade vs US, by Race/Ethnicity

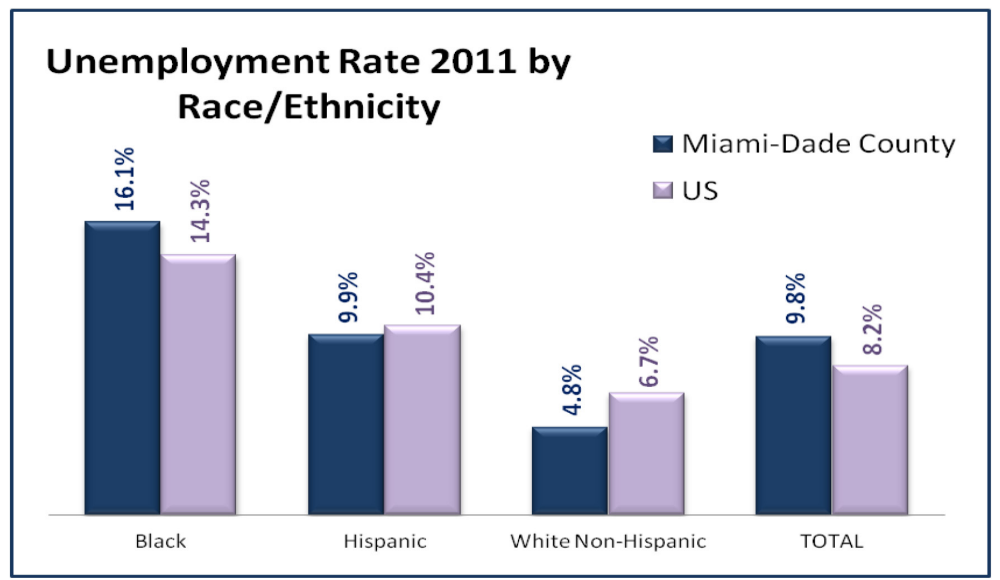

Source: Miami-Dade County Economic Assessment (Cruz)

\section{Housing Affordability}

The previous chapter discussed some of the broader trends at a national level that have contributed to the lack of affordable housing, including gentrification, revitalization, speculation, and the overall reduction in low-income housing stock. Miami is lacking in none of these, and the resulting housing "unaffordibility" is documented in many forms. Most of the various affordability indices and other sources discussed in the rest of this section use a common definition of "housing affordability," which says that a household should spend no more than $30 \%$ of its adjusted gross income for rent or mortgage payments. While exact calculations vary according to factors such as the number of adults and children in the household, geographic location, and income sources, utilization of the $30 \%$ figure as a guideline for determining affordability is a generally accepted indicator (Crowley et al. 2012).

Just as the nation saw a substantial decrease in its low-income housing stock from the 1970s through 1990s, Miami also lost much of its low-income units during this time 
period. The City of Miami, where the majority of low-income households are concentrated, has undergone a long period of gentrification, where low-income rental units have disappeared in favor of new luxury high-rise condos. From 1970 to 2008, there were 29,123 apartment units converted to condominiums in the City (Mensah 2009). The City's Consolidated Plans for 2004-2009 and then for 2009-2013 have focused on severe problems with housing affordability: first, the low-income housing rental market had been decimated by multiple factors; second, the poverty rate, particularly in specific concentrated neighborhoods was extreme, leaving unsubsidized housing out of reach (Haskins 2004; Mensah 2009).

From 1980 through the present, the City has experienced a significant overall loss in multi-family apartment buildings that traditionally support affordable rental housing in older urban neighborhoods, such as East Little Havana and Overtown. These two neighborhoods, designated as Neighborhood Development Zones (NDZ) due to their high poverty levels, are significant here, as the majority of "at-risk" subjects interviewed for this study resided in those two areas. By 2009, while the City's overall rental vacancy rate of 7.7 percent was in line with national trends, the vacancy rate for apartments in buildings over 18 months old, where the vast majority of low-income renters live, was $2 \%$ in 2007 and 5.8\% in 2009 (Mensah 2009). Thus, even as the recession was decimating the incomes of Miami residents, the vacancy rate for affordable units remained exceedingly low, keeping affordable housing out of reach even as rents supposedly fell.

The City's planners attributed the affordable rental housing supply imbalance to several factors: (1) the substantial loss of the City's rental housing supply as a result of 
condominium conversions, (2) the overall decline in rental housing production, and (3) the notable loss of small multi-family structure types. Barriers to construction of affordable housing in the City including land use and public infrastructure policies and decisions that limited private investment opportunities in the NDZs by creating "disincentives" to both private and non-profit developer sponsors (Haskins 2004; Mensah 2009).

Not only has Miami lost a great deal of affordable housing stock, but the stock that is left is far out of reach of the average low-income worker, and impossible for the extremely low-income. The Miami metropolitan area ranks nationally in the top $10 \%$ of least affordable rental markets (Center for Housing Policy 2012) and this affordability gap has persisted for many years. Within the City of Miami there is no neighborhood where an average household could afford to purchase a home without being cost burdened (Mensah 2009). Further, national studies have found that even when affordable housing exists in communities, it is frequently occupied by higher income individuals who could afford more expensive housing but choose to conserve their housing expenditures, thus bumping the lower-income households out of the market (Bolton 2012).

Numerous housing indexes focus on housing affordability specifically for renters, since it is low-income households that are more likely to be renters. Given that fully $42 \%$ of total households in Miami-Dade are renters (Crowley et al. 2012), and 64\% within the City of Miami are renters (US Census Bureau 2012), the implications for affordability in Miami are significant. In the NDZs of Overtown and Little Havana, $87 \%$ and $91 \%$ of respective households are renters (Mensah 2009). 
The National Low Income Housing Coalition’s 2012 annual report analyzing housing costs nationwide compared the Minimum Wage, Area Median Income (AMI), and Fair Market Rent (FMR) in metropolitan areas (Crowley et al. 2012). Using US HUD's calculation that households should spend no more than $30 \%$ of income on housing, there is not a single place in the United States where a household earning the minimum wage or average renter's wage working 40 hours per week can afford the FMR for a 2-bedroom apartment (Crowley et al. 2012). The Housing Wage, the estimated fulltime hourly wage need to afford a two-bedroom apartment at the FMR, exceeds the actual mean renter's wage in $86 \%$ of counties nationwide.

The Miami-Dade area scores particularly poorly in this area. In 2012, the FMRs established by HUD were $\$ 1,125$ for a two-bedroom apartment, $\$ 927$ for a one-bedroom apartment, and \$819 for an efficiency (Miami-Dade County Public Housing and Community Development 2012). In order to afford a two-bedroom apartment at the 2012 FMR of $\$ 1,125$, a household would need to earn at least $\$ 21.63$ per hour, working 40 hours per week, 52 weeks per year, in order to fall within HUD's guidelines for housing affordability. Yet, the estimated mean hourly wage for a renter is $\$ 14.46$, making an affordable monthly rent $\$ 752$ (Crowley et al. 2012).

The numbers are even harsher for persons at the lower end of the income spectrum. A person earning Florida’s minimum wage of $\$ 7.67$ would need to work 2.8 full-time jobs in order to afford a two-bedroom unit at the FMR. Nationally, one out of four renters are considered "Extremely Low Income" (ELI), with an income that is less than $30 \%$ of the Area Median Income (AMI). With Miami-Dade County's AMI at $\$ 52,600$, ELI households have an average annual income less than $\$ 15,780$, so that a 
monthly affordable rent is $\$ 395$. For persons living on Social Security Disability Income, the maximum federal monthly payment is \$698, making \$209 in monthly rent affordable. Yet, Miami-Dade’s FMR for an efficiency unit is $\$ 819$.

The gap is even wider within the City of Miami. With an average per capita income of $\$ 19,745,27.3 \%$ of the City population lives below the poverty level (US Census Bureau 2012). City planners project that by the year 2015, 24\% of all households will be of extremely low-income, $15 \%$ will be of very low-income and $17 \%$ of all households will have low to moderate incomes. Together, the extremely-low to low to moderate income level households will make up 56\% of future households that will be eligible for housing assistance. Further, fully $35 \%$ of households in the NDZs earn less than $\$ 10,000$ per year. Within the Overtown neighborhood where many of this study's participants lived, $41 \%$ of households were in that lowest income category. The Little Havana neighborhood had the largest number of households making under $\$ 10,000$.

Loss of housing units can also be attributed to an aging and increasingly substandard housing stock, particularly concentrated in the extremely low income neighborhoods of Overtown and East Little Havana. More than $72 \%$ of all occupied units in the City are more than 30 years old (US Census Bureau 2012). Code enforcement complaints regarding multiple families living crammed into single units, or building illegal structures to accommodate additional residents, were increasing (Haskins 2004).

The Miami-Dade area saw many units disappear not only to the usual cycles of speculation and development, but also to hurricanes that wiped out tens of thousands of units. Hurricane Andrew destroyed 63,000 homes in 1992 (HurricaneCity 2012). By the end of the 2005 hurricane season, when Hurricanes Katrina, Wilma and Rita ravaged the 
Miami area one storm after the other, more than 16,000 were damaged so badly that they required blue tarps over their roofs to keep the rain out. The ubiquitous "blue roofs" lasted for more than a year. The dire housing crisis already affecting Miami-Dade County was the primary factor in turning what could have been just a bad storm into a lifechanging event for many. One Red Cross shelter manager summed up the problem in describing the plight of the nearly 200 families forced to live in an emergency shelter for weeks afterward, saying "There are a lot of hotels in Miami, but there are very few facilities for the low-income. The light at the end of the tunnel here was smaller than the light at the end of the tunnel in other disasters," (Bradley 2005: p1B).

The hurricanes exposed a vast subpopulation of persons living in extreme poverty on the edge of homelessness, making explicit the linkage between ongoing poverty and homelessness. It was evident that those most vulnerable to sudden loss of housing were not the middle class. Those households, even when confronted with collapsing houses, managed to access other resources through family and friends. They were not, as the saying goes, "one paycheck away from homelessness." One local agency responsible for providing rental assistance to families displaced by the storms confirmed that the applicants were persons who were already living in marginal or substandard housing and who were "pushed over the edge" by the storm. As with many other organizations working with storm victims, staff found themselves dealing with many "special cases" and co-occurring problems in working with the storm victims. The agency's director explained:

"The people we were helping were not middle class folks who suddenly lost everything in the storm. They had been struggling before hand, and the storm was just the final straw. So they didn't just need housing 
assistance, they also needed help with education, employment, health care, drug treatment, and all kinds of supportive services."

When the 2005 storms exposed the County's overall lack of quality affordable housing to an alarming and highly visible degree, the community was temporarily moved to address the underlying issue. The Board of the newly established Partnership for Recovery (PFR) organization, comprised mainly of local corporate CEOs dedicated to helping oversee the recovery, initially declared that its mission would be two-fold: to address the immediate housing repair needs of victims and to address the long-term need for quality affordable housing. Board members spoke eloquently of the opportunity to harness community interest to effect real, long-term change in housing policy. A Subcommittee on Housing was established to take on the all-important affordable housing issue, the County Manager pledged county resources and participation, and public and private leaders signed on for the work ahead. New legislation requiring inclusionary zoning, which would have required incorporation of affordable housing along with all the new luxury units, was drafted.

Alas, the community-wide discussion recognizing the undeniable linkage between disasters, poverty, and poor housing stock was short-lived. The County Commission passed a watered-down version of the inclusionary zoning legislation that made participation voluntary and gave many concessions to housing developers. While the Miami Herald continued publishing articles that focused on Miami's housing crisis, the articles no longer pointed out the linkage to disasters. The community repaired the blue roofs and moved on. 


\subsection{Welfare Benefits in Miami}

The neoliberal welfare reforms that took place beginning 1996 were implemented in the State of Florida with particularly stringent requirements. The State offers no General Assistance welfare benefits of its own. Even homeless individuals are offered no form of direct cash support. The only cash assistance provided is the federal pass through of the Temporary Assistance to Needy Families (TANF) program, thereby eliminating single adults from eligibility for any support outside of social security or disability benefits.

Even attaining unemployment benefits which individuals have rightfully earned is more difficult in Florida than anywhere else in the country. The proportion of unemployed people who actually receive jobless benefits in Florida is $16 \%$, the country's lowest. Only one in three applicants for unemployment compensation in Florida receives any money. The difficulty in receiving unemployment was triggered by new requirements established by the Governor's office, with many groups suggesting an outright malicious attempt to lower the state's official unemployment rate by artificially reducing the number of persons receiving benefits. Requirements, which include completing a 45question skills assessment and applying only online, are particularly cumbersome for lower-income and lower-skilled individuals. The state also reduced the availability of benefits from 26 weeks down to 23 , even as other states lengthened periods of support (Olorunnipa 2012).

Housing subsidies are not an entitlement in Miami-Dade. Thus, tens of thousands of households who qualify for some type of rental assistance remain on long waiting lists. There are no priorities for persons who are homeless for standard mainstream housing 
subsidies, such as Section 8 vouchers or public housing, although it must also be noted that there are other specialized forms of assistance available through the homelessness delivery system. The number of households who qualify for scarce public housing assistance is so great that the county's Department of Public Housing maintains a waiting list for which it is extremely difficult to gain access to. Applications to the waiting list from the general public have not been accepted for the past four years. The last time the waiting list was opened, in July 2008, applications were accepted for a 10-day period only. The waiting list order was determined by lottery (Miami-Dade County Public Housing and Community Development 2012). As of September 2012, 70,000 households remained on the waiting list for public housing assistance through Section 8 or projectbased public housing assistance. The waiting list was opened once again for ten days in 2011, but only for applications from elderly households. Persons who do not hear about the 10-day window for application or who are unable to access help in applying during that time period have no recourse.

The Supplemental Nutrition Assistance Program (SNAP), formerly known as Food Stamps, has on the other hand found widespread implementation in Florida. The state ranks fourth in number of persons receiving the benefit. Funding for the program comes from the federal level and is the only form of welfare available to virtually all financially eligible households. In spite of the high number of persons receiving SNAP, though, Florida remains in the bottom of states regarding percentage of households who are raised out of poverty due to receipt of the benefit (Eslami, Filion, and Strayer 2011). Indeed, as discussed in the following chapters, food stamps were the one benefit reported as being readily accessible by nearly all interviewees. 
With the State of Florida not demonstrating much inclination to expand availability of public benefits any time soon, much of the responsibility for addressing the needs of persons living in extreme poverty or homelessness falls to counties and cities at the local level. How has Miami taken on the monumental task of addressing the needs of an extremely poor and vulnerable population?

\subsection{Miami’s Response to Homelessness}

In stark contrast to the stingy and sometimes draconian system of public benefits available to Miami residents stands the current system addressing homelessness. While still fraught with problems, the current system of care coordinated through the MiamiDade County Homeless Trust has been lauded by HUD as a "National Model" and "Best Practice" (Miami-Dade County Homeless Trust 2012a) and is frequently ranked in the top two or three systems in the country (Donley and Wright 2009). The story of how it came into being, however, suggests that it is not necessarily a purely altruistic endeavor of an unusually generous community. Rather, it is the culmination of rather messy mix of neoliberal policy development, pragmatic planning, and genuine compassion. Sometimes, the compassion was court-ordered.

As the 1980s decade was drawing to a close, Miami was undergoing the same alarming surge in visible homelessness that had overtaken the entire nation. An estimated $8,000-10,000$ persons (Miami Coalition for the Homeless 1987) lived on its streets, in parks, in abandoned buildings, and, most noticeably, in vast encampments spread under downtown's expressways. Two decades later, however, the number of persons living on the streets had been reduced to 894 . How did this change come about? 
Dissecting the development of Miami's homelessness response offers the opportunity to explore the many theoretical frameworks that have been used to explain communities' responses to poverty and homelessness over the past several decades. The remainder of this chapter will highlight two seminal events that illustrate the many facets of Miami's history with homelessness: the Pottinger v City of Miami settlement (Atkins, Senior US District Judge 1992) and the establishment of the Miami Homeless Plan.

First, the body of literature surrounding the question of who has the right to the city and its public places? (Mitchell 2003; Smith 1996; Wakin 2008; Wolch and Dear 1993; Wright 1997) can have no better case study than the Pottinger vs City of Miami case. Building upon the work of Lefebvre (1971) and Marx (1976), scholars have examined how social, political, and economic forces shape the discourse and practice around use of public space. They describe a system so driven by capitalism's unending drive for greater accumulation of wealth that the very right of the poor to exist is questioned, and inner city neighborhoods become hotly contested landscapes where those with political, economic, and social power seek to reshape their environment to their benefit. There is no doubt that Miami can be seen here.

Second, however, is more recent literature where some scholars have questioned this punitive framework, calling for a more nuanced approach within a context of "poverty management," described as the organized responses by elites and/or the state to contain potentially disruptive populations through a managerial and somewhat ambivalent response (DeVerteuil 2006). In this viewpoint, it remains important to consider the punitive measures, but it is also important to examine the many other responses seen around the country, including development of shelters and supportive 
services. The community's efforts to develop and implement the Miami Homeless Plan certainly suggest more at work than purely punitive motives.

\section{The Case of Pottinger $v$ the City of Miami}

Many scholars have posited a hostile, punitive and even vengeful underpinning to the development of policies aimed at moving persons who are homeless out of public spaces. Mike Davis (1990) examined the trend toward the co-opting of public space in his social history of Los Angeles, describing cities divided into private, gated spaces, where the built environment is transformed into fortified enclaves designed to keep out crime, disorder and the Other. The rich hire their own police forces, and policies of containment of persons who are poor and homeless emerge. Neil Smith (1996) takes an even more pessimistic view, describing the "revanchist city" as a place where outright vengeful policies and punitive measures designed to force the poor out of public places. Smith suggests that the negative effects that globalization has had on the middle and upper classes (although not the top elites), including declining real wages and loss of health care benefits, have led to a sense of anger and betrayal. Because "capitalism" and "globalization" are nebulous targets, unhappiness that should be directed at "the system" becomes hostility toward the most visible "problems" - the poor and marginalized, who are then blamed and punished for all that is wrong. Urban cities are transformed into dark places where the upper classes conspire against minorities, working people, the poor and homeless to create a "revanchist" city where gentrification is used as a weapon of revenge. Don Mitchell (1997; 2003) builds upon Davis and Smith in his argument that we have moved beyond revanchism to a "post justice" city, where the goal is no longer to move homeless people out of public spaces, but to annihilate them completely. Here, 
anti-homeless polices are designed to remove homeless people in an effort to make cities more attractive to capital. Subsidies are provided to corporations and public space is coopted for the desires of power-elites.

In 1988 Miami found itself in a massive fight over the use of public space, culminating in the landmark court case of Pottinger v City of Miami (Atkins, Senior US District Judge 1992) which was finally settled in 1992. Of course, the argument over public space did not begin in 1988 and did not end in 1992.

As previously described, the late 1980s saw an explosion of homelessness in U.S. cities, and Miami was no exception. Thousands of individuals and families lived in public areas, including, most noticeably, in downtown Miami's Bicentennial Park and in large encampments that spread for blocks underneath the expressways next to Biscayne Bay.

One of the largest encampments, known as the Mudflats, was located under the intersection of I-95 interstate highway and 836 Dolphin Expressway, both of which cut their way through the historically black neighborhood of Overtown. Formerly named "Colored Town," Overtown had been a thriving African-American neighborhood through the 1940s and 1950s, providing a home to many of that era's black luminaries. Legendary performers such as Ella Fitzgerald, Count Basie, and Cab Calloway had lodged in Overtown while not allowed to stay on Miami Beach when performing there. Still, Overtown had fallen into deep decline beginning in the 1960s. The neighborhood was beset with widespread poverty as jobs left in the 1960s and 1970s, and then ravaged by the crack cocaine epidemic and race riots in the 1980s (Portes and Stepick 1993). Many also blamed the deterioration of Overtown on the construction of I-95 and the 836 Dolphin Expressway, which were built in a way that literally divided the community in 
half, turning the previously walkable streets of a close-knit community into fragmented areas separated by impassable blockades preventing residents from moving from one side of town to the other.

While the homeless population in downtown Miami was viewed with great sympathy by many in the county, it was not so popular with those who lived or worked in the area. Many Miami residents were resentful of the panhandlers, drug users, and "vagrants" inhabiting public parks, including in particular the downtown Bicentennial Park. City officials were frequently called upon by constituents to do something about homeless individuals staying in specific areas, and they directed police officers to arrest and remove them by using any law possible.

The City of Miami police department responded with tactics so harsh that in 1988 the American Civil Liberties Union (ACLU) filed a class action lawsuit on behalf of Miami’s homeless population: Michael Pottinger, Peter Carter, Berry Young et al, Plaintiffs, vs. City of Miami (Atkins, Senior US District Judge 1992). Since it had already been found unconstitutional to arrest people for simple vagrancy, police had to find other reasons to remove persons from public places, and so invoked laws regarding trespassing, loitering, obstructing sidewalk, being in parks after hours, and other minor offenses. During the Pottinger hearings, plaintiffs presented 3,500 arrest records of homeless persons from 1987-1991, demonstrating a clear pattern of arrests for non-criminal, minor offenses such as sitting on pieces of cardboard or milk crates that did not belong to them, lying down on sidewalks, or even congregating in groups in parks. "Bum sweeps" or 'street sweeps" were conducted on a regular basis, arresting anyone who looked homeless in order to clear the streets before events such as the Orange Bowl. In one particularly 
egregious practice, homeless persons' personal belongings would be declared trash and disposed of. Few arrests even resulted in actual charges being filed, making it impossible for the "criminals" to even mount a defense. The arrests served their purpose quite well without any need for charges, as processing someone through being released still kept them off the street for a period of time and gave opportunity to dispose of all their personal belongings.

The first part of the class action lawsuit filed in December 1988 alleged that the "City of Miami has a practice and policy of arresting, harassing, and otherwise interfering with homeless people for engaging in basic activities of daily life, including sleeping and eating in the public places where they are forced to live" (Atkins, Senior US District Judge 1992:1). The suit also accused the city of using its arrest powers for purposes of "pest control" to "sanitize" the streets of unwanted homeless persons. The suit went on for a period of four years, with the court issuing numerous injunctions against the City in response to specific instances, with those injunctions frequently violated, bringing everybody back to the courtroom. Two incidents from Spring 1990 triggered the first serious injunction. In the first of these incidents, police officers woke up homeless individuals in the middle of the night, hand cuffed them, and then proceeded to dump all of their belongings, including personal identification, medications, and even a bible, into a pile which was set ablaze as they were forced to watch. The court ordered the police department to start following its own written policies regarding proper treatment of personal belongings. Similar incidents continued, though, and the City was found in contempt of court multiple times. 
As the case wound its way through the court system, several key issues were debated at length. Was the city's interest in maintaining its park and public areas, for purposes of promoting both business and tourism, compelling enough to warrant arresting persons for simply being homeless? Were there better options for dealing with the homeless problem? Most importantly, the case hinged on the question of whether or not homelessness was a choice. If it were a choice, perhaps police departments were somewhat justified in moving persons out of public spaces. If it were not a choice, however, then arresting persons who were involuntarily homeless could be deemed not only inhumane, but also unconstitutional.

Expert witnesses were called upon to testify about whether homelessness was a choice or was due to circumstances and factors beyond one's control. Judge Akins, noting testimony from sociologist James Wright and local doctor to the homeless, Dr. Pedro Jose Greer, Jr., declared that "homeless people rarely choose to be homeless." The judge went on to point out that with only 700 shelter beds available in the City to serve an estimated population of 6,000, "the plaintiffs clearly have no place to go" (Atkins, Senior US District Judge 1992 p6)

Some have suggested that this case was successful only because its final hearings coincided with the post- Hurricane Andrew period in Miami, when the hurricane had resulted in an estimated 20-25,000 people being made homeless through no fault or choice of their own (Howell 2007). Not only were these individuals were clearly involuntarily homeless, they were a sympathetic example of "the deserving poor." The court, declining the city's request to differentiate between victims of disaster and victims of economic hardships, now had no choice but to accept the testimony of those 
explaining how economic, physical, and psychological factors beyond the individual's control constrained the ability to leave homelessness.

When the case finally reached its conclusion in the fall of 1992, Judge Atkins found that (1992):

Plaintiffs have established that the City has a policy and practice of arresting homeless individuals for the purpose of driving them from public areas. The court concludes that the City's practice of arresting homeless individuals for performing inoffensive conduct in public when they have no place to go is cruel and unusual in violation of the eighth amendment, is overbroad to the extent that it reaches innocent acts in violation of the due process clause of the fourteenth amendment and infringes on the fundamental right to travel in violation of the equal protection clause of the fourteenth amendment. The court further concludes that the City's seizure of plaintiffs' personal property violates their fourth amendment rights (P 15).

The City of Miami was enjoined from arresting homeless individuals who are forced to live in public for performing innocent, harmless, or inoffensive acts such as sleeping, eating, lying down or sitting. The City was further ordered to establish at least two arrest-free zones where individuals with no alternatives could stay. And, via the settlement portion of the case, the City had to pay restitution to those in the class of individuals represented in the case. The concept of "choice" remained central - the underlying implication was that if individuals did have an alternative to homelessness, then the city was no longer enjoined from arresting them. To the police, politicians, and others in the community, this translated into meaning that you had to offer a homeless person a bed to stay in before you could take them to jail. They were going to need more shelter beds before they could return to arresting people who were homeless. 
Figure 2: (photo) Under the 395 overpass, downtown Miami

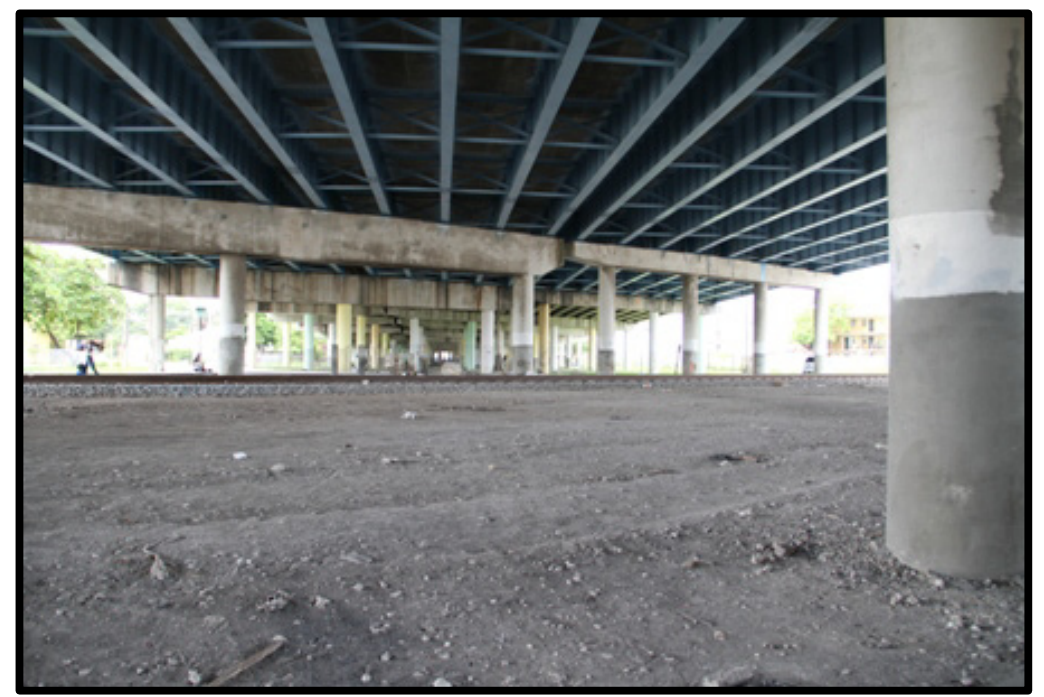

Underneath the 395 overpass, where thousands of individuals lived in encampments in the late 1980 s and early 1990 s.

Today, the area under the bridges has been cleared and fenced off to prevent new camps from appearing.

Twenty years later, the Pottinger case remains a contentious issue with many interests within the City of Miami. In particular, those businesses and residents who continue to contend with homeless persons sleeping, performing daily activities including eating and urinating, and/or pan-handling in front of their stores or homes are particularly vocal about blaming the Pottinger case for wrongfully taking away their own rights to live and operate in a safe and clean environment. A commonly cited perception is that today's homeless population is indeed homeless by choice, even though every homeless program in the county still maintains waiting lists for entry into housing or programs. Nonetheless, it is also true that the population on the street today is much more resistant to accepting services than the population living there two decades ago. How much "choice" is involved is a debated point.

In 2009, numerous groups began asking that the City direct its attorney to research how to overturn Pottinger. The Downtown Development Authority (DDA), a 
coalition representing businesses in the downtown area, expressed its extreme frustration with the population of persons living, eating, urinating, and pan-handling in public, declaring that "Pottinger has done more harm to downtown than anywhere else," (Lackner 2010). A public official working with the DDA stated unequivocally that "Pottinger is baloney. There's an industry built around the homeless issue. Just like we have code enforcement, we should mandate that it's illegal to sleep on the streets" (Lackner 2010). Resident groups from local condominiums and neighborhoods along Biscayne Boulevard, where some homeless persons had migrated, also complained that Pottinger had taken away the ability of police to enforce laws (Biscayne Bay Residents Association 2009).

In 2011, the City Commission attempted to enact legislation prohibiting anyone from providing food to persons living on the streets in downtown, professing a belief that "street feeders" were encouraging and enabling homelessness. After numerous contentious meetings, the issue was dropped when it was learned that the City lacked the necessary jurisdiction. Subsequently, the Commission Vice-Chair took up the Pottinger case as an issue, expressing a desire to have the case findings overturned on appeal. While as of September 2012 the City of Miami as an official entity had itself taken no official action against the Pottinger settlement, the Commission Vice-Chair continued to work with the City attorney to highlight repealing Pottinger as a priority desire.

\section{The Miami Homeless Plan}

As the Pottinger case was addressing Miami's homeless problem from a legal standpoint, others in the community were simultaneously considering it from a more civic point of view. By the time the City of Miami was officially enjoined by the courts 
to take better action in dealing with its homeless population, Miami-Dade County had already taken significant steps to develop a comprehensive plan to address the problem. The "Miami Homeless Plan" (the Plan) was developed as a pragmatic way to serve both public and private interests, attempting to solve the community's problem of unwanted homelessness, under the leadership of individuals working at least in part from a religiously-based sense of compassion.

The Pottinger Case and development of the Plan were certainly intertwined, although no formal direct link existed between the two. As one of the leaders of the Plan's development explained, "Well, Pottinger was this cloud hanging over the City of Miami the whole time we were working on this plan. It was on our mind, but it wasn't the direct reason we were working on the problem. We just needed to do something about this huge problem with thousands of homeless people."

Another community leader involved in development of the Plan explained his motivation for getting involved:

You know how the homeless problem was growing in the 1980s, we had all those encampments under the expressway. Every time we went to a Heat game at the Miami Arena, I had to explain to my kids why there were all these people with all their belongings on the sidewalk. But what I'll never forget was going home one day after the Grand Prix, which ran through downtown by Bicentennial Park, and watching the news to see the race on tv. And what dominated the screen was all the little shanty cardboard and plywood shacks built on the opposite side of the track. It was prominent and looked terrible -and that was what Miami was showing the world! We had a big embarrassing mess to fix.

The Plan was largely developed under the leadership of Alvah H. Chapman, Jr., a true power-broker in the Miami community who had played a crucial role in the development of Miami through the 70s and 80s. In addition to being the former CEO of 
Knight Ridder, which published the Miami Herald, he chaired the Greater Miami

Chamber of Commerce (GMCC) and the New World Center Action Committee, through which he proposed, aided, and assisted in bringing more than a billion dollars worth of development to the downtown Miami area. He considered himself to be very prodevelopment (City of Miami Commission 2007). When he'd become frustrated with the slow pace of getting things done in the community through the slow-paced structure of GMCC committees or other public processes, he formed what was known as the "NonGroup,” an informal association of local CEOs and other hand-picked leaders from throughout the committee (Stepick et al. 2003). The Non-Group wielded a good amount of power due its elite membership, yet was accountable to no one given that it was nothing more than an unofficial group of individuals who agreed to meet, usually over breakfast, once a month to talk about things that needed to be done in the Miami community. As the de-facto leader of this group, Alvah had ready access to a built-in power structure highly responsive to his requests. His connections proved extremely helpful when he took on homelessness as his primary issue, as he certainly had the personal stature and influence necessary to persuade others to get involved.

In 1991 the visibility of the massive amounts of people living in downtown Miami caught Alvah's attention when he moved to a new home which changed his morning commute to take him right by the "Mud Flats" tent city under I-95. He explained how he was soon enticed into taking on the problem (Kendrick 2001):

There was a terrible condition that existed in the middle of our city. I was sure somebody was "working on this." It was too serious a problem for someone not to be working on a plan. I wasn't aware of the plan, but I was sure that I would find the plan somewhere if I looked hard enough. That turned out not to be the case, because there was no plan. There was 
no money; there was no leadership; there was no ownership. The county said it was a city problem. The city said it was a county problem. And the Chamber of Commerce was not sure it was their problem. It turned out to be a problem that was awaiting resolution, awaiting leadership, awaiting someone to be in front of the parade. " P 6.

He goes on to describe praying over the issue with his wife and bible study group before deciding he had a duty to use his God-given leadership skills to address the homeless problem. In 1992 Governor Lawtwon Chiles appointed Alvah to chair the "Governor's Commission on the Homeless," tasked with developing a strategic plan for dealing with Miami's homeless problem. The committee devised a broad plan which required approval from the State Legislature. Gaining that approval has been described by many involved as a miracle (Kendrick 2001), with the measure passing in the last six minutes of that year's session. It only made it onto the agenda through a series of requests for personal favors by Alvah and his powerful task force members, who used their access to lobbyists and legislators to push the measure through.

The State legislature directed Miami-Dade County to form a new Task Force to develop a detailed implementation plan. The Task Force was co-chaired by Alvah Chapman, who largely represented the civic community, and Alex Penelas, who largely represented the political community. Alex later went on to become County Mayor. On the one hand, Task Force meetings were deeply contentious with much disagreement over how to proceed and most votes closely split. On the other hand, its influential members remained deeply committed to the process, meeting twice a week in early morning hours, to develop a fairly complex plan within a mere six weeks. They visited other cities to see what they were doing on homelessness. Many members freely admit that they knew little about homelessness, except that it was a big problem Miami had to 
solve. When it came time to vote on the final recommendations, the group set aside their differences and held hands to make a unanimous seconding of the motion to pass the recommendations.

In July 1993, the newly constituted 13-member Miami-Dade County Board of Commissioners unanimously adopted the group's recommendations, which called for two major initiatives: First, it levied a new 1\% Food and Beverage sales tax on restaurants in the County. The Task Force had recommended that the tax exclude Miami Beach and smaller restaurants without a liquor licenses, which effectively exempted all the fast food chains, whose corporate headquarters would likely have been a significant source of opposition to the tax. Additionally, it ensured that the tax targeted "persons who could afford to be eating nice dinners, not persons who were struggling for money and eating at Kentucky Fried Chicken.” As it was, the tax found little opposition, and has been renewed by the Commission every five years since then with little comment. The Commission's vote also created the Miami-Dade Homeless Trust, a public-private entity which would have responsibility for administering the tax dollars and coordinating the continuum of care services proposed by the Plan. Task Force members still speak of amazement at the "miracle" of getting the new County Commission to make its first act to pass a new tax.

The second major component passed was the directive to create a private partner entity that would fundraise and build up to three major new emergency housing facilities for homeless individuals and families. The Task Force had come to the conclusion that solving the homeless problem was neither a public nor private issue alone - it was something to be taken on by the community as a whole. More than 400 community 
leaders showed up to the first planning meeting regarding this new private partner entity, with over half signing commitment forms on the spot to give money or time (Kendrick 2001). The Community Partnership for Homeless was formed to serve as the private sector partner for the Miami Homeless Plan.

When the fundraising began, it was again accomplished through the personal commitment of Alvah and his connections. They took a calculated approach, believing that they needed six-figure gifts from all the local corporations, not wanting smaller $\$ 10,000$ gifts. They used their personal capital to get there. Alvah explained (2001 p20), "We said, in order for us to raise money in our community, and to establish credibility, we needed to have some very significant individual gifts from people who care about this community." His first stop was to his good friend Ted Arison, where they dined on Arison's yacht docked at Fisher Island. The Fisher Island census area is the wealthiest in the U.S., with its 2010 median income of $\$ 250,000$ and a poverty rate of $0 \%$ (Florida Demographics 2012). It is directly adjacent to Overtown, which has an average per capita income of $\$ 9,778$ and a poverty rate of $53.2 \%$ (Areavibes 2012), making for one of the greatest income disparities between any adjacent zip codes in the country. Alvah left the meeting with a $\$ 500,000$ commitment from the Arisons, and nearly every local corporation followed suit with significant private support as expected. Approximately $\$ 13,000,000$ was raised for the Community Partnership, and the planned public-private partnership between the Homeless Trust and Community Partnership was launched.

Not everybody agreed with the path chosen by the Homeless Task Force and Community Partnership. The Greater Miami Chamber of Commerce had also formed its own Homelessness Subcommittee in the early 1990s, with the same intent of addressing 
the massive homelessness problem in the community. With close ties to Alvah and his Non-Group, the Committee originally worked in concert with the County's Homelessness Task Force. However, serious differences in opinion regarding the best solution resulted in a split in 1993, with the Chamber's Homeless Committee separating itself from the larger Homeless Task Force. While also working under the leadership of prominent business leaders, this committee believed a better solution lay in developing more affordable housing, rather than more shelters. They formed a new non-profit organization, Carrfour Supportive Housing, with a goal of developing 1500 new units of housing for the homeless. The ongoing close relationship between the GMCC and Carrfour was evidenced by the fact that the GMCC homeless committee served as Carrfour's original Board of Directors, with meetings taking place at the GMCC offices. This non-profit was clearly a project of the business community.

The Carrfour organization was particularly sophisticated in its approach to attaining financing for housing construction, and was the first homelessness agency in the country to attain Low Income Housing Tax Credits for homeless units, thereby gaining access to a significantly greater source of public funding than other agencies were using, bringing in tens of millions of dollars in federal funding and equity investors to the local community. Their development activities, however, were not engendering more gentrification, but were actively creating housing for persons who were extremely low income and homeless. Today, Carrfour is a prominent member of the Homeless Trust's network, and has become the community's largest developer of supported housing for homeless individuals and families, surpassing its goal of developing 1500 new units. Few remember that the organization was begun as a project of the Chamber of Commerce. 


\subsection{Establishment of Miami's Homelessness Services System}

The original Miami Homeless Plan passed in 1993 has remained in effect through 2012, and its emphasis on the need for equal participation by the public and private sectors remains. The Food and Beverage tax has seen increased revenue throughout its duration, bringing in more than $\$ 97,000,000$ by the end of 2011 (Miami-Dade County Homeless Trust 2012a). Even during the economic recession beginning in 2008, revenues from the tax held steady, as people in Miami continued to dine out. These revenues helped provide Miami with a small buffer against all the other cuts to homelessness services made at State and Federal levels. In addition to the local tax, the Homeless Trust receives federal funds provided through the federal Stewart B. McKinney Homelessness Assistance Act of 1986 (1987). The Homeless Trust now coordinates a network of 27 local homeless provider agencies that construct and operate housing and services for persons who are homeless. More than 5,000 units of emergency, transitional and permanent housing for persons who are homeless have been built under the Trust's leadership (Miami-Dade County Homeless Trust 2012a).

The Homeless Trust itself is a public agency, formed as a department within Miami-Dade County government, but is governed by an independent Board of Directors comprised of representatives appointed by the Chamber of Commerce, the League of Cities, faith-based coalitions, and the local School Board, as well as local homelessness providers and individuals who have experienced homelessness. The question of "choice" has remained at the forefront of Homeless Trust policy development, and the entity has made concerted efforts to make sure its program models evolve with current research calling for more consumer, i.e. homeless individuals', choice in homeless programs. The 
original "Continuum of Care" model instituted in 1994 called for what was then a cutting-edge program design whereby individuals were moved through the system from emergency to transitional to permanent housing, succeeding if they complied with all the rules, regulations, and requirements along the way. While this was extremely helpful to many segments of the homeless population, there were many who were not as successful in a system with such rigorous controls. Curfews, case management plans, drug tests, and answering to staff did not seem like a very good "choice" to some individuals, including particularly single men who'd grown accustomed to the freedom of life on the streets. In fact, these issues were paramount in the concerns of subjects interviewed for this study. That is not to say, however, that these individuals would choose homelessness over housing; they would just choose it over life in a controlling shelter environment. Many posit that for these particular homeless men, this is indeed a very rational choice (Sosin and Grossman 2003; Tsemberis, Gulcur, and Nakae 2004).

Thus, embracing national research pointing to new program models that offered more choices with fewer rules, the Homeless Trust began reallocating funding to implement these new models. The minutes of Board meetings reflect rigorous debates about the line between offering choice to individuals, and simply enabling destructive behaviors, particularly relating to drug use. The impact of these new models, where individuals are placed into housing without having to first complete rigorous program requirements, has been great for those who were placed into the program. During the process of interviewing subjects for this study, several of the men who had spent 10 years or more living on the streets were placed into permanent housing situations, through these new style of programs. However, the extent to which these newer program models will be 
able to address homelessness is not yet known, with the long-term outcomes having many nuances and unknowns. Questions regarding cost effectiveness for persons without serious disabilities, funding sources, and the appropriateness of the model for specific subpopulations remain unanswered. Regardless of the social justice perspective, these programs are expensive operate and thus unable to serve the entire population of individuals who would benefit.

\subsection{Summarizing the Response}

Like most cities across the U.S., Miami witnessed an explosion of visible homelessness in the 1980s, finding itself utterly unprepared to handle the thousands of individuals and families suddenly living on its streets downtown. The causes can be traced back to the same national trends in housing and labor markets discussed in earlier chapters - affordable housing became scarcer as employment became harder to attain. Already a poor city, Miami was hit hard.

The development of Miami's Homelessness Plan, which was created at the same time Miami was contending with the Pottinger vs City of Miami lawsuit, provided a basis for establishing what would eventually become a national model for approaches to homelessness. With community leaders from many different sectors all involved, each for their own personal reasons, the plan was embraced at high levels and provided with enough resources for implementation.

Miami's response to homelessness can be viewed within several frameworks. From a neoliberal development perspective, it has provided a pragmatic way to move people off of the streets, clearing the way for development of the downtown area while still complying with the Pottinger court order. From a more punitive neoliberal 
perspective, it was a forced response after years of banishment policies resulted in the Pottinger court order, with the construction of shelters offering a means to resume policies of harassment and neglect. From a poverty management perspective, it provided a means to deal with 8,000 homeless persons without having to address Miami's extreme levels of income inequality and one of the worst housing markets in the U.S. It is important to note here, however, that that formation of Carrfour Supportive Housing by the Chamber of Commerce did represent a real effort by the business community to address the housing problem, rather than just the homeless problem. From a welfare state perspective, it provided an official government effort to establish a safety net for persons at the very lowest rungs of society. And, from a purely humanistic perspective, it has been an altruistic and compassionate response to persons in need.

However, regardless of the motives and primary driving forces behind Miami's response to homelessness, the empirical evidence of the results is undeniable: Miami has reduced the number of persons on the street to 894 , an $89 \%$ reduction in 16 years. 


\section{CHAPTER 5: CONTEMPORARY HOMELESSNESS IN MIAMI}

After decades of research on the characteristics of persons who are homeless, one of the most common findings is the heterogeneity of the overall population (Burt et al. 1999; Burt et al. 1999; Rosenheck, Bassuk, and Salomon 1998). While persons who are homeless share the common traits of poverty, poor access to affordable housing, and personal difficulty, they are incredibly varied when it comes to demographics, backgrounds, and characteristics. The nationwide heterogeneity of the homeless population holds true in Miami as well, with the homeless population comprised of a diverse mix of race, ethnicity, gender, age, family status, and personal characteristics including traumatic backgrounds and substance abuse, mental health, and medical problems. Of course, one would probably expect Miami's homeless population to be particularly diverse, given that the Miami-Dade County area is one of the most racially and ethnically diverse counties in the country, with a majority minority population that is now $65 \%$ Hispanic, $15 \%$ black, and $19 \%$ white non-Hispanic. The majority (52\%) of residents were born in a foreign country, with 94\% of those from Latin America (Cruz and Hesler 2011). Yet, the homeless population is diverse in a different way, and is not reflective of the racial/ethnic breakdown of the overall county. Blacks are significantly overrepresented in this subpopulation, as are single males. This chapter examines the overall demographics and characteristics of the homeless population, focusing on single, adult males. It seeks to answer Research Question 1: In Miami-Dade County, do black and Hispanic men who are homeless or at risk of homelessness have different personal characteristics and different experiences in avoiding and/or exiting homelessness? Specific hypotheses to be tested address differences between blacks and Hispanics 
regarding risk of becoming literally homeless; characteristics and needs, including disabilities; destination upon exiting programs; expressed needs; spatial distribution; and outcomes upon completing programs.

\subsection{Overview of Miami-Dade Homeless Population}

In 2011, more than 15,000 individuals were homeless in Miami-Dade County at some point during the year (Miami-Dade County Homeless Trust 2012b). This number represents the 15,077 unduplicated individuals who have records in the County's Homelessness Management Information System (HMIS), which means they were served at least one time by an agency providing emergency, transitional, or permanent supported housing. There are 27 agencies that receive some type of funding through the MiamiDade County Homeless Trust and are required to enter data on clients served into this HMIS system. Thus, the 15,077 figure represents the number of persons served in Trustfunded agencies, but does not include those served by other provider agencies external to the continuum of care network, or individuals who have had no contact with the homelessness system at all. So, it can be assumed that the real number is actually higher. On the other hand, it is also possible that some of the HMIS client records are actually duplicates, as some providers may have failed to follow procedures for sharing records between agencies and may have created a second record when an individual changed programs. Nonetheless, this figure provides a good starting point for analysis.

Amongst those individuals served in $2011,11,808$ were male or female adults. For purposes here, the time frame for analysis was expanded to cover the time period from June 2010 through December 2011, limited to all single males who were served in an emergency, transitional, or permanent housing program. This 18-month period 
includes everyone who was in a program for any period during that timeframe, whether they entered, exited, or simply remained in the program throughout the duration of those 18 months. The total number of duplicated subjects for the 18 -month period was 8,940 , which included 7,605 unduplicated subjects. A total of 88 records for individuals who did not fall into any of the targeted racial/ethnic groups represented less than $1 \%$ of the population and were removed rather than listed as "other."

Table 2 below shows the racial/ethnic breakdown of persons who are duplicated in the system because they entered a homeless program more than one time. This includes persons who entered the same program more than once (i.e., they moved in and out of emergency shelters over time).

Table 2: Repeat entries into homeless system for homeless males in Miami-Dade

\begin{tabular}{l|l|r|r|r}
\hline \multicolumn{5}{c}{ Repeat Entries into System } \\
\hline Entries into System & \multicolumn{1}{|l|}{ Black } & \multicolumn{1}{l|}{ Hispanic } & \multicolumn{1}{l}{ White } & \multicolumn{1}{c}{ Total } \\
\hline One entry & 3580 & 1949 & 1037 & 6566 \\
\hline \% within race/ethnicity & $73.5 \%$ & $72.1 \%$ & $76.1 \%$ & $73.4 \%$ \\
\hline Two or more entries in programs* & 571 & 323 & 145 & 1039 \\
\hline$\%$ within race/ethnicity & $11.7 \%$ & $11.9 \%$ & $10.6 \%$ & $11.6 \%$ \\
\hline TOTAL & $\mathbf{5 4 . 6 \%}$ & $\mathbf{2 9 . 9 \%}$ & $\mathbf{1 5 . 5 \%}$ & $\mathbf{7 6 0 5}$ \\
\hline
\end{tabular}

*Denotes that columns are significant with Chi-Square test $p<.05$

Source: Miami-Dade County HMIS Records, Homeless Males 2010-2011

Hispanics are more likely than blacks or whites to have entered the system more than once (with a Pearson Chi-Square significance $p<.01$ ), although the actual percentage difference is relatively small, at $11.9 \%$ versus $11.7 \%$ for blacks. Amongst persons who were entering the system for the second time, more than $80 \%$ were entering an emergency housing program, suggesting that the majority of these were not persons who 
were moving up in the system, but rather were re-entering after having failed the first time.

Throughout this analysis, data regarding individual characteristics is drawn from the unduplicated count to provide an accurate depiction of the population served. Data relating to program participation and outcomes is drawn from the duplicated set, so that differences in program experience are captured. Thus, an individual who was served in an emergency program and then later in a treatment program would be counted once in the overall demographic analysis, but two times or more (once for each program) when reviewing program-level data.

In most cases, the national data utilized for comparison purposes are drawn from HUD's report (ABT Associates 2011) on the 2009-2010 nationwide HMIS data provided from every continuum, which includes the exact data set used for the Miami information. Thus, it provides an excellent means of comparison. In general, the demographics of the average homeless individual in Miami correlate with demographics of the homeless population at the national level, although in aggregate Miami's racial/ethnic disparities far exceed national rates.

\subsection{Race and Ethnicity}

Individuals were grouped into three racial/ethnic categories, by combining the separate variables for race and ethnicity. The three combined categories were: Black (includes all Black/African-Americans, including Hispanic); Hispanic (includes all Hispanic racial groups except for black); and White (non-Hispanic only). A small percentage of individuals (less than 1\%) who did not fit into any of these categories, including those who refused to answer, were not included. 
The racial/ethnic breakdown of single, homeless males was $54.6 \%$ black, $29.9 \%$ Hispanic, and $15.5 \%$ white. As shown by Table 3 below, this is extremely disproportionate from the overall racial/ethnic breakdown of the general population in Miami-Dade County, even when controlling for extreme poverty. It is also disproportionate from the nationwide population of single homeless adults, which is $34.5 \%$ black, $8.5 \%$ Hispanic, and 47.2\% white (HUD ABT Associates 2011).

Miami provides a particularly extreme example of the steady increase in the overrepresentation of blacks as poverty increases. Blacks constitute $17.6 \%$ of the county's overall population and $29.7 \%$ of the population living in extreme poverty, yet constitute $54.6 \%$ of the homeless population. On the other hand, Hispanics comprise nearly $60 \%$ of the county's overall population and $50.6 \%$ of those living in extreme poverty, but only $30 \%$ of the homeless population. Whites are $21 \%$ of the county population but only $15 \%$ of the homeless population. Thus, it is clear that the safety net for blacks in Miami is not functioning as well as it does for other racial and ethnic groups. 
Table 3: Racial/Ethnic Make Up of Miami-Dade Population Compared to Local and National Homeless Population

\begin{tabular}{|c|c|c|c|c|c|c|}
\hline & White & Black & $\begin{array}{l}\text { Hispanic } \\
\text { (all races) }\end{array}$ & $\begin{array}{c}\text { Other } \\
\text { Minority }\end{array}$ & Total & $\begin{array}{l}\text { Estimated } \\
\text { Population }\end{array}$ \\
\hline Miami-Dade County gen & $15 \%$ & $17.2 \%$ & $65 \%$ & $2.8 \%$ & $100 \%$ & $2,434,465$ \\
\hline $\begin{array}{l}\text { Countywide Poverty } \\
(\text { at/below } 100 \%)^{2}\end{array}$ & $13.7 \%$ & $26.5 \%$ & $58 \%$ & $1.8 \%$ & $100 \%$ & $\begin{array}{l}325,514 \\
(13.7 \% \text { pop })\end{array}$ \\
\hline $\begin{array}{l}\text { Countywide Extreme } \\
\text { Poverty (at/below } 50 \%)^{2}\end{array}$ & $17.7 \%$ & $29.7 \%$ & $50.6 \%$ & $2.1 \%$ & $100 \%$ & $\begin{array}{l}166,321 \\
(7 \% \text { of pop) }\end{array}$ \\
\hline $\begin{array}{l}\text { Miami-Dade Homeless } \\
\text { Males }^{3}\end{array}$ & $15.5 \%$ & $54.6 \%$ & $29.9 \%$ & $\mathrm{~N} / \mathrm{A}$ & $100 \%$ & 7605 (18-mos) \\
\hline $\begin{array}{l}\text { Homeless Single Adults } \\
\text { (national) }\end{array}$ & $47.2 \%$ & $34.5 \%$ & $8.5 \%$ & $9.9 \%$ & $100 \%$ & $\begin{array}{l}1,043,042 \\
63 \% \text { of homeless }\end{array}$ \\
\hline National Poverty $^{4}$ & $45.5 \%$ & $22 \%$ & $16 \%$ & $16.6 \%$ & $100 \%$ & \\
\hline
\end{tabular}

${ }^{1}$ US Census/American Community Survey 2010 - Miami-Dade County Summary (Cruz and Hesler 2011)

${ }^{2}$ US Census/ American Community Surveys 2005 (Ruggles et al. 2007)

${ }^{3}$ Miami-Dade County HMIS June 2010-December 2011. ("Other minority" $<1 \%$ so not included).

${ }^{4}$ US HUD Annual Assessment Report Oct 2009-Sep-2010. Figure includes male and female adults.

Disparities at the national level appear in a different manner. The proportion of

whites within the poverty population is nearly identical to proportion in the homeless

population. While the overall minority population is the same for poverty and

homelessness, it diverges when separating blacks and Hispanics. In that case, as in

Miami, blacks are overrepresented in the homeless population and Hispanics are

underrepresented, compared to the poverty population. However, the disparity is at a

much lower level than seen in Miami.

Figure 3 provides a visual illustration of the significant disproportion between the percentage of male and female adults in Miami-Dade County who are black or Hispanic, versus the percentage who become homeless. 
Figure 3: Racial/Ethnic Make-Up of Miami-Dade Homeless Population Compared to General Population

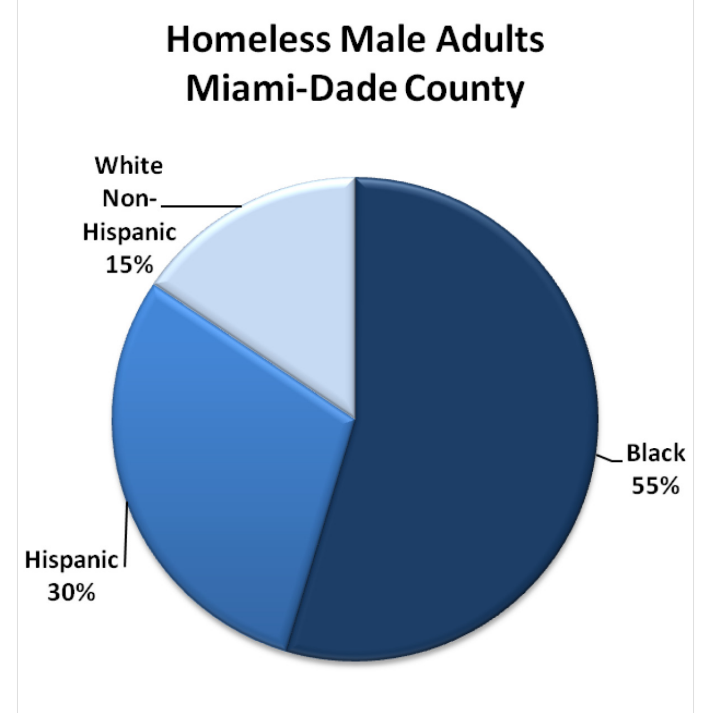

1 Source: Miami-Dade County HMIS 2010-2011

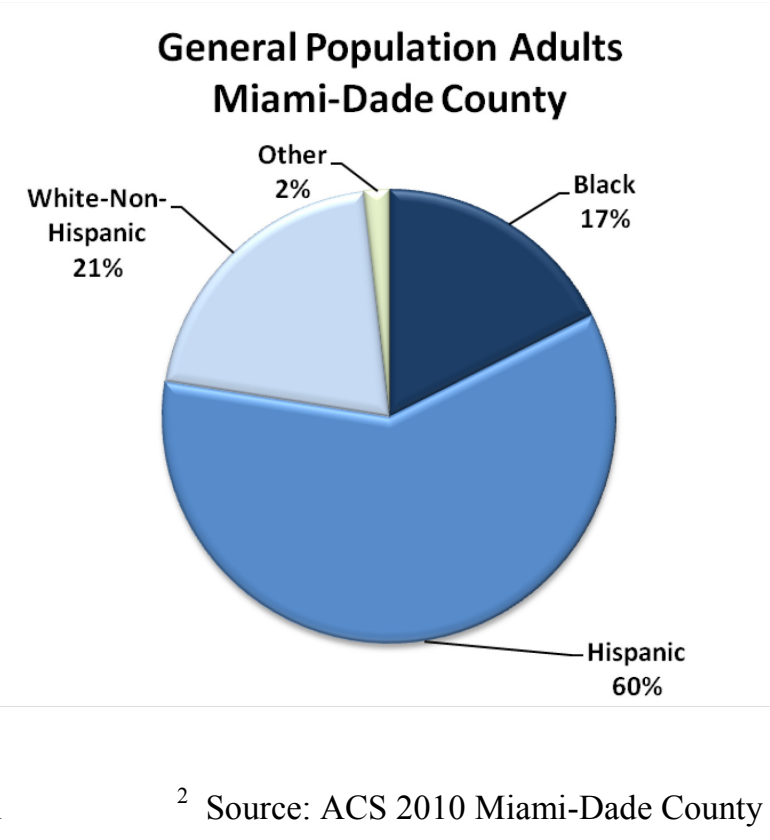

Miami-Dade County

${ }^{2}$ Source: ACS 2010 Miami-Dade County

This disproves the null hypothesis $(1 \mathrm{~A})$ : Blacks are at greater risk of becoming literally homeless than are Hispanics, even when controlling for income level prior to homelessness. In fact, amongst the general population, blacks are 6.2 times more likely to become homeless than Hispanics. Amongst the population of persons living in extreme poverty, they are 3.1 times more likely to become homeless than Hispanics. These figures regarding the disparity in likelihood of becoming homeless suggests that factors beyond poverty and income play a role in determining why blacks become homeless at a greater rate than Hispanics. 


\subsection{Characteristics and Disabilities}

Age

The average age of a homeless male in Miami is 46. Ages range from 18 to 92. Two-thirds fall between the ages of 25-54, with more than a quarter (26\%) being over 55 . Hispanics are older than their black and white counterparts, with a mean age of 47.8, and over-representation amongst the elderly group over 55 (31.7\%) (chi-square pearson test significant at $\mathrm{p}<.001)$. Miami’s homeless population is clearly not a young population, having an average age of 46 , with nearly a quarter being age 55 or older and only $6.8 \%$ under age 25. Miami's homeless population is also older than the national homeless population, which has only $17.1 \%$ over age 50 (ABT Associates 2011). The implications are that Miami may expect to see greater health needs and a higher level of disabilities that come with an aging population.

Table 4: Age Distribution of Homeless Men in Miami-Dade

\begin{tabular}{|c|c|c|c|c|c|c|c|c|}
\hline & \multicolumn{2}{|l|}{ Black } & \multicolumn{2}{|c|}{ Hispanic } & \multicolumn{2}{|l|}{ White } & \multicolumn{2}{|l|}{ Total } \\
\hline Mean Age & \multicolumn{2}{|r|}{45.5} & \multicolumn{2}{|c|}{47.8} & \multicolumn{2}{|c|}{46.8} & \multicolumn{2}{|c|}{46.4} \\
\hline Range & \multicolumn{2}{|r|}{$18-86$} & \multicolumn{2}{|c|}{$18-92$} & \multicolumn{2}{|c|}{$18-85$} & \multicolumn{2}{|c|}{$18-92$} \\
\hline $\begin{array}{l}\text { Age } \\
\text { Groups }\end{array}$ & \# & $\%$ within race & \# & $\begin{array}{c}\% \text { within } \\
\text { race }\end{array}$ & \# & $\begin{array}{c}\% \text { within } \\
\text { race }\end{array}$ & \# & \\
\hline $18-25$ & 311 & $7.5 \%$ & 127 & $5.6 \%$ & 76 & $6.4 \%$ & 514 & $6.8 \%$ \\
\hline $26-54$ & 2851 & $68.7 \%$ & 1425 & $62.7 \%$ & 788 & $66.7 \%$ & 5604 & $66.6 \%$ \\
\hline $55-64$ & 857 & $20.6 \%$ & 523 & $23.0 \%$ & 271 & $22.9 \%$ & 1651 & $21.7 \%$ \\
\hline $65+$ & 132 & $3.2 \%$ & 197 & $8.7 \%$ & 47 & $4.0 \%$ & 376 & $4.9 \%$ \\
\hline Total & 4151 & $100 \%$ & 2272 & $100 \%$ & 1182 & $100 \%$ & 7605 & $100 \%$ \\
\hline
\end{tabular}

Source: Miami-Dade County HMIS, Homeless Males 2010-2011

Veteran Status

The percentage of males who are veterans within Miami-Dade's homeless population $(11.2 \%)$ is nearly the same as it is nationwide (11\%) (National Alliance to End Homelessness 2012). Within the 7,605 HMIS cases, 119 were missing data; of the 
remaining, $11.2 \%$ had marked that they were veterans. It is possible that in some of the records where "No" was answered, the question was not actually asked but the field still filled in.

Table 5: Veteran Status amongst Homeless Males in Miami-Dade, by Race/Ethnicity

\begin{tabular}{l|r|r|r|r}
\hline Veteran Status & \multicolumn{1}{|c|}{ Black } & \multicolumn{1}{|c|}{ Hispanic } & \multicolumn{1}{|c|}{ White } & \multicolumn{1}{c}{ Total } \\
\hline \# Yes (frequency) & 516 & 115 & 207 & 838 \\
\hline \# No (frequency) & 3572 & 2133 & 943 & 6648 \\
\hline Total Population & 4088 & 2248 & 1150 & 7486 \\
\hline$\%$ YES within race/ethnicity* & $12.6 \%$ & $5.1 \%$ & $18 \%$ & $11.2 \%$ \\
\hline
\end{tabular}

*Denotes difference is significant at Pearson Chi-Square $p<.001$

Source: Miami-Dade County HMIS, Homeless Males, 2010-2011

The percentage of individuals who are veterans varies between all the racial/ethnic groups at a significance level of .001, with $18 \%$ of whites, $12.6 \%$ of blacks, and only $5.1 \%$ of Hispanics being veterans. The difference in veteran status is relevant to this study, as it affects an individual's access to veterans' benefits, including both cash and non-cash benefits. Whites are much more likely to be veterans than other racial groups within the homeless population, with nearly 1 in 5 white homeless persons being a veteran.

\section{Disabilities}

Single males who are homeless in Miami-Dade County suffer from serious disabilities in large proportions. More than three quarters $(78 \%)$ have at least one serious disability. Data regarding prevalence of disabilities is drawn from the number of men who have at least one disability recorded in their HMIS record, with the disability being one of several that meet HUD's criteria: alcohol abuse, drug abuse, mental health disorder, medical/health problems (including HIV/AIDS), and/or other disabilities including developmental disabilities, vision, and hearing impairments. 
When examining presence of disabilities, it is useful to separate out persons who are "sheltered" in an emergency, transitional, or institutional setting, compared to those who are living in a permanent supported housing program (See Table 6), because the way HUD categories persons in permanent housing is correlated with disability status. We would expect the number of persons with disabilities in permanent programs to be higher, as HUD requires the presence of a qualifying serious disability in order to live in many of its permanent programs. Typically, individuals who are ready to move into permanent housing but who lack a qualifying disabling condition would move into market-rate housing or housing subsidized by a non-homeless program, including HUD's Section 8 program, tax-credit funded affordable housing projects, or temporary rent-assistance programs. However, individuals who enter any of those program types are no longer tracked in the HMIS system and thus do not appear in this data set. Note that for the oneon-one interviews conducted for this study, discussed later in this chapter, formerly homeless individuals living in these non-homeless programs were included. 
Table 6: Prevalence of Disabilities Amongst Miami-Dade Homeless Males, by Race/Ethnicity

\begin{tabular}{l|l|l|l|l} 
& Black & Hispanic & White & Total \\
\hline \multicolumn{4}{l}{ Sheltered in Emergency/Transitional (Non-Permanent) } \\
\hline Any Disability & $67.0 \%$ & $64.3 \%$ & $67.0 \%$ & $66.2 \%$ \\
\hline Alcohol Abuse* & $26.0 \%$ & $20.7 \%$ & $32.5 \%$ & $25.5 \%$ \\
\hline Substance Abuse* & $44.4 \%$ & $29.7 \%$ & $28.6 \%$ & $37.6 \%$ \\
\hline Mental Health* & $29.5 \%$ & $35.2 \%$ & $31.4 \%$ & $31.5 \%$ \\
\hline Medical Problem & $27.0 \%$ & $27.5 \%$ & $27.3 \%$ & $27.2 \%$ \\
\hline Living in Permanent Housing Program & $93.0 \%$ & $92.8 \%$ & $91.8 \%$ \\
\hline Any Disability & $90.8 \%$ & $16.5 \%$ & $27.6 \%$ & $26.0 \%$ \\
\hline Alcohol Abuse* & $31.7 \%$ & $23.0 \%$ & $32.2 \%$ & $38.3 \%$ \\
\hline Substance Abuse* & $49.4 \%$ & $75.9 \%$ & $74.3 \%$ & $64.0 \%$ \\
\hline Mental Health* & $54.2 \%$ & $32.8 \%$ & $25.7 \%$ & $34.9 \%$ \\
\hline Medical Problem & $38.1 \%$ & &
\end{tabular}

*Denotes difference is significant with Pearson Chi-Square $\mathrm{P}<.01$

Source: Miami-Dade County HMIS, Homeless Males, 2010-2011

Nationwide, only $36.8 \%$ of homeless adults in shelters or non-permanent housing programs have a serious disabling condition (HUD ABT Associates 2011) compared to $66.2 \%$ in Miami. Homeless men in Miami are almost twice as likely as homeless individuals nationwide to have a disabling condition recorded in their HMIS record. For those in permanent housing programs, Miami has $91.8 \%$ compared to $78.8 \%$ nationwide.

While there is no significant difference between racial/ethnic groups regarding the likelihood that at least one disability will be present, we do see significant disparities in the disability types between racial/ethnic groups. For persons in emergency or transitional programs (i.e. non-permanent) each of the following test significant with Pearson ChiTests at $\mathrm{p}<.001$ (See : Figure 4 and Figure 5)

- White are more likely to have an alcohol abuse problem than Hispanics or blacks, and Hispanics are less likely to abuse alcohol than blacks; 
- Blacks are more like to have a substance abuse problem than Hispanics or whites;

- Hispanics are more likely to have a mental health disorder than are blacks or whites;

- There are no significant differences between those with medical or other disabilities.

Figure 4: Disabilities Amongst Men in Non-Permanent Housing Programs

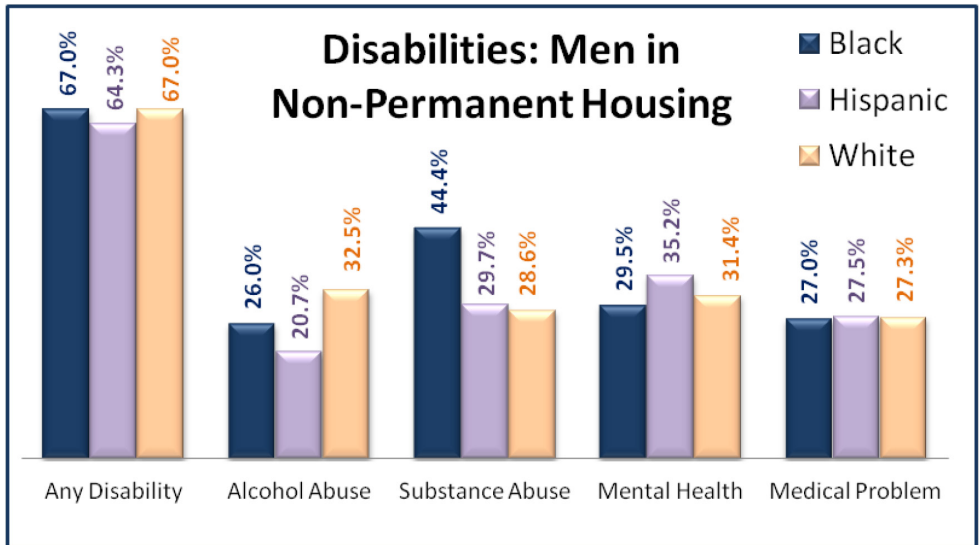

Source: Miami-Dade County HMIS, Homeless Males, 2010-2011

Figure 5: Disabilities Amongst Men in Permanent Housing Programs

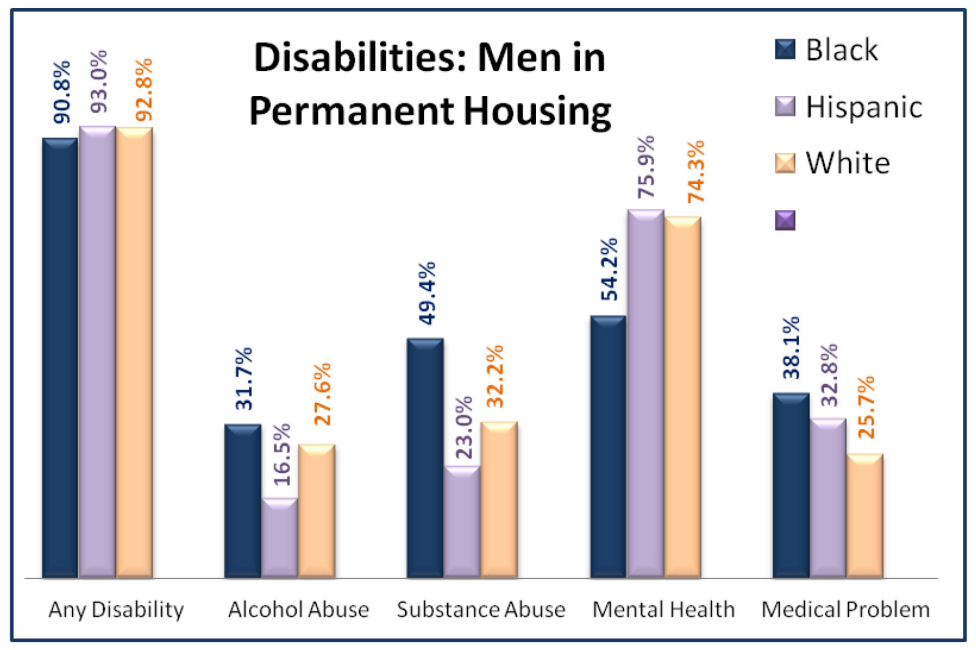

Source: Miami-Dade County HMIS, Homeless Males, 2010-2011 
This data disproves the null hypothesis: Black and Hispanic men who are homeless in Miami do have different disabilities. Thus, it would seem that their needs for exiting homelessness will be different.

\subsection{Self Expressed Needs}

While the above describes characteristics and disabilities as they are entered into a client's case file by a staff member at an agency, Table 7 describes the needs that are expressed directly by the clients themselves. This data is drawn from the Miami-Dade County Annual Point in Time Survey, where clients are able to decide for themselves what services they would most like to receive. Ideally, the information contained in the HMIS file will match up with the information regarding what the client themselves sees

as their greatest needs. However, in some cases a staff worker or counselor may believe a client needs additional services before they are ready to live on their own, resulting in differences between the HMIS and Point-in-Time data.

Overall, the greatest need expressed was for jobs (46.3\% of total respondents), followed by healthcare $(44.2 \%)$. The strong desire for a job was confirmed by the oneon-one interviews. Healthcare, however, was not commonly specified as a "need" during interviews with persons living on the streets. As discussed in more detail in the section on health care findings, interviewees may not have named healthcare as a primary need because they believed their healthcare needs were already being met through the services available through Healthcare for the Homeless programs.

Table 7 shows there are several areas where discrepancies between race/ethnicity appear when examining the self-expressed needs captured by the Point-in-Time survey. 
Table 7: Services Needs Expressed by Homeless Men in Miami-Dade

\begin{tabular}{l|l|l|l|l|l}
\multicolumn{1}{c|}{ Expressed Need } & \multicolumn{1}{|c|}{ Black } & Hispanic & White & \multicolumn{1}{|c|}{ Other } & \multicolumn{1}{|c}{ Total } \\
\hline Education * & 157 & 50 & 23 & 8 & 238 \\
\hline \% within Race/Ethnicity & $31.9 \%$ & $20.8 \%$ & $23.5 \%$ & $29.6 \%$ & $27.8 \%$ \\
\hline Healthcare & 214 & 111 & 43 & 11 & 379 \\
\hline \% within Race/Ethnicity & $43.5 \%$ & $46.3 \%$ & $43.9 \%$ & $40.7 \%$ & $44.2 \%$ \\
\hline Alcohol/Drug TX* & 116 & 35 & 35 & 5 & 191 \\
\hline$\%$ within Race/Ethnicity & $23.6 \%$ & $14.6 \%$ & $35.7 \%$ & $18.5 \%$ & $22.3 \%$ \\
\hline Mental Health Tx* & 141 & 110 & 30 & 7 & 288 \\
\hline \% within Race/Ethnicity & $28.7 \%$ & $45.8 \%$ & $30.6 \%$ & $25.9 \%$ & $33.6 \%$ \\
\hline Food & 200 & 90 & 38 & 10 & 338 \\
\hline$\%$ within Race/Ethnicity & $40.7 \%$ & $37.5 \%$ & $38.8 \%$ & $37 \%$ & $39.4 \%$ \\
\hline Job* & 242 & 91 & 48 & 16 & 397 \\
\hline$\%$ within Race/Ethnicity & $49.2 \%$ & $37.9 \%$ & $49 \%$ & $59.3 \%$ & $46.3 \%$ \\
\hline Job Training* & 175 & 47 & 19 & 8 & 249 \\
\hline$\%$ within Race/Ethnicity & $35.6 \%$ & $19.6 \%$ & $19.4 \%$ & $29.6 \%$ & $29.1 \%$ \\
\hline Contacting Fam/Friends & 28 & 20 & 7 & 1 & 56 \\
\hline \% within Race/Ethnicity & $5.7 \%$ & $8.3 \%$ & $7.1 \%$ & $3.7 \%$ & $6.5 \%$ \\
\hline Access Benefits & 84 & 58 & 17 & 5 & 164 \\
\hline$\%$ within Race/Ethnicity & $17.1 \%$ & $24.3 \%$ & $17.3 \%$ & $18.5 \%$ & $19.2 \%$ \\
\hline
\end{tabular}

*Columns percentage differences are significant with Pearson Chi-Square $\mathrm{P}<.01$

Data Source: Miami-Dade County Point-in-Time Survey, Homeless Men N=857

The biggest disparities in expressed needs are for alcohol/drug treatment, mental

health treatment, and job training. Hispanics are much less likely to request drug/alcohol treatment than blacks or whites, and much more likely to request mental health treatment than blacks or whites. This fits with the data examined above, which indicated that blacks are more like to have alcohol or drug abuse problems and Hispanics are more likely to have mental health problems.

Hispanics are also less likely to request assistance with education, job training, or job placement, but more likely to request assistance accessing benefits. (However, only the first three items test significant on the Pearson Chi-Square test at $\mathrm{p}<.01$ ). 
Figure 6: Expressed Needs for Healthcare, Drug/Alcohol Treatment and Mental Health Treatment

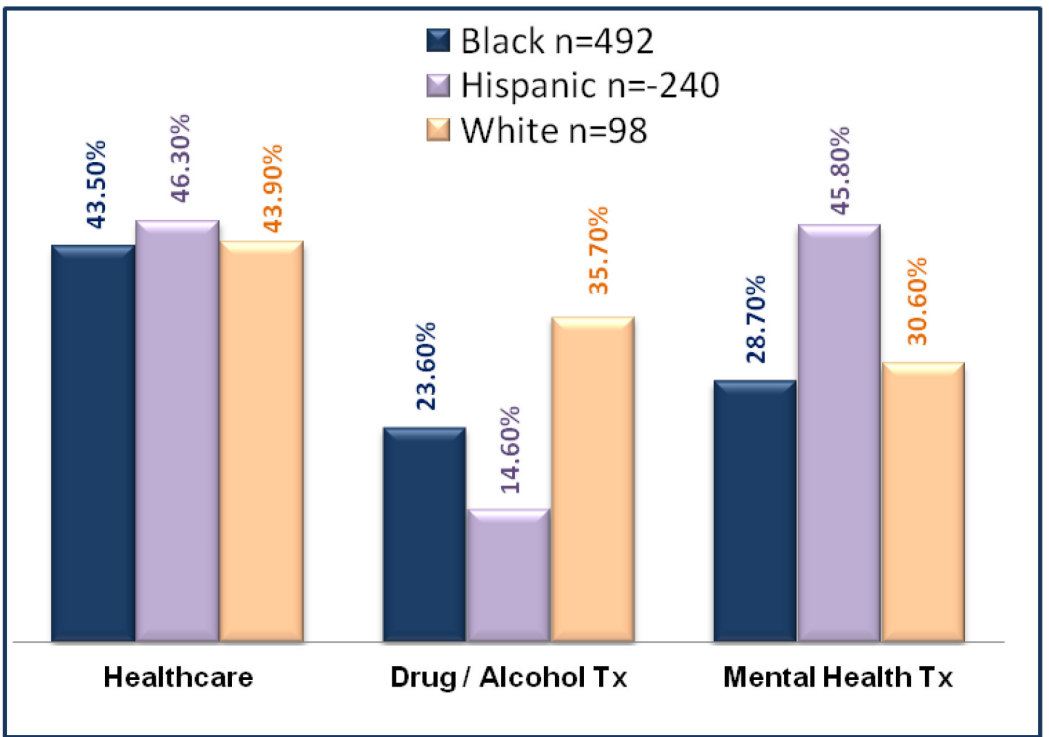

Data Source: Miami-Dade PIT Survey $2012(\mathrm{n}=857)$

Figure 7: Expressed Needs for Jobs, Training, Education and Benefits

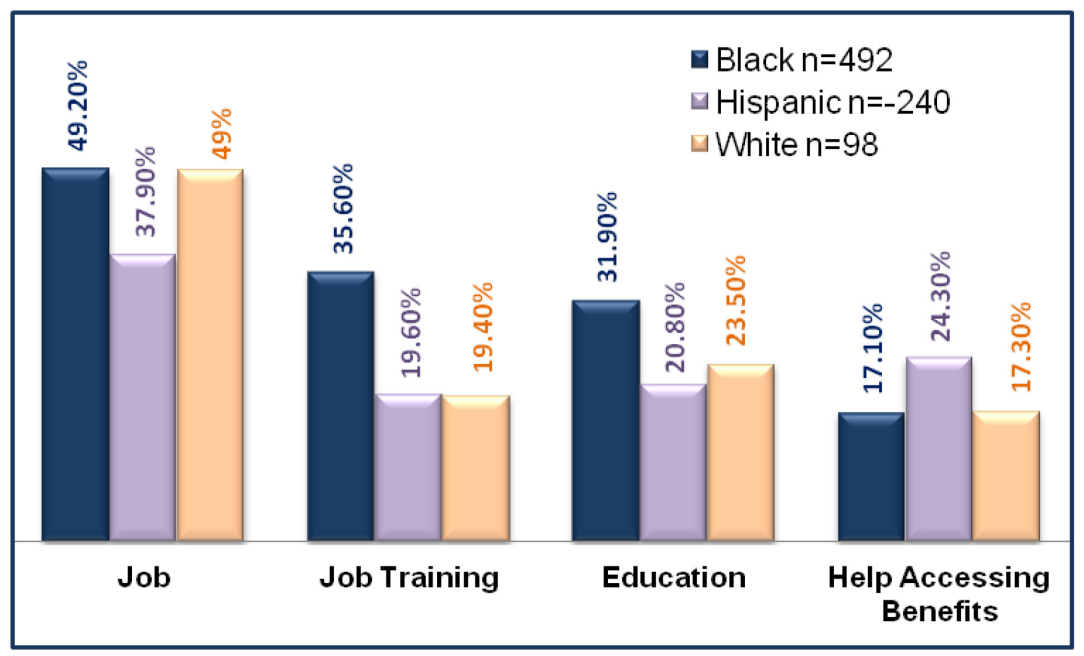

Data Source: Miami-Dade PIT Survey $2012(\mathrm{n}=857)$

This disparity is also found amongst the men who participated in the one-on-one interviews for this study. Hispanics were less likely to be earning income and more likely to have attained benefits than blacks. Additionally, the qualitative feedback from the interviews showed that Hispanics expressed putting more effort into seeking out benefits, 
whereas blacks expressed more acceptances of their current situation and intention to earn income. It is important to note that Hispanics did express a desire to earn income, with many stating that their preference would be to attain employment, but that they felt their likelihood of attaining employment was minimal. This is discussed in more detail in Chapter VI.

This data would disprove the null hypothesis, that black and Hispanic men who are homeless do not express different desires for the type of help they believe they need. In fact, the Point-in-Time survey found a statistically significant difference in the needs expressed by black and Hispanic men in Miami. Blacks are more likely than Hispanics to express a need for drug or alcohol treatment; Hispanics are more likely to express a need for mental health services. In addition, blacks are more likely to state they would like assistance with job training, education, and job placement, while Hispanics are more likely to request assistance accessing benefits. These results fit with the findings from other sections: Blacks are more likely to report having drug and alcohol problems and to be placed into treatment programs, while Hispanics are more likely to report having mental health disorders. Both the HMIS data and the one-on-one interviews revealed that blacks were more likely to be earning income, and that Hispanics were more likely to be receiving benefits and to be more active in attempting to attain benefits. What these findings do not make clear, however, is causality. Are blacks more likely to request drug and alcohol treatment because they are being referred to treatment programs where they are diagnosed as addicts? Are Hispanics more likely to be diagnosed with mental illness because they are being referred to programs that focus more on mental health than on drug addiction? Are they more likely to seek benefits because they are 
mentally ill and unable to work, or are they more likely to declare that they have a mental illness because this can facilitate attaining benefits? There is clearly a difference in the characteristics, needs, and program participation between black and Hispanic homeless males in Miami-Dade. The following two sections review how this relates to the spatial distribution of minority, homeless and at-risk males across Miami-Dade County, as well as the actual outcomes for males who participate in various homelessness programs in Miami-Dade.

\subsection{Spatial Distribution by Race/ Ethnicity}

With 27 different agencies providing services to persons who are homeless in Miami-Dade County, there exists a wide range of program areas of expertise. In an ideal system, individuals would be referred to the agency best suited to their specific treatment and/or housing needs. However, many factors come in to play in determining which program a client enters. There are two primary methods by which an individual may enter most programs: 1) via self-referral; and 2) via referral or placement from another entity. Self-referral allows individuals to attempt to enter the program they believe most suited to their needs. Their decision making process may include a range of factors, including geographic location, their perception of the racial/ethnic make-up of clients served and whether they believe they will fit with the culture of the organization; their past experience with the program; and the reputation of the program itself. Some programs accept walk-ins and self-referrals, while others will require a referral from another agency or outreach team. Placement from other entities, including providers and outreach teams may take into account geographic proximity to the individual's location; the expertise of the agency; the expressed desire of the individual; and the availability of 
an open bed. There is opportunity for bias to be introduced in many of these decisionmaking factors.

Analyzing the racial/ethnic make-up of the population of males served by the various agencies participating in the Miami-Dade County system of care for homeless persons shows that there are significant differences in the populations served by each agency. There are further differences when looking at specific programs within agencies. Table 8 lists the major programs, by provider agency, along with the racial/ethnic breakdown of males served. Each letter denotes a different agency, with multiple programs operated by the same agency listed below each letter. Some agencies operate different programs at locations distributed across the county. 
Table 8: Racial/Ethnic Make-Up of Homeless Males Served by Provider/Agency

\begin{tabular}{|c|c|c|c|c|}
\hline & Black & Hispanic & White & Total $(100 \%)$ \\
\hline Agency A: Perm Hsing* & $3(16.7 \%)$ & $12(66.7 \%)$ & $3(16.7 \%)$ & 18 \\
\hline A: Transitional* & $10(38.5 \%)$ & $11(42.3 \%)$ & $5(19.2 \%)$ & 26 \\
\hline B: Permanent Housing* & $41(87.2 \%)$ & $3(6.4 \%)$ & $3(6.4 \%)$ & 47 \\
\hline B: Transitional/ Treatment* & $235(58.2 \%)$ & $91(22.5 \%)$ & $78(19.3 \%)$ & 404 \\
\hline B: Permanent Housing* & $47(82.5 \%)$ & $5(8.8 \%)$ & $5(8.3 \%)$ & 57 \\
\hline C: Permanent Housing * & $22(37.9 \%)$ & $25(43.1 \%)$ & $11(19.0 \%)$ & 58 \\
\hline C: Permanent Housing & $16(72.7 \%)$ & $5(22.7 \%)$ & $1(4.5 \%)$ & 22 \\
\hline C: Emergency Housing* & $335(84.2 \%)$ & $38(9.5 \%)$ & $25(6.3 \%)$ & 398 \\
\hline C: Transitional Housing & $55(65.1 \%)$ & $31(31.6 \%)$ & $12(12.2 \%)$ & 98 \\
\hline C: Transitional/ Treatment* & $55(96.5 \%)$ & $0(0 \%)$ & $2(3.5 \%)$ & 57 \\
\hline C: Permanent Housing $*$ & $56(68.3 \%)$ & $22(26.8 \%)$ & $4(4.9 \%)$ & 82 \\
\hline C: Transitional Housing* & $69(78.4 \%)$ & $14(15.9 \%)$ & $5(5.7 \%)$ & 88 \\
\hline C: Permanent Housing * & $49(76.6 \%)$ & $10(15.6 \%)$ & $5(7.8 \%)$ & 64 \\
\hline C: Transitional (veterans) ${ }^{*}$ & $33(50.8 \%)$ & $10(15.4 \%)$ & $22(33.8 \%)$ & 65 \\
\hline D: Permanent Housing & $21(48.8 \%)$ & $14(32.6 \%)$ & $8(18.6 \%)$ & 43 \\
\hline D: Transitional Housing* & $26(61.9 \%)$ & $6(14.3 \%)$ & $10(23.8 \%)$ & 42 \\
\hline D: Permanent Housing* & $40(71.4 \%)$ & $10(17.9 \%)$ & $6(10.7 \%)$ & 56 \\
\hline D: Permanent Housing & $43(66.2 \%)$ & $16(24 . \%)$ & $6(9.2 \%)$ & 65 \\
\hline D: Permanent Housing* & $31(50.8 \%)$ & $25(41 \%)$ & $5(8.2 \%)$ & 61 \\
\hline D: Permanent Housing & $28(44.4 \%)$ & $26(41.3 \%)$ & $9(14.3 \%)$ & 63 \\
\hline D: Permanent Housing* & $5(31.3 \%)$ & $6(37.5 \%)$ & $5(31.3 \%)$ & 16 \\
\hline D: Permanent Housing & $22(61.1 \%)$ & $9(25 \%)$ & $5(13.9 \%)$ & 36 \\
\hline E: Emergency Housing * & $1976(53 \%)$ & $1169(31.3 \%)$ & $586(15.7 \%)$ & 3731 \\
\hline E: Emergency Housing * & $544(50 \%)$ & $386(35.4 \%)$ & $159(14.6 \%)$ & 1089 \\
\hline F: Permanent Housing* & $68(31.6 \%)$ & $135(62.8 \%)$ & $12(5.6 \%)$ & 215 \\
\hline F: Permanent Housing* & $20(35.1 \%)$ & $34(59.6 \%)$ & $3(5.3 \%)$ & 57 \\
\hline G: Transitional Housing* & $33(66 \%)$ & $9(18 \%)$ & $8(16 \%)$ & 50 \\
\hline G: Permanent Housing* & $5(11.9 \%)$ & $30(71.4 \%)$ & $7(16.7 \%)$ & 42 \\
\hline H: Permanent Housing & $9(69.2 \%)$ & $4(30.8 \%)$ & $0(0 \%)$ & 13 \\
\hline H: Permanent Housing* & $6(26.1 \%)$ & $8(34.8 \%)$ & $9(39.1 \%)$ & 23 \\
\hline I: Permanent Housing & $153(55 \%)$ & $72(25.9 \%)$ & $53(19.1 \%)$ & 278 \\
\hline J: Emergency Housing & $384(56.5 \%)$ & $182(26.8 \%)$ & $114(16.8 \%)$ & 680 \\
\hline K: Transitional/Treatment* & $104(37.3 \%)$ & $100(35.8 \%)$ & $75(26.9 \%)$ & 279 \\
\hline L: Permanent Housing* & $32(60.4 \%)$ & $20(37.7 \%)$ & $1(1.9 \%)$ & 53 \\
\hline L: Transitional/Treatment & $6(54.5 \%)$ & $3(27.3 \%)$ & $2(18.2 \%)$ & 11 \\
\hline M: Emergency Housing* & $39(34.5 \% 0$ & $42(37.2 \%)$ & $32(28.3 \%)$ & 113 \\
\hline M: Emergency Housing* & $65(41.7 \%)$ & $58(37.2 \%)$ & $33(21.2 \%)$ & 156 \\
\hline M: Emerg Hsng *(veterans) & $47(58.8 \%)$ & $11(13.8 \%)$ & $27.5 \%)$ & 80 \\
\hline M: Emergency Housing* & $115(70.1 \%)$ & $40(24.4 \%)$ & $9(5.5 \%)$ & 164 \\
\hline $\mathrm{N}$ : Permanent Housing & $25(62.5 \%)$ & $12(30 \%)$ & $3(7.5 \%)$ & 40 \\
\hline TOTAL & $4873(54.5 \%)$ & $2704(30.2 \%)$ & $1363(15.2 \%)$ & 8940 \\
\hline
\end{tabular}

*Significant with Pearson Chi-Square p<.05; Data Source: Miami-Dade County HMIS Data 2010-2011 
Fully $70 \%(28 / 40)$ of the programs listed serve a male population that has a racial/ethnic make-up that differs from that of the general homeless population. Some are disproportionately Hispanic, whereas others are disproportionately black or white. Figure 8 shows the location of programs serving homeless persons, over census tracts. Each census tract is color coded according to the majority racial/ethnic group in that tract, and each agency is color coded according to the majority racial/ethnic group served.

Figure 8: Racial/Ethnic Population Served by Agency, Over Census Tract Race/Ethnicity

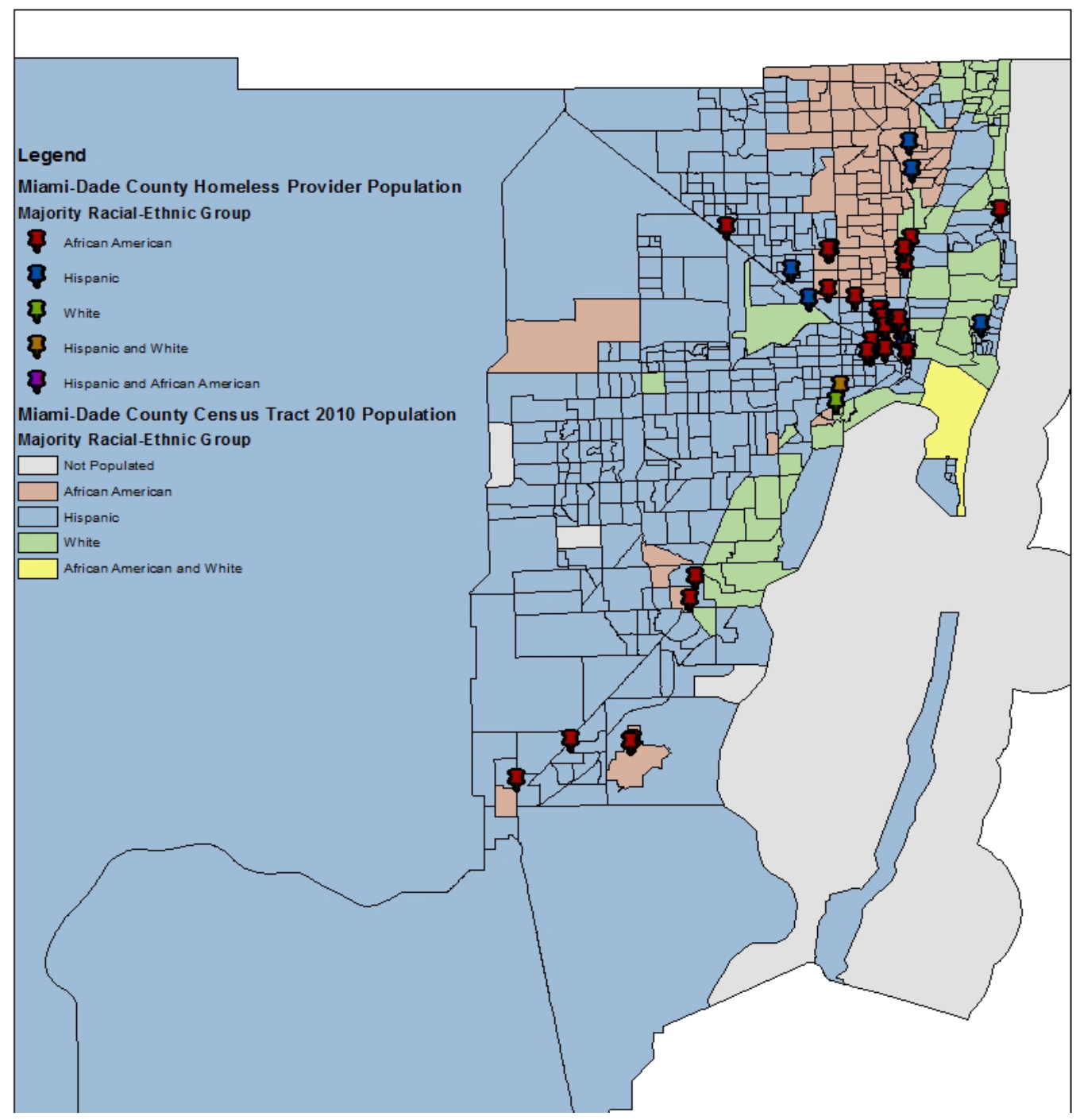


Figure 8 shows the majority of programs clustered in the downtown Miami area served predominantly black populations. Agencies serving predominantly Hispanic populations are located further west and further north. Agencies serving predominantly white populations are located near predominantly white census tracts in the South Miami area. While most of the South Dade census tracts are predominantly Hispanic, the only three agencies in that area serve a predominantly black population; however, two of those three agencies are located in isolated black census tracts. A lone program located in the North Beach area of the map is in a predominantly white and Hispanic area, while serving a predominantly black population. When this program opened approximately ten years ago it was met with significant neighborhood opposition in spite of the fact that it was a housing program and not an emergency program. The program did not encounter any issues with neighbors after it was open.

The HMIS data includes the client's zip code from their last permanent address prior to becoming homeless. This information can be utilized to develop a visual depiction of the areas where persons who are homeless come from. The following sideby-side maps in Figure 9 show those areas where blacks have lived prior to becoming homeless, compared to Hispanics. Comparison of these maps shows that most persons who become homeless, regardless of race/ethnicity, come from the centrally located census tracts in the downtown Miami area. These are the same areas where the majority of providers are located on the previous pages. Outside of the central area, Hispanic homeless persons tended to come from more Hispanic areas out west, and blacks tended to come from predominantly black areas north of downtown. 
Figure 9: Last Address of Homeless Men in Miami-Dade, by Race/Ethnicity
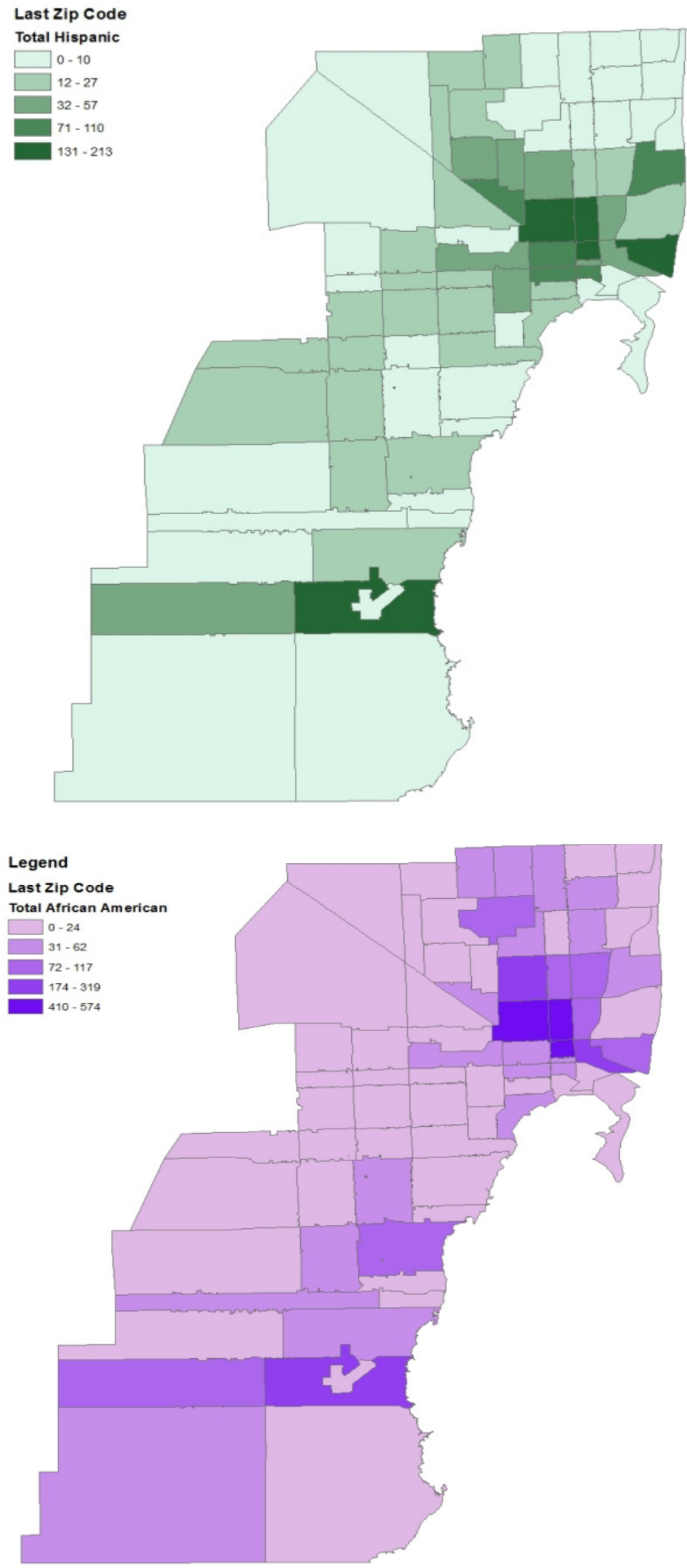
While the fact that the distribution of the last addresses of persons who become homeless correlates with their race/ethnicity is not surprising, it suggests that persons may be living in their home neighborhoods, or otherwise surrounded by friends or family with shared race/ethnicity and culture, prior to becoming homeless. Coupled with the previous map which shows that programs tend to be located in geographic areas with similar racial/ethnic breakdowns as the program population served, suggesting that agencies may tend to serve individuals from their area, it is possible that the neighborhood one lives in at the time of becoming homeless will influence which agency they go to. Thus, persons of different races and ethnicities may be predisposed to having access to different types of resources via the type of agency they go to upon becoming homeless.

The addresses of housed persons interviewed for this study also show clustering based on race/ethnicity. The following maps in Figure 10 and Figure 11 show the countywide distribution of persons interviewed, with shape denoting whether they were formerly homeless or at-risk of homelessness. As noted elsewhere, the line between formerly homeless at-risk was blurred, with many individuals falling into both categories. However, these maps categorize persons according to their status at referral to the study, so they are either "formerly homeless" or "at-risk of homelessness." The shapes are also color coded to show race and ethnicity of the individual. The first map shows all of Miami-Dade county, and the second map shows a close-up of the central Miami-Dade area where the majority of interviewees lived. The distribution of at-risk versus formerly homeless individuals, as shown by the round and square shapes on the maps, does not appear to have any pattern. Overall, persons who are at-risk or formerly homeless tend to 
inhabit the same neighborhoods, with a few exceptions revealed during the interviews. Interviews also revealed some underlying attitudes, both positive and negative, regarding the neighborhoods in which they lived, discussed more below.

Figure 10: Addresses of Formerly Homeless / At-Risk Interviewees, by Race/Ethnicity

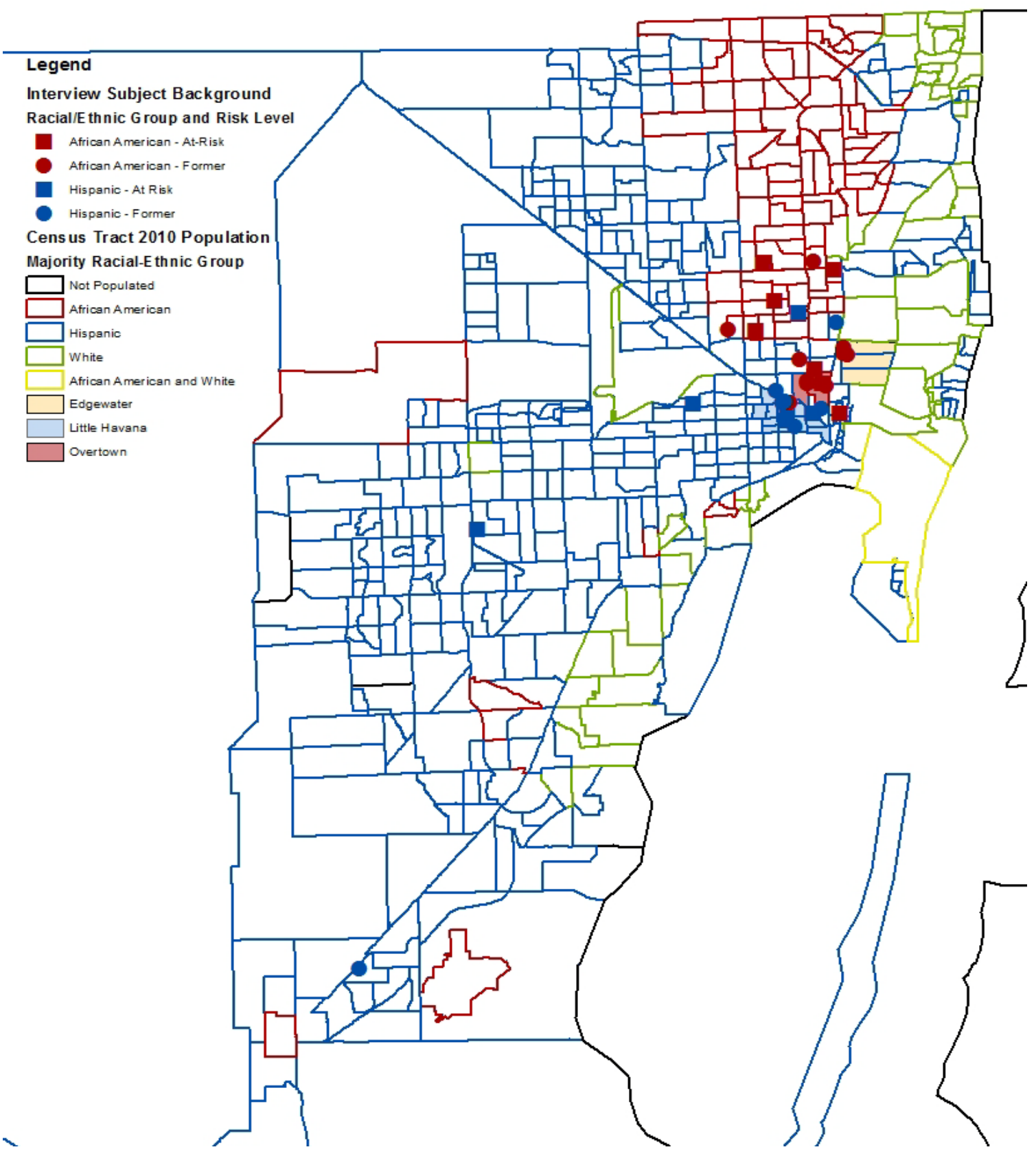

Data source: Zip code race/ethnicity from US Census data 
Figure 11: Addresses of Interviewees, by Race/Ethnicity (Neighborhood Close-Up)

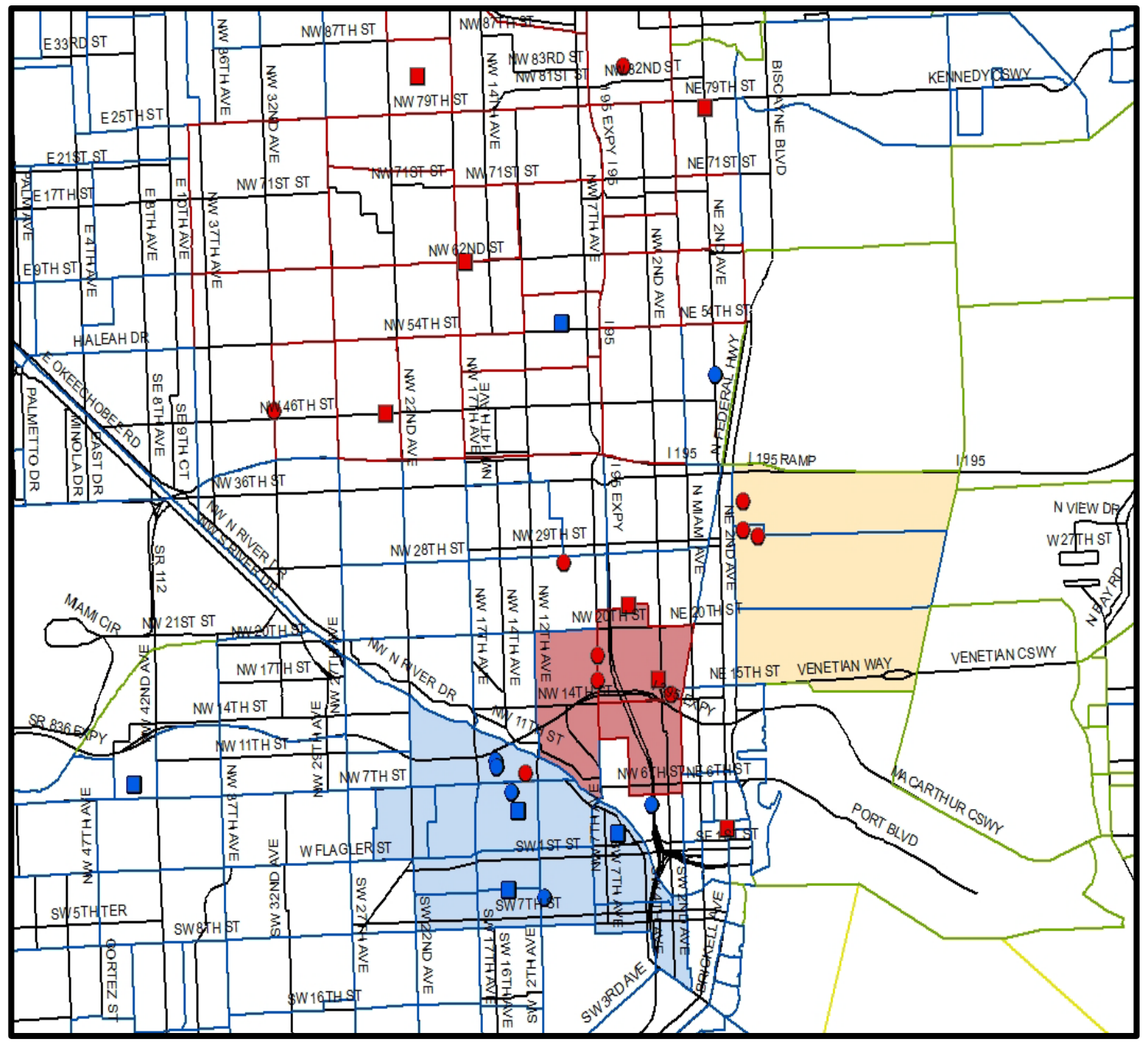

\section{Legend}

\section{Interview Subject Background}

Racial/Ethnic Group and Risk Level

- African American - At-Risk

- African American - Former

- Hispanic - At Risk

- Hispanic - Former

\section{Census Tract 2010 Population}

Majority Racial-Ethnic Group

\begin{tabular}{|c|}
\hline Not Populated \\
\hline African American \\
\hline Hispanic \\
\hline White \\
\hline African American and White \\
\hline Edgewater \\
\hline Little Havana \\
\hline Overtown \\
\hline
\end{tabular}


The two specific neighborhoods of East Little Havana and Overtown are color coded on the map, making it clear that most Hispanics were in the East Little Havana area, and most blacks were in the Overtown, Liberty City and north of downtown areas. The color coding of the borders of census tracts by race and ethnicity also shows how the distribution of interviews by race and ethnicity matches the overall geographic distribution of blacks and Hispanics in Miami-Dade County. The highlighted East Little Havana and Overtown neighborhoods are the same areas described in the previous chapter on trends in Miami as having been designated as Neighborhood Development Zones (NDZs) because of their extreme poverty. As discussed in that chapter, the rate of renter households in the Little Havana NDZ was $87 \%$ and in Overtown was 91\%, compared to just $42 \%$ for the rest of the County (Mensah 2009). In Overtown, $41 \%$ of households made less than $\$ 10,000$ per year; the largest volume $(6,230)$ of households making under $\$ 10,000$ was in Little Havana. With these two areas being the poorest neighborhoods in the County, and having the largest percentage of renters, it is not surprising that the majority of housed individuals referred for this study were living in those neighborhoods.

During the time period when interviews were taking place, a new stadium for the Miami Marlins baseball team was under construction right in the middle of the East Little Havana neighborhood, with the overcrowded and aging apartments occupied by interviewees drawing a loose circle around the new stadium. The Miami Herald noted the incongruity of the expensive new building in the midst of this neighborhood (Roth 2012):

East Little Havana needs urgent help. No doubt about it. The Marlins Park, which looks like a flying saucer stuck in a blighted and squandered neighborhood, has come to highlight how impoverished the surrounding 
area is, populated by residents living in deplorable conditions. What is doubtful is the political will of City of Miami officials to improve the awful conditions of this neighborhood.

In addition to the housed interviewees, many of the homeless Hispanic interviewees reported sleeping in this neighborhood; one interviewee showed the house he had grown up in, located a few blocks away from the abandoned house where he now slept some nights. While a few interviewees spoke of hoping to earn income in connection with the opening of the stadium, through official part-time employment or via underground work such as selling water or hot dogs to game attendees, the majority of interviewees viewed it as a novelty which would have little impact on the day-to-day struggles of their life. In fact, one of the biggest issues for residents was the loss of onstreet parking during the 81 game days a year, leaving the working class residents having to walk quite far when returning home for work. While this issue created front page headlines, it had little impact on the interviewees for this study, who could not afford cars to have to park somewhere. Nonetheless, the response of the Marlins' president to the outcry from residents was emblematic of the overall disinterest on the part of the team and public officials regarding the lives of the local residents, as noted in a Miami Herald column (Roth 2012):

Marlins president David Samson, when asked about how the parking restrictions affected Little Havana residents, said simply that residents "would eventually get used to walking a few blocks to get home on game nights." That, sadly, is the same attitude that many powerbrokers have about the defenseless residents of Little Havana: "They'll get used to it." 
Figure 12: (photo) Luis, in East Little Havana, in front of the stadium

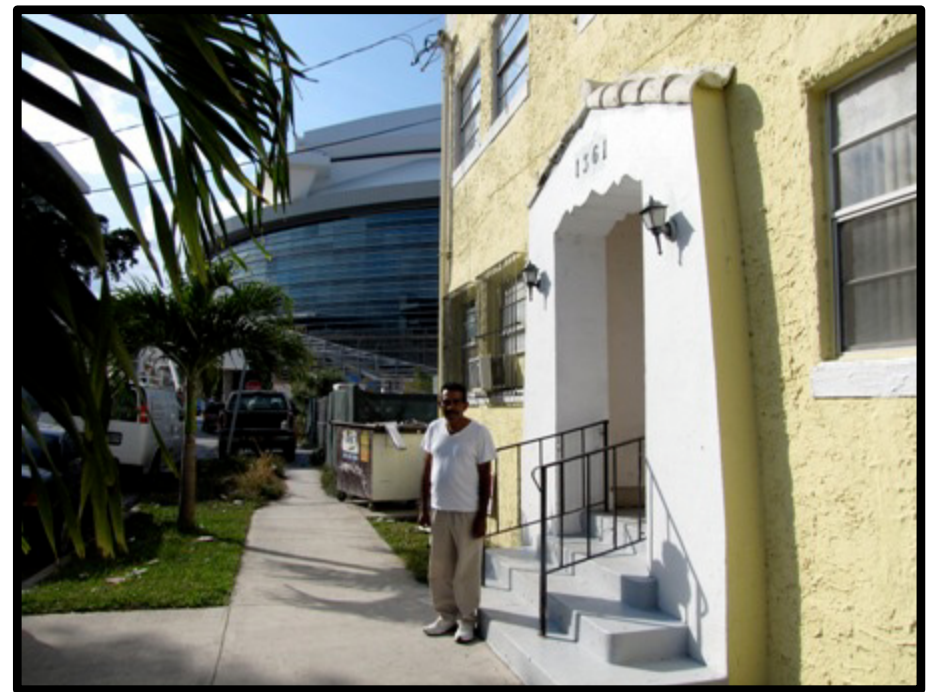

Luis was living doubled-up with a friend in this Little Havana apartment, sleeping on a couch in the living room. Although the new baseball stadium was directly next door, Luis had not been successful in finding employment associated with the new facility. So far, the only results he's seen from the massive public project was a daily dose of thick construction dust coating the truck he used for travel to odd jobs.

The ability to move away from "bad" neighborhoods was considered important by many interviewees. For some, it had influenced where they moved to and was a source of pride; for others who were unable to afford anything else, staying was a source of frustration. For example, Figure 11 shows three formerly homeless black males living within blocks of each other in the Edgewater neighborhood, east of Biscayne Boulevard just north of downtown. While these individuals were unaware of each other, this neighborhood had been deliberately chosen because it was close to transportation and downtown, but was still far enough away from the Overtown streets where they used to "hang out" and buy and sell drugs. Unlike much of Biscayne Boulevard, these blocks had not yet been gentrified and thus contained older, affordable rental units. Although the buildings were worn, these residents considered these apartments in a safe neighborhood near the water to be a symbol of their success in leaving homelessness and addiction behind. 


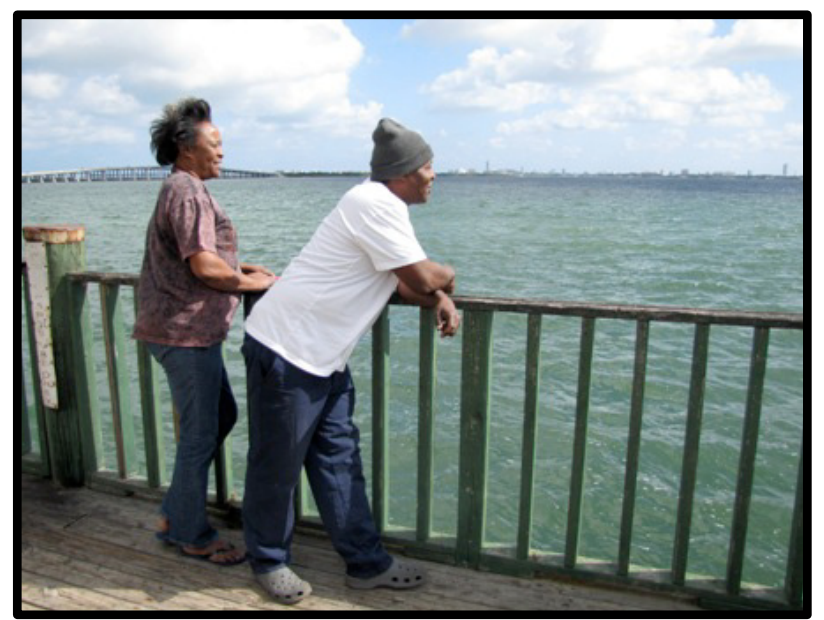

Jimmy and his girlfriend share an apartment in the Edgewater neighborhood, having completed drug treatment and left homelessness. The view of the water was important to him, serving as a reminder of how far he had come since the low point in his life. The apartment was both a symbol of success, and a source of stress: Asked to talk about the most difficult thing in his life, Jimmy stated he was most afraid of not being able to maintain enough employment to keep paying the rent on his apartment. He explained that had he gone back to the Overtown neighborhood where he had stayed on the streets and known all the drug dealers, he would be homeless again:

"I like this area because, um laid back, you know. It's not a lot of--I don't see no drugs around here, you know. No one's addicted to drugs, so I want to change you know. The programs, they tell you to change people and places. On the other hand, on the other hand I feel like if I would've moved back in Overtown, we wouldn't be having this interview right now."

Not everybody was as happy as Jimmy, though. As described in the methods section, some interviewees declined to be interviewed in their homes out of embarrassment or fear for their own safety or that of the researcher. Some invited the researcher in, but described dissatisfaction with where they lived. Generally, complaints were not about the physical condition of the units, but about the location in buildings or neighborhoods that were high crime areas with drugs sold out in the open on street corners. This was particularly true in Overtown, although some of the East Little Havana residents also complained about the "class" of individuals living in that neighborhood. Individuals who had managed to leave homelessness, only to find themselves still not earning enough money to move to a better neighborhood, were disappointed, even though they were quick to qualify their disappointment with recognition that it was still better than the streets. 
Figure 14: (photo) Larry and the two views of his apartment

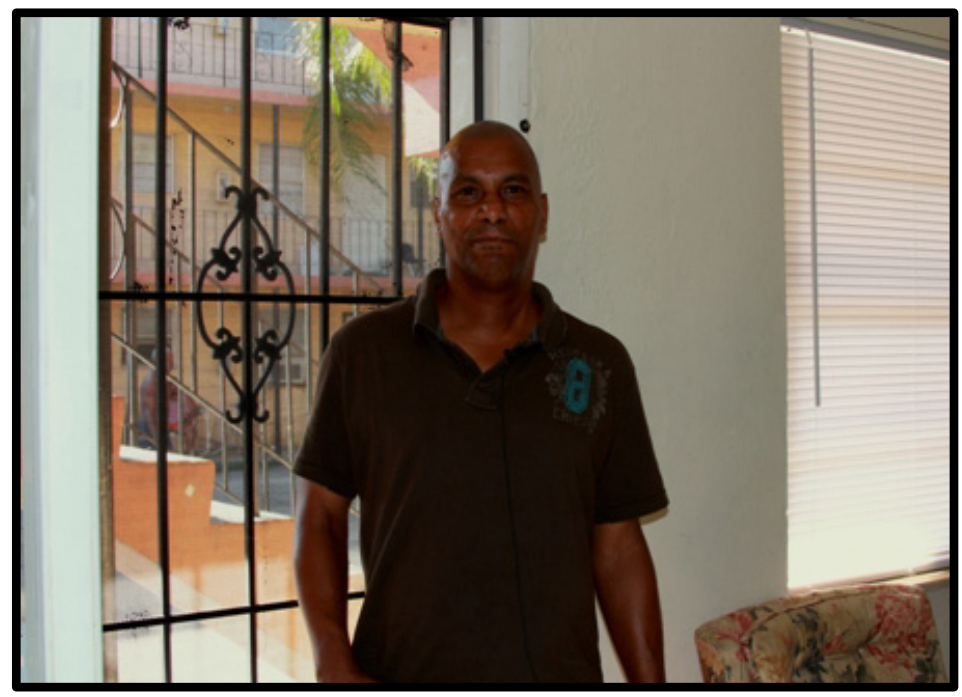

The two photographs Larry wanted to take demonstrated the contradictory emotions that arose out of the socio-spatial situations of formerly homeless individuals:

First, Larry showed his front door, which he was compelled to keep both locked and closed because he did not feel safe in his building:

"OK, well this is what I mean. Now it's like 4 or whatever in the afternoon, but you see I got all my blinds closed because I have like a bunker type mentality living here. Now, uh, but I don't want to, you know, I would love to open my blinds and have sunlight in here, but uh from the disrespect of

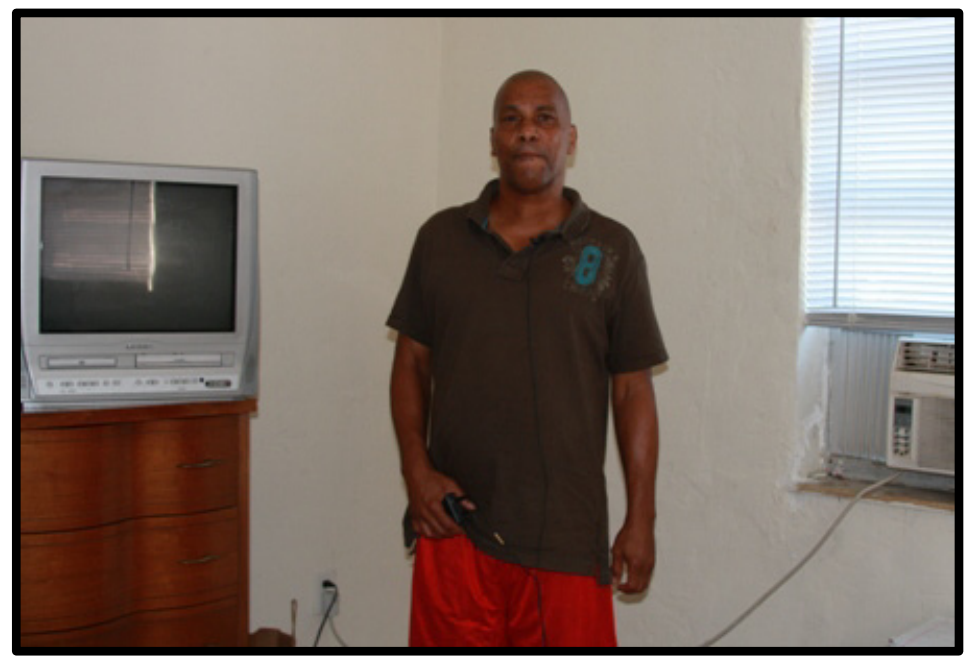
people, you know, it's just uh that kind of thing."

But immediately after that photo, he wanted another picture in his living room to show how much he loved having his own apartment:

"I'm proud, I'm really proud of uh what I have you know. Cause I know a lot of people, you know, don't have this. It's out here, like I said, when you come from being straight homeless to having, you know, your air, your tv...it's just beautiful... Like to some people it may not mean much, but to me it's like a million."

An additional factor in dissatisfaction with the location of homes was their

location far away from friends or family. This led to comments about loneliness, but also tied into individuals' access to social capital. Some reported that they did have family who would be able to lend a hand with food or small amounts of money, but that because they lived on the other side of the county, it was difficult to reach them. Miami's poor public transportation system meant that visiting a sister in Hialeah could require multiple 
bus changes and turn into a full day endeavor. Cuban Hispanics were particularly concerned with living near other Cubans, and were quick to note that East Little Havana was predominantly non-Hispanic Cubans, making them feel isolated.

The socio-spatial distribution of where persons who are at-risk of homelessness or formerly homeless live is an influencing factor in determining how they survive, and whether they are able to avoid homelessness. Unfortunately, the decision on where to live is largely out of the control of individuals with extremely low or no incomes in Miami. The stock of extremely low income affordable housing units is concentrated in a few neighborhoods, forcing some individuals into situations where they are drawn away from their support networks, or, are drawn back into proximity to negative social networks. It is possible to escape, as demonstrated by some of the interviewees, but it is not easy and thus remained out of reach of some individuals struggling with many other obstacles in their lives. When examining the choices available to low-income men, it is thus important to consider geography as another factor in their daily negotiations.

\subsection{Program and Housing Outcomes}

Considering that homeless men living in shelters, transitional, and permanent housing programs present with different demographics, disabilities, and needs, it is reasonable to ask whether they experience different outcomes. Table 9 describes where individuals went upon discharge from emergency shelters. The choices available in the HMIS system were condensed into seven categories: Street/Unknown; Emergency or Transitional Programs; Permanent Subsidized Housing (including supported homeless programs, Section 8 vouchers, or other subsidized options); Independent Housing (rental or ownership without a subsidy); Family; Treatment (substance abuse and 
mental health treatment facilities); or Other (including hospitals, jails, or other). This table focuses on individuals leaving emergency shelters, as that is the first step in leaving the streets, and the destination upon leaving the shelter is vital to determining whether they will succeed in attaining permanent housing.

\section{Table 9: Homeless Men's Destination Upon Exiting Emergency Shelter in Miami-} Dade

\begin{tabular}{|c|c|c|c|c|}
\hline & Black & Hispanic & White & TOTAL \\
\hline & \multicolumn{3}{|c|}{ Count (\% within race/ethnicity) } & \\
\hline Street/Unknown & $1564(47.5 \%)$ & $877(47.5 \%)$ & $486(51.0 \%)$ & $2927(48.1 \%)$ \\
\hline Emerg/Trans Program & $368(11.2 \%)$ & $202(10.9 \%)$ & $103(10.8 \%)$ & $673(11.1 \%)$ \\
\hline Permanent Subsidized & $155(4.7 \%)$ & $89(4.8 \%)$ & $33(3.5 \%)$ & $277(4.5 \%)$ \\
\hline Independent* & $265(8.1 \%)$ & $189(10.2 \%)$ & $59(6.2 \%)$ & $513(8.4 \%)$ \\
\hline Family* & $260(7.9 \%)$ & $195(10.6)$ & $91(9.5 \%)$ & $546(9.0 \%)$ \\
\hline Other & $387(11.8 \%)$ & $219(11.9 \%)$ & $137(14.4 \%)$ & $743(12.2 \%)$ \\
\hline Treatment* & $291(8.8 \%)$ & $74(4.0 \%)$ & $44(4.6 \%)$ & $409(6.7 \%)$ \\
\hline \multirow[t]{2}{*}{ TOTAL } & 3290 & 1845 & 953 & 6088 \\
\hline & $100.0 \%$ & $100.0 \%$ & $100.0 \%$ & $100.0 \%$ \\
\hline
\end{tabular}

*Denotes differences are significant with Chi-Square $\mathrm{P}<.01$

Data Source: Miami-Dade County Homeless Trust HMIS records 2010-2011

Approximately half of men leaving shelters return to the streets, with no

significant disparity amongst racial/ethnic groups. Significant differences do appear, however, in the group of men who transition into independent living or go to live with family, with Hispanics being more likely to access those options than blacks.

Additionally, blacks are more than twice as likely as Hispanics (8.8\% versus $4.0 \%)$ to enter a substance abuse treatment program.

\section{These data disprove the null hypothesis, that single men exiting homeless}

\section{programs in Miami-Dade County go to similar destinations when broken down}

race/ethnicity. Rather, it appears that Hispanics are more likely to go to independent living or to live with family, while blacks are more likely to go to a treatment program. 
Given that blacks suffer from addiction at greater rates than Hispanics, the fact that more go to treatment programs is not surprising. However, it still suggests that further research may provide more detail regarding how the different resources of independent living and family are made available to Hispanics.

\section{Reasons for Leaving Programs}

The reason given when an individual leaves a program is also an opportunity for examining differences in the reasons minority males exit programs in Miami-Dade. The choices available for reason for leaving were condensed into five categories: Completed Program; Left On Own (for another housing opportunity); Discharged for Violation (breaking rules, criminal activity, failure to comply with case plan); Other; or Unknown/Disappeared (left without completing discharge interview, went AWOL overnight, etc.). Data was examined for those leaving emergency shelters, as well as for those leaving all other types of programs.

Table 10 below shows that there are actually very few major differences in reasons for leaving programs. However, the small differences do test as significant with Pearson Chi-Square values of $\mathrm{p}<.05$. Whites are slightly more likely than blacks and Hispanics to leave an emergency shelter before completing the program, and blacks are the least likely to be discharged for a program violation. Within all non-emergency shelter programs, there are no significant differences in reasons for leaving a program. 
Table 10: Homeless Men's Reasons for Leaving Programs in Miami-Dade

\begin{tabular}{|c|c|c|c|c|}
\hline REASON FOR LEAVING & Black & Hispanic & White & Total \\
\hline \multicolumn{5}{|c|}{ EMERGENCY HOUSING PROGRAM } \\
\hline Completed Program* & $2108(64.2 \%)$ & $1147(62.2 \%)$ & $571(60 \%)$ & $3826(62.9 \%)$ \\
\hline Left on Own* & $50(1.5 \%)$ & $35(1.9 \%)$ & $26(2.7 \%)$ & $111(1.8 \%)$ \\
\hline Discharged for Violation* & $316(9.6 \%)$ & $211(11.4 \%)$ & $107(11.2 \%)$ & $634(10.4 \%)$ \\
\hline Other* & $160(4.9 \%)$ & $104(5.6 \%)$ & $64(6.7 \%)$ & $328(5.4 \%)$ \\
\hline Unknown/ Disappeared & $652(19.8 \%)$ & $347(18.8 \%)$ & $184(19.3 \%)$ & $1183(19.5 \%)$ \\
\hline \multirow[t]{2}{*}{ TOTAL } & 3286 & 1844 & 952 & 6082 \\
\hline & $100.0 \%$ & $100.0 \%$ & $100.0 \%$ & $100.0 \%$ \\
\hline \multicolumn{5}{|c|}{ TRANSITIONAL AND PERMANENT HOUSING PROGRAMS } \\
\hline Completed Program & $(61.5 \%)$ & $287(60.4 \%)$ & $190(66.9 \%)$ & $1066(62.1 \%)$ \\
\hline Left on Own & $134(14 \%)$ & $76(16 \%)$ & $42(14.8 \%)$ & $252(14.7 \%)$ \\
\hline Discharged for Violation & $132(13.8 \%)$ & $56(11.8 \%)$ & $37(13 \%)$ & $225(13.1 \%)$ \\
\hline Other* & $33(3.4 \%)$ & $33(6.9 \%)$ & $3(1.1 \%)$ & $69(4 \%)$ \\
\hline Unknown/ Disappeared & $69(7.2 \%)$ & $23(4.8 \%)$ & $12(4.2 \%)$ & $104(6.1 \%)$ \\
\hline \multirow[t]{2}{*}{ TOTAL } & 957 & 475 & 284 & 1716 \\
\hline & $100.0 \%$ & $100.0 \%$ & $100.0 \%$ & $100.0 \%$ \\
\hline
\end{tabular}

*Difference is significant at Pearson Chi-Square $\mathrm{p}<.05$

Source: Miami-Dade County HMIS 2010-2011

These data do not support the null hypotheses, although the variation is not

large: Single men exiting homeless program in Miami-Dade County have slightly

different outcomes regarding successful or non-successful program completion when

broken down by race/ethnicity. The difference in outcomes is only true for men exiting emergency shelter programs; there is no significant difference when leaving transitional or permanent housing programs. The variations in reasons for leaving emergency shelter are fairly small in nature, but they do test significant (Pearson Chi-Square $p<.001$ ) given the large data set. Blacks are more likely than Hispanics or whites to complete a program (64.2\% versus $62.2 \%$ and $60 \%$ respectively). Whites and Hispanics, on the other hand, are more likely to leave on their own or be discharged for a program violation. In this 
area, there is room for further research to determine why blacks seem to be more program compliant than Hispanics or whites. It is possible that Hispanics and whites have other options and therefore do not have as much to lose in leaving a program early, or in being discharged for a violation. Have access to other resources could also explain why the difference disappears for transitional and permanent programs, as by the time an individual enters one of those longer-term programs, they likely do not have as many outside resources.

Nonetheless, in spite of the differences in backgrounds, disabilities, and program destinations, the final outcomes for men of different races and ethnicities are similar when exiting transitional or permanent programs. The similarity in outcomes is particularly true when looked at within a broader framework regarding whether the program was completed or not. While the details on where they go still varies slightly, there is almost no variation between rates of program completion and non-completion. 


\section{CHATER 6: EARNED INCOME AND BENEFITS}

I had a stroke and it super changed my life...you know when you're rigorous and take of yourself and I used to work out a lot and everything, and then the stroke just really freaked me out and it just totally changed my life. But in a way... before the stroke, when I was homeless, just straight up homeless, like uh not have any kind of income, so the stroke in a sense has given me an income because now I'm on disability. You know, money per se. But I praise God for it because it at least covers things like housing, and stuff like that. Whereas before it was messed up being homeless in Miami. - Larry

What leads a man to praise God for having a debilitating stroke? For homeless adult men in Miami, access to jobs or resources can become so out-of-reach that living with a painful, disabling medical problem can seem like a fair trade-off because it can open the door to help in attaining housing. In this chapter I will discuss how the homeless male subjects of this study negotiate Miami's current labor market and attain sources of income, including cash and non-cash resources, in their efforts to attain and/or maintain housing, noting in particular where there are differences between blacks and Hispanics. This chapter addresses Research Question 2: How does Miami's response to extreme poverty and homelessness, including availability of public benefits and the presence of public and private helping organizations, either maximize or constrain the choices available to this population? It will test specific hypotheses regarding the availability of public benefits, efforts to attain benefits, success rates of attaining benefits.

Having a source of income is, of course, central to being able to avoid or exit homelessness. Given a choice, nearly every man interviewed for this study would choose to earn their income through a job. Unfortunately, that choice is largely unavailable to most of them, for a variety of reasons discussed further below. Thus, survival depends on 
patching together resources from other sources including public benefits, social capital from friends and family, and assistance from programs and charities.

First, I will discuss employment options, including the effect of changes to the labor market as well as the subjects' personal characteristics that affect individual employability. Second, I will discuss cash benefits, focusing on Social Security Income/ Social Security Disability Income (SSI/SSDI), which is one of the few options available to single men in Florida. Third, I'll discuss access to healthcare, examining the role of health problems in contributing to the homeless situation of interviewees, but also exploring how the healthcare safety net actually strengthens for persons once they become literally homeless. Fourth, I'll cover food security, an area in which the safety net appears to work fairly well. Finally, throughout the chapter I'll discuss how these resources intersect with individuals' access to affordable housing, helping them to exit and/or avoid homelessness.

\subsection{Employment}

The desire for a job was the most commonly shared theme from all the interviews. Not a single person said their first choice was to live on welfare. Nobody asked the researcher for money; lots asked for help getting a job interview. Months after the interview, subjects would call the researcher asking if she had any job leads. Even subjects who were unable to work due to a disability usually expressed that they would rather be working if they could.

However, the job hunting process for these men had been frustrating and largely unsuccessful. The most common barrier to finding employment was having a criminal background. Low education and low skills were frequently cited as problems. Living on 
the street exacerbated employment difficulties, with individuals lacking access to phones or computers, transportation, and the social connections that play a central role in attaining a job for most people. And, simply being homeless was a turn-off to potential employers.

\section{Earned Income}

Approximately 1 in 5 homeless men from the countywide data set reported having earned income. The percentage was much higher for the homeless men who were subjects of this study, with $61 \%$ reporting some type of earned income. The higher percentage of individuals reporting earned income in the interviews may be due in part to underreporting in the countywide data. Specifically, interviews took into account underthe-table work including illegal activities, but individuals may be less likely to report this during the official intake interviews that form the basis of the countywide data. Any type of earned income, including part-time, seasonal, and underground work, was included as earned income in the interviews.

\section{Table 11: Earned Income Amongst Homeless Men in Miami-Dade}

\begin{tabular}{|c|c|c|c|c|}
\hline & Black & Hispanic & White & Total \\
\hline Countywide Perm Housing* 1 Count & 182 & 55 & 34 & 271 \\
\hline \% within Race/ Ethnicity & $25.0 \%$ & $11.8 \%$ & $21.3 \%$ & $20.0 \%$ \\
\hline Countywide Trans \& Emerg Housing* ${ }^{1} \quad$ Count & 904 & 387 & 215 & 1506 \\
\hline$\%$ within $\mathrm{R} / \mathrm{E}$ & $23.2 \%$ & $18.4 \%$ & $19.3 \%$ & $21.2 \%$ \\
\hline Study Subjects (Homeless \& At Risk) ${ }^{2}$ & 21 & 12 & $\mathrm{~N} / \mathrm{A}$ & 33 \\
\hline $\begin{array}{l}\text { \% within } \\
\mathrm{R} / \mathrm{E}\end{array}$ & $65.6 \%$ & $54.5 \%$ & & $61.1 \%$ \\
\hline
\end{tabular}

*Denotes that column differences test significant with $\mathrm{p}<.05$

Data sources: ${ }^{1}$ Miami-Dade County HMIS, Homeless Males, 2010-2011; ${ }^{2}$ Researcher interviews

In each category, blacks had a higher percentage of individuals report earning some type of income. This difference tested significant with $\mathrm{p}<.05$ within the county's 
larger data set, but did not within the smaller set of interviews. Whites were not included in the interviews and thus are not available for comparison. Figure 15 below shows the proportional differences in the percentage of each race/ethnicity:
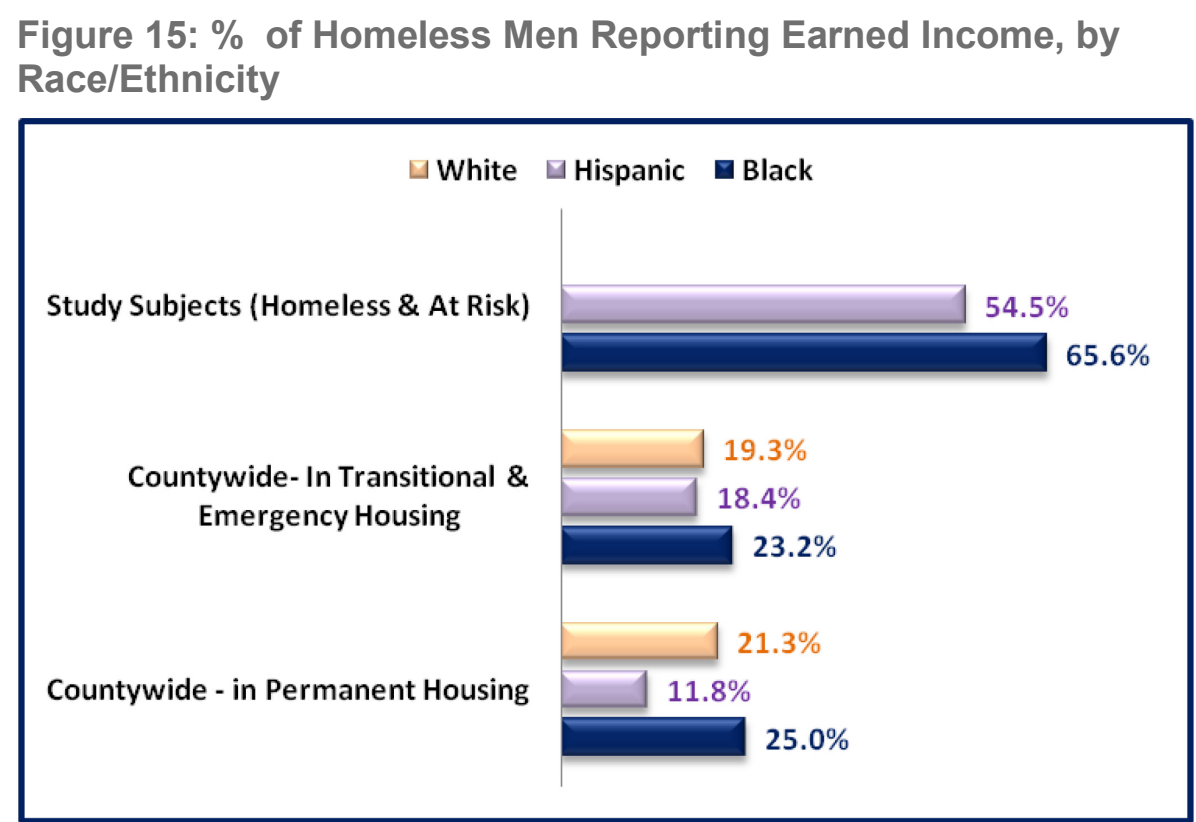

Data Sources: Study Subjects -Researcher Interviews;

Countywide data: Miami-Dade County HMIS Homeless Males, 2010-2011

The countywide data shows that the percentage of blacks earning income goes up for those in permanent housing, while it goes down for Hispanics in permanent housing. This may be because Hispanics in permanent housing receive disability benefits at a higher rate than blacks, as discussed more in the following section on benefits. Thus, Hispanics may be less physically able to work, or may be less likely to report underground work that could affect their disability benefits. Hispanics may also include individuals who lack documentation that would allow them to work legally in the U.S.

Full-time jobs were almost non-existent amongst the interviewees. Two individuals indicated they worked full-time. However, one had been furloughed without 
pay for two weeks while the company closed for maintenance, and the other earned just $\$ 8.00$ with no benefits for a 40 -hour week. The majority of part-time jobs were seasonal or event based, so that the workers were unable to predict how many hours of work they would have on a week-to-week basis. Several subjects who were housed reported working concessions or janitorial at American Airlines arena, while numerous persons living on the streets reported earning money in parking lots outside of the same events. Sometimes the parking attendants were hired by legitimate companies; sometimes the parking attendants were illegally charging money for spots that were not theirs, for as long as they could before the police caught on.

Individuals described a wide range of creative means for earning income. Underground work included: completing on-line food stamp applications for persons unfamiliar with computers ( $\$ 5$ each); drawing portraits of college students ( $\$ 10$ each); selling coconuts to tourists ( $\$ 5$ each); catching and selling fish on the beach (5 for $\$ 15)$; and selling water, flowers, and perfume on street corners. The desire to sell something, rather than panhandle, was common, although sellers reported being arrested on a frequent basis for charges such as operating a business without a license.

Doing odd-jobs and chores included sweeping stores, cleaning garages and patios, mowing lawns, moving furniture, washing cars, helping street vendors set up their hot dog cars; doing dishes, or anything else friends or kind strangers were willing to pay for. Finding these jobs was through word-of-mouth or going door to door, and individuals tried to develop ongoing relationships with the stores or residents that would hire them.

What one person referred to as "the extreme work" included selling drugs, burglary, hustling, and panhandling, defined as "It's like begging but you try to do it in a 
way that you got to look class and style." Other illegal activities included selling food stamps, although individuals reported that was less common because they actually needed the food and because the new debit card system made it more difficult. It was more common to share food stamps in trade for being allowed to stay in a room for a night or two, take a shower, or cook a meal in someone's kitchen.

\section{Figure 16: (photo) Larry, selling coconuts on Ocean Drive}

Larry earns money selling fresh coconut juice to tourists, keeping them cold on ice that local hotels give him (some hotels are nice, and some are "jerks"). He is frustrated over his repeated arrests for vending without a license, particularly since legitimate vending licenses are not available. He and his friends are sometimes able to pool their money to rent a room for a few nights.

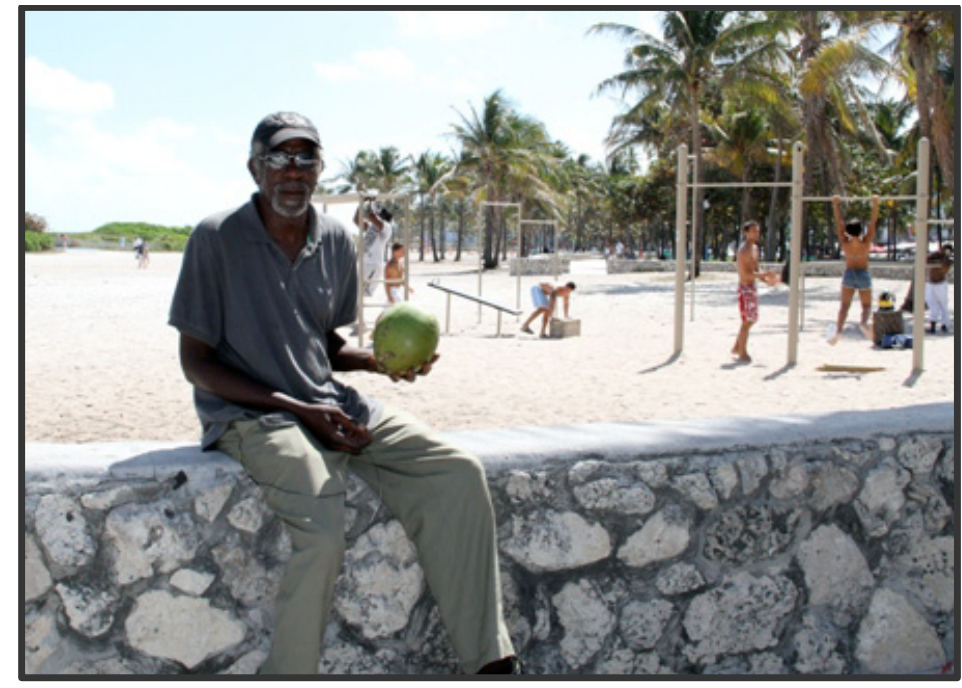

"But normally, when they take you to jail it's just overnight. Yeah, 'cause the judge is trying to keep the jailhouse clear and it's not really a crime."

And what would Larry do to end homelessness? "I would change the law, I would change the whole police force out here 'cause see a person selling water and coconuts, that's not doing any harm. And then you can't even got a vending license for the beach. They would open up that area, you let more people you know, apply for their license and actually get one, it wouldn't be any problems."

Some subjects claimed panhandling was fun, while others described it as an embarrassing activity done only out of desperation. Rafael recalled his panhandling days with tears in his eyes:

"I didn't like it, I couldn't stand the heat, I had to, needed my alcohol, I had to panhandle and not for food, how well we learn how to lie, to get money to buy alcohol. I was really embarrassed all the time so I was really, really, like oh my God I have to do this again but my body needed alcohol. About 20--I was happy if I make 20 dollars." 
Others, like Willie, considered it their job:

Figure 17: (photo): Willie, panhandling in downtown Miami

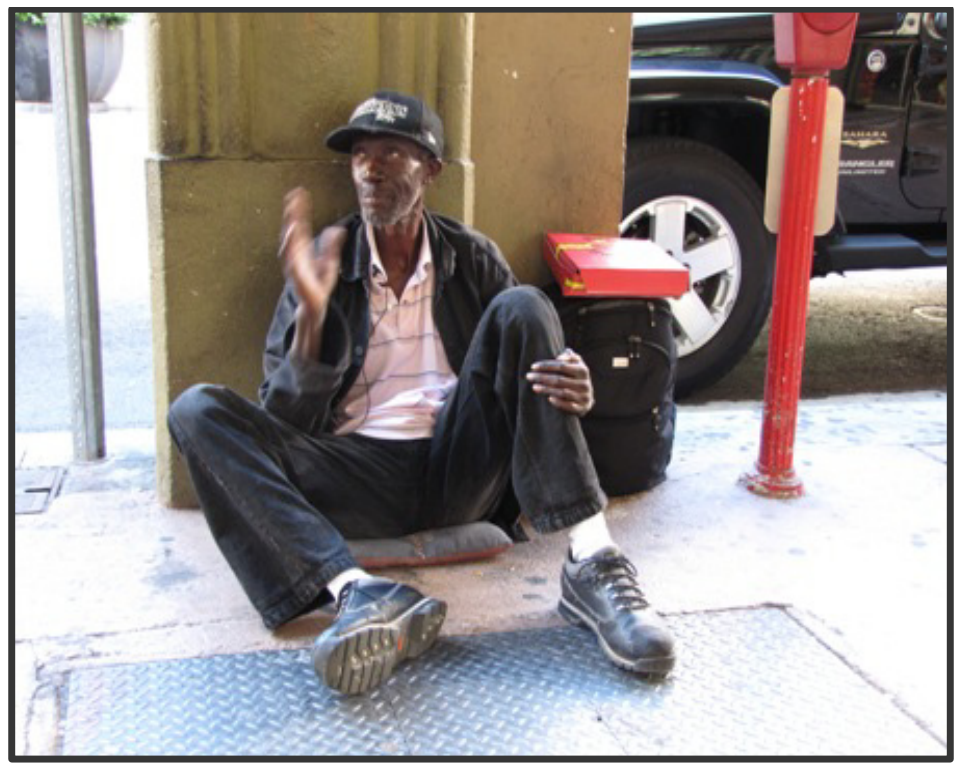

Willie started out with a regular job doing janitorial work. He developed a drug problem that led to him losing his steady job. For years he got by working labor pools. But as he got older the heavy work became too hard, and the labor pools disappeared anyway. Now he makes about $\$ 40$ for 4 hours of panhandling. He estimates half the people are nice and half are not, and that locals are equally as generous as tourists.

Having been in and out of drug programs, Willie is afraid he'll die on the streets:

"I come back, fall back right in the same trap. It's hard out here but I don't give up though, I'm at the point now getting tired of it for me, it's not as good as it used to be anyways...I don't want to die on the streets so I got to make a change somewhere."

The fact that nearly all of the men interviewed wanted to earn their own money instead of accepting welfare does not mean that they dreamt of nine-to-five office jobs in the suburbs. They were willing to work for their money, but they sought out mostly lowskilled jobs, generally focused on construction or kitchen work. The most common types of jobs they'd held in the past were general construction; truck driving; maintenance; trades such as carpentry and electricians; cashiering; and food services. The collapse of the construction industry in Miami beginning in 2008 had put many of construction and trade workers out of a job. Food service workers described being in and out of employment as restaurants opened and closed on Miami Beach and in downtown Miami. 
The loss of labor pools was lamented by many. The ability to do one or two day's work when one wanted to earn money had enabled individuals to maintain a minimal standard of living, even with a drug habit. Patricio remembered doing day labor on construction projects building new condos along Biscayne Boulevard, and being able to rent a room with a friend in one of the old motels on the same street. But the day labor jobs became scarce, and the cheap rooms disappeared, and Patricio slid from being marginally housed into literal homelessness. Martin voiced an opinion shared by several subjects when he explained how the existence of labor pools had allowed individuals such as himself to avoid criminal activity, even with his drug habit:

"Oh nah, when there was like temporary jobs and day labor you understand me, I wasn't really out there doing nothing, you know, illegal or anything kinda like really, really wrong to get these drugs, because I went out like worked every day, got off work, took a little money I had, you know I'd go out there and you know I'd do my thing. When I would get through, when I'd get through I'd just call it a day, everything set down and go find me somewhere to lay down, go to sleep, start the next day all over again."

Michael similarly pointed out that people who used to work in day labor were now idle during the day, inviting opportunity for more trouble: "Like, a lot of these guys, if labor pools were still open, a lot of these guys wouldn't be here. You'd only see them at night time, they wouldn't be hanging around here all day."

The evaporation of the day labor market had taken away one of the few legitimate work options for many men managing to get by on the edge of homelessness. When that work dried up, they not only lost an important source of income, but they also gained more free time that they filled at least partially with drugs and associated criminal 
activity. It also took away the sense of self-worth provided to individuals who'd taken pride in supporting themselves, even if it wasn't at a high standard of living.

The tightened job market meant that persons with the least experience, lowest skills, and most problematic backgrounds found themselves unable to get hired. John summarized the issue, explaining that he was willing to work, but that there was always someone better than him applying for the same job: "Lot of places not hiring anymore, and uh when they have some kind of job opening, there's a whole line of people that wanna apply for it. They'll hire the best one." Unfortunately, John didn't think he would ever be the best one. The homeless men interviewed for this study exhibited many characteristics and issues that made them less than ideal candidates for scarce jobs. In the following pages, I'll review some of the most prevalent problems.

\section{Criminal Backgrounds}

"HAH! It's really hard for a black man to get a job out here. Since you, they have these questionnaires and I'm a truthful, I try my best to be truthful though and they ask me, where am I from? Boston, Massachusetts. You got a criminal record? Can we speak on it? Nah. Case closed, see you later. Some of these restaurants, I applied for a job and never got it. And stuff like that so I gave up on it." - Christopher

Having a criminal background was the biggest impediment to employment for the homeless men interviewed. As the following charts show, the issue is particularly significant for blacks, with nearly $2 / 3$ having criminal records: 
Figure 18: \% of Homeless Interviewees with Criminal Backgrounds, by Race/Ethnicity
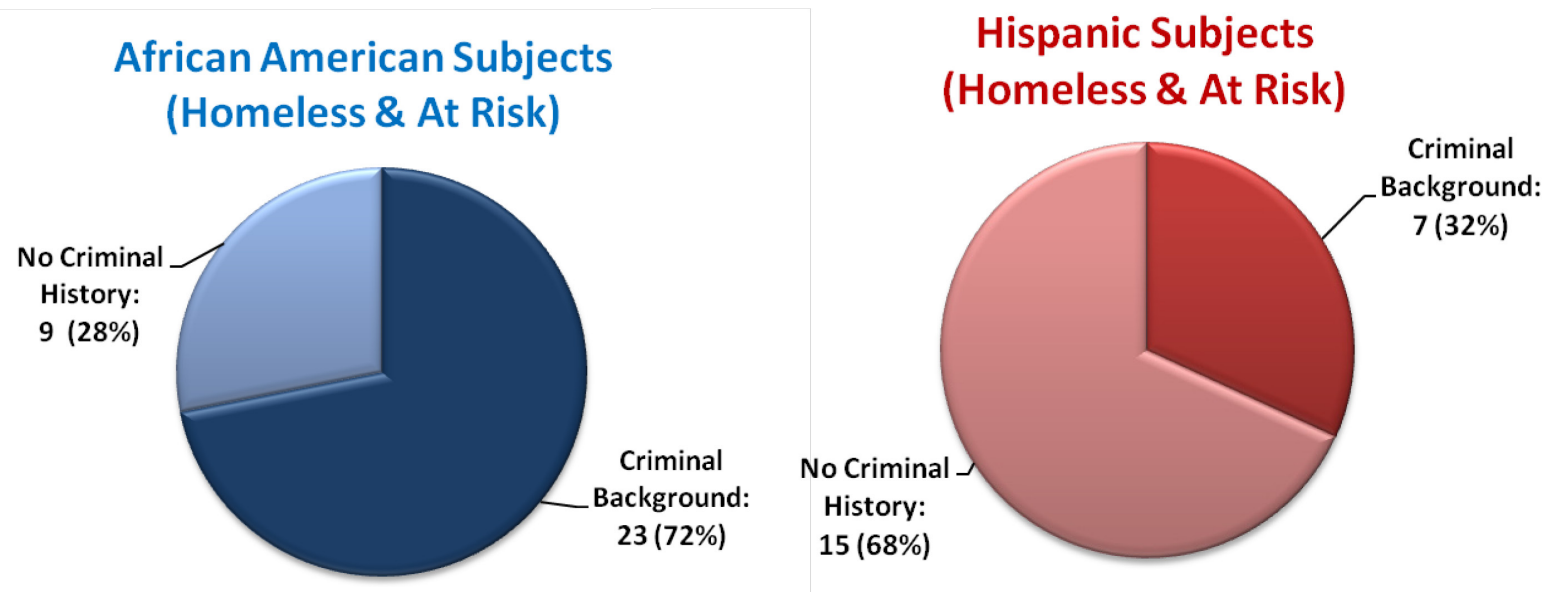

Source: Researcher interviews

Among the black interviewees who were still living on the street, fully $12 / 13$ (91\%) had criminal records that they reported interfered with their ability to get a job. Their criminal histories were intertwined with their homeless situation, with each compounding the other. Having a record made it extremely difficult to attain the income they needed to exit homelessness; living on the street further increased their risk of arrest; having no job led some to attain income through more criminal activity and to fill free time with more drug use; increased drug use led to more arrests.

While blacks were more likely to have a record, the emotions expressed by both blacks and Hispanics on the subject were similar; they ranged from frustration to hopelessness to surrender. Table 12 lists comments representative of those expressed throughout the interviews: 


\section{Table 12: Comments on Employment Opportunity for Criminal Backgrounds}

So my... my background hurts me a lot. And then when they try to tell you "start over" ain't a lot of people giving you a chance but McDonald's or something like that. And even now they're kind of strict.

Cause if you ask yourself on a serious note, what's wrong with me that I can't get a job? Well number one if they don't like hiring criminals, or past criminals, and a lot of time I wish it wasn't so. There's so much I could teach somebody else, and learn from somebody else, and there's nothing about a building I don't know.

A lot of jobs, even when you look at the application, they ask you have you been to jail. I don't even fill out the application because my mind is already made up they're going to say no, you know.

Well, we supposed to look in the halfway house uh but the problem is once you get the job, they didn't say you have to tell them you're in prison, you've been in prison, they don't like that.

Once they see you do application or doing interviewing, when they do the criminal background check, you taboo. Nobody want to touch you. But it's really double jeopardy because you got people that they willing to change and you're not giving them the chance to.

You know, I done been to places where I done, where they say we're looking for 65 people and I make it in the door, but by the time I call they be like ok we gonna call ya'll in a couple days for interviewing. I never get the call. Then when I start calling back they tell me oh, you gotta have a clean record. But that's not what ya'll said at the beginning, ya'll if I had known that I wouldn't even wasted my time going down there. So it be kinda like it ain't hard, but it's just ridiculous sometimes you know.

Because every time they ask you, have you ever been convicted of a felony or have you been to jail before? You check yes, like ok that's it. They don't give you a chance or nothing like that.

It really, it really did cause for a lot of people the first thing they saw, you know, they said, "Ah, felony, what'd you do?" I said, "Well, burglary." That turn them clean off, you know?

Well they gonna ask for my record, you been in jail, you been in this or that, they're gonna turn me down you know?

It's just depressing, it's really, it's like, I've given up on it. Because now, now they do background checks.

(And, one person expressed hope): Push on, you know, one door might close, that don't mean the next one won't be open, you gotta keep pushing on, you know. Life is what you make it.

Source: Researcher Interviews

Men who had succeeded in finding employment in spite of their felony

backgrounds explained that they had found the job through word-of-mouth, and that their

employer was understanding about their background. Small businesses were reported to

be more likely to give someone a chance, with many larger corporations having non-

negotiable policies against hiring anyone with a criminal past.

Geraldo dealt with the situation by lying on his job applications and working until

they found out and terminated him. He was on his third job in two months, but was 
happy to at least have income coming in. He expressed an aversion to any welfare support, talking about giving up his food stamps so that he could be independent, and the fact that he was being blocked from attaining steady employment because of his past was difficult for him to accept.

Most men, however, were not as willing as Geraldo to falsify their applications. So, they continued submitting applications, and asking for interviews, and scrapping together underground work while they searched for a better opportunity. Some gave up entirely, resorting to panhandling or odd jobs as their sole means of income. Michael was still trying a year after the interview. When the researcher asked an outreach worker to check in with him to see how he was doing twelve months after the initial interview, Michael sent a message back to the researcher: "I continue to support myself by creative means, and I would like for you to get me a job interview."

\section{Education and Skills}

Poor education and lack of job skills was an issue for many of the men interviewed. Blacks and Hispanics had similar education levels, with approximately half of the total interviewees having completed high school: 
Figure 19: Education Level of Homeless and At-Risk Interviewees

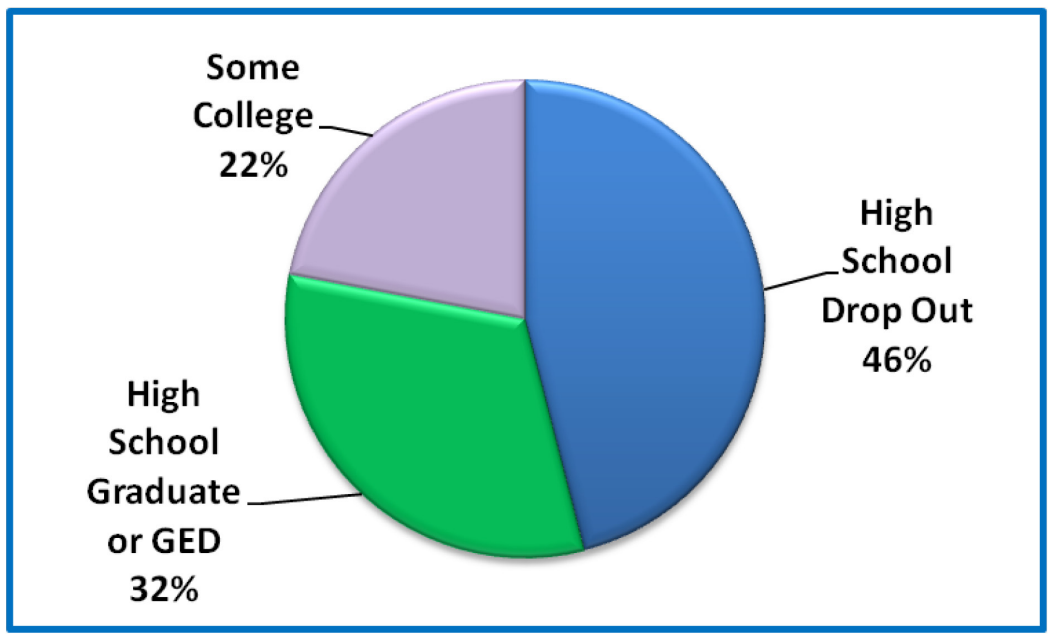

Date source: Researcher Interviews

Some interviewees had grown self conscious over their level of education after having spent so much time on an unsuccessful job search. Carlos explained, "You got competition and, I don't know why, I'm not good at writing application, I'm not really good reading and writing." Others attributed their uncompetitiveness to not having "letters behind their name" or vocational training; and to just having "no education."

Figure 20: Andre, in private apartment living room

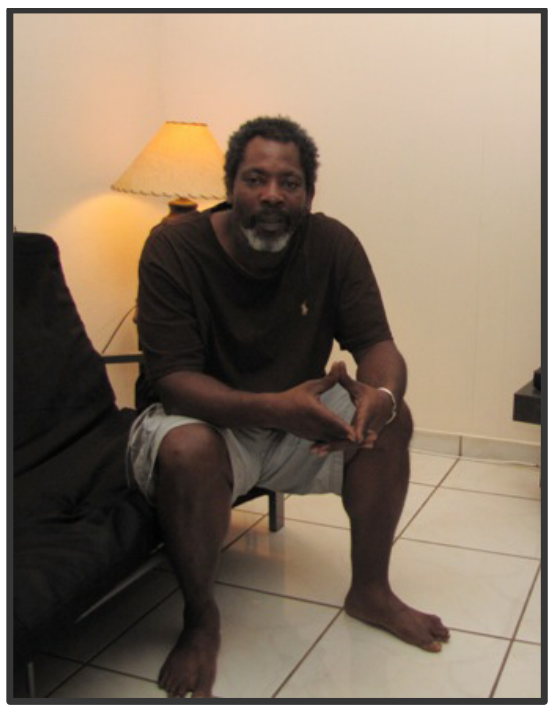

Andre chose to be photographed on the futon in his living room, where he was grateful to spend his free time quietly watching television. He appreciated just having a roof over his head after years of addiction and homelessness. Still, he said, "My life is not quite where I want it to be, but it is what it is."

He regretted dropping out of high school: "You know, I could find some work but a good job, a career or something like that, it's pretty difficult. Um, I often think a lot about my level of education and how it affects my ability to get a good job, you know what I mean. And then it's not the fault of anyone, it's just because again another bad decision on my behalf." 


\section{Communication and Technology}

Lack of computers and phones was repeatedly brought up as another barrier to finding employment, even from persons who were not homeless. Internet access was a luxury many of the persons who were housed but still in extreme poverty could not afford. Ronald, living with his grandmother while he looked for work, explained:

"Um, I go to fill out applications here and they have the application on computer and internet, and not everyone has internet to get up and do that. And it's like, you fill out job applications, you fill out job applications and after the application no one wants to call, no one could keep in touch every time you call back."

In addition to internet access, overall computer literacy requirements was perceived as problematic by some. Businesses that required all applicants apply through computer-based systems or in-store kiosks, even for positions that didn't require computer usage, such as in the stockroom or warehouse, were not an option for many of the older individuals who hadn't been in a school since the 1960s. They expressed feeling unprepared for the current job market.

Not having a phone was an ongoing issue for many. To compensate for not having a phone number, job applicants tried to set up interviews in person, returning on bike or on foot to follow-up on a regular basis. The State of Florida operates the "SafeLink" program, whereby low-income and homeless persons are provided cell phones with limited minutes, to assist with job search activities. However, interviewees described finding the program largely inaccessible for numerous reasons. Most importantly, the program required that the individual provide an address, and only one phone was allowed per address. With most persons living on the street using the same mailing address at Camillus House as the place to receive their mail, they were all barred 
from the program unless they could find a friend willing to lend their address. Persons who had managed to use somebody's address described issues with the phones not working, with running out of minutes early in the month if they were put on hold by any calls, and with finding the customer service unreachable and/or unhelpful. Asked if they had a SafeLink phone, most persons knew what it was, but responded that they didn't qualify due to lack of an address, or that they'd had one but given up on it.

Not having a phone was also a red flag to potential employers. Lee described applying for nearly 100 retail jobs while staying at a local homeless shelter, and losing two potential jobs when they realized they had called him back in a homeless shelter:

"People that are homeless you know, are, are sometimes stereotyped as drug abusers or people that cannot manage their lives or had something happened that could affect their jobs. Nobody employer is gonna pick somebody that they know is homeless. If they're really, really picky about that, most people don't want to give you a chance... That happened to me on two jobs actually, they were gonna hire me and when they called the number they're like what is this number? For some reason the job was no longer available."

\section{Poor Social Capital}

The poor and homeless men interviewed for this study were well aware that they lacked the social capital that would provide them with valuable connections to job leads, even if they didn't label it that way. Charles summed up his job hunting experiences:

"And you tryin' to get a job out here, you would have to go face to face with people, online is impossible, unless you know somebody, that's how I see it. If you don't know anybody, in the work industry, you don't never find a job."

Having personal connections that could help with job referrals, interviews, and references takes on extra significance for persons trying to conduct a job search from the street. Indeed, most persons who had part-time or full-time work reported that someone 
they knew had helped them find the position. Persons with criminal backgrounds had especially depended upon connections, frequently through other friends with similar records, to find jobs. It was also common for individuals lacking regular employment to get by doing underground work and odd jobs for friends and family. The role of social capital in the lives of homeless men in Miami is discussed more in the following chapter.

\subsection{Accessing Public Benefits}

When income from employment, including under-the-table work, is not available or is not enough to help someone maintain housing, public benefits or private support are the other options for avoiding or exiting homelessness. Attainment of public benefits has repeatedly been shown to be one of the most effective intervention for helping persons who are homeless to move into and then maintain permanent housing (Burt and Smith Nightingale 2010; National Alliance to End Homelessness 2011). (The role of private support is discussed in the following section.)

Recognizing the important role of such benefits, the US Department of Housing and Urban Development (HUD) and other federal agencies, as well as the Miami-Dade County Homeless Trust, have made connecting persons who are homeless to mainstream public benefits a central component of communities' Ten-Year Plans to End Homelessness (Miami-Dade County Homeless Trust 2007; National Alliance to End Homelessness 2011). In these plans, mainstream benefits are generally discussed as including Temporary Assistance to Needy Families (TANF), Social Security Income/Social Security Disability Income (SSI/SSDI), Medicaid/Medicare, and the Supplemental Nutrition Assistance Program (SNAP). Housing subsidies such as Section 
8 vouchers are also included in this category, although their scarcity does make them more difficult to access. Additionally, Veterans Administration benefits for veterans are sometimes included in this category.

TANF is the cash assistance program established under the Personal Responsibility and Work Opportunities Act (1996) which enacted the current Welfare Reform provisions. TANF provides time-limited cash assistance to eligible families with children. Because it is only available to families, the single adult men who are the subjects of this study are not eligible to apply for this benefit. Thus, I do not discuss it in any more detail, other than to note that it is significant only for its absence in the pool of potential resources for homeless men. The remaining benefit sources are discussed in the rest of this chapter.

Table 13 shows the percentage of homeless men in Miami-Dade County receiving benefits of SSI/SSDI, Medicaid/Medicare, or SNAP, according to data from the County's Homelessness Management Information System. The data separates men residing in permanent housing programs from those in non-permanent (i.e. emergency or transitional programs), because individuals in permanent housing programs are far more likely to have a disability, since this is a requirement for living in HUD-funded Supportive Housing Programs, and thus are more likely to qualify for SSI/SSDI: 
Table 13: \% of Homeless Men Receiving Public Benefits in Miami-Dade, by Race/Ethnicity

\begin{tabular}{|c|c|c|c|c|c|}
\hline & & Black & Hispanic & White & Total \\
\hline \multicolumn{6}{|c|}{ ALL PERMANENT HOUSING PROGRAMS } \\
\hline \multirow{2}{*}{$\begin{array}{l}\text { Social Security } \\
\text { Disability (SSI/SSDI)* }\end{array}$} & Count & 364 & 319 & 89 & 772 \\
\hline & $\%$ within $\mathrm{R} / \mathrm{E}$ & $50.1 \%$ & $68.3 \%$ & $55.6 \%$ & $57.0 \%$ \\
\hline \multirow[t]{2}{*}{ Medicaid/Medicare* } & Count & 151 & 185 & 38 & 374 \\
\hline & \% within $\mathrm{R} / \mathrm{E}$ & $24.4 \%$ & $41.0 \%$ & $25.9 \%$ & $30.7 \%$ \\
\hline \multirow[t]{2}{*}{ SNAP (Food Stamps)* } & Count & 326 & 308 & 84 & 718 \\
\hline & $\%$ within $\mathrm{R} / \mathrm{E}$ & $52.7 \%$ & $68.3 \%$ & $57.1 \%$ & $59.0 \%$ \\
\hline \multicolumn{6}{|c|}{ ALL NON-PERMANENT HOUSING PROGRAMS } \\
\hline \multirow{2}{*}{$\begin{array}{l}\text { Social Security } \\
\text { Disability (SSI/SSDI)* }\end{array}$} & Count & 716 & 315 & 185 & 1216 \\
\hline & $\%$ within $\mathrm{R} / \mathrm{E}$ & $18.4 \%$ & $15.0 \%$ & $16.6 \%$ & $17.1 \%$ \\
\hline \multirow[t]{2}{*}{ Medicaid/Medicare } & Count & 57 & 27 & 14 & 98 \\
\hline & \% within $\mathrm{R} / \mathrm{E}$ & $1.5 \%$ & $1.3 \%$ & $1.3 \%$ & $1.4 \%$ \\
\hline \multirow{2}{*}{ SNAP (Food Stamps)* } & Count & 1929 & 1143 & 543 & 3615 \\
\hline & $\%$ within $\mathrm{R} / \mathrm{E}$ & $50.4 \%$ & $55.1 \%$ & $50.1 \%$ & $51.7 \%$ \\
\hline \multicolumn{6}{|c|}{ TOTAL - ALL HOMELESS PROGRAMS } \\
\hline \multirow{2}{*}{$\begin{array}{l}\text { Social Security } \\
\text { Disability (SSI/SSDI)* }\end{array}$} & Count & 1080 & 634 & 274 & 1988 \\
\hline & $\%$ within $\mathrm{R} / \mathrm{E}$ & $23.4 \%$ & $24.7 \%$ & $21.5 \%$ & $23.5 \%$ \\
\hline \multirow[t]{2}{*}{ Medicaid/Medicare* } & Count & 208 & 212 & 52 & 472 \\
\hline & \% within $\mathrm{R} / \mathrm{E}$ & $4.7 \%$ & $8.4 \%$ & $4.2 \%$ & $5.8 \%$ \\
\hline \multirow[t]{2}{*}{ SNAP (Food Stamps)* } & Count & 2255 & 1451 & 627 & 4333 \\
\hline & $\%$ within $\mathrm{R} / \mathrm{E}$ & $50.7 \%$ & $57.5 \%$ & $51.0 \%$ & $52.8 \%$ \\
\hline
\end{tabular}

*Denotes that difference is significant with $\mathrm{p}<.05$

Source: Miami-Dade County Homeless Trust, Homelessness Management Information System, Records for July 1, 2010-December 31, 2011

Note that in every category with exception of Medicaid/Medicare for persons in non-permanent housing programs, the difference in percentage of persons within each race/ethnicity receiving benefits is statistically significant. In permanent housing, Hispanics have the highest percentage of persons receiving benefits in each category, with blacks having the lowest and whites in the middle. In emergency and transitional programs, however, blacks have a slightly higher rate of receiving SSI/SSDI and 
Medicaid. Potential reasons for the difference are discussed more in the rest of this

chapter.

Figure 21: \% Homeless Men in Miami-Dade in Permanent Housing Receiving Public Benefits, by Race/Ethnicity

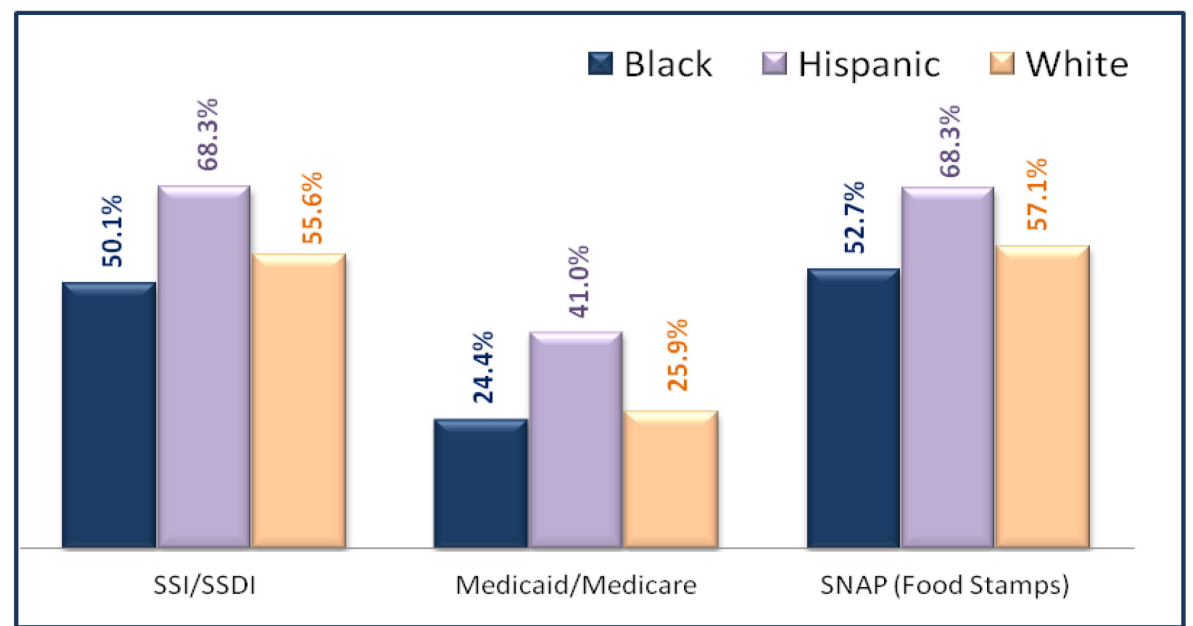

Source: Miami-Dade County HMIS, Homeless Males, 2010-2011 n=7,605

Figure 22: \% Homeless Men in Miami-Dade in Emergency/ Transitional Program Receiving Public Benefits, by Race/Ethnicity

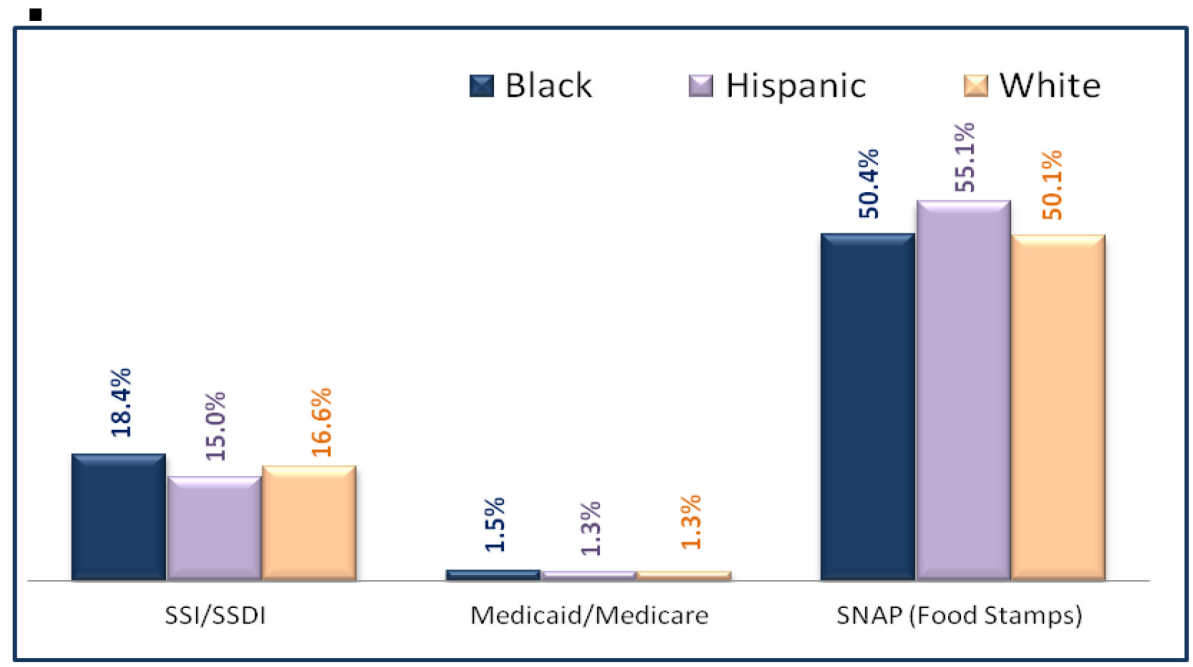

Source: Miami-Dade County HMIS, Homeless Males, 2010-2011 n=7,605 
As Table 14 below shows, amongst the 54 men interviewed for this study, a similar pattern is seen with Hispanics having a higher percentage of their population receiving SSI/SSDI and Medicaid/Medicare than blacks. However, while 50\% of Hispanics have disability benefits compared to $25 \%$ of blacks, the difference does not test as significant with $\mathrm{p}<.05$. The difference for receipt of Medicaid does test significant with $p<.05$. With SNAP, a higher percentage of blacks receive the benefit. Note that as described in the methods section, this population is not an exact match for the overall County data used above, but does include a great deal of overlap. The primary difference is that the interviewees include men who were at risk of homelessness, but who had not entered the homelessness system.

Table 14: \% of Homeless and At-Risk Male Interviewees Receiving Benefits

\begin{tabular}{||l|l|r|r|r||}
\hline \multicolumn{2}{||}{} & Black & Hispanic & \multicolumn{1}{c|}{ Total } \\
\hline \multirow{2}{*}{$\begin{array}{l}\text { Social Security } \\
\text { Disability (SSI/SSDI) }\end{array}$} & Count & 8 & 11 & 19 \\
\cline { 2 - 5 } & $\%$ within Race/Ethnicity & $25.0 \%$ & $50.0 \%$ & $35.2 \%$ \\
\hline \multirow{2}{*}{ Medicaid/Medicare* } & Count & 8 & 12 & 20 \\
\cline { 2 - 5 } & $\%$ within Race/Ethnicity & $25.0 \%$ & $54.5 \%$ & $37.0 \%$ \\
\hline \multirow{2}{*}{ SNAP (Food Stamps) } & Count & 25 & 16 & 41 \\
\cline { 2 - 5 } & $\%$ within Race/Ethnicity & $78.1 \%$ & $72.7 \%$ & $75.9 \%$ \\
\hline
\end{tabular}

*Denotes that difference is significant with $\mathrm{p}<.05$

Source: One-on-one interviews

Figure 23 shows a further breakdown that separates Hispanics into Cuban and non-Cuban categories. Amongst Hispanics receiving benefits, Cubans are disproportionately represented. They comprise 14/22 (63.6\%) of the total Hispanic respondents, but 10/11 (91\%) of Hispanic SSI/SSDI recipients. Fully $71.4 \%$ of Cubans were receiving disability benefits and $78.6 \%$ receiving Medicaid, compared to $25 \%$ of 
blacks and just $12.5 \%$ of Non-Cuban Hispanics for each category. The percentages for food stamps, however, were similar.

Figure 23: \% of Homeless / At-Risk Males Receiving Benefits, within Race/Ethnicity

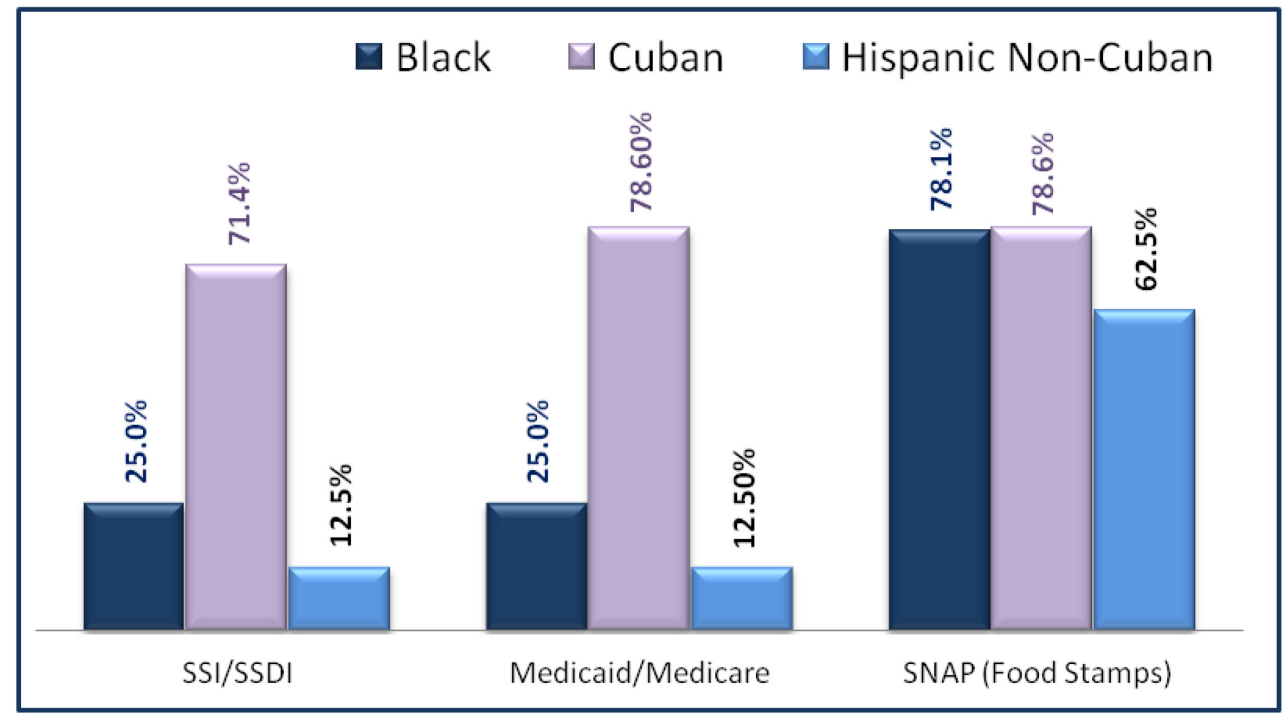

Source: One-on-one interviews 2010-2011

The differences between blacks and Hispanics in attaining and using benefits are discussed more below.

Social Security Disability

SSI and SSDI refer to two forms of direct cash assistance provided by the US Social Security Administration to persons who are disabled. Social Security Disability Income (SSDI) is for individuals who have a work history and have paid into the social security system before becoming disabled. The amount of assistance is based upon their historical social security earnings. Social Security Income (SSI) is for disabled individuals with limited income and resources, who do not have enough work history to qualify for SSDI. The amount of assistance is based upon need up to a maximum federal 
benefit level, which was $\$ 698$ as of January 1, 2012 (Social Security Administration 2012b). While receiving SSI or SSDI, an individual may earn up to $\$ 85$ per month, if they have no other income sources, before the Social Security Administration begins to reduce the benefit amount. Qualifying for SSI/SSDI also qualifies a person to receive Medicaid or Medicare.

The SSI/SSDI programs are meant to provide a means of support for persons disabled by a medical/physical problem or mental health disorder, with very specific criteria for determining who is eligible. As previously shown in Table 6, 27.2\% of Miami's sheltered male homeless population has a serious medical disability, and $31.5 \%$ have a serious mental illness; the figures are $34.9 \%$ and $64 \%$ respectively for men in permanent housing programs. Amongst the 54 men interviewed for this study, $48.1 \%$ reported a serious medical problem and $20.4 \%$ reported a mental health disorder.

Figure 24: Disabilities Prevalence Amongst Homeless /At-Risk Male Interviewees

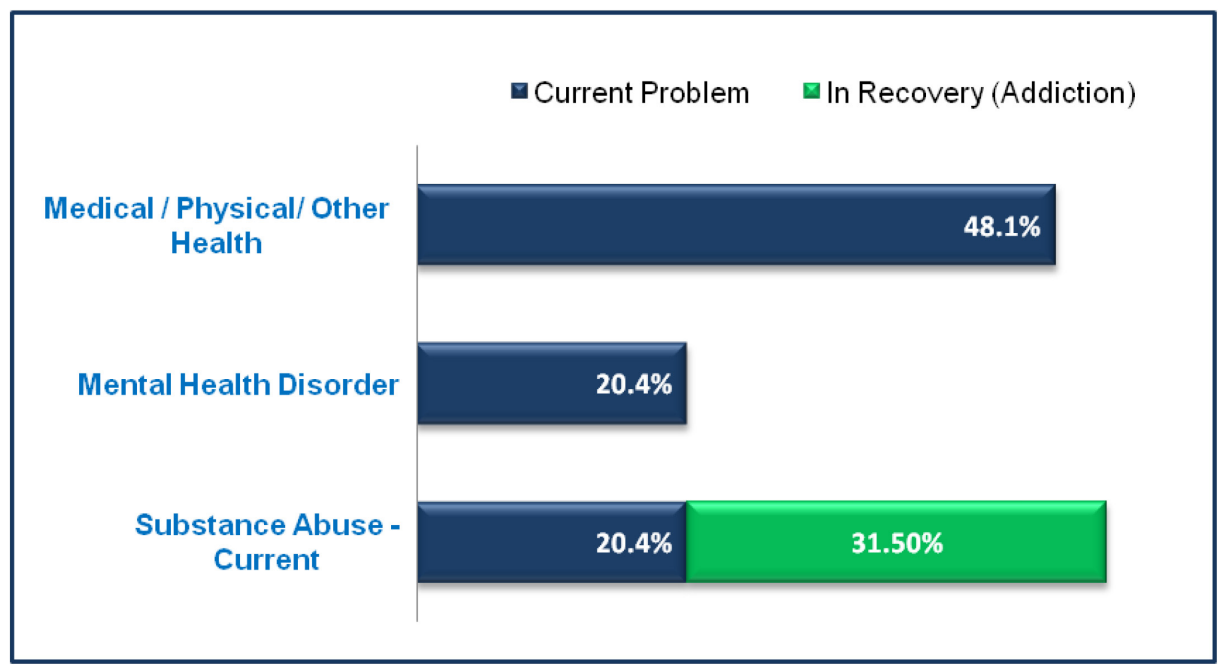

Source: Researcher Interviews $\mathrm{n}=54$

Note that while $51.9 \%$ reported having an active or recovering substance abuse addiction, this makes them eligible for HUD’s Supportive Housing Programs, but does 
NOT qualify for SSI/SSDI on its own. As shown in Table 14, 35.2\% of the male interviewees were receiving SSI/SSDI. While everybody receiving disability benefits reported either a medical, physical, or mental health problem, the vice versa was not true, as numerous individuals had applications pending, had been denied, or simply had never applied.

Qualifying for either SSI or SSDI can be a long and difficult process. Nationally, more than $2 / 3$ of initial applications are denied, and $89.5 \%$ are denied again after a requested reconsideration. Florida has higher denial rates, with only $28 \%$ of initial applications and only $9.8 \%$ of reconsiderations approved (SSDFacts 2012). For persons who are homeless and have no one to assist them with the application, approvals rates are closer to 15\% (Substance Abuse and Mental Health Services Administration 2012). After a reconsideration is denied, applicants may request a hearing before an administrative judge. Nationally, $42 \%$ of hearings result in a denial. In Miami, the denial rate is $47.5 \%$ (SSDFacts 2012). While one might expect uniform approval rates across the country, since SSI/SSDI is a national program with one set of eligibility criteria, variance across jurisdictions still appears with applications reviewed at local levels, and administrative judges having a wide range of approval rates. In Florida, for example, annual denial rates range from $13.1 \%$ to $82.1 \%$ amongst judges around the state (SSDFacts 2012).

Waiting times can be extremely long. It can take 4-6 months for review of an initial application, and several more months for a reconsideration. In Miami, the average time period from when an application for a hearing is filed until ruling is 392 days, with Miami ranking 135/165 in length of processing times (Social Security Administration 
2012a). Thus, the average time from initial application through a hearing can easily top two years. For a person living on the streets, two years is an incredibly long time to wait. Nineteen states offer some type of General Assistance program, which typically provides direct cash assistance targeted to persons who are temporarily disabled and unable to work, and/or who are waiting for SSI/SSDI applications to be processed. Florida, however, is not one of those states (Penucci 2009).

The federal Substance Abuse and Mental Health Services Administration (SAMHSA) summarizes the problem created by difficulties with the SSI/SSDI process for persons who are homeless (2012):

The SSI/SSDI application process is complicated and difficult to navigate, particularly for people who are homeless or who are returning to the community from institutions (jails, prisons or hospitals). For those who have a mental illness, substance use issues, or co-occurring disorders that impair cognition, the application process poses an even greater challenge; yet accessing these income and health care benefits is often a critical first step on the road to recovery.

In response, SAMHSA created the SSI/SSDI Outreach, Access and Recovery (SOAR) project, which created streamlined processes and special training for case managers working with persons who are homeless or at risk of homelessness with a mental illness or co-occurring disorder. The Miami-Dade County community has been heavily involved in the implementation of SOAR, with many entities, including nonprofit organizations and public agencies, providing SOAR training to staff. As a result, Miami has seen reduced waiting times and increased success rates for homeless applicants if they are working with SOAR trained case workers (Wall 2010).

The importance of attaining benefits, and the associated effectiveness of the SOAR program at a local level, is evidenced by a recent evaluation conducted by 
Camillus House, the agency that operates several programs from which subjects were referred, on its low-demand shelter program. "Low-demand" is a program model whereby individuals who have longer histories of homelessness and higher prevalence of disabilities such as addiction and mental illness, and who are more resistant to entering programs with strict requirements, can enter shelter or housing without having to commit to an intensive level of services. Emphasis is placed on helping individuals to attain income, usually through benefits, in preparation for being able to move into housing. When Camillus evaluated data regarding individuals who stayed in the program during the two-year period, it found that the most important factor in determining who left to move into a more stable housing situation was attainment of public benefits (cite here). Specifically, qualifying for SSI/SSDI was the biggest predictor of who was able to move on. Attainment of a Section 8 housing subsidy was also effective for individuals, although rare due to the limited availability of the program in Miami.

Given that SSI/SSDI is one of the few cash benefits available to single, adult men in Miami, how is the benefit perceived, accessed and utilized by this population? Table 15 summarizes the comments made by the men interviewed for this study: 


\section{Table 15: Interview Comments Regarding SSI/SSDI Benefits}

\section{Black Respondents}

Wanted it at first; now would rather get a job

Receives SSI, but still lives on street while

waiting for housing subsidy

Wants it for retirement - will then move to

Georgia where he can afford to live on it

Had no difficulty in qualifying for SSDI, but

believes it is easy if you aren't lying about your

disability

Believes he could qualify due a permanent injury

in leg, but doesn't try because he would rather

work and support self

An outreach team helped him apply, and provided rent assistance while the application is pending.

Believes the approval will come through before the rent assistance runs out.

Application was recently approved (spinal

injuries) but still awaiting initial payments;

living on street while waiting.

Uses SSI to maintain bills and buy food;

volunteers since he can't work

Applied once years ago, was rejected, didn't try

again

Receives SSI for prosthetic leg; uses it for living

expense and is happy with it.

Received SSI through VA (Gulf War Syndrome),

expresses frustration with doctors not writing

correct things in the process

Years ago used SSI to buy crack; now is clean

and uses it for rent and living expenses.

No reason to apply because have no ailments; but

wishes he could qualify.

Has had application pending for last 4 years; has not followed up to find out its status

Hasn't applied for SSI, but would consider it if outreach workers helped him.

Not on SSI, but has been thinking about starting

to work on it; he's getting older and isn't able to

work

Receives SSI, not SSDI - earned everything he is

getting

Data Source: Researcher Interviews $n=54$

\section{Hispanic Respondents}

His SSI approval was a beautiful part of this country; talks about working under table while application was pending

Lost his SSI benefit while in prison, has not tried to reapply since being released 6 years ago; now lives on the streets.

Receives SSI for leg problems; works well

Believes everybody in shelter is healthy and wants benefits "esp the Cubans" (resp is Venezuelan)

Application was denied, so he tried again, then got a lawyer. Now has SSI, but also wants Section 8 to pay his rent.

Describes multiple weekly appointments with case worker re current application; has diabetes. Has friends who went to CA because easier to do applications there.

Has received check from the government for a long time, but couldn't afford an apt without Sec 8 help; believes this is best country in the world Currently appealing denial. Can't take jobs because that would affect the application. Has seen friends do well after getting their check.

Was denied due to lack of work history; didn't understand the process.

Was denied 7 times, but won it after getting an attorney. Helps pay his rent and bills, but does work on the side for extra money.

Was turned down for physical disability, now trying again with a psychiatrist

Receives SSI because was shot in head; has to live simply but appreciates the health care Receives SSI, but is struggling to make ends meet because the amount has not gone up in 4 years, and he is unable to work to supplement it Applied 3 times to get it. Had to get SSI because work history was under the table, so didn't qualify for SSDI 
Overall, Hispanic respondents described having been much more thorough and dedicated in their attempts to attain disability benefits. If they were denied, they applied again, and, when necessary, attained the assistance of attorneys. One respondent who had recently attained SSDI described the process:

"Oh my God, they denied me 7 times for it. So, 7 times they denied me and then when I went into Camillus uh Marina from the Camillus Clinic she tried to help me, they denied me again, so then I had to go to a attorney and that's how I got approved, with an attorney."

He explains that his SSDI is for a mental illness, rather than a physical disability, so that he is still able to continue underground work to supplement the income.

"Well uh right now it's like I got disability, I've been disabled and with that helps me pay my rent, it helps me pay by bills, and then sometimes I go out and paint here or do little jobs, odd jobs or any extra things I need for the home."

Blacks, on the other hand, also frequently mentioned having applied, but did not report having put in as much effort to try again once denied. They seemed to accept the denial as expected. Others who may have qualified had not even applied, indicating that outreach workers had suggested they could apply, but they had yet to initiate the process. There was also a hesitance by some to claim they suffered from mental illness. John's response was typical of those living on the streets, as he laughed out loud at the prospect of receiving income from a disability check, stating, "I can't, ain't nothing wrong with me." He noted that his problem was addiction, rather than mental illness. Upon further contemplation, he added, "I wish I could get a check." John's other options were limited, though, as he had a long arrest history, was 55 years old, and had lived on the streets 
downtown for more than 15 years. Still, he had no intention of attempting to qualify for disability benefits.

Individuals who had succeeded in attaining SSI/SSDI benefits described how long and difficult the process had been; only a few indicated they had been approved on the first try. Trevor detailed his frustrations at getting the required medical forms completed in a manner that satisfied the requirements:

"Oh the disability is a different story now. I believe that most of the time, the doctors don't write a couple notes in the patient's chart for whoever is reading the charts gonna understand. Let me give you a situation ok. I was in the Gulf War, most of the information is there on Gulf War syndrome, symptoms... Every time I go to that particular doctor and when I look at the notes, the notes are not saying anything concerning what I'm saying. So in order for me to file a claim, the representative is saying that it needs to be identified in my chart stating that this person is suffering from unidentified whatever whatever. And it's not saying that! The bus pass is simple, you go to the VA, tell them who you are, what you need it for, they take you down to the government center with a Florida ID and they let you buy it."

Having the required medical or psychiatric examination performed by a doctor who was familiar with how to complete the forms and document the correct diagnoses could make all the difference in whether or not an application was approved. Individuals who described an easier approval process had applied more recently, and thus had been working with staff members trained in the previously described SOAR program. In these cases, individuals reported satisfaction, even happiness, with the process.

Jackie was typical of individuals benefiting from improved application processes for persons who were homeless: 
Jackie wanted his picture taken with the key to his apartment, something he had not possessed for 25 years. He said he didn't want to leave the apartment now, because he was afraid it would not be there when he came back. He described what it was like to be brought into the apartment and helped with SSI:

"Man, that's a blessing from God. It was raining, I was sleeping on the sidewalk, pouring down rain, Mr. Willy (outreach worker) one that came, he came and try to sign up for program. I ain't going to no program, I thought he was talking about a drug program so I'm like, no program man. So ok, I was sleeping one Tuesday...It's November, it's raining real hard, about 11 or 12 o'clock... Yeah,

November, bout the middle of November, got here. And I've been here ever since. I've been going back and forth, doing what they tell me to do. What I've been doing, I was getting tired so I said, let me try this for a change and I can go down, stay here..... They pay the rent and the light bill for me. For ten months. And, they try to help me get a little disability. And uh, the ten months is up I'd be able to manage on my own. And take care of my own disability, so they try to do that now before the ten months is up. So I'm waiting to it come through, I'm not sure. So and um, that's my story."
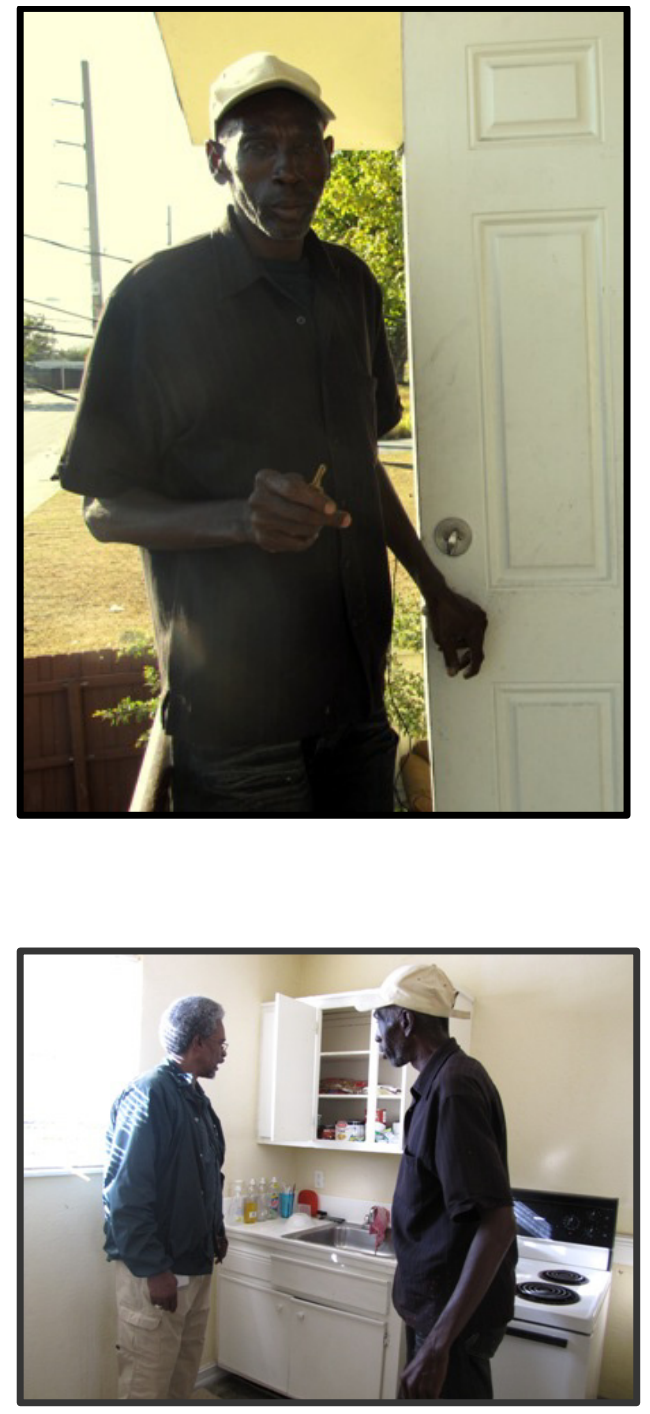

An outreach worker checks to make sure Jackie has food in his cupboard, and gives him an update on the status of his SSI and food stamp applications.

He had lived on the streets in downtown Miami for 25 years, making a few dollars a day taking out the trash for local stores or just panhandling. His medical problems with his stomach were serious enough that he was in and out of the local hospital, sometimes for months at a time. At the time of the interview, he'd been living in an efficiency 
apartment in Wynwood for two months, while outreach workers worked on his disability application. It would take several months for the application to be approved, so in the meantime his rent was paid by a temporary rent assistance program funded by a one-time federal program. Given the seriousness of his medical condition, Jackie probably would have qualified for SSI/SSDI long ago, but he had not attempted the process on his own and had resisted efforts to place him into a "program" with rules.

James had just recently begun receiving SSDI. He'd found himself homeless after losing his job because he needed surgery for a collapsed spine, but only needed to spend one month in a shelter before getting back on his feet in his own apartment. He described an easy process of qualifying for disability benefits: "Well, it's a hard process if you make it to be hard. It's the easy process if you really need the help. If you go with the truth, you can get help. If you go lying, you gonna be in trouble. That's the bottom line."

\section{Figure 26: James, on sidewalk in front of Overtown apartment}

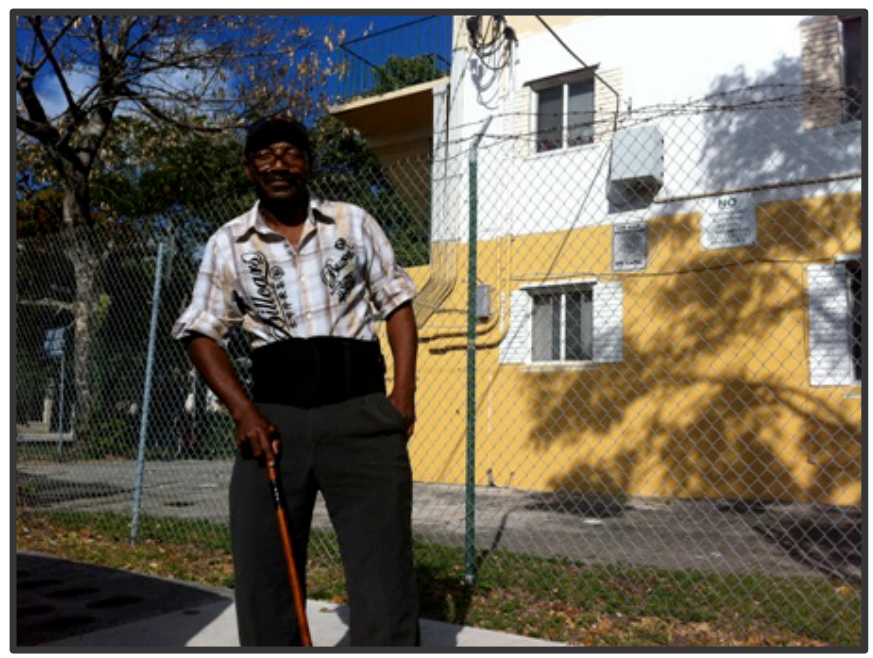

James wanted his photograph taken in front of his apartment building, with the cane he used to get around. He wanted to show what it was like to have to rent a small apartment in what he considered a bad neighborhood. He was eager to get back to work so he could increase his income and leave Overtown.

Regarding living a scaled-back life while on SSI/SSDI:

"I got a connection for the cable but I ain't got the money to do it yet. But, thanks God, it's gonna happen, you know. So how much money do I have left at the end of the month to carry me going by me not working? Maybe 50, maybe 60 dollars a month. And then I'm still gonna spend that right back on food. So, I, do you know, do I have very much without work? That's why I'd rather be working. At least when I'm working I know I'm gonna be making me 250 dollars a week. I can survive.” 
In spite of having just begun to receive SSDI benefits, James still spoke mostly about wanting to go back to work as soon as his surgery recovery was over, stating "I'm going back to work, I can't sit around, I'm going back to work. If you sit down, you're gonna fall down, get up again." His motivation to go back to work was not just from his own desire to be self-sufficient, but was also in recognition of the small amount of money he'd be receiving if he stayed on SSDI.

While the SSI and SSDI benefit programs are frequently combined into one category (i.e. "SSI/SSDI") in the literature and in reporting on program data, the distinction between the two was noted by the subjects. Specifically, numerous subjects receiving SSDI were adamant that the interviewer note that they received SSDI, rather than SSI, and that they did not consider this a "benefit." Rather, it was something they had earned by paying into it through their work history prior to becoming disabled.

Thomas, for example, had spent years as a tractor trailer driver before getting sick with Cryptogenic Organizing Pneumonia (COP) and becoming homeless. Because he had such a long work history, he qualified for enough SSDI assistance that he was able to exit homelessness. He spoke proudly of living independently in his own efficiency, and was careful to point out that his SSDI income was not welfare:

"I have put in all them years doing the do, see ain't no body-ain't no body giving me nothing. See everything - I don't like 'em to give me nothing everything, everything that I got today I earned that, see what I'm saying?"

Hector, a Cuban immigrant, had worked for many years installing marble for Jacuzzis in expensive homes, before a work accident injured his back, eventually necessitating spinal surgery. Now sharing an apartment with his son, he was embarrassed 
that he was no longer able to work and support himself. When asked about receiving disability benefits, he became upset while explaining that he should have qualified for SSDI, rather than SSI, but because his previous employer had sometimes paid him under the table his work history was not long enough to qualify him for SSDI. Thus, he had to accept the SSI benefits, even while remaining critical of those he didn't think had earned their benefits:

Figure 27: Photograph - Hector, inside apartment with fan

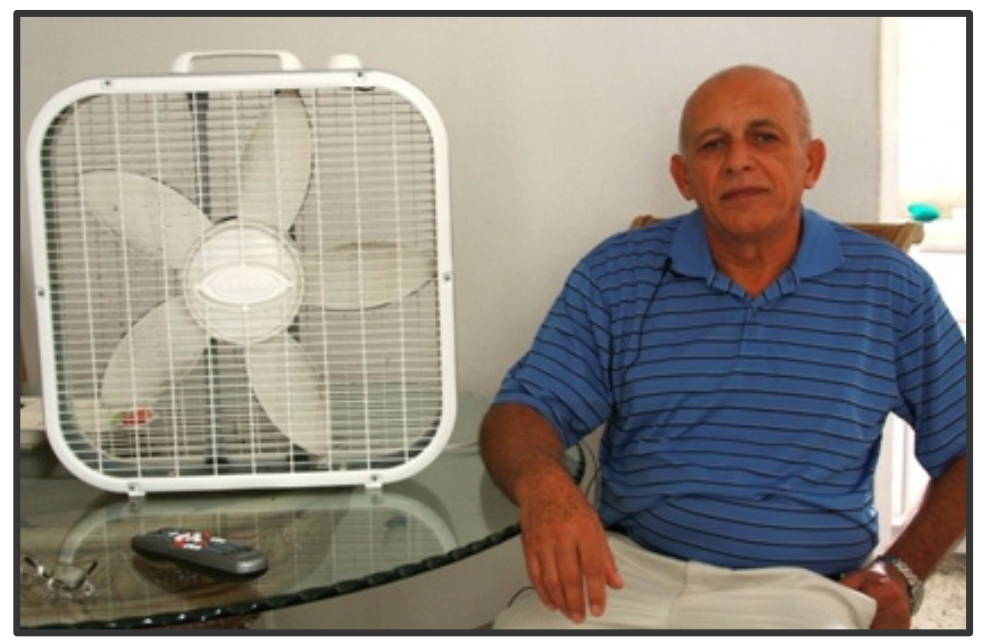

When asked what photo would depict his life now, Hector wanted to show how simply he now had to live. He chose to be photographed sitting next to the fan in the living room, symbolic of the step down his life had taken now that he could not stretch his disability check enough to afford air conditioning. Receiving SSDI, instead of SSI, would have made the difference.

"Yes, that's why I'm, it's more difficult for me, because I've worked a lot in this country and I've returned money, I've returned so much money, 10,000 dollars in taxes, I returned.... To see us people who are poor because we've fallen on hard times, there's another percentage that they don't want to work, that I see a lot like that. One, two, three, four, five kids, a single mom that lives off a food stamps check living off the taxes of other people. Because when I worked I paid a lot of taxes and people that live off the government, no, they life off of the taxpayers in this country."

While pride was one of the central emotions expressed by Hector in discussing the difference between SSI and SSDI, there was also an underlying resentment over the difference in amounts. Were he receiving the SSDI he had earned, his monthly check would be $\$ 1,000$, compared to $\$ 698$. The impact on his life had been significant. His old 
neighborhood in Hialeah was too expensive, and he had been forced to move to East Little Havana where he lacked friends and missed having Cuban neighbors. He had never imagined he would be juggling utility bills while waiting for surgery.

Overall, individuals in the group of persons who were at-risk of homelessness, but who had never actually been homeless, were the least satisfied with trying to survive with SSI/SSDI as their only income. For these individuals, their current situation was among the worst situations in which they'd ever lived. Becoming sick or disabled had been a major life change, forcing them to leave behind paying jobs, nicer homes, and the comfort of having spending money. They spoke at length about how much better they'd lived before.

For persons accustomed to life on the street, however, living on the $\$ 698$ per month provided from SSI looked like a step up. Jose was only 28 years old, but had been unemployed and living under a bridge for nearly two years. He had given up looking for employment, and was instead focused on attaining SSI/SSDI benefits for his mental health difficulties. His initial applications had been denied, and he now had an attorney helping him file the appeal for a hearing. He was vigilant about complying with the requirements to qualify for SSI/SSDI, stating that he would not even take a part-time job out of fear that it could jeopardize his pending application. Unable to find a job, feeling out of place at shelters full of people he did not relate to, Jose had pinned all of his hopes for finding a pathway out of homelessness on attaining SSI benefits. He described how two of his friends have recently been able to leave the streets with SSI benefits:

"Yeah, him and Danny are doing really well because they just got their Social Security or whatever and they got apartments and I see that their 
life is changed drastically and they're doing really good for themselves and I'm proud of them."

Felipe expressed similar feelings after seeing friends exit homelessness with the help of SSI, speaking of his friend's heart attack as if it had been a stroke of good

fortune: "He got a heart attack so he got now, he's a Cuban guy, he got Social Security, they give him disability and he's now is a resident, he's a US resident." Felipe reiterated that he was appealing the denial of his own application, working with a new doctor this time.

Figure 28: Jose, under bridge where he sleeps on Miami River
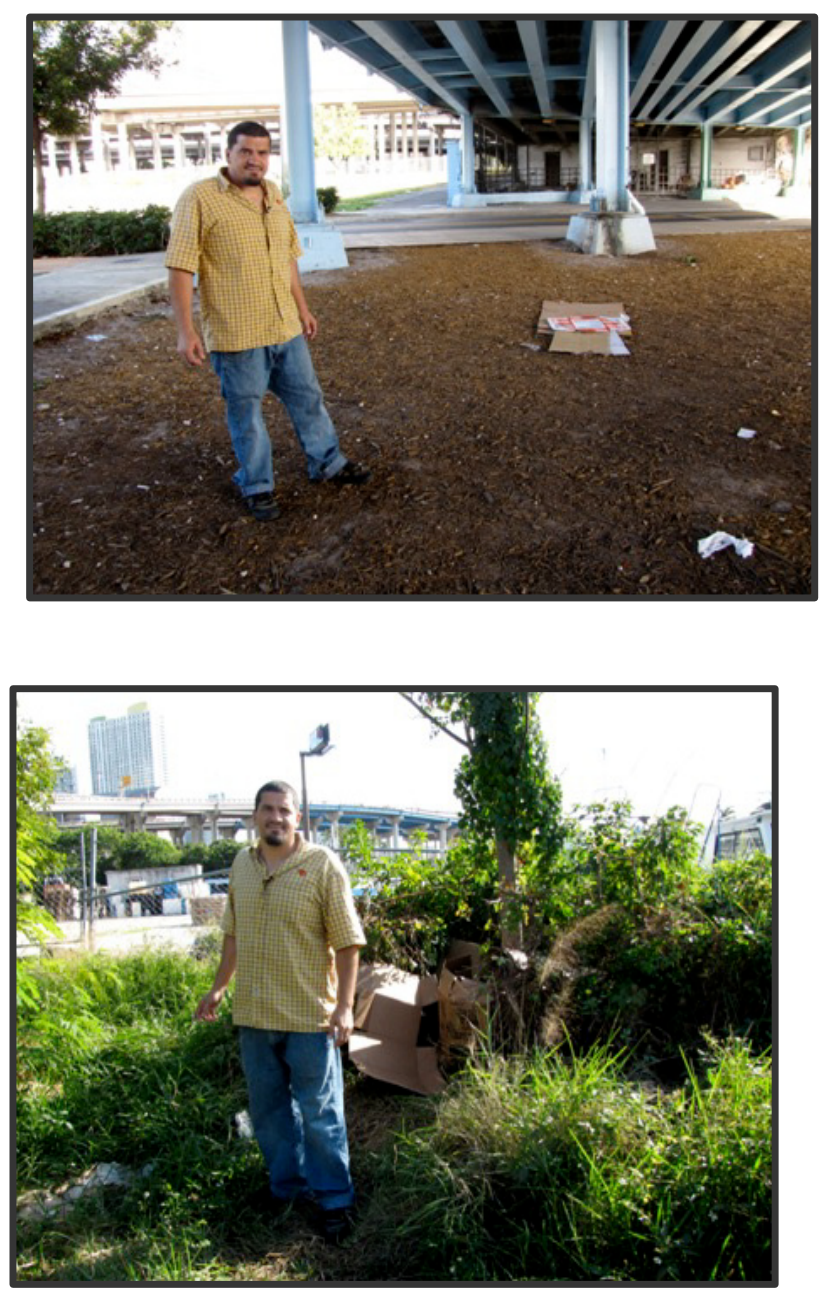

Jose gave the researcher a tour of the area around the bridge where he stayed with some acquaintances. He said that even after two years, he still found it difficult to believe he was living like this. He was desperate to get off of the streets, but was uncomfortable staying in shelters. Here, he pointed out the cardboard he would use to sleep on that night, unless he got back too late and it had been claimed by somebody else, a common occurrence.
Jose shows where he and a friend sometimes hide belongings, under the pile disguised to look like trash. He is particularly concerned about having a place to keep clean clothes, as he does not want to look homeless. Sometimes he is able to take a shower at one of his friends' apartments. While they are able to invite him over to take showers, cook meals, and get out of the sun, the small apartments they now rent with their SSI benefits are too small for him to move in. 


\subsection{Health Care Benefits}

Health problems are both a cause and consequence of homelessness (National Health Care for the Homeless Council 2010; Wright 1990), and the men interviewed for this study provided evidence of both. The role of physical and medical health problems in the lives of this study's subjects was complex. In numerous cases it was the primary cause of having been pushed into poverty and/or homelessness; however, it was also a catalyst for helping individuals attain housing and supports needed to exit and/or avoid homelessness. Access to health care was unavailable to many persons who were housed, yet readily available to persons once they became literally homeless. The importance of health care in their lives fell at opposite ends of the spectrum - for those who were sick or injured, health care was a primary concern discussed at length in the interview; for those who were relatively healthy, it was not a topic of concern at all and likely would not even have been mentioned were it not for direct interview questions.

In Miami-Dade’s 2012 Point-in-Time Survey of homeless individuals, 44.2\% (379/857) of Miami's male homeless population listed access to health care as an important need (see Table 7). However, it is not clear from the wording of the survey question whether this was considered an unmet need or not. A major survey of users of Health Care for the Homeless facilities across the country found that $73 \%$ reported at least one unmet health care need in the past year, and $49 \%$ reported two or more unmet needs (Baggett et al. 2010). This included 32\% reporting unmet needs for medical or surgical care; $36 \%$ for prescription medications; $41 \%$ for eyeglasses; and $41 \%$ for dental care. 
Men who are homeless have poorer health status and more medical or physical problems than the general population (Baggett et al. 2010; O'Connell et al. 2005; Wright 1990). Estimates are that rates of serious illnesses and injuries amongst persons who are homeless are three to six times the rates of other people (National Health Care for the Homeless Council 2010). Nationwide surveys put the percentage of homeless persons reporting a serious chronic illness at $46 \%$ (Burt et al. 1999) up to $72 \%$ amongst individuals seen at Health Care for the Homeless clinics (Zlotnick and Zerger 2008). At the local level, Miami-Dade's countywide HMIS system documents that $27.2 \%$ of homeless males in emergency/transitional programs and $34.9 \%$ in permanent housing programs report having a disabling medical or physical condition (see Table 6). This does not include the larger number of individuals who suffer from health problems that are not serious enough to be considered a disabling condition, but nonetheless are real health problems.

The health/medical status of this study's interviewees ranged from self-reported generally healthy to seriously disabled, with most subjects having some type of health problem. Nearly half (48.1\%) reported having a serious medical disability, which is defined here as a health or physical problem severe enough to interfere with their ability to carry on daily life activities in some way (see Figure 24). Of those who were housed (including those at-risk of homelessness and formerly homeless), approximately $60 \%$ had a medical disability; amongst those living on the street, it was nearly one in three (29\%).

Not everybody who reported a health problem qualified for disability income; conversely, not everybody with SSI/SSDI had a medical problem, as some individuals' disabilities were for mental rather than physical health. Qualifying for SSI/SSDI 
automatically makes one eligible for Medicaid/Medicare, so examining receipt of SSI/SSDI is a good predictor of having Medicaid/Medicare for adult males, particularly since single adults in Florida cannot qualify for Medicare/Medicaid based on income alone. Of the 26 individuals with reported serious health conditions, ten (38\%) were not receiving SSI/SSDI or Medicaid/Medicare.

Reported problems covered a wide range: prosthetic legs; lack of any teeth; diabetes; strokes; Cryptogenic Organizing Pneumonia (COP); vision impairment; heart problems; and others. Four interviewees showed their scars from old gunshot wounds. Numerous others showed scars from surgeries, automobile accidents, and work-related accidents.

As documentation of the importance of health events in the lives of interviewees, many individuals, when asked to choose a photo set up that told a story about their life, chose photographs that depicted their many prescription bottles, hospital bills, and medical equipment, as well as themselves with their canes, walkers, and wheelchairs. Of those participating in the photo interviews who had medical disabilities, one third $(8 / 24)$ chose photos depicting an aspect of their medical issues. For example: 
Figure 29: (Photo) Horacio, with the bills he manages to cover

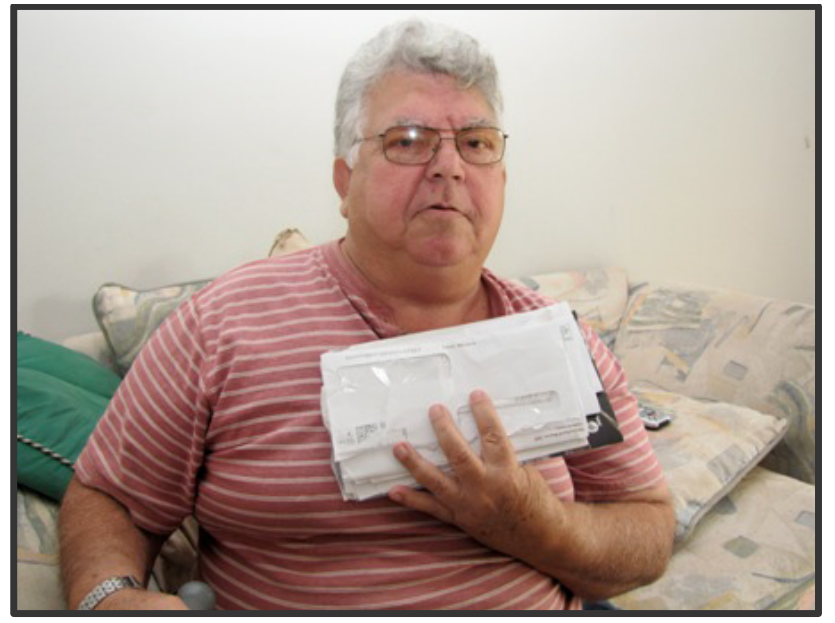

Horacio, a Cuban immigrant, supported himself until he suffered a stroke. With both SSI and Section 8 benefits, he is grateful to the government. Asked what told a story about his life, he picked up his pile of bills, explaining that while they totaled a lot, he was able to cover them all with the help he received:

"This country helps you a lot. They help you in everything money. If you use the money for your things, it's not a lot of money, but at least for your things. You use the money for rent, everything, rent, light, cable."

Figure 30: (photo) James, in his efficiency with his walker

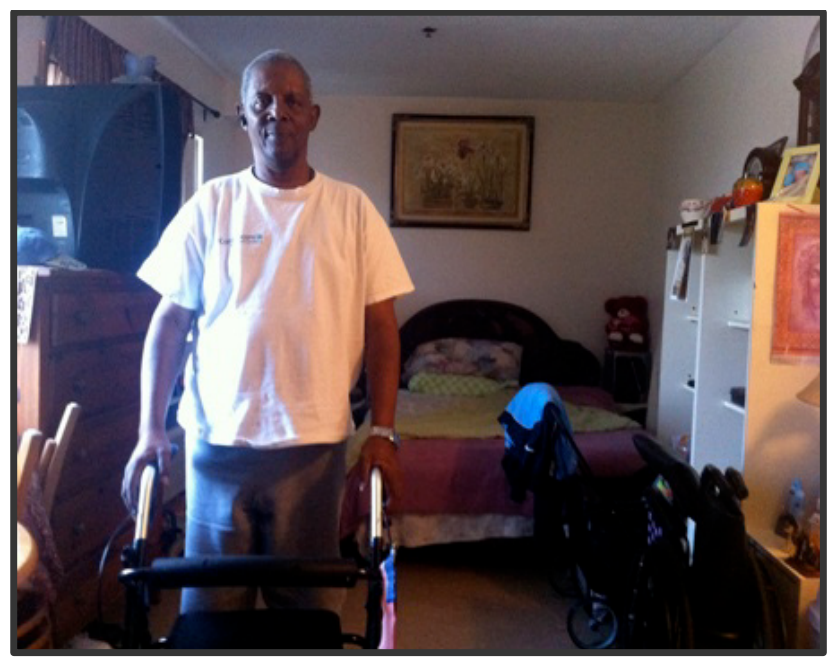

James suffers from a number of heart and neurological problems that make it hard for him to get around. It was his medical problems that brought him to finally enter a shelter after years on the street. His walker symbolized the good and bad in his life: "It makes things easier for me because I can't walk 'cause I'm off balance, but I love the walker. But I want to get off this walker, you know? Understand what I'm saying?... So I'm going to this program in Coral Gables. It's a very expensive place and they very good about helping people."

Figure 31: (photo) David's medical equipment

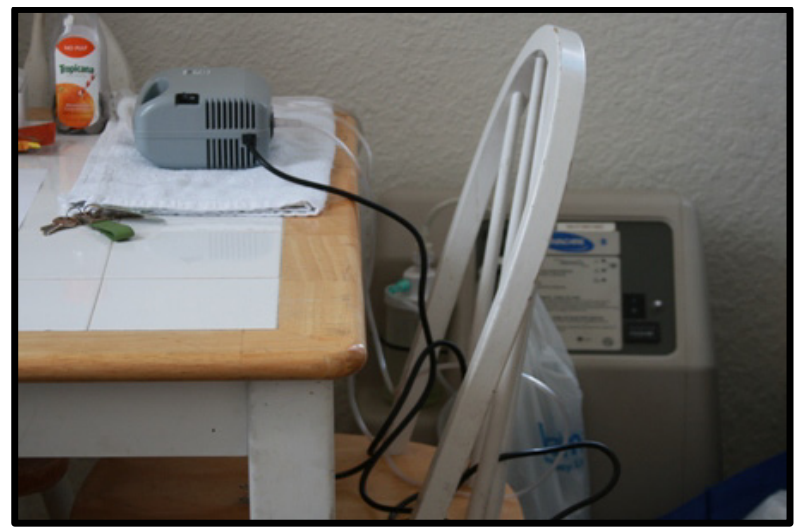

David explained that his medical problems, requiring breathing machines and other equipment, were the most difficult parts of his life. But he was proud to live on his own, finding his SSDI check to be sufficient: "The people that get SSI...that's made for people to find a place to live, it's not made, it's not made for you to get that money and you go out and you do crack and you drink, it's not made for that, it's made for the roof over your head, where you can survive." 


\section{Health Problems as Cause of Homelessness}

For persons struggling to pay the rent, a serious illness or disability can start a downward spiral into homelessness, beginning with a lost job, depletion of savings to pay for care, and eventual eviction (National Health Care for the Homeless Council 2010). Medical problems are the primary cause of personal bankruptcy for Americans, with more than half attributed to health issues (National Health Care for the Homeless Council 2010). The problem is more nuanced than just having high medical bills; for serious problems, those bills can be coupled with an ongoing inability to maintain steady employment, resulting in a total loss of the ability to support oneself for an indefinite period of time.

Asked to describe what had put them on their path toward extreme poverty or homelessness, ten respondents attributed their situation to medical problems. Five had major accidents (workplace and automobile); two were victims of gun shots that produced permanent repercussions; and three experienced the sudden onset of a debilitating illness or stroke. These subjects shared a common trait of lacking family in the area who could help when their troubles set in. As discussed more in the following chapter on social capital, some individuals did have relatives nearby; however, their relatives were unable to provide ongoing support for a variety of reasons, including living in poverty themselves.

Several of the interviews who fell into the category of being at-risk of homelessness, but having never become homeless, had stories similar to Alberto, a former business owner now struggling to make ends meet on the $\$ 698$ per month he 
received from his disability benefits. He'd previously earned a nice living, owning his own business publishing real estate advertising magazines. But when he broke his hip falling down a flight of stairs, during the same time period when his mother died, he found himself unable to work and keep up with his business as it went down with the real estate crash. With his disability check and help from his friends, he had managed to get by until he had to spend $\$ 400$ to keep his car running, an expenditure which led him to eviction proceedings. While temporary rent assistance had kept him housed, he still lived in fear of the next unexpected event that could cost him his housing. Like many of the interviewees, it was important to him during the interview that people understand how hard he'd worked his entire life, and how much he wanted to be able to work again.

Figure 32: (Photo) Alberto, in apartment and with old business equipment
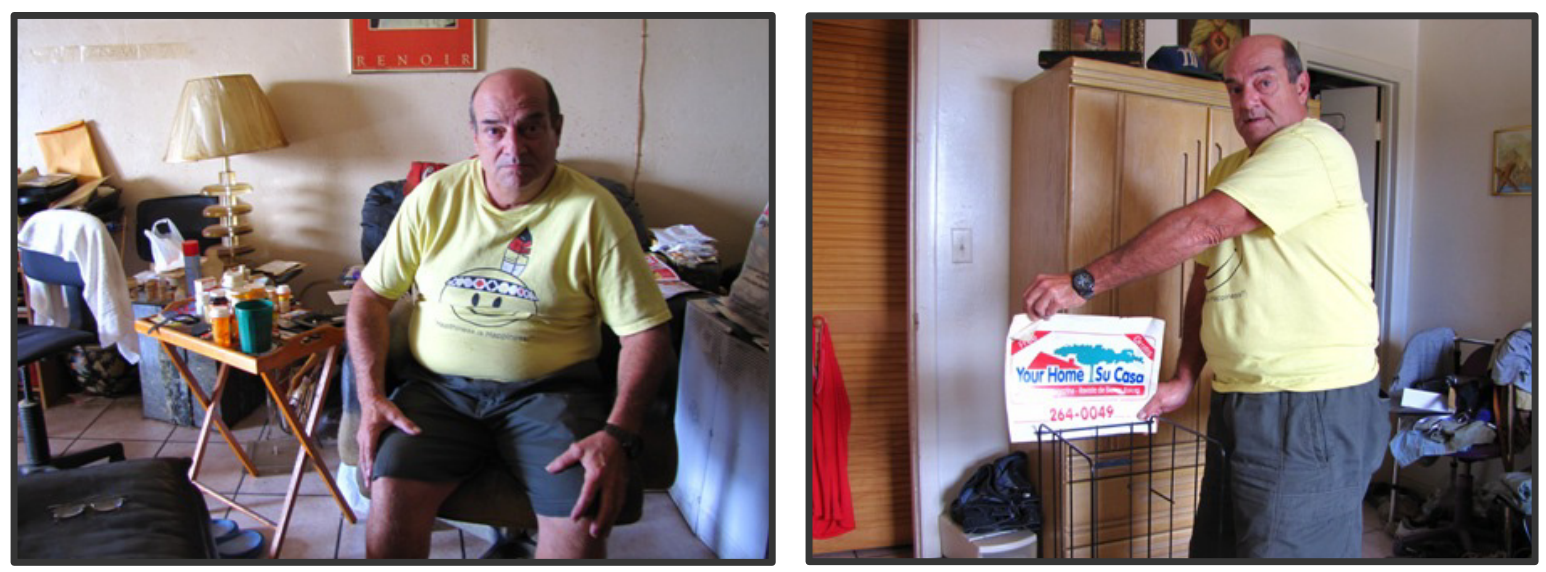

Two issues dominated Alberto's discussion of his life. First was the boredom of the life he now had to live compared to his previous life when he had money to spend and a healthy body. He longed to eat out, play sports, and hang out with his friends. Second, he wanted to work again. His business was his life, and he wanted to be photographed showing off the magazine sales racks left over from the business. He'd kept them in hopes of someday starting the business again. 
Insurance and the Safety Net

For the subjects who were at risk of homelessness, but still housed and thus ineligible for care in the homeless system, access to health care was difficult. When asked what he would do if he got sick, Fredrick's response was typical of persons in this group: "Well, depends on the sickness. A cold or all that, I know how to do it, buy the Tylenol, buy something and drink a lot of juice." And, if he got really sick: "Really sick? I don't know. Can never happen.”

Lawrence was confused by the question about where he accessed health care, since accessing health care anywhere was not an option: "What you mean? Like when I go to the doctor?" (Interviewer: "Yes"). "I don't go to the doctor. No insurance that I got....I try to stay healthy though."

A recent study of persons receiving services at health care for the homeless facilities found that individuals who had been employed in the past year were more likely than those who had not to be uninsured (68\% vs. $49 \%)$ and to have unmet needs for medical care and prescription medications (Baggett et al. 2010). The odds of lacking insurance actually increased with the duration of employment. The researchers posited that having earned any type of income may have made individuals ineligible for free or publicly funded care, and pointed out that the low-wage jobs held by homeless or nearly homeless individuals rarely offered health insurance benefits. Homeless and at-risk workers may fall into a gap in which they do not qualify for benefits yet are unable to afford their own care.

Steven was an example of the above described phenomenon, working 40 hours a week at a low-wage job while moving in and out of homelessness. Health status was a 
big concern of his, and while glad to be rid of the costly insurance provided by his employer, which hadn't actually provided much coverage, he was now worried about the poor treatment and attitudes he expected to receive if he had to go to the emergency room for care. For Steve his best option for getting health care would be to become homeless again, thereby becoming eligible for care at the local Health Care for the Homeless facility.

Figure 33: (Photo) Steven, outside in park

Steven wanted to be interviewed outside in a park, because he did not want anyone to see the apartment where he currently lived. Describing the photo of himself, he explained that he tried to maintain dressing nicely, but had grown sickly and thin from the stress of moving in and out of homelessness and from not having enough healthy food to eat.

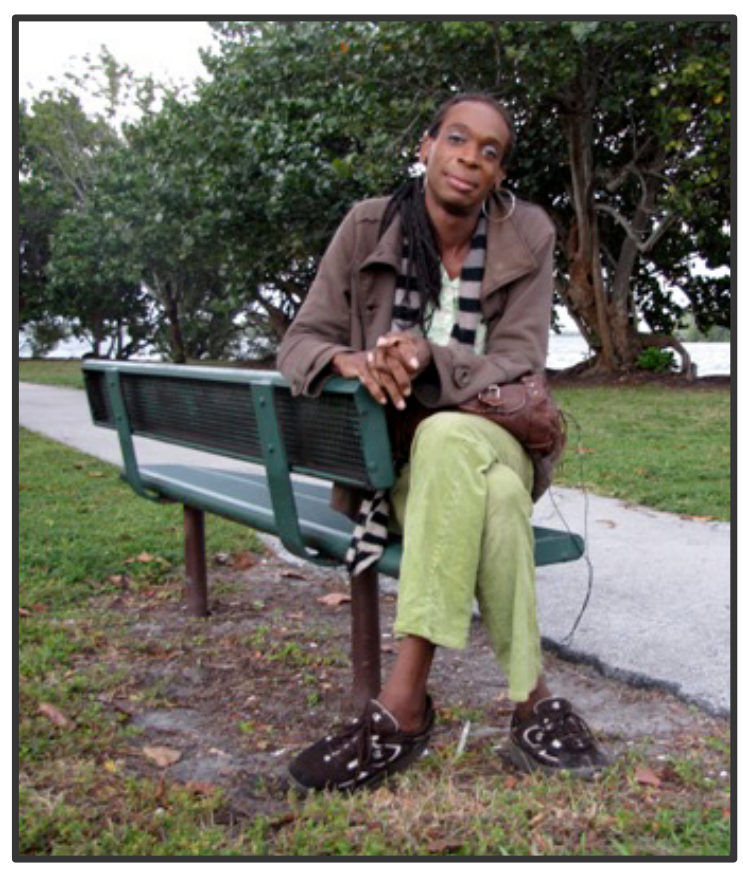

Talking about the poor quality health insurance his job had just rescinded, Steven was grateful: "They just recently got cancelled which thank God because um, I cannot afford them because it was, a month 120 dollars um, out of my check a month. For health insurance! There is no way that where I was at, where I'm at with my bills and things like that I cannot afford to lose--even though, I need the health insurance, I really really do.... If I get sick and I have to go to the hospital, they're gonna have to treat me, which they will do, and I'm gonna have a medical bill. There's just nothing else I can do. Because I can't be sick, you know, um, I just can't be."

It appears that the health care safety net in Miami functions quite well for persons once they become literally homeless. Becoming homeless bestows a status that makes 
persons eligible for a range of healthcare benefits, including access to federally funded Healthcare for the Homeless facilities, even if a person does not qualify for Medicaid/Medicare. Thus, amongst the men interviewed for this study, those who were at-risk of homeless and ineligible for Medicaid/Medicare expressed having no options at all for care, while those who were currently homeless expressed much satisfaction with their access to care.

However, by the time a person has been relegated to life on the streets, access to healthcare is a low priority compared to the need for housing. Thus, healthcare did not come up on its own as an issue unless the person was already sick, or if prompted by the researcher. Still, even though having access to healthcare was not a priority issue for many respondents, most reported having been to the Camillus Health Concern clinic.

Many persons living on the streets also referred to having a "J-11" card, provided by the local public hospital to cover costs of medical care and prescription medication for indigent persons. In order to attain the $\mathrm{J}-11$ card, a patient must be homeless and must get a referral from the Camillus Health clinic verifying that the individual is a patient of the clinic and confirming their homeless status. According to clinic staff, the hospital will not provide the card without a referral from Camillus Health, and will not allow Camillus Health to verify the homeless status of anyone who is not enrolled as a Camillus patient. It has become common, therefore, for persons who are not homeless to present themselves at the Camillus Health clinic claiming to be homeless in an attempt to attain a J-11 card. The clinic staff now must dedicate time to verifying the homeless status of individuals, because so many are providing false information in hopes of gaining access to the J-11 card. Individuals who are not homeless report to staff that they have been told 
by friends and through general "word of mouth" that pretending to be homeless is a good way to get access to health care.

It is also important to note that at the time of the interviews, individuals with $\mathrm{J}-11$ cards who were prescribed medication by a Camillus Health physician could get their prescription filled at no cost through the public hospital's pharmacy, thereby ensuring access to needed medications for virtually everyone living on the streets. However, since the time of the interviews, the public health system revised its policy to tighten eligibility criteria and require appointments with the hospital physicians before prescriptions could be filled. Prescriptions written by the Camillus Health physicians were no longer honored at the pharmacy, as the hospital made a new determination that although the physicians had privileges at the hospital, and had access to the electronic referral system, they did not qualify as "staff" and thus were not authorized to write prescriptions for the pharmacy to fill. Thus, patients must now attain an appointment with a hospital physician in order to get their prescription filled through the public hospital pharmacy. With such appointments difficult to come by, many homeless individuals have found themselves unable to attain medications, including psychiatric prescriptions. Outreach workers have reported visible results on the streets with increasing numbers of persons who would benefit from psychiatric medicines no longer taking them. Thus, a portion of the safety net documented in the study results had ceased to exist.

Regarding quality of care, it is also important to note that subjects with Medicaid/Medicare insurance expressed high levels of satisfaction. There were no complaints; rather, individuals gave positive reports about the quality of their doctors, their access to medications, and their overall experience with the program. 
Figure 34: (Photo) James, outside shelter with his cane and medical documents

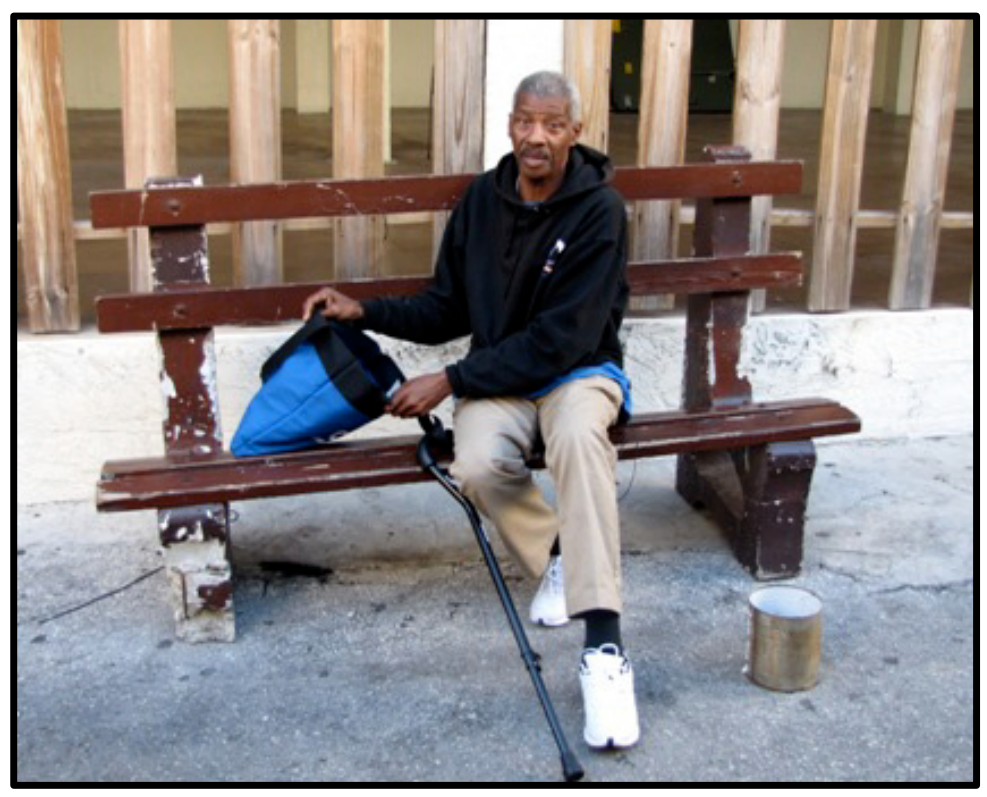

James suffered from ongoing health problems after having been hit by a car, followed by a work accident with a steal beam. To show what his life was like now, he chose pictures of himself with his cane, in various locations around the shelter where he spent all day. The bag he kept with him at all times contained all of his personal and medical documents.

James' description of his interaction with the clinic staff was typical of those who spoke about their relationships with the agency:

"Camillus Health Concern, I go there more than I go to Jackson. You know, because they know me. They been dealing with me for quite some time. Now I feel like they is my doctor, Dr. Suarez and Nurse Claire, you know so they better with me than I am with the doctors in Jackson. So when something happen, I go straight to Camillus clinic, yeah. 'Cause they know me, they know, you know they got my walkers right in there. They know me, you know what I mean."

Interviewees tended to be very specific when talking about getting their health care from the Camillus Health clinic, specifying not just the clinic but the name of the doctor or nurse they worked with. Two interviewees suggested the researcher contact their health care provider at the clinic to get more information, since they felt that their provider could explain their story better than they could themselves. The personal connection was important to them.

\section{Health Care as Outreach}

While health problems could push persons into homelessness, they could also serve as a catalyst for exiting homelessness. A recent study found $12.6 \%$ of newly 
homeless adults in two urban centers reported going to a health care facility for the homeless as their first stop to obtain assistance (O'Toole et al. 2007).

Several interviewees described how a health problem had also served as the impetus for establishing a relationship with an organization, thereby beginning the process of transitioning off of the streets. Jose described how his path off of the streets began after he sought help from Camillus Health Concern, the local clinic providing free care to persons who are homeless: "I'm a diabetic and I went to the Camillus Clinic and Dr. Suarez saw that my sugar was close to 500, almost 600 . And he said, you cannot stay no more on the streets." He went on to explain how staff helped him get placed into a shelter, and then into another transitional program at another agency, and then into a permanent housing program operated by yet another agency. A year and half after walking into the clinic, he was living in his own apartment. For Jose, a series of bad events in his life had led to homelessness; but once homeless and diagnosed with diabetes, he received the help he needed to get back on his feet.

\subsection{Food Security}

Food was a central concern of most interviewees' lives, yet, it was also an area where most persons felt they were getting by. More than half $(52.8 \%)$ of males with records in the countywide HMIS system reported receiving Supplemental Nutrition Assistance Program (SNAP) benefits, otherwise known as foods stamps. This included $50.7 \%$ of blacks and $57.5 \%$ of Hispanics. Amongst those interviewed for this study, the percentage was much higher, with more than 3 out of $4(75.9 \%)$ reporting they received SNAP, including $78.1 \%$ of blacks and $72.7 \%$ of Hispanics. It is unclear why the numbers were so much higher amongst interviewees compared to the county's HMIS system. It is 
possible individuals were not reporting receiving SNAP benefits upon entry into programs.

Most persons on the streets were receiving the maximum allowed for an individual, which is $\$ 200$. Housed individuals tended to receive lower amounts, as they frequently had some type of income that would offset the benefit. SNAP was generally described as being one of the easiest benefits to attain. Applications can be completed online, and two industrious interviewees generated income for themselves by charging $\$ 5$ to help somebody complete the on-line application using the internet access at the public library. Most were aware of the renewal deadlines and process and did not seem to think it was difficult to comply. Leroy's description of how simple the process was typical:

"Yeah, yeah because what happened is that you can go online and as long as you meet the requirements then you will get it. It's not very difficult to get as long as you are required to get it you know. You have to be a legal resident you know."

Many individuals indicated that their first application had been completed with the help of someone else, such as friends, neighbors, co-workers, cousins, sisters, agency staff members, other homeless persons, and even staff at the food stamps office. After being shown how, most were able to keep up with the renewals on their own.

Fraud was a topic of concern. Individuals expressed beliefs that others were misusing SNAP, creating a bad impression for persons who really needed the help. While suspicion of fraud by others wasn't limited to SNAP, with similar concerns voiced over SSI/SSDI and Section 8 , people spoke most about SNAP since this was the most widely used program. 
Only two individuals admitted to selling their food stamps for cash. Jesse recalled, "Of course I've sold my stamps. Cause I needed the cash. But I also bought food. Now they are cracking down and it's really hard to sell them." More common were descriptions of creative ways to make more use of the benefit. For individuals sharing living quarters, SNAP benefits could be utilized to buy food for the group, as a means of contributing to the overall household expenses in lieu of rent. Pooling resources for food was common amongst both housed and homeless persons.

While attaining SNAP benefits was considered fairly easy, making effective use of them while living on the street was not as easy. Interviewees explained that SNAP cannot be used for prepared meals, making meal preparation difficult for persons with no refrigerators to store food and no stoves to cook it: "You got 200 a month food stamps, no place to put it, you gotta be a magician."

Interviewees adapted in numerous ways. Some found friends with apartments who allowed them to store food and prepare meals. Some found local stores that would sell hot food in spite of the official rules. Some used up their benefit on sandwiches and junk food early in the month, relying on food banks and charities for the rest of the month. Walter, who lived in his car, gave an explanation that was reflective of the thoughts of many, indicating that the SNAP benefit definitely helped out, but still had its limitations:

"I got food stamps. That helps out. You know? But sometimes it's like, where can I put it? So I buy potato chips, soda, water or whatever. And them sometimes it's sitting there in my car. But it runs out pretty quick cause you're not buying meals; you know?" 
Eating healthy on food stamps was not viewed as easy. Fresh fruit and vegetables, as well as meat, were more expensive than packaged food. Interviewees offered instructions on how to make food go farther, adding lots of rice and beans to meals and ordering packages of inexpensive meat in bulk. Interviewees with diabetes reported having difficulty complying with the doctor-ordered diet when living on SNAP alone. Overall, eating enough while relying only on SNAP was problematic:

"You on the slim diet though, you know what I'm saying, you on a very slim diet. You can't go out there and splurge now to make it last you know what I mean. You on a, you know, you be surprised to know how much 200 dollars how far it'll go, it's not far, in this economy."

However, nobody indicated they were actually going hungry. Food stamps were supplemented by a range of food banks, churches, and "street feeders," or unofficial groups who would offer meals by pulling up in a car or van to distribute donated food. It was also common for individuals to report being able to get a meal or two from friends or even family members who lived nearby but were unable to offer more than a meal or a shower on occasion. Drug users indicated that friends or family members who would not help them with cash or a place to stay would still offer food when needed.

The loss of food stamps due to other income was a sore point for some individuals, although most also recognized that the increased income was still a net benefit. On the other hand, giving up food stamps was a source of pride for some individuals who'd improved their living situation. No longer needing the help was a sign that they'd made it on their own again. 
Figure 35: (photo) Jerome, on his couch after a day's work

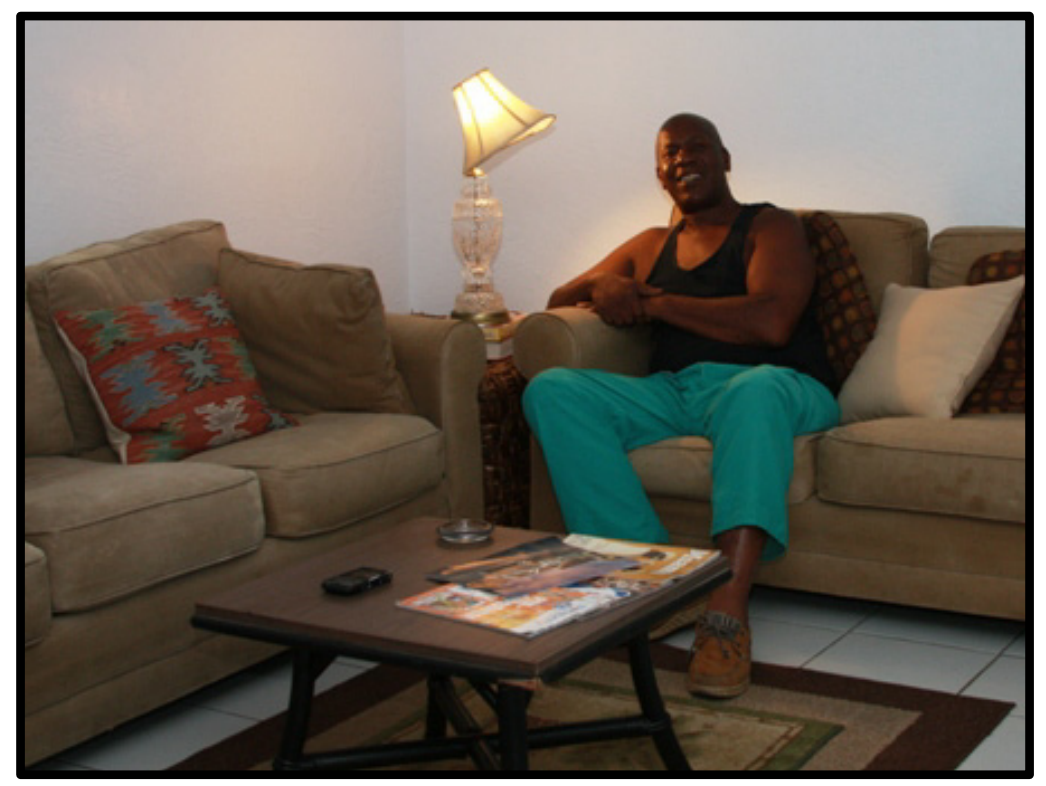

Jerome, now employed fulltime after exiting

homelessness, was excited to show off the apartment he rented with his own money, along with the furniture he'd bought second hand. But with his new employment came a loss of his food stamps. In spite of his frustration, Jerome still laughed when telling the story:

"I made two dollars too much they told me, I couldn't believe it. Two dollars too bad I was so aggravated I couldn't believe it. Oh, I was so angry at this woman (laughing) I was working up, I said I'm telling the truth, I'm paying this much for rent and I don't have this and this, "I'm sorry you made two dollars too much." Can you imagine? I couldn't believe it. I was so furious I didn't know what to do. Some people go down and get them all the time, you know what I'm saying?"

\subsection{Summary of Findings on Income and Benefits}

This chapter explored the question posed by Research Question \#2: Does Miami’s response to extreme poverty and homelessness, including availability of public benefits and the presence of public and private helping organizations, either maximize or constrain the choices available to this population? Focusing specifically on the ability to earn income, attain social security disability benefits, and access health care and food resources, this chapter has examined how black and Hispanic men survive living in extreme poverty or homelessness, finding that there are differences between the racial 
and ethnic groups. The primary finding, though, is that the majority of subjects of either race/ethnicity would, given a choice, choose to earn their own income. After all, earned income is a source of pride, freedom, and improved living standards. However, for many poor or homeless men a range of barriers makes regular employment an unattainable dream.

The first hypothesis for this research question is that the formal system of care for homeless men in Miami-Dade is constrained by state and federal regulations regarding benefits, eligibility criteria, and program requirements. The responses from the subjects of this study would support this statement. To begin with, for many homeless men, a range of barriers makes regular employment an unattainable dream. Criminal backgrounds, under-education, and lack of skills make them less-thanideal candidates for many positions. In a competitive economy, where there are not enough jobs for the willing, the less-than-ideal have a hard time passing the application phases, let alone getting through an interview. Thus, for many, the only places to earn an income are through underground and informal work, including work that may not be legal. Even trying to earn a living by selling items on the street will be punished by arrest, while pan-handling is allowed.

One alternative to earning an income, or to supplementing income, is to attain public benefits. However, the types of benefits available to single, adult men with no children is so limited in Florida that individuals must prove they are seriously disabled in order to qualify for cash benefits. Even if one does qualify for disability benefits, the amount received, averaging $\$ 698$ per month, is exceedingly difficult to live on. It creates a minimal standard of living, but it is a low safety net. 
The safety net also functions to provide health care for people who are homeless, but again, it is a very low net, available only to persons actually living on the streets. By the time an individual qualifies for health care, they have already lost their housing and other supports. Health care has likely been relegated to a low priority, unless a health problem is the cause of their homelessness. In either case, the safety net has kicked in too late.

The second hypothesis was that utilization of public benefits does not differ between blacks and Hispanics, including: (i) efforts to apply for benefits; and (ii) success in qualifying for the benefits. In this case, the data would indicate that the opposite is true. Blacks were more likely to be seeking employment rather than benefits, and Hispanics were more likely to apply for, and attain benefits. Hispanics appeared to be more thorough in their efforts to apply for benefits, and follow up when needed. With vast majority of SSI/SSDI applications denied on the first try, it requires additional effort to qualify for the benefit. Hispanics were more likely to report submitting reapplications, and to hiring attorneys when necessary. Blacks, on the other hand, seemed more willing to accept their current status as is.

The third and final hypothesis for this research question is that men who are homeless or at risk of homelessness sometimes fail to access benefits for which they would qualify because of bureaucratic barriers, with differences between racial/ethnic groups. This appears to be true in some cases, but not in others. Regarding cash benefits for SSI/SSDI, bureaucratic barriers do appear to discourage blacks from applying more than Hispanics. However, when it comes to health care and food, the systems in place appear to do well in reducing barriers for persons who are homeless. 
Subjects from both racial/ethnic groups reported having very little problems accessing health care, once they were homeless. For persons who had not yet become homeless, though, health care was equally unavailable to both groups. Attainment of food stamps was largely equal for both groups, and was generally reported to be an easy process. If earned income and public benefits are difficult to attain for single homeless men, what resources can they still turn to? In the following chapter I'll examine how blacks and Hispanics utilize social capital and the formal and informal networks of friends and family to avoid, survive, and/or exit homelessness. 


\section{CHAPTER 7: SOCIAL CAPITAL AND PRIVATE RESOURCES}

"But you know what, they never have any money either, you know. Everybody is always broke. And I think that's kinda common in today's day and age. I don't think it's because they're holding back or anything . Nobody has any money now, you know, not to help, you know.

Somebody, everybody, you gotta stand on your own two feet, you know. And that's how it is. My mother her bills, she's just like mine you know, check to check, you know. Everything, she don't have some big saving, she better not have a problem or she could be facing being behind in rent and everything too. It's just that's how it is with everybody. So."

$$
\text { - Lee }
$$

I guess it really is the individual, because you got so many resources here in Miami that a person really don't have to be homeless if they don't want to really. But I think it's just they done been that way so long to them, they got accustomed to it and it's like, that's what they want you know. That's what they want.... I think some of them choose to be homeless because some of 'em got family and stuff that will take them in if they would just change their ways and they don't want to change. But you got places like Camillus House, you know, all kind of shelters, churches that willing to help people. But you know, but you got to want to be helped."

\section{- Julio}

When public benefits are not an option or are not enough, private resources including social capital and assistance organizations play an important role in filling that gap. In this chapter I'll examine how homeless men in Miami utilize social capital, which I'll define as access to social networks that can provide value to individuals or groups. While social capital is a broad concept with many definitions and interpretations, I will use it here specifically in a context of how friends and family can provide valuable resources, both tangible and intangible, to persons who are poor and/or homelessness. I will also discuss how the network of organizations designed to provide housing and services to Miami's homeless population works from the perspective of men on the street, focusing in particular on the role of the main entry points into the countywide homelessness delivery system. 
This chapter specifically addresses Research Question 3: What is the experience of single, adult men living in extreme poverty in Miami-Dade, who are homeless or at risk of homelessness, in negotiating their daily survival? It focuses on the first two hypotheses included under this question, examining access to social capital, and access to private programs and services.

\subsection{Social Capital}

Access to friends and family who are able to provide resources, or even just lend a couch, can make all the difference regarding whether somebody struggling with extreme poverty remains housed or becomes homeless. (Bassuk and Rosenberg 1988; Bassuk et

al. 1997; Eyrich, Pollio, and North 2003; Hawkins and Abrams 2007; Hopper 2003; Irwin et al. 2008; National Health Care for the Homeless Council 2003; Rossi 1989; Shinn, Knickman, and Weitzman 1991; Wright, Rubin, and Devine 1998; Wright 2009; Zugazaga 2008). In this section I will examine how the homeless and precariously housed men interviewed for this study discussed their own access to support from family and friends, including how this varies between the racial and ethnic groups, as well as according to housing status.

Interviewees were asked whether they had persons they could ask for material support, including cash, a place to stay, or food. Help from family versus friends was discussed separately. When asked about family, most interviewees gave a simple yes or no answer. As discussed more below, further discussion revealed that the actual level of support available ranged from monetary assistance to just meals. However, subjects determined for themselves whether they considered it a valuable source of support and thus their answer was recorded as yes or no. When it came to discussing support from 
friends, however, subjects gave more ambiguous answers. Individuals on the street in particular were prone to answer "maybe." Further questioning revealed that they differentiated between levels of support. They wanted to say that their friends would help, but the help would be in the form of a shared meal or loaning $\$ 5$ when needed. Thus, answers here were dichotomously broken into two categories: small or significant. Race and Ethnicity

Figure 36 shows how blacks and Hispanics reported their perceived access to help from family and friends. Blacks were more likely to report being able to attain help from family, or small types of support from friends, but less likely to report expecting significant help from friends.

Figure 36: Access to Social Capital, by Race/Ethnicity

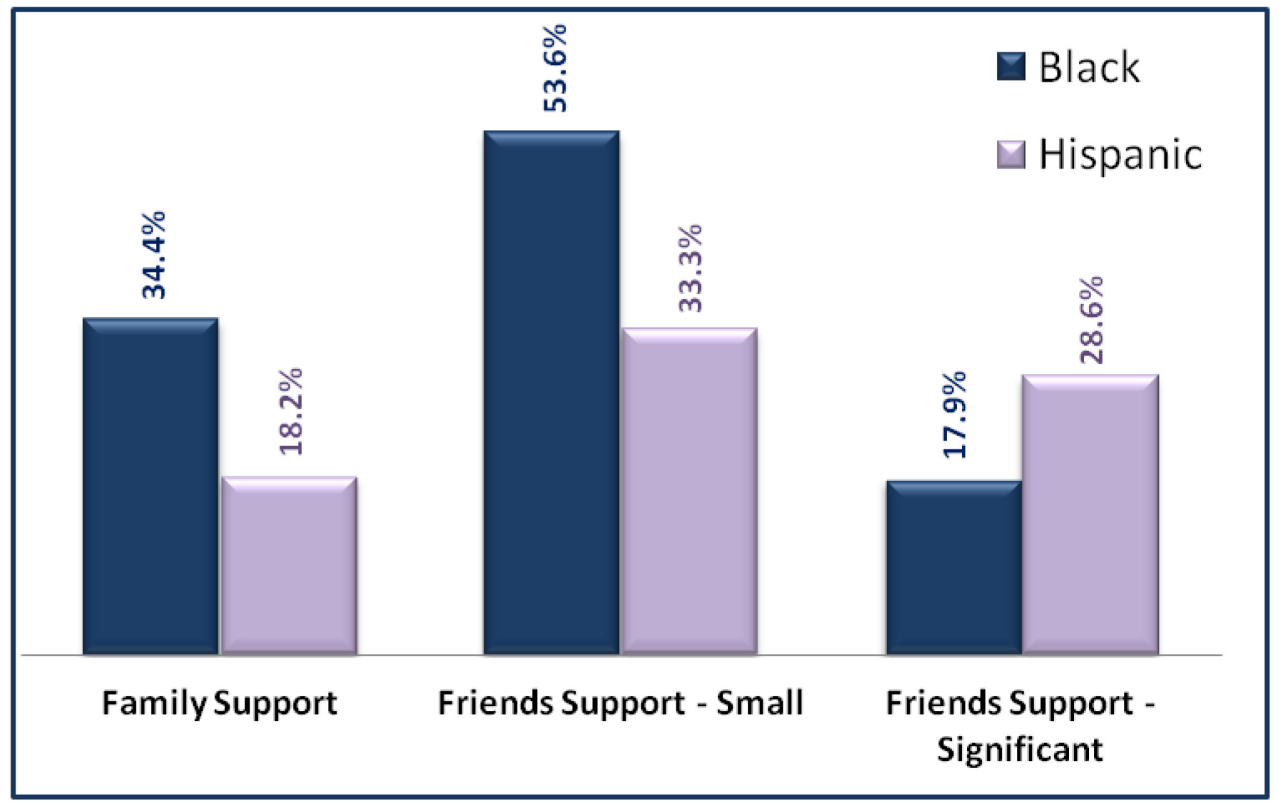

Source: Researcher Interviews 
Examining the data at a more granular level reveals that there are no significant changes in these proportions when considering the housing status of individuals. However, it is difficult to draw any conclusions from the more detailed data because the numbers in each category are so small, aside from noting that no areas seem to present a large difference from the data above. These findings might appear counter-intuitive to the hypotheses that one of the reasons blacks become homeless at greater rates than Hispanics is because Hispanics have great access to social capital. However, several factors need to be considered before drawing any conclusions.

First, the sample pool includes persons who have already become homeless or were at such risk that they had accessed rental assistance or other programs. Thus, this group represents people for whom access to significant sources of social capital had already failed. While it is still valid to examine the role of social capital in helping people exit homelessness, it is difficult to determine how effective it is in preventing it.

Second, the data is confounded by the large presence of immigrants in the population of Hispanics, including in particular Cubans. The majority of persons in Miami were born in foreign countries (Cruz and Hesler 2011) and this held true for the sample of Hispanic individuals, at every level of housing status. In fact, only two of the Hispanic respondents were born in the U.S. Cubans represented $62 \%$ of respondents, a number close to the representation of Cubans in the overall Hispanic population in Miami-Dade County (54\%) (Cruz and Hesler 2011). Amongst Cuban respondents, a large number reported having come to the U.S. alone during the Mariel boatlift. Thus, while the overall Cuban community may be close-knit, the individuals who become atrisk and/or homeless are outside of that community. They reported having no family here 
to turn to for help. Additionally, as discussed more below, many were reluctant to ask for help out of a sense of pride, guilt, and embarrassment.

\section{Figure 37: (photo) Osvaldo, under Metro station in downtown Miami}

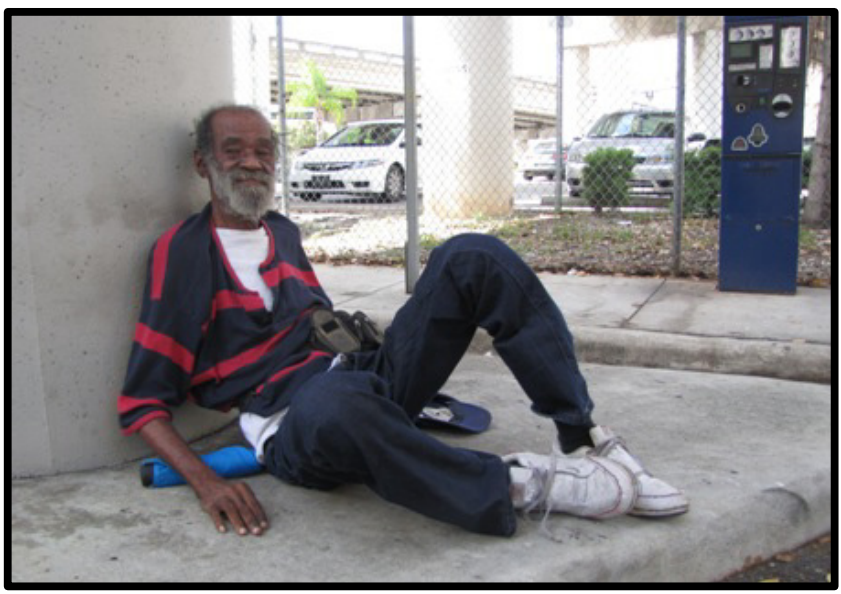

Osvaldo had arrived in the U.S. in 1980 as part of the Mariel boatlift when a large number of Cubans immigrated to Miami. He came alone, living in a tent city for a period of time. Problems with drugs were followed by a car accident resulting in a serious, permanent injury to his leg. For a while he survived on Social Security Income, but lost his housing when he could no longer afford to cover rent, utilities and living expenses on the limited income. With no family in the country, he became homeless and now sleeps under the Metro Mover station near Government Center. His mental status has led him to resist accepting attempts from outreach teams to help him find housing.

\section{Social Capital and Housing Status}

The subjects' self-reported access to friends or family who would lend support or material resources was examined according to their current housing status. For purposes here, individuals who fell into both categories of being formerly homeless and currently at-risk of becoming homeless again were categorized as being formerly homeless, assuming that the experience of having exited homelessness at least once was the more important factor. Figure 38 below shows the responses: 
Figure 38: Access to Social Capital, by Housing Status

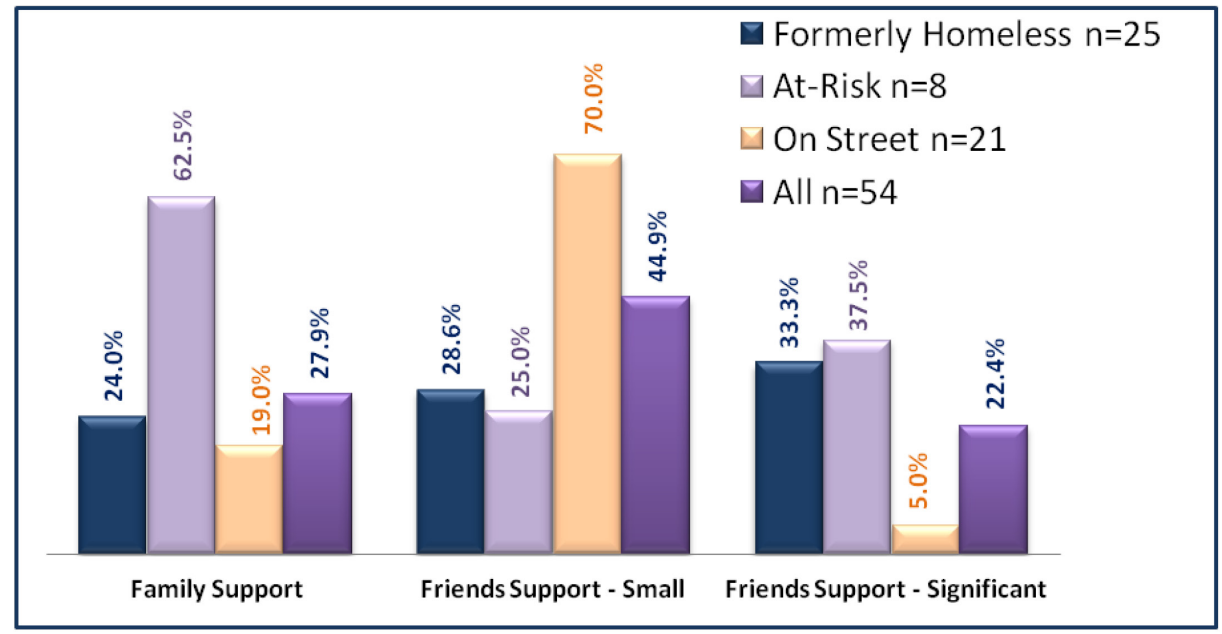

Source: Researcher Interviews

This chart shows that persons who were at-risk of homelessness, but had never been homeless before, were the most likely to report feeling they could turn to family for help. Persons living on the streets were most likely to report that friends would lend small amounts of support if needed; but were least likely to report a friend could lend significant help that might help them exit homelessness. Persons who were formerly homeless were in the middle regarding their perceived access to help from family and friends. If one combines the two friend categories into one category including both small and significant potential support, $61 \%$ of formerly homeless and $62.5 \%$ of the at-risk group report being able to ask friends for some sort of help. More details on each of these findings are described below.

\section{Social Capital and Risk of Homelessness}

Persons at risk of homeless were most likely to report that family members would be able to provide a significant amount of help if needed. In fact, numerous persons in 
this category had already moved in with family members. They had been referred to the study as persons who had recently received temporary rental assistance in order to help them stay in their current apartment. However, by the time of the interview, $3 / 8(38 \%)$ had nevertheless lost their apartment and moved in with family members.

Others were still living independently, but credited a close family member with having helped them through their difficulties. Trevor, for example, repeatedly brought up the vital role his sister had played in helping him find the resources he needed to stay housed, saying "Yeah my sister always lend a hand. She always on the phone checking on something with somebody. So give her credit for that." Harold, raised by his grandmother, spoke of having gone back and forth staying with her whenever he was having difficulty finding employment: "Currently staying with my grandmother who practically raises me, has raised me throughout the years and still continues to play a big part of my life."

Persons at risk of homelessness were also the most embarrassed about their situation, with four out of the eight declining to be in the photos themselves. Some were willing to participate in the photo process, but did not want their own image used out of fear that friends, family, or co-workers might see it.

\section{Currently and Formerly Homeless}

Responses from persons who were currently or formerly homeless were similar, as persons who had previously experienced homelessness were likely to weave in accounts of their previous street life when talking about their relationship to friends and family. One area where there was difference was that persons who were formerly 
homeless sometimes referred to the process of re-establishing relationships with friends and family, re-building the bridges they had previously burned.

Responses from blacks and Hispanics were similar in their descriptions of sharing resources and receiving small amounts of support from friends and family. Amongst their circle of friends who were also homeless, they described sharing food, cigarettes, and small amounts of money, usually up to around $\$ 5$. Any more than that would lead to trouble:

"I did it two times, but then, like I said, I'm homeless, I can't get no job, you know., when I do have money, when I give it to them, I want it back on this time on this day and then when this day come they don't have it. I get upset about it because your word supposed to be bond as a man so I stop lending them money."

Blacks and Hispanics were also similar in being able to get small amounts of help from housed contacts, including taking showers, using kitchens to prepare food, and using the internet to job search. Several individuals spoke of friends or acquaintances who could not accommodate them in their homes, but allowed them to stay in a van behind their business, on a porch, in a tool shed, or in a car parked in the backyard, “There's a friend who has a place with a big yard. He says I can park back there. Sometimes I park there or leave my car there and go for a walk."

They were reluctant to ask for more though, out of sense of pride and because they felt their families were struggling to get by enough on their own. Their families were themselves living on limited incomes, or had lost jobs, or had already taken in other relatives and were living in overcrowded housing. Additionally, relatives who were living in public housing were prohibited from allowing others to live in the unit. 


\section{Figure 39: (photo) Larry in his old neighborhood in Overtown}

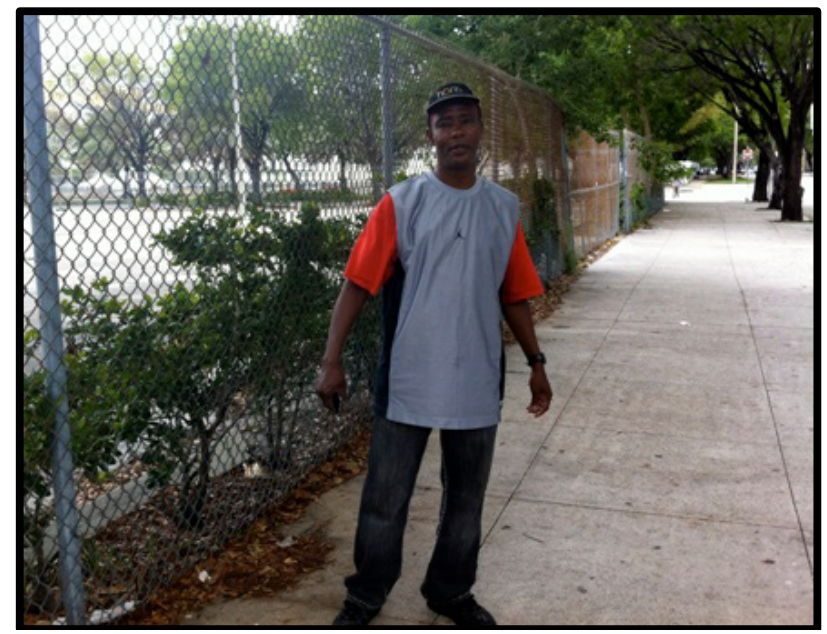

Larry was born and raised in Miami, and had bounced in and out of homelessness in the area for the past 15 years. He described having an aunt nearby from whom he used to get help, but, being a 50-year-old man who ought to be on his own, he just didn't want to burden her anymore:

"I got one Aunt. I stayed with her on and off. I'm already old enough and trying to get myself situated. But she older now and got grandchildren, other grandchildren now live with her, the house is full. I don't bother her for food or money, if I'm hungry I can go to Camillus House to eat."

Blacks and Hispanics both talked about guilt regarding their family relationships, but for different reasons. For blacks, they regretted having put burdens on the family and for having caused trouble with drugs or incarceration. Sometimes they reestablished relationships, but not trust, as Marvin explained: “I can go to mom’s but they don't ever give me cash. They probably don't believe I am clean so they afraid to give me money." Still, Marvin's mother wasn't going to let her son go hungry, and he was welcome for meals. Paul, on the other hand, felt deep regret over having lost his mother before he got clean and could have made amends: 


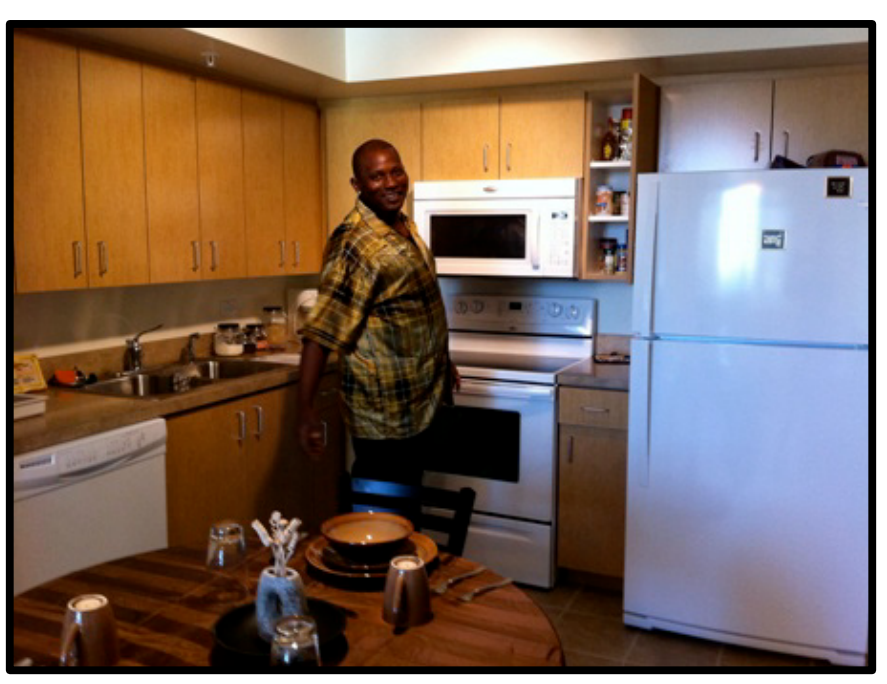

Paul considered himself the family disappointment, saying:

"I'm the only one in the family that's, you know, a bum you know. Everybody else preachers you know, singing and all of that did the church, and I was like the bum. So I was like the disgrace of the whole family."

Today, though, he lives in his own apartment in a supported program, and was proud to show the researcher the detail of every amenity in his building. He was rebuilding family relationships, but the death of his mother weighed heavily on him:

"I was stealing from her, stuff like that you know. I wish she could see me now, you know, 'cause that would really make her feel good."

For Hispanics, their guilt was not over actions they'd taken against their families, but was over having failed to provide for their family. The feeling of not being able to support their family, including sending money home to parents in other countries, brought up deep emotions, bringing two of the Hispanic respondents to tears.

One area where there was significant disparity between blacks and Hispanics was regarding the pull of negative social capital. While numerous blacks talked about having to distance themselves from previous social circles, and even family members, in order to avoid going back to a life of drugs, Hispanics made no mention of having to separate from previous friends or family members. Blacks spoke of having to make new friends, of having to move out of old neighborhoods, and of having to tell their drug-using friends that they were not welcome to visit or stay with them. Aaron spoke sadly of having to avoid the one close family member he had:

"Well, basically I have another sister that I was kind of like real real close to...I was you know really really close to her because me and her 
we was like, out of all the kids, like we was the only black sheep's in the family...I don't really see her that much because I'm trying to do something else, you know. She's still using. I don't need the distraction. When I see her I see her but as far as going looking for her and all that, I don't do that."

Finally, an area of similarity between the majority of blacks and Hispanics interviewed was their tendency to point to one individual who had been instrumental in helping them avoid or exit homelessness. A sister, a cousin, a neighbor, a doctorsomebody, one person, had taken an interest in them and helped them. Help came in many forms: making the phone calls to get them benefits; bringing them in person to an agency that could help; offering a place to stay so they could get back on their feet; providing job leads and references. In fact, one of the most common traits amongst those who claimed to be doing okay was being able to count on at least one person for some sort of help, whether material or emotional. Many of them referred to their helper as their “angel."

Even when asked if they'd ever received help from an agency, respondents spoke of the specific staff members who had helped them. Their relationship was not with the agency; it was with their case worker or counselor. Some weren't even sure which agency the staff member worked for - they just knew that "Carmen is helping me find housing." 
Figure 41: (photo) Herman and his favorite agency staff member

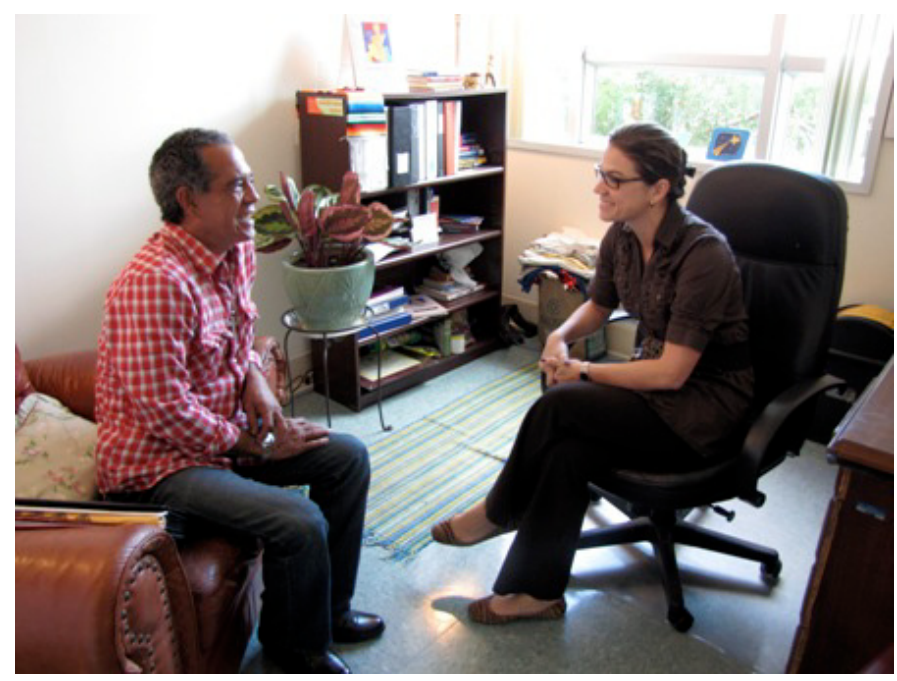

Herman had been in and out of homelessness as he struggled with health problems and unemployment. When he sought help for a health condition, he was connected to a case worker he credited with saving his life. He insisted on taking the researcher to her office to have his photo taken with her, saying that she was by far the most important thing in his life.

The role of agencies in filling in the gaps where social capital had failed is important. After all, as described in previous chapters, the Miami community has put in place an extensive homelessness delivery system designed to help persons experiencing homelessness. It is supposed to help everyone exit homelessness, particularly those with no other resource. So, how is that system working for the minority men interviewed for this study?

\subsection{Private Agencies}

Doors are open, depends on what door you wanna go through. And sometimes you can't make your own decision about the door, you can't choose the door. The door's open and if you walk through it, you'll be surprise what's on the other side. - Anthony

Miami-Dade County has developed a sophisticated system offering integrated housing, programs, and basic services for persons who are homeless. As previously discussed, the Miami-Dade County Homeless Trust serves as the central coordinating entity, facilitating a network of 27 provider agencies offering everything from emergency, transitional, and permanent housing to drug treatment, health care, 
employment training, and mental health services. Efforts are made to offer a range of program models so that individuals are able to access the type of help they need. Yet, there are still homeless people, predominantly minority men, living on the streets of Miami. What is missing for this group of individuals?

While an evaluation of the continuum of programs and services available in Miami-Dade would be the subject of another study, I will discuss two issues here that were brought up as barriers perceived by interviewees. First, the primary method of entry into the homelessness system has been the two Homelessness Assistance Centers (HACs) constructed in the mid-1990s. While the model offered by the HACs has been extremely successful for tens of thousands, many individuals and families, it has not worked for many of individuals interviewed for this study. Second, the type of assistance requested most, which was for job placement, is a difficult request to fulfill when working with men with backgrounds such as theirs.

Yet, in spite of these barriers, nearly every interviewee still expressed a belief that help was available for anyone willing to accept it. Help sometimes came with strings attached, and that is where the concept of choice came into play. Getting off of the streets was possible, but might require giving up freedoms, choice, and self-determination. The homelessness service delivery system was continually making efforts to make that choice easier for individuals to make; and individuals were continually evaluating at what point they were ready to accept one of the choices available and leave the street.

The HAC was known to every respondent who had ever been homeless. Interestingly, when asked if they had ever received help from a program, many said no. Upon further questioning, though, they would acknowledge that of course they had been 
to the HAC. They did not view the HAC as a program, as they associated the word "program" with drug treatment or more clinically based services. Attitudes toward the HAC were generally ambivalent. Most described it is an "okay" place with well-meaning staff that simply had not been able to meet their own needs, for two reasons. First, the $\mathrm{HAC}$ has a $7 \mathrm{pm}$ curfew that was mentioned by most respondents as being too much an infringement on their freedom. As discussed more in the following chapter, the issue of having freedom from curfews and rules was particularly important to individuals who had spent periods of time incarcerated. They would rather sleep on the street than submit to someone else telling them what time to come home, what time to get up, and what time to eat.

The second issue was the 60-day time limit imposed by the HAC. While this time limit can be extended in some cases, it generally had not been for these individuals as it had not appeared they had made significant progress. The primary purpose of services at the HAC was to help individuals attain employment and get back on their feet. However, simply because they were staying at the HAC did not erase all of the other barriers to employment they had been experiencing. Most, for example, still had criminal backgrounds and little work experience. So, 60 days seemed like way too short a time for them to have addressed their situation. They left on their own or were discharged from the program.

The HAC is by no means the only type of program available in the county. Other emergency shelters exist with varying levels of program requirements, including the Camillus House program referenced by many interviewees. However, no matter how flexible various shelters and programs were, each still required some minimal level of 
commitment and conformance to rules that could be perceived as a barrier by some. Interviewees recognized that conforming to the rules, though, would most likely help them escape homelessness. Walter explained that while he had not necessarily enjoyed giving up his freedom, agreeing to do what he was told by his case worker had ultimately helped him exit homelessness, and his interview was conducted in an apartment he now rented by himself:

"I did what someone told me to do. So I followed the rules and regulations to get my help. I didn't disobey, I didn't buck, I didn't say 'Oh you're trying to do this to me, you're trying to do this to me.' I did what they told me to do. I got help. If they would do the same thing, they would get the help too."

The Homeless Trust has recognized that the models offered by the HAC and other programs were insufficient for meeting the needs of some individuals, particularly those who had been on the streets for extended periods of time. New program models have been implemented, whereby individuals are placed directly into permanent housing situations without having to pass through the HAC or other programs in the county's network of programs. The most common of these new program types is known as "Housing First," (Tsemberis, Gulcur, and Nakae 2004), a model developed in New York and now promoted at the national level. Developed specifically to address the needs of individuals who have chosen homelessness over programs with strict compliance rules, this model has proven extremely effective in helping many persons who have been homeless for long periods of time to transition out of homeless. If fact, several of the interviewees who had been living on the street at the time of the interview were in their own apartments when the researcher followed up a year later, having been placed through Housing First type programs. However, the funding for this expensive program model is 
limited. Thus, the choice is not yet readily available to the entire population of persons living on the streets.

The other issue regarding availability of programs and services to help individuals exit homelessness is not with the rules, but with a mismatch in the actual services. Many interviewees noted that they didn't want benefits, or a program, or free housing. They wanted a job, and that was frequently the one thing a program couldn't help them with. John explained why he thought some people remained homeless in spite of the plethora of programs available in Miami:

Not getting the help they need, right, not getting the help they need. Like more places, they offer all types of programs, but they never say, well let's see if we can offer some jobs. You see what I'm saying?

Michael succinctly summed up why he "chose" to remain homeless in spite of the availability of programs that were supposed to help him: "I needed a job and they couldn't help me with a job. They couldn't help me at that time. So I got frustrated and I do what everybody else do: move to the streets."

Of course, even the best homeless programs cannot combat the two of the larger social problems contributing to homelessness: a poor economy with not enough jobs; and laws and corporate policies preventing persons with criminal backgrounds from attaining many types of jobs. Job training programs were readily available for many of the men interviewed; but at the end of that training, there were no employers waiting to hire. Thus, even while the larger public discourse dictated that homeless men should "just get a job," this choice not actually available to many. 


\subsection{Summary of Social Capital and Resources Findings}

In this chapter I have examined the question posed in Research Question \#3: What is the experience of single, adult men living in extreme poverty in Miami-Dade, who are homeless or at risk of homelessness, in negotiating their daily survival?

First, the discussion around the private resources available through social capital addressed the first hypothesis for this research question: Single men who are homeless or at risk of homelessness rely on social capital, including access to friends or family who can provide help, to replace the lack of access to public benefits, with differences between blacks and Hispanics. The conclusions in this area are ambiguous. While friends and family have a role to play in helping persons who have experienced homelessness, they typically are unable to provide large amounts of monetary help. Instead, they are able to offer smaller pieces that can supplement the other mix of resources the men use to survive. Thus, for example, food comes from food stamps, charities, and the occasional meal at a mother's house. Individuals can take a break from the street with a hot shower and change of clothes at a friend's house, but cannot move in there. These findings are similar to studies examining how persons living on the street share resources and utilize their limited social capital (Hawkins and Abrams 2007; Molina-Jackson 2008; Snow and Anderson 1993).

However, I have also noted that for persons who become literally homeless in Miami, there is not much difference between blacks and Hispanics, with these findings possibly confounded by the presence of immigrants from other countries in the sample. The manner in which racial/ethnic groups in Miami utilize social capital appears to differ from findings from similar studies in Los Angeles, which found that African Americans 
had stronger access to social capital (Molina-Jackson 2008), whereas in Miami it was Hispanics who were demonstrating greater use of social capital. Additionally, the LA study found that Hispanic immigrants were utilizing networks to focus on attaining employment, whereas in Miami Hispanics were utilizing their networks to gain access to attaining public benefits, while African Americans were more likely to attempt to utilize networks to find employment. Exploring the potential reasons for the different findings between Los Angeles and Miami is an important area for further research.

\section{The second hypotheses is that single men who are homeless do not have} access to adequate programs and services necessary to help them exit homelessness. Whether or not the null is true here depends on your perspective. On the one hand, most interviewees agreed that Miami offers a wide range of programs and services that would be able to help almost anyone exit homelessness. On the other hand, however, many interviewees did not view this is a choice they wanted to make, given the requirements they would have to meet in order to access the help. Thus, the network of private agencies working together to help persons exit homelessness and maintain their own housing is effective for some, but not for others. In particular, the rules and constraints of the typical emergency housing entry point are too much for persons with long histories on the streets and/or in prison. New models addressing this exact issue are effective, but in short supply. The concept of "choice" plays multiple roles here. Staying on the street versus accepting help may be a choice, but it involves pros and cons not considered by persons on the outside. The choice involves deciding where one's need for help exceeds one's desire for freedom. Whether or not these requirements are really too excessive, or 
whether the individuals were simply too demanding on how far society needs to go to meet their own desires, is an area for further discussion.

Additionally, the "choice" to attain employment in order to exit homelessness may not even exist for a larger subpopulation of homeless men. So, what is it like to exist in this realm of limited choices? The following chapter examines life in extreme poverty and homelessness as told through the eyes of the men themselves. 


\section{CHAPTER 8: EXPERIENCING HOMELESSNESS}

"Um, I remember one day, you know, first encounter with a homeless person was at the restaurant I worked at, you know, they used to make buns and they carve them out and toast them for the clam chowder, and they were throwing them away or whatever. And I remember since I washed dishes, I would clean up the kitchen and throw away the trash. And there was a guy by the trash can and he was like, looking in the trash can for food and I had never experienced that before. And I gave him a bun, and the owner came and saw me and he was like, 'No! You don't give 'em a bun, they're like dogs. Once you feed 'em you'll never get rid of them, and then they'll bring their friends.' A and I was like, Wow. And you know, I really couldn't comprehend that. But then once I was homeless, it was days where I wished someone would have given me something to eat like that. And I was like, wow, just, people. You know what I mean."

- Albert

Society, including the Miami community, has established a multitude of laws, practices, benefits, and systems to address homelessness. Some, like provision of public benefits and the establishment of programs and services, are aimed at helping persons living in poverty and homelessness. Others, like restrictions on benefits and laws regarding use of public space are designed to discourage "undesirable" behaviors. The resulting set of systems creates a complex network of both resources and obstacles that comprises the choices available to men who are poor or homeless. This chapter addresses the second set of hypotheses associated with Research Question 3: What is the experience of single, adult men living in extreme poverty in Miami-Dade, who are homeless or at risk of homelessness, in negotiating their daily survival? Specifically, it will test the last two hypotheses, which examine how they experience poverty and homelessness, as well as differences in how black and Hispanic men believe they are treated and provided access to helpful resources. 
I will examine how this system, or network of disparate systems, looks from the perspective of those negotiating it on a daily basis. I will begin with an analysis of the photographs the interviewees chose to depict their lives, looking at how they present themselves and the things important to them. Second, I will discuss the interviewees' own descriptions of the experience of being homeless, including their answers regarding how they feel about their current situation and what they believe it would take to end homelessness. Finally, I will review their comments regarding the role of race and ethnicity in being homeless.

\subsection{What's Important?}

The men interviewed for this study were presented with the opportunity to participate in telling their own story to the rest of the world. At the conclusion of the regular interview, they were invited to work with the researcher to choose a set of photographs to take that would show what was important to them, and what they would want others to know and understand about their lives. This Photo Elicitation Interview (PEI) is an effective means of drawing out information that might not come up in a semistructured interview (Collier and Collier 1986; Collier 2003; Prosser and Scwartz 1998). By choosing the photos and then talking about their meaning, the interviewees take on a greater role in the direction of the interview and may reveal more than they otherwise would. The role of the interviewee and researcher can be reversed, and the interviewee can point to new things that the researcher did not know to ask (Clark-Ibanez 2007; Harper 1989b). Of particular importance is not just the content of the photos, but the choice of what photos to take. 
Of the 54 interviewees, 48 chose to have photos taken. Out of those 48,44 chose to be in the photos themselves. In this section I will analyze the photos in two ways. First, I will examine what they chose to photograph, using the data to illuminate those aspects of their lives they consider most important. Second, I will examine how they chose to depict themselves in the photos, using that data to consider how it is they want the rest of the world to view their position.

The three tables below provide an overview of the content of the photos interviews chose to take, comparing black and Hispanic subjects. The tables are separated according to whether they were living on the street, were formerly homeless or were housed but at-risk of homelessness. As previously discussed, the line between "former" and "at-risk" was blurred, with subjects referred for one category frequently falling into both. They were currently at risk of becoming homeless, and they had previously been homeless. For purposes here, I have categorized someone as "formerly homeless" if they had ever been homeless before. This decision was made based on the assumption that the experience of having ever been homeless would have a greater influence on their current priorities and outlook. Because so many of the at-risk subjects turned out to have been homeless before, the at-risk category in this section is therefore relatively small. Each table is color coded to indicate whether the subject was smiling in the picture, was not smiling, or chose not be in the photograph at all. The act of smiling in the photos is discussed more later in this section. 


\section{Table 16: Photo Contents of Homeless Men Living on Streets}

\begin{tabular}{|c|c|}
\hline Black & Hispanic \\
\hline $\begin{array}{l}\text { Smiling on top of bench on Ocean Drive; walking } \\
\text { past buildings he has seen gentrified over last } 20 \\
\text { yrs; park where he used to live; spot on rocks by } \\
\text { water spends days; catching fish to eat and sell }\end{array}$ & $\begin{array}{l}\text { Sitting on couch in office at shelter; Standing with } \\
\text { plastic bags of food and "junk"; did not want to go } \\
\text { outside where could be seen }\end{array}$ \\
\hline $\begin{array}{l}\text { Spot on sidewalk where sleeps; spot under ledge } \\
\text { for when it rains; down street from arena where } \\
\text { sells parking spots }\end{array}$ & $\begin{array}{l}\text { Spot under bridge on Miami River where sleeps } \\
\text { with a group; Place where hides belongings; } \\
\text { Cardboard pieces to sleep on at night }\end{array}$ \\
\hline $\begin{array}{l}\text { On Ocean Drive wall on south beach, showing } \\
\text { how to make coconut drinks to sell to tourists }\end{array}$ & $\begin{array}{l}\text { Walking in park where sleeps; Spot down by water } \\
\text { where sleeps at night, out of the way }\end{array}$ \\
\hline $\begin{array}{l}\text { Smiling in office where interviewed; pulling } \\
\text { luggage by Miami-Dade college }\end{array}$ & $\begin{array}{l}\text { Sitting on sidewalk outside of shelter; Belongings } \\
\text { hung on fence; Walking toward shelter because } \\
\text { afraid will miss lunch }\end{array}$ \\
\hline $\begin{array}{l}\text { Spot on sidewalk where sleeps; Spot where hides } \\
\text { belongings; Looking at broken bike }\end{array}$ & $\begin{array}{l}\text { Restrooms at Government Center building- only } \\
\text { clean ones around; Sitting on bench outside Gov } \\
\text { Ctr, where spends most days alone }\end{array}$ \\
\hline $\begin{array}{l}\text { Sitting on steps with food box given to him; } \\
\text { Sitting on sidewalk panhandling in usual spot }\end{array}$ & $\begin{array}{l}\text { Sitting on sidewalk with radio; Wanted only } 1 \\
\text { picture because that is all he does }\end{array}$ \\
\hline $\begin{array}{l}\text { Showing off artwork, favorite drawings; With } \\
\text { friend Robert; Sitting at MetroStation where } \\
\text { draws for college students to earn money, carries } \\
\text { all belongings }\end{array}$ & $\begin{array}{l}\text { Showing abandoned lot where sleeps; sees bed } \\
\text { cushions have been stolen; pail used to wash } \\
\text { clothes; abandoned building where also sleeps; } \\
\text { someone else's bed now in the building }\end{array}$ \\
\hline $\begin{array}{l}\text { Empty lot where hangs out days with friends; } \\
\text { With his dog (best friend) }\end{array}$ & $\begin{array}{l}\text { Spot on sidewalk under ledge where he sleeps at } \\
\text { night, shares spot with others }\end{array}$ \\
\hline \multicolumn{2}{|l|}{$\begin{array}{l}\text { Spot on sidewalk where sleeps; Showing around } \\
\text { sidewalk, talking about survival }\end{array}$} \\
\hline \multicolumn{2}{|l|}{$\begin{array}{l}\text { Spot on sidewalk where sleeps; U-haul storage } \\
\text { where keeps clothes \& tent }\end{array}$} \\
\hline $\begin{array}{l}\text { On bench at shelter with belongings- medications; } \\
\text { With cane for walking; Watching movie at shelter } \\
\text { activity center }\end{array}$ & \\
\hline
\end{tabular}

Pink highlight: Smiling in photos; Blue highlight: No smile; No highlight: Not in picture 
Table 17: Photo contents, Formerly Homeless Men

\begin{tabular}{|c|c|}
\hline Black & Hispanic \\
\hline $\begin{array}{l}\text { Painting of flowers- gift from friend; in efficiency } \\
\text { apt with walker; in front of bldg where lives in } \\
\text { wheelchair with case worker }\end{array}$ & $\begin{array}{l}\text { Happy to be in own apartment; Family photos; } \\
\text { Medical scars }\end{array}$ \\
\hline $\begin{array}{l}\text { In new apt on couch with tv remote; kitchen eating } \\
\text { food given from staff; Showing off kitchen cabinets }\end{array}$ & Standing in apt with bible \\
\hline $\begin{array}{l}\text { In own apt with lots of decorations; Proudly } \\
\text { showing card from treatment staff; Outside of } \\
\text { building }\end{array}$ & $\begin{array}{l}\text { Proud of new apartment; Happy to have } \\
\text { homemade curtains; Just one chair in apt but will } \\
\text { get more; Keeps kitchen clean }\end{array}$ \\
\hline $\begin{array}{l}\text { In new apartment - proud of kitchen and living } \\
\text { room; Tour of building accessories - fitness center, } \\
\text { computers; Difference in appearance in drivers } \\
\text { licenses - before \& after treatment }\end{array}$ & $\begin{array}{l}\text { In communal kitchen where prepares food; } \\
\text { Unlocking bike he uses for travel to } 2 \text { jobs }\end{array}$ \\
\hline $\begin{array}{l}\text { Photos of family; closet where keeps clothes neatly } \\
\text { organization; keeps kitchen clean }\end{array}$ & $\begin{array}{l}\text { Proud of own apartment and clean kitchen; Wall } \\
\text { of family photos; Bookcase full of books; }\end{array}$ \\
\hline $\begin{array}{l}\text { In own apartment showing off own kitchen; proud } \\
\text { to sit on own couch and just watch tv }\end{array}$ & $\begin{array}{l}\text { In apartment shares with friend, not his } \\
\text { decorations; Shares a closet; Proud of new truck } \\
\text { he bought so he can work; Apartment is in front } \\
\text { of new stadium }\end{array}$ \\
\hline $\begin{array}{l}\text { Walking outside of apartment enjoying view of } \\
\text { water; showing ice cream from company he works } \\
\text { at }\end{array}$ & $\begin{array}{l}\text { Necklace of cross that gets him through hard } \\
\text { times; Picture with social worker who saved his } \\
\text { life }\end{array}$ \\
\hline $\begin{array}{l}\text { Outside building in Overtown with walker and back } \\
\text { brace; Inside happy with girlfriend }\end{array}$ & $\begin{array}{l}\text { In doorway opening door to own apartment; } \\
\text { Showing balcony at apt; Pile of utility and } \\
\text { medical bills; In sparsely furnished apartment } \\
\text { with cane }\end{array}$ \\
\hline $\begin{array}{l}\text { In own apartment, proud of all the furniture he } \\
\text { bought himself for } \$ 200 \text {; wearing work clothes }\end{array}$ & $\begin{array}{l}\text { In apartment with table of medication bottles; } \\
\text { Sitting on bed holding bag of food donated by } \\
\text { friend; Apologizes for appearance }\end{array}$ \\
\hline $\begin{array}{l}\text { Sitting in park - didn't want to show apt; Showing } \\
\text { how skinny has become; Smiles so will still look } \\
\text { nice }\end{array}$ & $\begin{array}{l}\text { Lying on bed in shared living room with no } \\
\text { privacy; All belongings stacked next to bed }\end{array}$ \\
\hline $\begin{array}{l}\text { Showing key to own apt; proud of own apartment; } \\
\text { stereo to listen to music; with outreach worker - is } \\
\text { his "favorite thing" }\end{array}$ & \\
\hline \multicolumn{2}{|l|}{$\begin{array}{l}\text { Show fridge with little food; Standing by door } \\
\text { keeps locked in bad neighborhood; Shelf full of } \\
\text { donated canned goods }\end{array}$} \\
\hline $\begin{array}{l}\text { Proud of own efficiency apt; Bought artwork on } \\
\text { wall; Medical equipment }\end{array}$ & \\
\hline
\end{tabular}

Pink highlight: Smiling in photos; Blue highlight: No smile; No highlight: Not in picture 
Table 18: Photos Content, Men at Risk of Homelessness

\begin{tabular}{|l|l|}
\multicolumn{1}{|c|}{ Black } & \multicolumn{1}{c|}{ Hispanic } \\
\hline $\begin{array}{l}\text { In own apt, with photos of family; Veteran } \\
\text { medals and photos of self as vet; Looking out } \\
\text { window - likes his neighborhood }\end{array}$ & $\begin{array}{l}\text { In own apartment - cluttered but likes it that } \\
\text { way; Magazine racks left over from previous } \\
\text { business, wants to start business again }\end{array}$ \\
\hline $\begin{array}{l}\text { Sparsely decorated apartment; One decoration } \\
\text { hung on wall; Bike in living room used for } \\
\text { transportation; Tinfoil on window in kitchen and } \\
\text { patched wall }\end{array}$ & $\begin{array}{l}\text { Outside of apartment looking up stairs - is in } \\
\text { nice building; Fridge has very little food in it; } \\
\text { Next to fan because no air conditioning }\end{array}$ \\
\hline $\begin{array}{l}\text { Inside grandmothers house; Flowers display } \\
\text { giving faith; Stereo for listening to music; Car } \\
\text { that doesn't work }\end{array}$ & $\begin{array}{l}\text { Sitting on bed in bedroom in daughter's house, } \\
\text { has all belongings stacked in one room }\end{array}$ \\
\hline
\end{tabular}

Pink highlight: Smiling in photos; Blue highlight: No smile; No highlight: Not in picture

The photos chosen by men living on the street revolved around showing where they slept at night. In some cases this was the location where the interview took place; in some cases the subject asked to walk or drive to the location to show it. In conjunction with sleeping spots, a concern with where to go when it rained was bound up with concerns about the police. Getting out of the rain required finding an area protected by an overhang or ledge; however, those spots were usually in front of buildings and were considered private property. Staying there on a regular night would result in being awoken by police in the middle of the night. However, on rainy nights most, but not all, police officers were more lenient and individuals could gather into groups under ledges. 
Figure 42: (photo) Overhang where Heriberto seeks shelter from rain

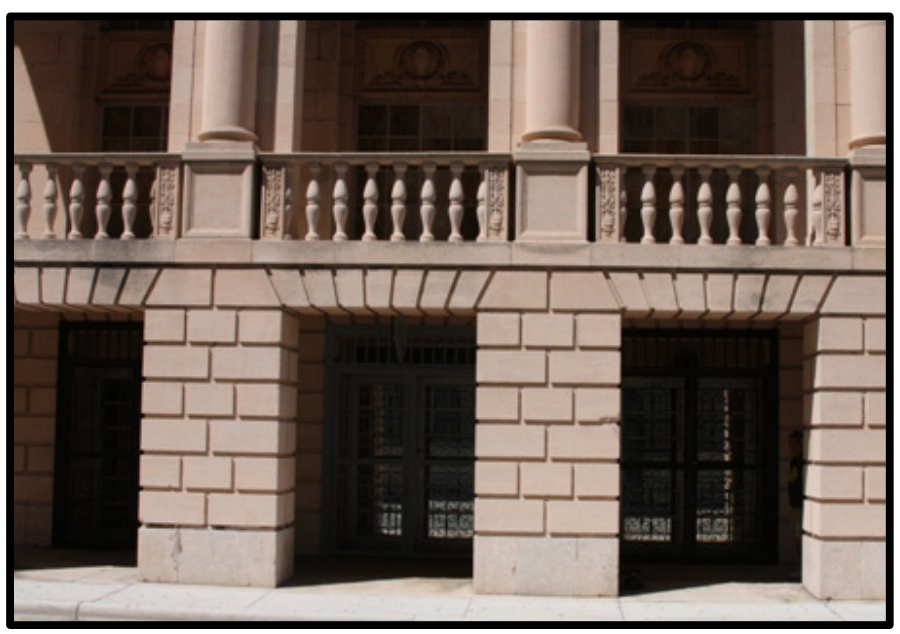

Heriberto showed the front of the church downtown where he stayed, illicitly, on rainy nights:

"When it rain, know, I go to place which I'm not supposed to go over there. No but I go there anyway, no cause it's raining.

Well, we-we sleep over here when it rains, because it's covered over here. And it's couple guys here with me, we come here every night, and uh just we come. In the morning, morning the people with the green shirts, when they see you, they wake you up. And decide to get up know and that's when we walk to Camillus House and just take a shower, and wash up, know and have breakfast."

Some individuals who slept in places other than the street chose to be photographed there, as a way of showing the rest of the world how they lived, and how hard it was to be homeless. Antonio was quick to state that he was miserable, and did not find anything freeing or fun living on the street: "Well my life right now is, I'm not too happy with my situation because obviously I'm homeless. Um, I try to make the best out of my situation but um it's not fun, it's kinda depressing."

On the other hand, a few subjects were proud to show that they slept outside in what they considered to be a beautiful place, where they had freedom and sunshine. They focused on the outside air, the sun, and beaches. Additionally, individuals liked to show how they had found quiet spots, away from crowds and trouble makers. 
Figure 43: (photo) Jimmy in abandoned building and empty lot
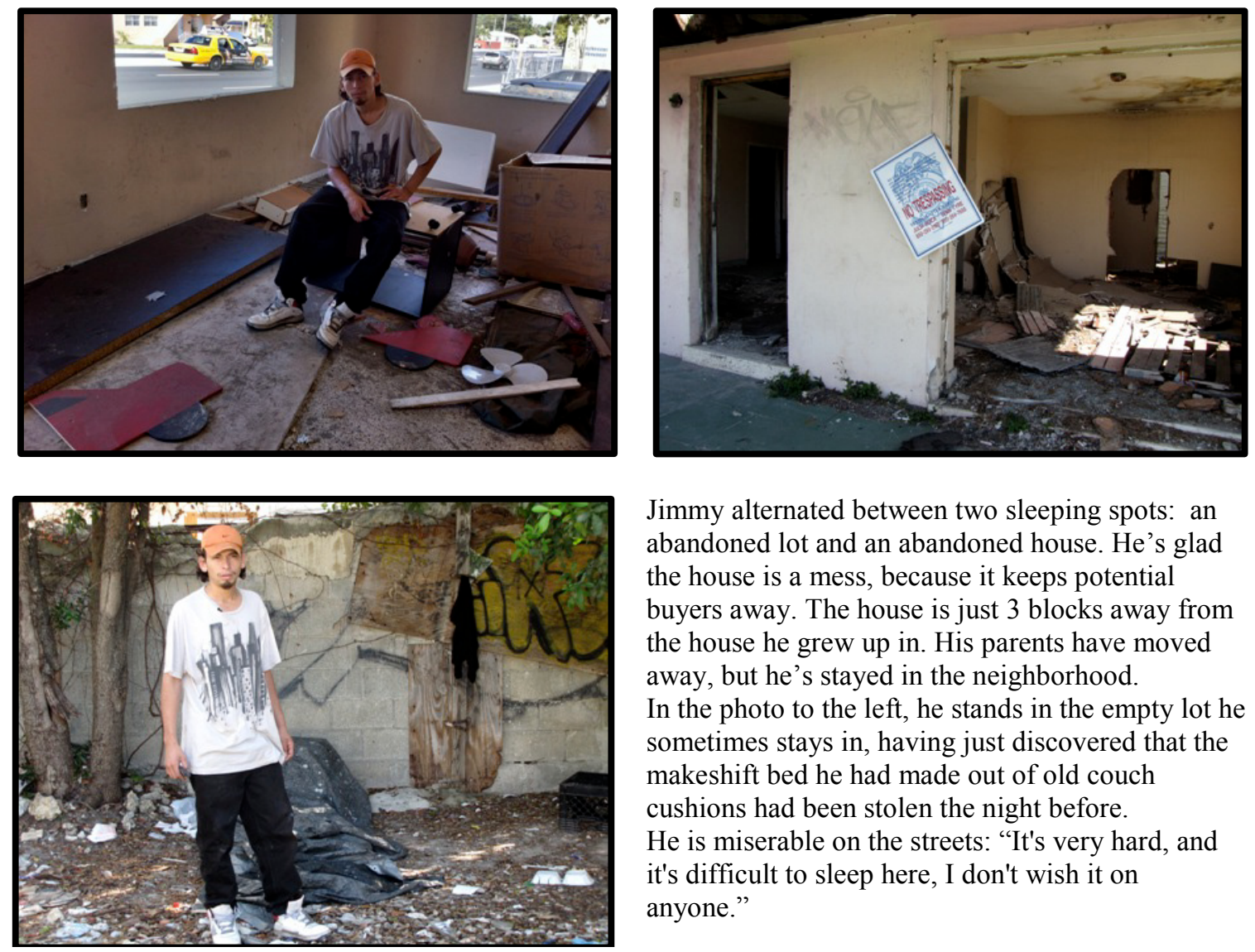

Jimmy alternated between two sleeping spots: an abandoned lot and an abandoned house. He's glad the house is a mess, because it keeps potential buyers away. The house is just 3 blocks away from the house he grew up in. His parents have moved away, but he's stayed in the neighborhood.

In the photo to the left, he stands in the empty lot he sometimes stays in, having just discovered that the makeshift bed he had made out of old couch cushions had been stolen the night before. He is miserable on the streets: "It's very hard, and it's difficult to sleep here, I don't wish it on anyone."

\section{Figure 44: (photo) Richard, in one of many spots he's slept on the beach}

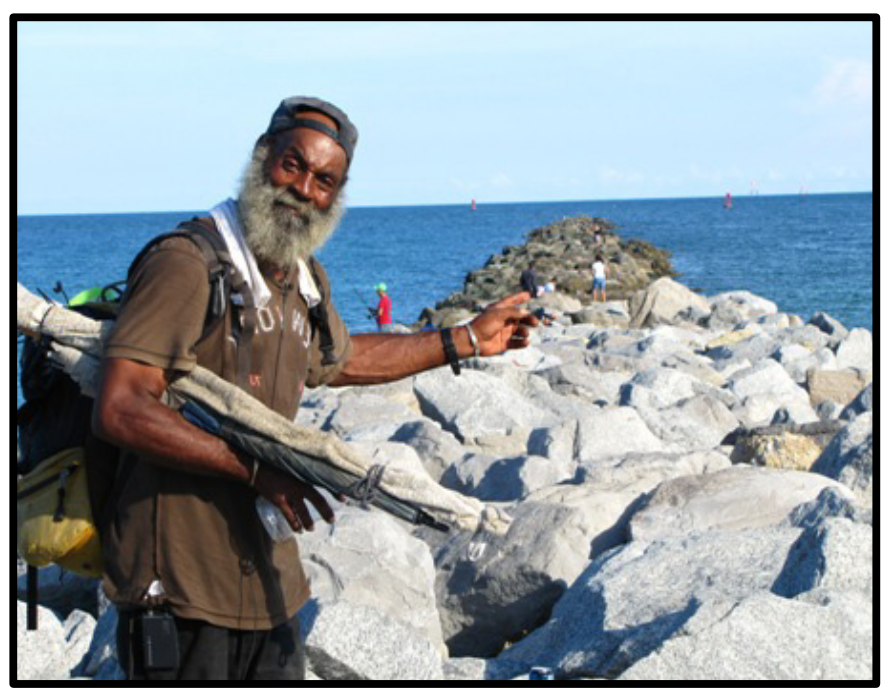

Richard brought up "freedom" frequently during the interview, expressing happiness with having spent more than 20 years living on the water on Miami Beach. Now and then he mentioned how hard it was when it got cold or rained. Several months after the interview, Richard had allowed himself to be placed into an apartment through a HUD-funded housing program. The apartment, located on Miami Beach, allowed him to still spend his days outdoors, but he slept inside at night.

Here, he shows one of the many spots he stayed in over the years, before the police had made him move.

"Come into my apartment now, I hope you're ready for my apartment, I love my, I still miss my apartment. I can point where me and three other guys... we dug a hole under the boardwalk, we dug it out, we had lawn chairs and everything in there...It's fun, I'm telling you it, half these people know me from being here." 
Related to where one slept at night was where one could keep belongings. Nearly everybody who lived on the street reported having had their belongings stolen. For some, the theft had been significant, with individual reporting loss of all their personal identification; all of one's prized drawings; and, in one case, a full set of dentures that left the individual completely toothless. Surprisingly, when asked if they had been the victim of a crime, most said no. Theft was so common it was not considered a crime.

Figure 45: (photo) Berry and his spot on the sidewalk

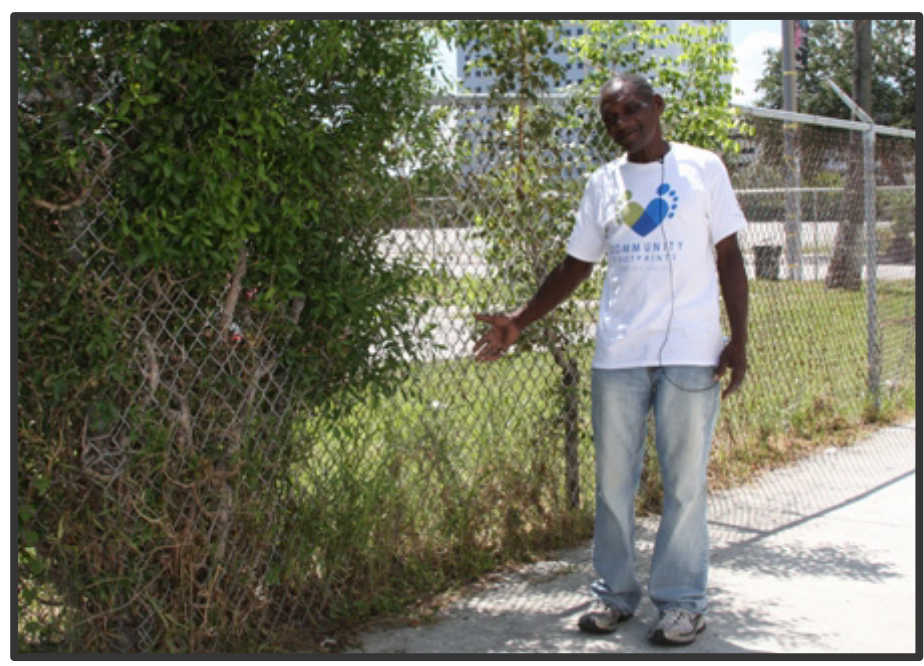

Berry sleeps on the street near the homeless shelter where he goes during the day. But keeping his belongings clean, and not stolen, is a major concern:

"So at night when I'm ready to lay down, I come over and get my-get my blankets and my sleeping bag, which is balled up over here by the rocks... I had a backpack on my back and I was sleep one night and somebody rip it off. I had my teeth in there. Ah, man that hurt me so bad."

Figure 46:(photo) Jeffrey and his storage space

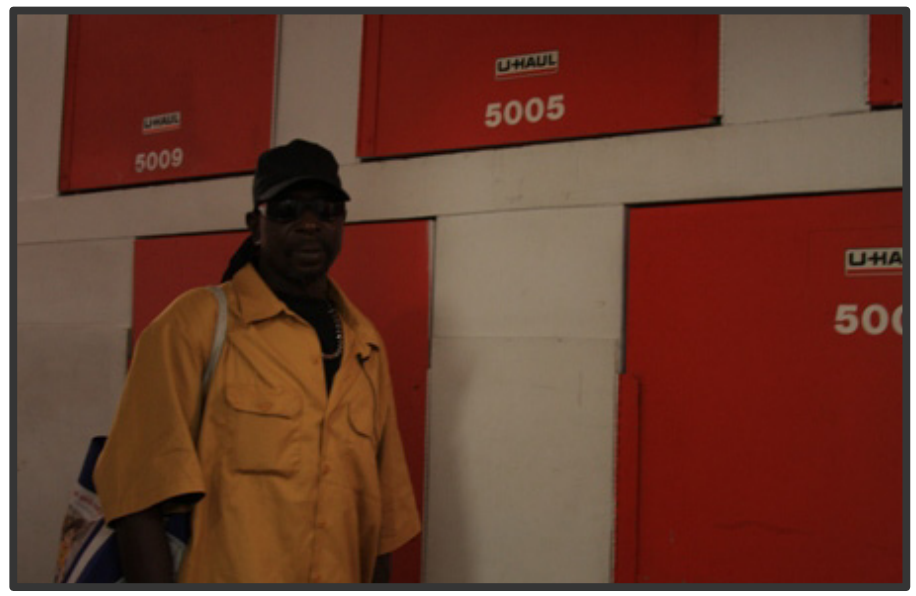

Jeffrey sleeps on the street but does not want to succumb to looking homeless, so he spends what little money he has to rent storage for his clothes and tent:

"How I get up in here? I have to get the ladder and I go up the ladder and it's like a flat surface and I stand in there and then I have to crawl in the box. But I basically know where everything's at so I don't be here too long cause it's hot in this box.

I come here every morning to return my tent and my suitcase with the blankets in it and then, I come every evening you know to get my blanket and my tent to set up." 
After showing where they slept, interviewees also took pride in showing how they earned money. This included showing where they parked cars, where they sold items such as fish and coconuts, where they sold commissioned artwork, and even where they panhandled. Along with the photos came long descriptions of their work activities, and it was clear that the details of how they earned income was important.

Figure 47: (photo) Arthur and the artwork he sells
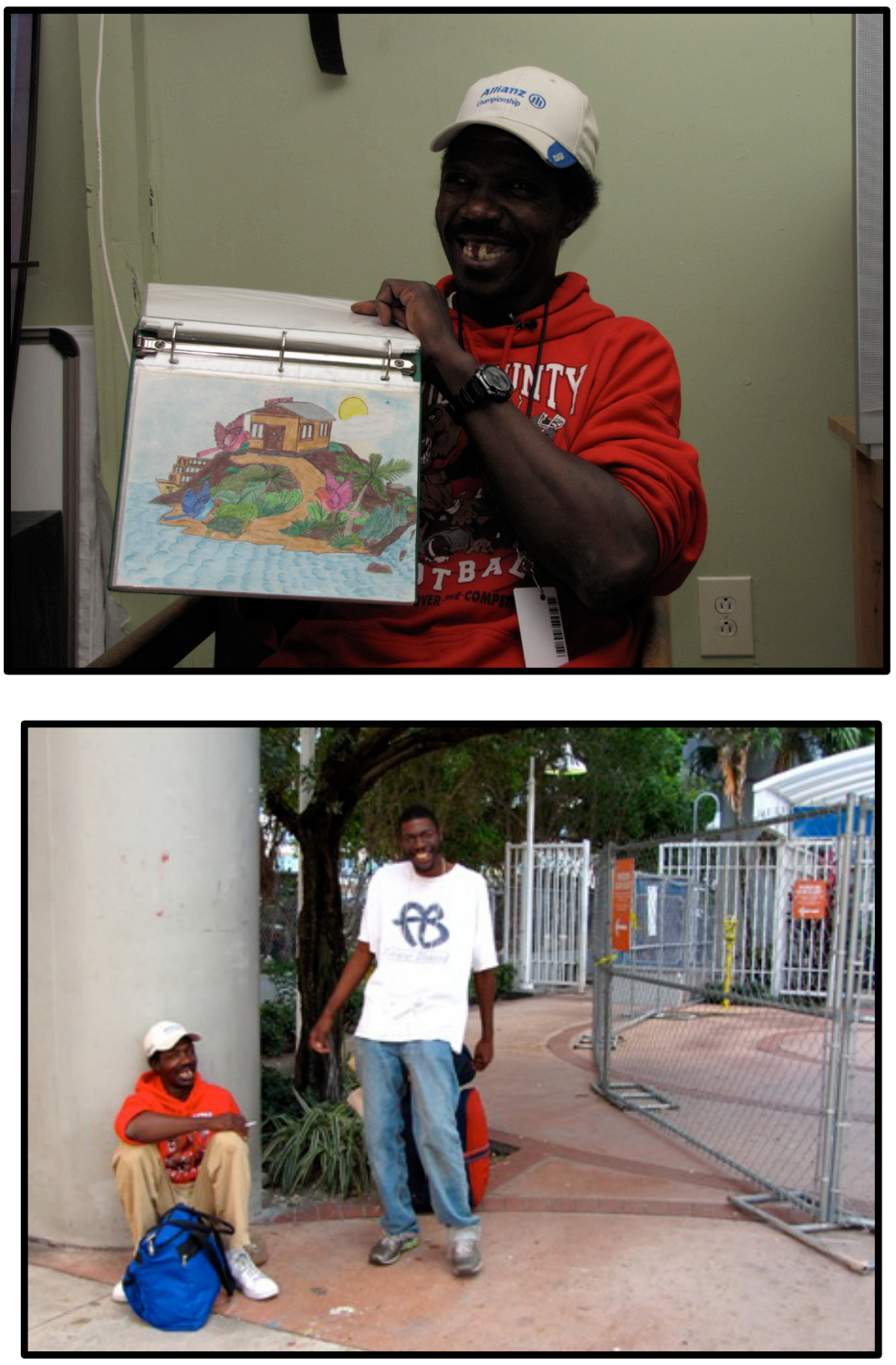

Arthur was proud to be an artist, and he earned money by charging $\$ 5$ or $\$ 10$ for pictures he sold. Here, he showed each of the pictures he'd recently completed, describing not only the drawing but also the person who'd asked for it.

"And this is one of my best pictures. They ordered it but they didn't come pick it up. And this is one of my prized pieces. That's one of my prized possessions."

Arthur (and his friend Robert) spent most of his days at the MetroMover station next to Miami-Dade College. It was important to Arthur to show that he was not a panhandler, but rather earned income by selling his drawings. His blue bag - his only possession - was filled with art supplies and drawings. Many students stopped to say hello as they passed by during the interview, and Art considered them all friends:

"And, some days I get a lot done, some days I have more fun talking to the kids. They talk to me about they little problems, you know and some kids go through what we went though in life, and some of 'em just look for someone to pour their hearts out too and they can't talk their parents about something." 
For persons who were formerly homeless, the photos focused almost exclusively on showing off their apartments, exhibiting much pride with how well they were now doing. This was closely tied up with their desire to be in the photographs themselves, to demonstrate that they were happy with their lives. Paul brought the researcher on a tour of his entire building, pointing every amenity it had. He had never believed he would live somewhere with a library and a fitness center. Two of the individuals insisted on being photographed with an agency staff member or outreach worker who had helped them. Jackie, for example, went to get his outreach worker who was outside, stating he wanted his picture "With Mr. Willie. That's my favorite thing, Mr. Willie."

Persons who were at-risk of homelessness were the least likely to want to be in the photographs, expressing embarrassment over their situation. They tend toward photos that depicted things that were broken (a car, a window, the air conditioning), emphasizing how frugally they were living in an attempt to get by. Individuals sharing housing with friends or family showed how crowded their space was, and how much they lacked privacy:

\section{Figure 48:(photo) Jorge, in small bedroom with belongings}

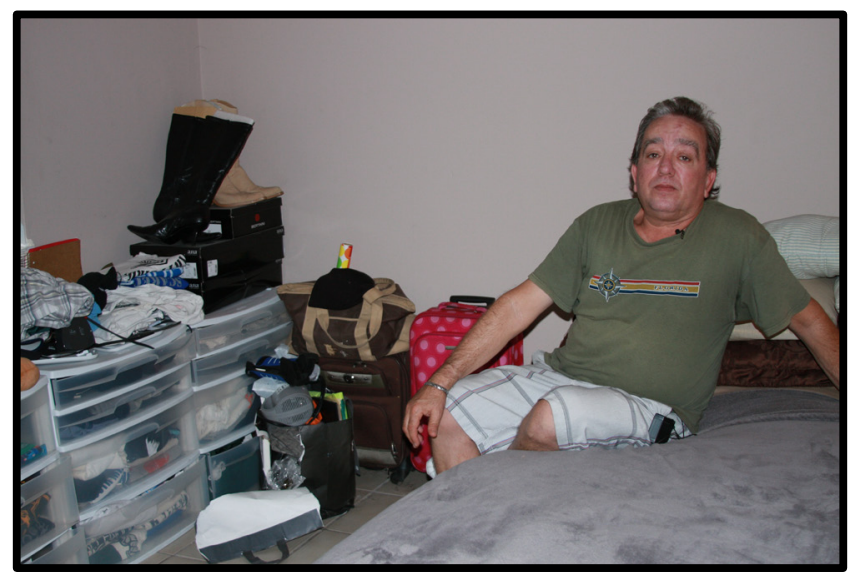

Jorge was embarrassed to have to live with his daughter, keeping all of his belongings in the corner of a bedroom. Dependent on family for support, lacking a space of his own, he was depressed and giving up hope. The lack of privacy and control over his own life was terrible for him:

"It's like, like being in a prison without being a prisoner." 
The interviewees were generally happy to take the researcher on a tour of where they lived, slept and spent their days. Whether they were happy with their situation or unhappy about it, they wanted the world to know how they lived. So, how else did the subjects portray their lives?

\subsection{Portraying One's Self}

Another avenue for analyzing the photos is to examine not just the content the subjects chose, but also the way in which they chose to portray themselves. Specifically, did they smile or not? Subjects were not given any direction regarding how to pose for a picture. While they may have smiled, or not smiled, for many reasons, their choice could be interpreted at least in part to reflect how they wanted to present themselves, and their feelings about their situation, to the rest of the world. In their interviews, some subjects expressed satisfaction, happiness, or hope about their lives, while others expressed stress, unhappiness, and resentment. This section examines whether there is a difference in the face subjects present to outsiders that correlates with their living situation and/or race/ethnicity

Figure 49 shows the difference between blacks and Hispanics in the emotion they expressed in their photo, or whether they wanted to be in the photo at all. It shows that $81.5 \%$ of blacks were smiling in the photos, while only $38.1 \%$ of Hispanics smiled. It is possible that the difference is simply a cultural difference in how to pose for a picture. However, when looking at all the pictures, the expressions of subjects give the impression that overall Hispanics were much less happy to be in their current situation. 
Figure 49: \% of Homeless/At-Risk Men Smiling in their Photos

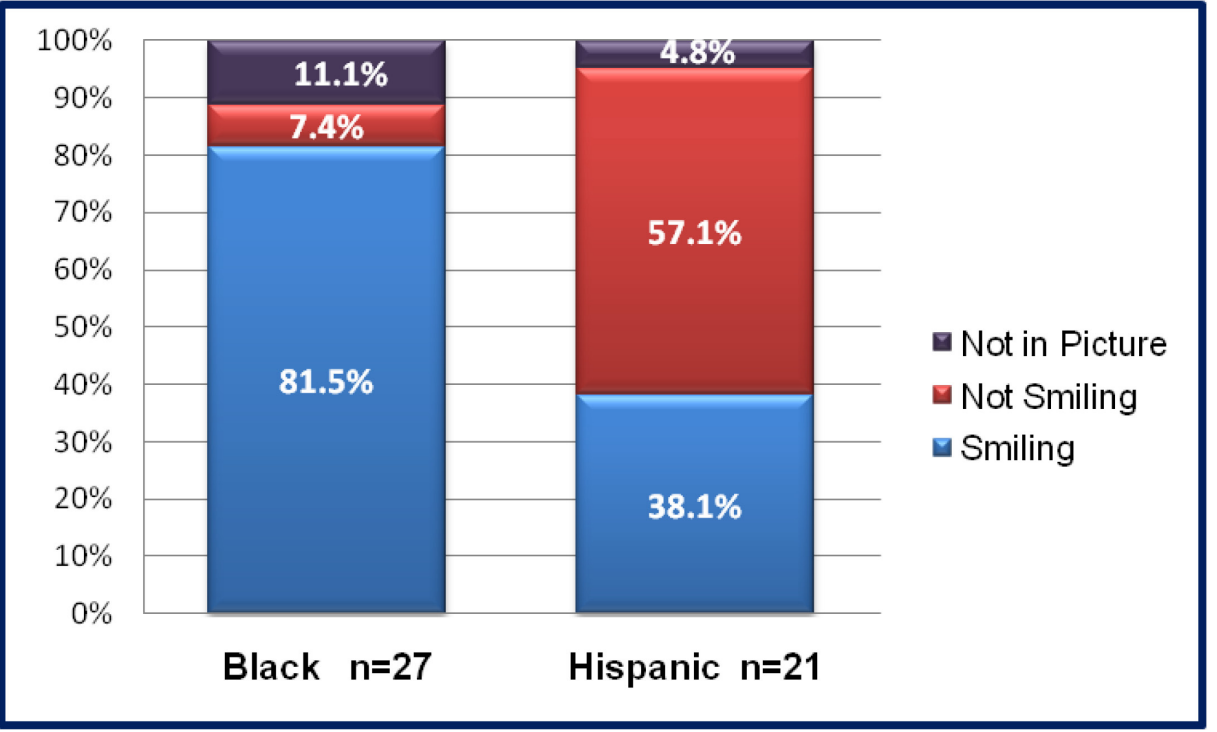

Source: Researcher Interviews

Figure 50 shows the difference in expressed emotions based upon whether they were living on the street; were formerly homeless; or were at-risk but had never been homeless. This shows that people who had previously experienced homelessness in their lives, but were currently housed, were much more likely to appear happy, with fully $86.4 \%$ smiling. Whether or not they were truly happy cannot be determined, but that is the impression they want to give. Persons who were at-risk, but not yet homeless, showed the least happiness, with only $25 \%$ smiling. However, this category was particularly small $(n=4)$ because so many people who were at-risk turned out to have been homeless before. Approximately half (55.6\%) of persons on the street expressed happiness or satisfaction. 
Figure 50: \% of Homeless/At-Risk Men Smiling in Photos, by Housing Status

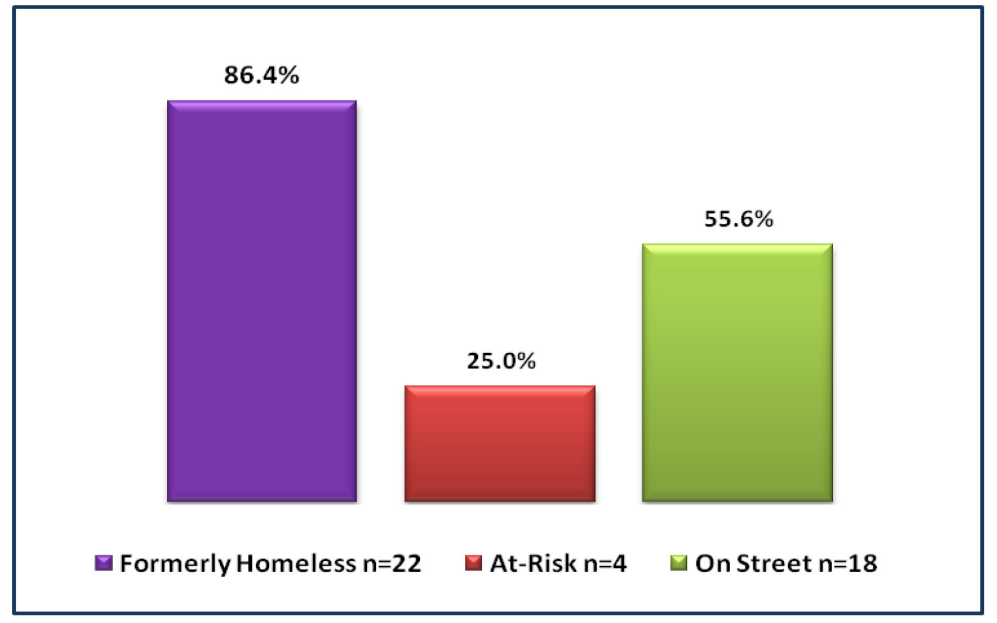

Source: Researcher Interviews

Several themes emerged during the interviews. For persons on the streets, they spoke of misery, but also sometimes of acceptance, or freedom. Persons who were formerly homeless were grateful, but frequently expressed a fear of going back. Persons who were at risk for the first time were stressed, unhappy, and sometimes resentful.

\section{Living on the Street}

For persons living on the streets, Hispanics generally spoke more of misery and blacks spoke more of acceptance. Hispanic comments tended to include expressions of distress. They had not adjusted to life on the streets: 


\section{Table 19: Hispanic Interviewees Comments re Life on Street}

“...my mental condition was such that I wanted to kill myself."

"Well homeless you don't have anything, not even happiness, you don't have anything that can be life in something, an advance, nothing, and it's suffering, crying, and sleeping.

"But it's not fun to be waiting in those lines. A lot of people don't shower, a lot of people like to fight, a lot of people are usually drinking. So it's not the best place to be in."

"Imagine all this stress out here all day, you gotta carry that, I don't have storage, I got carry all my stuff, I ain't got no storage....It's crazy life."

"I no like that. I never be homeless."

"It's very difficult for one, because after you have a regimen of a different life, and to see yourself, it's hellish, it's not easy."

Source: Researcher Interviews

Blacks, on the other hand, seemed to have lower expectations. Most comments

indicated acceptance of life on the streets. In fact, five individuals $(38 \%$ or $5 / 13)$ used the

exact same phrase of "It is what it is," unprompted. Even when pointing out the

hardships, they were also quick to point out the ways they dealt with it, both physically

and emotionally.

\section{Table 20: Black Interviewees, Comments re Life on Street}

"You know I take it as it comes. So, other than that I'm alright, I go to my cousin's house to take a bath."

"So you got to accept what it is and life still got to go on, no matter what. It is what it is, life still gotta go on."

"But you gotta keep a sense of humor about this whole thing, you gotta keep some perspective.... There's gonna be better days. It's gonna be better day. It may get rough before it gets better, but it's some better days coming....I'm already low enough so if I fall on the floor, it ain't gonna hurt, you know?"

"So everything happens for a reason, and a purpose, so I don't know why it's happening to me but I can't question God so I'm just waiting, just waiting."

"Life is what you make it, life is what you make it, everybody got a chance in life as long as you're breathing, know what I'm saying, it's what you make it.

"And if you make the streets hard, it gets harder. But if you get up every day and just be grateful for what you have because there's people in this world don't have nothing, and this is how I look at my everyday life, is that I'm grateful for small things, instead of looking for greater things."

"And them choices that we made, we're just living it." 
Blacks were also more likely to blame themselves for the situation, saying things like, “There are always consequences. I'm reaping what I've sown. So I have to apologize to people I've hurt and that will make me a better person." However, those who directly blamed themselves were using language similar to that used in drug or alcohol treatment programs, where acceptance of one's own role is a central tenant. Thus, the fact that most blacks on the streets had histories of drug abuse suggests that many had been in treatment programs where they had learned to claim responsibility for their situation.

Freedom was also a common theme amongst black respondents. Approximately $69 \%(9 / 13)$ spoke of the freedoms that come with life on the street. Some spoke of freedom in the context of not feeling they were ready to take on the responsibilities of rent and bills. However, many of these same individuals talked about their desire for a job, and the difficulty in attaining one, so taking on responsibilities for rent would be a daunting task without income. When prodded more, most indicated they would rather leave the streets if they had other options. Some respondents explicitly linked their desire for freedom to previous periods of incarceration. Years of confinement, behind bars with few windows, led them to prefer staying outside as much as they could. More importantly, they did not want anyone telling them what to do ever again. Any rules, particularly the rules and curfews associated with many shelter programs, were something they simply were not going to tolerate: "After being, going to jail for awhile, you hate how that people tell you when to eat, when to go to sleep, when to get up, when to go to bed and that's frustrating." 


\section{Figure 51: (photo) Wilbur on downtown streets}

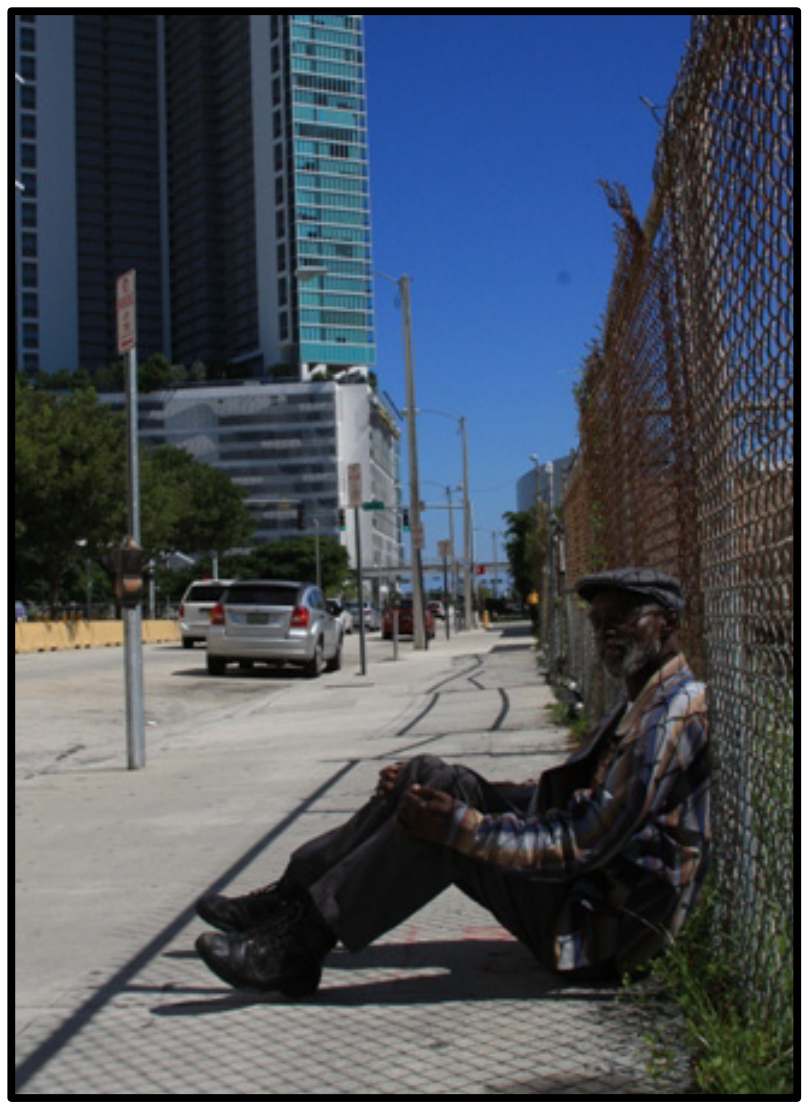

Wilbur is ambivalent about the 15 years he has spent living on the streets of downtown Miami. He made few complaints during the interview, other than a wish that the police would stop harassing him for various activities. Here, he sits on the sidewalk where he frequently sleeps, with new condos and American Airlines arena in sight a few blocks away. He's glad to make money parking cars during events, but resentful of the increased police sweeps that take place before basketball games now. With his long arrest history and drug problem, he doesn't see much opportunity for regular employment, but, given a chance, he would want to leave the streets. Speaking of others who received disability benefits but remained on the streets, he explained their decision but still spoke of wonder at their choice:

"There's some people on the street right now with checks that wont' even get a room, been on the street so long you can't put him in a room. They don't want to pay no bills. I had a guy the other day tell me I don't want to pay no bill. I said man, you get a check, you can at least get a room! He says, man I ain't getting nobody my check. I says, man, you're crazy, get a room. You can have tv, refrigerator, eat what you want man."

\section{Formerly Homeless}

Persons who had previously been homeless were the happiest of those

interviewed. As shown in Figure 50, 86\% were photographed smiling. Additionally, in this area, Hispanics were also proud of their new lives, expressing less displeasure than their homeless and at-risk counterparts. Both black and Hispanic subjects were proud of their apartments and new lives, and wanted to show the world how well they were now doing. They bragged about having bills to pay. Marlon was typical of subjects who wanted their apartment itself photographed as symbolic of how far they'd come: "Show 
them my apartment. So you can show 'em all, you can say, 'Hey boy, this is, this is where he live. See, you can have all of this, if you do what you gotta do.'"

\section{Figure 52: (photo) Dudley in his own apartment}

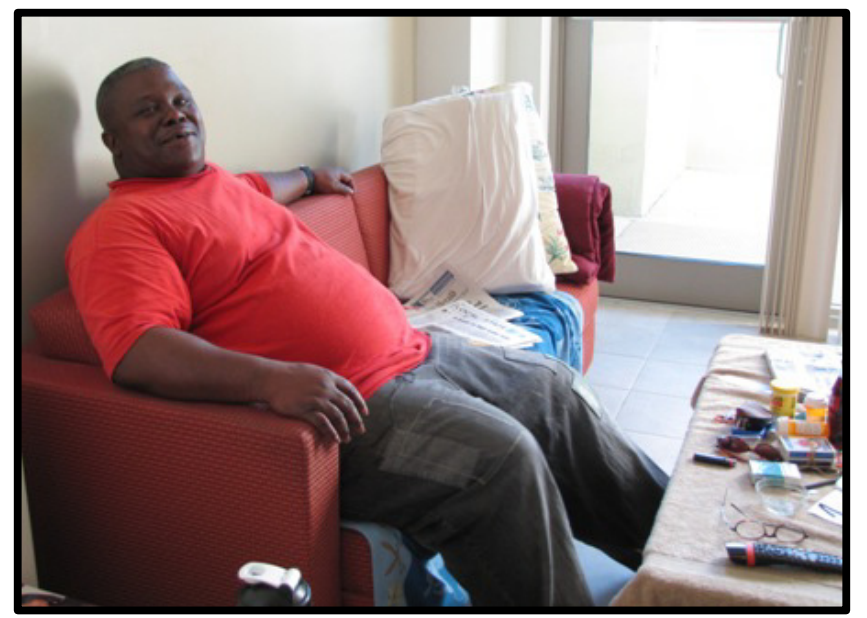

Dudley, a recovering addict who'd spent years bouncing between family, friends, prison, and the streets, was proud to be living in his own apartment in a supported housing program. He wanted to be photographed sitting on the couch, where he spent as much as time as possible enjoying the calm and simplicity of his new life:

"All the time, much as possible. I mean, the remote control, you see where it at, where I can reach it. I got another TV in my room that I bought. With a DVD player so I've been watching DVDs and watching TV. If I wanna bring a friend over, I can."

The one area where the formerly homeless group expressed any negativity was

regarding their fear of going back to homelessness. Some were at risk, having lost jobs or struggling with reduced hours. When asked to describe the most difficult part of their life right now, they talked about their desperation to find enough employment to keep themselves housed:

\section{Table 21: Formerly Homeless Men, Comments re Fear of Going Back}

'I'm in the process you know, I don't care, a dishwashing job, I don't care right now what it is, as long as I can work....the thing is, I don't want to become homeless. People look at you, 'oh what happened'",

"Keeping income, steady income, and paying my bills on time, it is very important to me right now. Even though I might be broke, but I have a roof, you know what I mean. I won't have to back to the streets, you know."

"The difficult part? Um, trying to hold on to keep the place here. Trying to keep from going back on that sidewalk, and sleep outside."

"The most difficult thing in my life right now, I'm just trying to get me a full-time job. If I could get me a full-time job, I mean, things would go so smoothly. Trying to manage from, living paycheck to paycheck then trying to paying my rent because I don't want to become homeless." 
In spite of their frustration at not being able to attain better employment, they still returned to their gratefulness, and their recognition that life was better now than it used to be. They lived simply, in efficiencies and one-bedroom apartments in low-income neighborhoods, but they were proud to show off their furniture, their clean kitchens, their closets. No matter how small or sparsely furnished, it was better than where they'd been.

\section{At-Risk of Homelessness}

The group of persons at risk of becoming homeless were the least happy group.

Of the four who allowed themselves to be photographed (one declined the photos at all, and three declined to be in the photographs), only one smiled. They described themselves as stressed out and frustrated. The Hispanic group were all individuals who had worked and earned higher incomes before either becoming sick or retiring with little income, and they reminisced about how much better their lives had been before they'd fallen on hard times. Several had been forced to move in with friends or family, and the lack of privacy, and having to live under someone else's roof and rules, was an issue.

\section{Figure 53: (photo) John in shared living space}

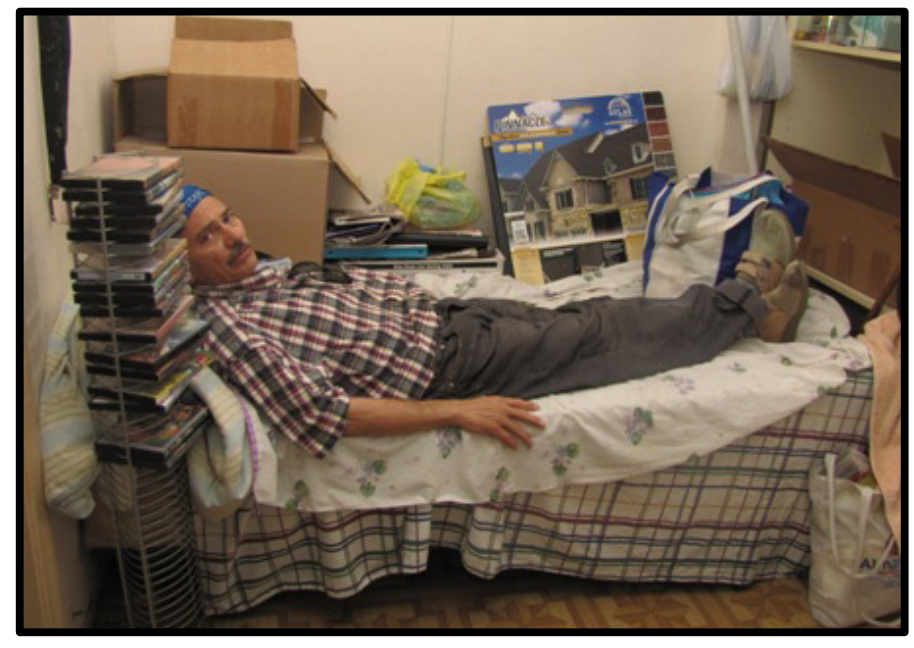

John had unsuccessfully looked for a job for more than a year. Sharing a studio with three men, his tiny bed was crammed into a nook in the living room, with all of his belongings stacked in boxes around him. He lamented his old life:

"Yeah, I had my own apartment and uh I had my furniture and stuff and I had a car. Uh, you lost a job and uh you're stuck now 'cause you got no money to pay for rent and things like that and even when I was working I was just getting by. I was making good money but I was getting by with that cause I had to pay all bills. You know." 
While all of the subjects fell into the category of persons contending with extreme poverty, their attitude toward it was usually dependent on their stage within the continuum between homelessness and housing. Having experienced homelessness, and then escaped it, gave individuals a perspective that no matter what, their life could be worse. Blacks were more likely to indicate a desire to make it on their own, without asking for more public benefits. Some Hispanics who were receiving disability benefits found themselves still struggling on the extremely low, and limited incomes, and expressed dismay at the prohibition against them earning more income on their own. Yet, when pressed, they still indicated they were mostly happy with their life.

\subsection{Causes of Homelessness}

When asked what could be done to end homelessness, both blacks and Hispanics gave similar answers. The number one answer was jobs; number two was affordable housing. Blacks also talked about a need for more programs, but specified that they wanted programs that would help them get back on their feet to be independent again. Drug treatment and education were the types of programs they wanted to see more of. Blacks and Hispanics also had different answers regarding what causes homelessness. As Figure 54 shows, blacks were more likely to blame the economy and a lack of jobs, while Hispanics were more likely to blame drugs or choice. Frequently, when talking of drugs as the primary cause of homelessness, Hispanics pointed out that they were referring to others and not to themselves. They felt that others were using benefits to feed drug habits, or were simply too lazy to take responsibility for their lives. 
Figure 54: Interviewees Perceptions of Causes of Homelessness

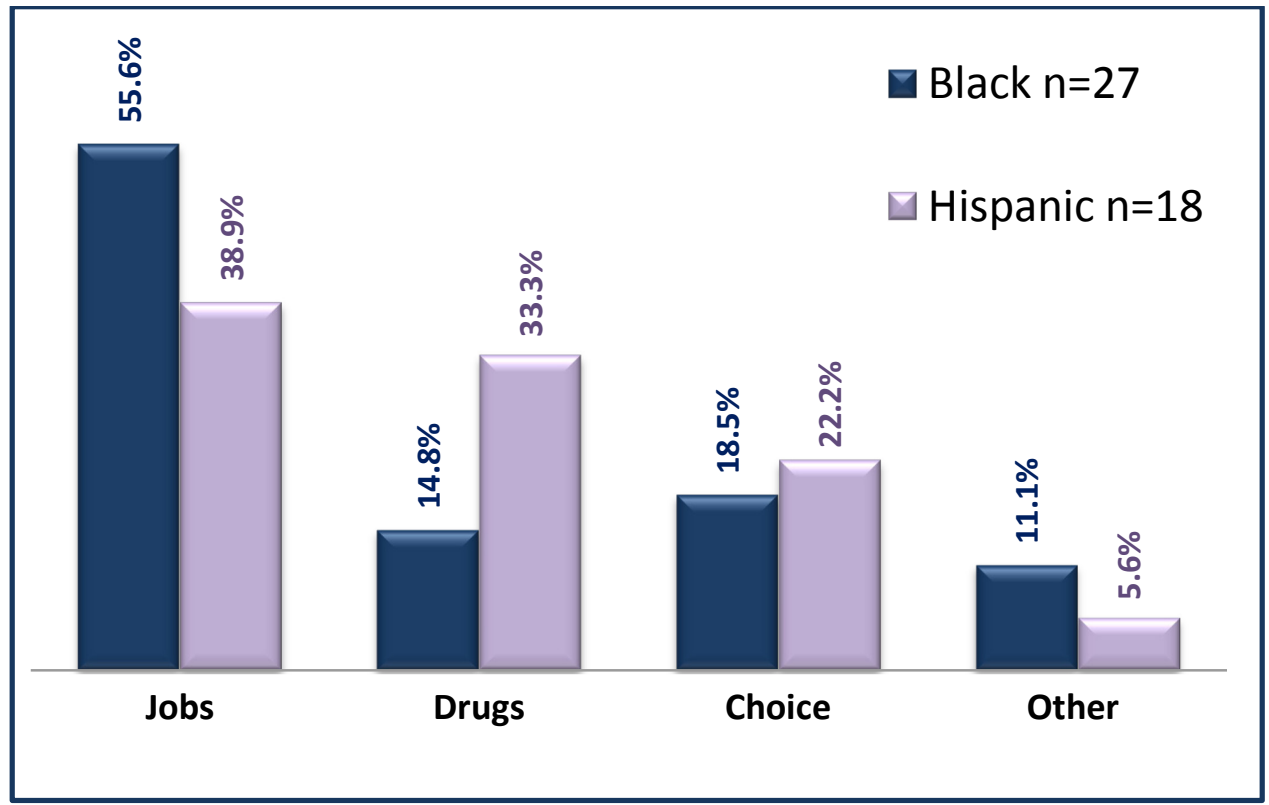

Source: Researcher Interviews

Additionally while blacks pointed to jobs as the number one cause of

homelessness, they also tended to qualify their answers by emphasizing the uniqueness of each individual's situation. Warren, for example, was reluctant to point to any one factor:

"Bad decisions, mental illness, depression, drug abuse. Um, you know, uh, turn of events in life, you know what I mean, some people lose their jobs, you know, uh separate, divorce, break up, it's a lot of different things, you know. Um, it's hard to just look at someone and determine how they got there you know what I mean?"

\subsection{Homelessness and Race}

In discussing the causes and solutions to homelessness in the context of race, the vast majority of subjects indicated that they did not believe blacks and Hispanics experienced much difference when it came to being homeless, or to accessing resources to exit homelessness. They felt once they had become homeless, their treatment by the 
public was the same, whether positive or negative. Additionally, they generally felt that their treatment by homelessness provider agencies was the same. The consensus was the homelessness is a class that supersedes race:

\section{Table 22: Interviewees Comments re Homelessness and Race}

“Let me tell you, there's no difference, not at all. Because in society people look at homeless people, no matter what color they is or whatever, a bum is just a bum you know, they gonna treat you the same way."

"When you're homeless, it don't matter what color you is, homeless don't know no color."

"I don't believe there's a difference. I believe the important thing is how you go through the survival journey."

"Nah, it's the same. Homeless, it's hard anybody, it don't matter."

"I don't think there's any difference, you know, I think that um everybody got their fair share of pain everybody got their share of help, you know what I mean."

"Not at all. Any which one, it doesn't really matter who you are at all. The situations come out of the dark, you don't even see it coming for different reasons, from bills, friendships, relationships, addictions, so many different others."

"Homeless don't have no color line. And if you out here on the street, you see every race."

"No. (laughing) It used to be, but we're in the same boat now."

"I don't for this purpose. I think if you Hispanic or you Black and you homeless, if they open up a shelter down there and it's open and you welcome to come there and rest.'

"I don't care if you green, purple, orange, whatever you come from. I mean, when you come in, when you come in to Miami, it's a struggle, and you got people that's coming here every day."

"It's equal discrimination."

Source: Researcher Interviews

However, there were some areas where some subjects did perceive differences in experiences for blacks and Hispanics. A number of blacks expressed feeling at a disadvantage in the labor market, for a variety of reasons. This included feeling that Hispanics had an advantage for being bilingual, and that Hispanics did a better job as a group of helping and hiring their own. Amongst those who spoke of the capacity of Hispanics, and particularly Cubans, to help each other, they did not begrudge Hispanics for their advantage, but rather lamented that blacks had failed to do the same thing. 
Thomas explained the feelings of several interviewees when he questioned why blacks hadn't been able to build the same types of support networks as Hispanics, particularly when it came to hiring:

You know what, it's like an inside job with Hispanics. We don't have any inside people, we got Mr. Jones (social worker) but we talking about people outside somewhere. I see what our kind, us blacks, we don't help each other like they help each other, we don't. I don't see that."

Others noted that they didn't necessarily blame racism, but they couldn't help questioning why the unemployment rate was so much higher for blacks: "I wouldn't say race plays a factor, but I would say that the majority of the men unemployed are black males, young black males." And another put it more succinctly: "The majority of the black men are out of work. I don't figure that." Aside from talking about their ability to gain employment, blacks didn't bring up other differences between races.

Hispanics saw differences in two areas. A few brought up feeling disadvantaged because so many Hispanics started out without legal documentation that would allow them to work, whereas blacks were born with it. And, several Hispanics attributed black homelessness to higher drug use and more criminal activity. For the most part, though, Hispanics felt that blacks and Hispanics had fairly equal opportunities to avoid or exit homelessness.

\subsection{Summary of Findings on Perceptions}

The experience of being poor and homeless is difficult to survive, and to exit. In this chapter, I examined the subjects' own perceptions, focusing on the last two hypotheses from research question 3. These were: a) Black and Hispanic men who are homeless or at risk of homelessness do not express different opinions regarding how 
they believe they are treated by others and provided access to helpful resources; and

\section{b) Black and Hispanic men who are homeless do not express different opinions}

regarding the experience of being poor and homeless. Findings show some support

for these hypotheses, although nearly all subjects agreed that the experience of

homelessness itself actually superseded race. While blacks and Hispanics exhibited some

suspicion of advantages held by the other group, they overall agreed that poverty and homelessness was hard on all of them alike.

There were some differences expressed by blacks and Hispanics. Blacks were more likely to blame homelessness on lack of jobs, with more than half (55\%) naming employment as the primary cause, compared to only $36 \%$ of Hispanics. Blacks were also more likely to express feeling disadvantaged by their race in the labor market, pointing to the necessity of speaking Spanish for many jobs, as well as for the tendency of Hispanic business owners to hire Hispanic employees. They lamented the fact that blacks did not own more of their own businesses so as to be able to build that same sort of community capital.

The men interviewed for this study were acutely aware of how society perceived them, and wanted to show the world how different their lives were from how they were portrayed and perceived. Given the opportunity to choose for themselves how they would be depicted, they focused on showing the difficulties of where they lived, how simply they lived, and how they tried to support themselves. As would be expected, having exited homelessness was a far better feeling than being on the verge of homelessness. 


\section{CHAPTER 9: CONCLUSION}

"Ok, let's flip the script. Give me your wealth and you take my poorness. You wear the other shoe. Let me wear your Gucci's and you wear my flip flops and you tell me the story." - Jimmy

Poverty and homelessness are complex issues with myriad causes generated at many levels. Yet, no matter what global phenomenon has triggered a housing crisis or an economic recession, the results are felt at the individual level. For black and Hispanic men living in poverty and homelessness in Miami, their lives are a daily struggle, limited to choices largely out of their control. It has become popular amongst politicians and the media to portray persons who are poor as lazy, and undeserving of resources. Many individuals who have themselves achieved success in life expect others to do the same, but pay little attention to whether or not persons who are poor or homeless even have the option. For the men in this study, attempting to earn their way out of poverty and homelessness has been a long and difficult struggle, often with little results.

This dissertation has sought to answer a number of questions regarding the experiences of single men, focusing in particular on differences between the experiences of black and Hispanic men in Miami. After all, even when controlling for living in extreme poverty, blacks become homeless at far greater rates than their white or Hispanic counterparts. Do blacks experience different reasons for becoming homeless? Do they have different experiences and outcomes in avoiding or exiting homelessness? How do they negotiate their daily survival? And, what are the choices available to them as they attempt to escape homelessness and poverty? The previous chapters demonstrate that there are real differences in how blacks and Hispanics negotiate extreme poverty and homelessness in Miami. 
Focusing on single men contributes to the existing body of literature by highlighting the difficulties experienced by this group, which is excluded from many forms of benefits available to women and children. After welfare reform a great deal of research examined the affects of welfare changes on women and children, including studies of how they utilize public and private resources to get by, but not as much focused on the plight of single men. Additionally, little research on homelessness has been conducted specifically in the Miami community. As an urban center at the forefront of globalization, but still struggling with extreme income inequality, Miami can have much to offer as an example to other cities. Studying how minority men negotiate their survival in this context can help inform public policy. Additionally, incorporation of the voices of the subjects themselves can help dispel myths about their lives, painting a new, more accurate picture of what it is actually like to be poor in a modern urban center.

The findings of this study contradict the common discourse heard through the media and political debates that poor and homeless are lazy. Given a fair choice, the vast majority of poor and homeless men interviewed for this study, including both blacks and Hispanics, would choose to earn their own income. The desire to support themselves was the most common theme in all of the interviews. In some cases, this was out of pride. Nobody wants to be considered a "bum". They wanted to be active, engaged in society, and a source of pride for their families.

In other cases, it was out of recognition that an earned income would be higher than any welfare benefit. Indeed, trying to live on welfare benefits alone was extremely difficult. With the maximum SSI disability benefit capped at $\$ 698$ a month, an amount lower than most rental units in the county, living on SSI alone virtually guaranteed a life 
of poverty. Two types of people chose this avenue: persons with serious disabilities who had no capacity to work and no family to help; and persons who had so given up on finding employment that they saw a disability check as their only option for getting off of the streets.

Why do so many men in Miami have such difficulties finding employment? The reasons are closely bound up with race and ethnicity. For blacks, their rates of incarceration and resulting felony records were extremely high, with the vast majority of respondents unable to attain any job that required a background check. In spite of having served their time, they were permanently locked out of the regular labor market. On top of that, the recent recession had eliminated one of the only sources of potential employment for persons with low skills and criminal backgrounds: construction, and particularly day labor.

Society does not want to see people sleeping on the streets, and thus a set of resources have been put in place meant to prevent and alleviate homelessness. Many of these have been successful in helping millions of individuals and families to stay housed, or quickly exit homelessness. Public benefits, including the Temporary Assistance to Needy Families (TANF), and Section 8 housing vouchers are meant to help persons most in need. Yet, TANF is only available to families with children, and Section 8 has been winding down, with no new vouchers provided from the federal level. Thus, the only cash support available to most men is Social Security Income/Social Security Disability Income (SSI/SSDI). If they are not disabled, they are left to fend for themselves.

There are still several areas where the safety net has functioned for single homeless men. Health care for persons who are homeless is readily available in Miami- 
Dade, and this study's subjects reported great satisfaction with their access to care. Unfortunately, they had to become literally homeless before it became available. The safety net in this case exists, but it is so low that it has limited impact.

The other area that seems to function well is the provision of Supplemental Nutrition Assistance Program (SNAP), or food stamps. While not enough to live on alone, most respondents were receiving it, and nobody reported suffering from extreme hunger. SNAP, when mixed with the many other food resources available in Miami, was doing a good job of providing enough food for people to survive.

The findings in this study suggest areas for further research. While this study identified numerous areas where there are differences between blacks and Hispanics in how they experience poverty and homelessness, the relationships and potential causalities leave much room for further exploration. In particular, the association of blacks with drug and alcohol disabilities and related treatment programs, and of Hispanics with mental health disorders and related programs, is an area for further study. Are blacks more likely to request drug and alcohol treatment because they are being referred to treatment programs where they are diagnosed as addicts? Are Hispanics more likely to be diagnosed with mental illness because they are being referred to programs that focus more on mental health than on drug addiction? Are Hispanics more likely to seek benefits because they are mentally ill and unable to work, or are they more likely to declare that they have a mental illness because this can facilitate attaining benefits?

Findings here also suggest different patterns of utilization of social capital and other resources amongst blacks and Hispanics, compared to other urban centers such as Los Angeles. Whereas in Miami it appeared that homeless blacks had weaker social 
capital than Hispanics, similar studies in Los Angeles have found that black living on the streets demonstrated stronger social capital than Hispanics. At the same time, Miami blacks expressed greater desire to find employment compared to Hispanics, who were more likely to be seeking benefits, while in Los Angeles it was Hispanic and immigrant groups that were focused more on attaining employment. The fact that the findings are reversed in these areas suggests that the utilization of social capital and resources may be dependent more on place, with the behavior of racial/ethnic groups influenced by specific time and place, rather than solely on the "culture" of any specific racial or ethnic group. Another area for further research would be the relationship between perception of resources and the actual availability of resources. Many of the men in this study seemed to have given up hope. They exhibited diminished expectations out of society, out of themselves, and out of life. How correct are they in believing they will not be able to find employment or attain benefits? Do they have more choices than they believe? What could be done to provide them with more viable choices for assuming control of their own lives again?

I would also suggest that future research should continue to highlight the voice of poor and homeless men. The men in this study wanted to send a message to the world. They expressed gratitude for being included, as they felt they were frequently left out of the national conversation about themselves. When given the opportunity to share what was important to them, to tell a story about their lives, they chose to focus on their desire to earn an income, and to demonstrate that they were neither lazy nor greedy. It was not welfare benefits that they wanted, but rather the opportunity to maintain a decent standard of living. 
The Miami community has taken great strides over the past 20 years to implement a homelessness services delivery system that is flexible, effective, and responsive to the needs of persons living on its streets. The programs and services developed were generally well-regarded, and have clearly had a tremendous influence on improving the lives of tens of thousands of individuals. But the organizations working to address and end homelessness cannot fix the larger issues by themselves: homelessness will be ended when there is enough affordable housing to go around and there are enough jobs for people to pay for it.

At the beginning of this dissertation, I recalled the metaphor of homelessness being like a game of musical chairs, where housing is the chairs, and vulnerable populations are the ones jostling for a seat when the music stops. The men I interviewed in this study knew they were in that game of musical chairs, and had given up hope on ever winning. They were older, less educated, and more disabled than the rest of the players. They were members of racial and ethnic minority groups. They had been born into poor neighborhoods and lacked the social connections needed to find good jobs. Still, the majority of them had not given up on finding a way to support themselves, whether through earned income or attaining benefits.

Poverty and homelessness in the United States has been so pervasive for so long that it is almost accepted as an unfortunate, but inevitable, outcome of capitalism and modernity. For many in the mainstream, homelessness is seen as a condition resulting from an individual failure to properly compete, to make the most of the freedoms and opportunities afforded by modernity. For those living it, though, it is a terrible daily struggle to survive in a world that has left them out. They live lives of exclusion, from 
housing, from job opportunities, from good schools, from nice neighborhoods, and from networks with friends and family able to offer support. It is true that as individuals they have agency over their daily lives. But that does not mean they have access to the same resources and opportunities as the rest of us. Those with access to lots of social capital will do well; those without it will inevitably struggle. Ultimately, agency and social capital are about power: who has it, who doesn't, and how it is retained, accessed, or denied.

In my dissertation I have explored how much agency and choice minority men actually have, finding that their choices are very limited. Marx has remarked that actors make history, but not in circumstances of their own choosing. While it is easy to say that the poor should pull themselves up by their bootstraps, we need to make sure they have any bootstraps to begin with. Hopefully, the stories shared by the men in this study will help to inform future public policy surrounding how they are addressed and portrayed in contemporary society. 


\section{REFERENCES}

"Personal Responsibility and Work Opportunity Reconciliation Act of 1996."1996. 42 USC(1305).

"Stewart B. McKinney Homelessness Assistance Act of 1986."1987. 42 USCS(11302).

"'Welfare Queen' Becomes Issue in Reagan Campaign."1976. New York Times, Feb. 15, 1976, .

ABT Associates. 2011. 2010 HUD Annual Homeless Assessment Report. Washington, DC: US Housing and Urban Development.

Agnew, John. 2005. Hegemony. Philadelphia, PA: Temple University Press.

Areavibes. 2012. "Overtown, Miami, FL Employent and Jobs Overview." Miami, FL: Area Vibes Inc., Retrieved 9/15, 2012 (http://www.areavibes.com/miamifl/overtown/employment/).

Atkins, Senior US District Judge. 1992. "Pottinger v. City of Miami Case 88-2406-CIVATKINS.". Retrieved August 10, 2012 http://osaka.law.miami.edu/ schnably/pottinger/pottinger.html.

Badenhausen, Kurt. 2012. "America's most Miserable Cities." Forbes Magazine, February 2, 2012, . Retrieved

9/15/2012 http://www.forbes.com/sites/kurtbadenhausen/2012/02/02/americas-mostmiserable-cities/.

Baggett, Travis, James O'Connell, Daniel Singer and Nancy Rigotti. 2010. "The Unmet Health Care Needs of Homeless Adults: A National Study." American Journal of Public Health 100:1326-1333.

Banks, Marcus. 2001. Visual Methods in Social Research. Thousand Oaks, CA: Sage Publications.

Barnes, Sandra L. 2005. The Cost of Being Poor: A Comparative Study of Life in Poor Urban Neighborhoods in Gary, Indiana. Albany, NY: State University of New York Press.

Bassuk, Ellen L., John C. Buckner, Linda F. Weinreb, Angela Browne, Shari Bassuk, Ree Dawson and Jennifer Perloff. 1997. "Homelessness in female-headed families: childhood and adult risk and protective factors." American Journal of Public Health 87(2):241-248. 
Bassuk, Ellen L. and L. Rosenberg. 1988. "Why does family homelessness occur? A case-control study." American Journal of Public Health 78(7):783-788.

Belle, Deborah E. 1983. "The Impact of Poverty on Social Networks and Supports." Pp. 89-103 in The Ties that Bind: Men's and Women's Social Networks, edited by L. Lein and M.B. Sussman. New York, NY: Haworth Press.

Biscayne Bay Residents Association. 2009. "Board Meeting Minutes for April 8, 2009.". Retrieved July 20, 2012 www.baysideresidents.homestead.com/BRA_minutes_040809.doc.

Blau, Joel. 1992. The Visible Poor: Homelessness in the United States. New York, NY: Oxford University Press.

Bolton, Megan. 2012. Housing Spotlight: The Shrinking Supply of Affordable Housing. Washington, DC: National Low Income Housing Coalition. Retrieved August 5, 2012 http://nlihc.org/sites/default/files/HousingSpotlight2-1.pdf.

Bourdieu, Pierre. 1986. "The Forms of Capital." Pp. 241-258 in Handbook of Theory and Research for the Sociology of Education, edited by J.G. Richardson. New York, NY: Greenwood Press.

------. 1977. Outline of a Theory of Practice. English Language Translation ed. New York, NY: Cambridge University Press.

Bowie, Stan L., Carol D. Stepick and Alex Stepick III. 2000. "Voices From the welfare vortex: A descriptive profile of urban, low-income African American women on the eve of devolution." Race, Gender and Class 7(4):37.

Bradley, Theresa. 2005. "No Shelter from the Storm." Miami Herald, November 9, 2005,

Briggs, Xavier d. S. 1998. "Brown kids in white suburbs: Housing mobility and the many faces of social capital." Housing Policy Debate 9(1):177-221.

Burt, Martha R. and Demetra Smith Nightingale. 2010. Repairing the U.S. Social Safety Net. Washington, DC: Urban Institute Press.

Burt, Martha, Laudan Aron, Toby Douglas, Jesse Valente, Edgar Lee and Britta Iwen. 1999. Homelessness: Programs and the People They Serve - Summary Report of the Findings of the National Survey of Homeless Assistance Providers and Clients. Washington, DC: Urban Institute Press.

Burt, Martha, Laudan Aron and Edgar Lee. 2001. Helping America's Homeless. Washington, D.C.: Urban Institute Press. 
Carpiano, Richard M. 2006. "Toward a neighborhood resource-based theory of social capital for health: Can Bourdieu and sociology help?" Social Science \& Medicine 62(1):165-175.

Castells, Manuel. 2002. "The informational mode of development and the restructuring of capitalism (1989)." Pp. 255-284 in The Castells Reader on Cities and Social Theory, edited by I. Susser. Malden, MA: Blackwell.

Center for Housing Policy. 2012. Paycheck to Paycheck: Housing Rental Affordability Index 2012. Washington DC: National Housing Conference.

City of Miami Commission. 2007. "Meeting Minutes January 2007.". Retrieved 9/15/2012 http://egov.ci.miami.fl.us/meetings/2007/1/1412_M_City_Commission_07 -01-25_Verbatim_Minutes_(Long).pdf:.

Clark-Ibanez, Marisol. 2007. "Inner-City Children in Sharper Focus: Sociology of Childhood and Photo Elicitation Interviews." Pp. 167-196 in Visual Research Methods: Image, Society, and Representation, edited by G.C. Stanczak. Thousand Oaks, CA: Sage Publications.

Coleman, James S. 1990. Foundations of Social Theory. Cambridge, MA: Belknap Press of Harvard University Press.

-----. 1988. "Social capital in the creation of human capital." American Journal of Sociology 94 Supplement:S95-S120.

Collier, John J. 2003. "Photography and Visual Anthropology." Pp. 235-254 in Principles of Visual Anthropology, edited by P. Hockings. New York, NY: Mouton de Gruyter.

Collier, John J. and Malcom Collier. 1986. Visual Anthropology: Photography as a Research Method. Revised and Expanded Edition ed. Alburquerque: University of New Mexico Press.

Crouse, Gil, Susan Hauan and Annette Waters Rogers. 2008. Indicators of Welfare Dependence: 2008 Annual Report to Congress. Washington, DC: US Department of Health and Human Services. Retrieved 6/20/2010.

Crowley, Sheila, Elina Bravve, Megan Bolton and Linda Couch. 2012. Out of Reach 2012: America's Forgotten Housing Crisis. Washington, DC: National Low Income Housing Coalition.

Cruz, Robert. 2012. Economic Situation Assessment: Miami-Dade County Strategic Planning Workshop Presentation. Miami, FL: Miami-Dade County. Retrieved 9/15/2012. 
Cruz, Robert and Robert Hesler. 2011. Miami-Dade County Summary of the American Community Survey 1-Year Estimates Miami, FL: Miami-Dade County Economic Development and International Trade. Retrieved August 2, 2012 http://www.miamidade.gov/oedit/library/2010-acs.pdf.

Danseco, Evangeline R. and E. W. Holden. 1998. "Are There Different Types of Homeless Families? A Typology of Homeless Families Based On Cluster Analysis." Family Relations 47(2):159-165.

Danziger, Sandra K. 2010. "The decline of cash welfare and implications for social policy and poverty." Annual Review of Sociology 36:533-545.

Davis, Mike. 1990. City of Quartz. London, UK: Vintage.

DeVerteuil, Geoffrey. 2009. "Complexity Not Collapse: Recasting the Geographies of Homelessness in a Punitive Age." Progress in Human Georgraphy pending.

------. 2006. "The local state and homeless shelters: Beyond revanchism?" Cities 23(2):109-120.

Donley, Amy and James Wright. 2009. Miami-Dade County Homeless Trust Continuum of Care Evaluation Report. Orlando, FL: Institute for Social and Behavioral Sciences, University of Central Florida.

Edin, Kathryn and Laura Lein. 1997. Making Ends Meet: How Single Mothers Survive Welfare and Low-Wage Work. New York, NY: Russel Sage Foundation.

Ehrenreich, Barbara. 2001. Nickel and Dimed: On (Not) Getting By in America. New York, NY: Metropolis Books.

Eisenhauer, Emily and Carlos Sanchez. 2011. The State of Working Florida 2011. Miami, FL: Florida International University, Center for Labor Research and Studies.

Eslami, Esa, Kai Filion and Mark Strayer. 2011. Characteristics of Supplemental Nutritional Assistance Program Households: Fiscal Year 2010. Alexandria, VA: US Department of Agriculture, Food and Nutrition Service, Office of Research and Analysis. Retrieved

7/28/2012 http://www.fns.usda.gov/ora/MENU/Published/SNAP/FILES/Participation /2010Characteristics.pdf.

Esping-Anderson, Gosta. 1990. The Three Worlds of Welfare Capitalism. Cambridge, UK: Polity Press. 
Eyrich, Karin M., David E. Pollio and Carol S. North. 2003. "An exploration of alienation and replacement theories of social support in homelessness." Social Work Research 27(4):222(10).

Ferguson, James. 2006. Global Shadows: Africa in the Neoliberal World Order. Durham and London: Duke University Press.

Fischer, Claude. 2010. Made in America: A Social History of American Culture and Character. University of Chicago Press.

Florida Demographics. 2012. "Fisher Island, FL Demographics." Cubit Planning, Inc., Retrieved 9/15, 2012 (http://www.florida-demographics.com).

Fox Piven, Frances. 2002. Work, Welfare, and Politics: Confronting Poverty in the Wake of Welfare Reform. Eugene, OR: University of Oregon Press.

FP Magazine. 2010. The Global Cities Index 2010. Washington, DC: Foreign Policy Magazine, AT Kearney and Chicago Council on Foreign Affairs. Retrieved 9/15/2012.

Giddens, Anthony. 2001. Sociology. 4th Edition ed. Oxford, UK: Polity Press and Blackwell Publishers.

Gittell, Ross and Avis Vidal. 1998. Community Organizing: Building Social Capital as a Development Strategy. Newbury Park, CA: Sage Publications.

Glyn, Andrew. 2006. Capitalism Unleashed. New York: Oxford University Press.

Goode, Judith and Jeff Maskovsky. 2001. The New Poverty Studies: The Ethnography of Power, Politics, and Impoverished People in the United States. New York, NY: New York University Press.

Granovetter, Mark S. 1973. "The strength of weak ties." American Journal of Sociology 78(6):1360-1380.

Grunberg, Jeffrey. 1998. "Homelessness as a Lifestyle." Journal of Social Distress and the Homeless 7(4):241-261.

Harper, Douglas. 1989a. "Interpretive Ethnography: From "Authentic Voice" to "Interpretive Eye"." Visual Sociology Review 4(2 (Special Issue)):33-42.

-----. 1989b. "Visual Sociology: Expanding Sociological Vision." Pp. 81-97 in New Technology in Sociology: Practical Applications in Research and Work, edited by G. Blank, J.L. McCartney and E. Brent. New Brunswick, NJ: Transaction Publishers. 
Hartman, David W. 2000. "Policy implications from the study of the homeless." Sociological Practice: A Journal of Clinical and Applied Sociology 2(2):57-76.

Hartwell, Stephanie. 2003. "Deviance over the life course: The case of homeless substance abusers." Substance use \& Misuse 38(3-6):475-502.

Harvey, David. 2005. A Brief History of Neoliberalism. New York: Oxford University Press.

Haskins, Linda. 2004. City of Miami Consolidated Plan 2004-2008. Miami, FL: City of Miami Department of Community Development.

Hawkins, Robert L. and Courtney Abrams. 2007. "Disappearing acts: The social networks of formerly homeless individuals with co-occurring disorders." Social Science \& Medicine 65(10):2031-2042.

Herbert, Steve and Elizabeth Brown. 2006. "Conceptions of Space and Crime in the Neoliberal Punitive City." Antidope 38(4):755-777.

Hopper, Kim. 2003. Reckoning With Homelessness. New York: Cornell University Press.

Howell, Shirley. 2007. "Please Don't Feed the Homeless: Pottinger Revisted." Modern American, Spring 2007, pp. 15.

HurricaneCity. 2012. "Hurricane Andrew Statistics." Hurricane City, Retrieved 9/15, 2012 (http://www.hurricanecity.com/andrew.htm).

Irwin, Jay, Mark LaGory, Ferris Ritchey and Kevin Fitzpatrick. 2008. "Social assets and mental distress among the homeless: Exploring the roles of social support and other forms of social capital on depression." Social Science \& Medicine 67(12):1935-1943.

Kasarda, John D. 1993. "Urban Industrial Transition and the Underclass." Pp. 43-64 in The Ghetto Underclass: Social Science Perspectives, edited by W.J. Wilson. Newbury Park, CA: Sage Publications.

Kendrick, Dennis P. 2001. "The Community Partnership for Homeless: A Narrated History by Alvah H. Chapman, Jr.".

Koegel, Paul M. 2004. "Causes of Homelessness: Overview." Pp. 50-58 in Encyclopedia of Homelessness, edited by D. Levinson. Thousand Oaks, CA: Sage Publications.

Koegel, Paul M., A. Burnam and Jim Baumohl. 1996. "The Causes of Homelessness." Pp. 24-33 in Homelessness in America, edited by J. Baumohl. Phoenix, AZ: The Oryx Press. 
Lackner, Catherine. 2010. "No Free Lunch: Miami to Vote on Licensing Feeding of Homeless." Miami Today, February 24, 2010, . Retrieved August 18, 2012 http://www.miamitodaynews.com/news/100225/story5.shtml.

Larson, Christina. 2010. "Swoons Over Miami." Foreign Policy Magazine, Aug 27, 2010 .

Lee, Barrett A., Townsand Price-Spratlen and James W. Kanan. 2003. "Determinants of homelessness in metropolitan areas." Journal of Urban Affairs 25(3):335-355.

Lefebvre, Henri. 1971. The Production of Space. English Translation, 1991 ed. Maiden, MA: Blackwell Publishers, Inc.

Liebow, Elliot. 1993. Tell Them Who I Am: The Lives of Homeless Women. New York, NY: Penguin Books.

Lin, Nan, Walter M. Ensel and John C. Vaughn. 1981. "Social Resources and Strength of Ties: Structural Factors in Occupational Status Attainment." American Sociological Review 46(4):393-405.

Lockhart, William H. 2005. "Building bridges and bonds: generating social capital in secular and faith-based poverty-to-work programs." Sociology of Religion 66(1):45(16).

Loury, Glenn C. 1977. "A dynamic theory of racial income differences." Pp. 153-186 in Women, Minorities, and Employment Discrimination, edited by P.A. Wallace and A. La Mond. Lexington, MA: Heath.

Lyon-Callo, Vincent. 2004. Inequality, Poverty, and Neoliberal Governance: Activisit Ethnography in the Homeless Sheltering Industry. Toronto, CA: Broadview.

Malson, Michelene. 1983. "The Social-Support Systems of Black Families." Pp. 37-57 in The Ties that Bind: Men's and Women's Social Networks, edited by L. Lein and M.B. Sussman. New York, NY: Haworth Press.

Marr, Matthew. 2012. "Pathways out of homelessness in Los Angeles and Tokyo: The multilevel contexts of limited mobility amid urban marginality." International Journal of Urban and Regional Research 36(5):980-1006.

------. 2010. "More Than a Solo Act: Organizational Contexts, Trust, and Affective Aid in Transitional Housing Programs, Los Angeles and Tokyo.".

Marx, Karl. 1976. Capital: Volume 1: A Critique of the Political Economy. New York, NY: Penguin Books, in association with New Left Review. 
McChesney, Kay Y. 1990. "Family homelessness: A systemic problem." Journal of Social Issues 46(4):191-205.

Mensah, George. 2009. City of Miami Consolidated Plan 2009-2013. Miami, FL: City of Miami Department of Community Development. Retrieved

9/15/2012 http://www.ci.miami.fl.us/communitydevelopment/Docs/Reports/Consolid ated Plan FY2009-2013 version 1.0s UTO 9-22-2009.pd.

Miami Coalition for the Homeless. 1987. A Report on the Homeless. Miami, Florida: $\mathrm{MCH}$.

Miami-Dade County Homeless Trust. 2012a. "Homeles Trust Accomplishments." Miami, FL: Miami-Dade County, Retrieved September 12, 2012, 2012 (http://www.miamidade.gov/homeless/accomplishments.asp).

------. 2012b. Homelessness Management Information System Year 2011 Report for Miami-Dade County. Miami, FL: Miami-Dade County.

------. 2007. Ten-Year Plan to End Homelessness: Addendum to the Miami Homeless Plan. Miami, FL: Miami-Dade County.

Miami-Dade County Public Housing and Community Development. 2012. "Miamidade.gov Web Portal." Miami, FL: Miami-Dade County, Retrieved Aug 20, 2012 (http://www.miamidade.gov/housing/public-housing.asp).

Mitchell, Don. 2003. The Right to the City: Social Justice and the Fight for Public Space. New York: The Guilford Press.

-----. 1997. "The Annihilation of Space by Law: The Roots and Implications of AntiHomeless Laws in the United States." Antidope 29(3):303-335.

Molina-Jackson, Edna. 2008. Homeless Not Hopeless: The Survival Networks of Latino and African-American Men. Lanham, MD: University Press of America, Inc.

Morgen, Sandra and Jeff Maskovsky. 2003. "The Anthropology of Welfare "Reform": New Perspectives on U.S. Urban Poverty in the Post-Welfare Era." Annual Review of Anthropology 32:315-338.

Morrell-Bellai, Tammy, Paula N. Goering and Katherine M. Boydell. 2000. "Becoming and remaining homeless: a qualitative investigation." Issues in Mental Health Nursing 21(6):581-604.

Moser, Caroline O. N. 1998. "The asset vulnerability framework: reassessing urban poverty reduction strategies." World Development 26(1):1-19. 
National Alliance to End Homelessness. 2012. State of Homelessness in America for 2012. Washington DC: NAEH.

-----. 2011. Ten Essentials for Ending Homelessness. Washington DC: NAEH. Retrieved 08/01/2012 http://www.endhomelessness.org/pages/ten-essentials.

National Health Care for the Homeless Council. 2010. Homelessness and Health: What's the Connection? Washington DC: NHCHC.

-----. 2003. Social Supports for Homeless Mothers. Newton Centre, MA: National Center on Family Homelessness.

National Law Center on Poverty and Homelessness. 2012. Homeless and Poverty In America. Washington DC: NLCHP.

Nelson, Margaret K. 2000. "Single Mothers and Social Support: The Commitment to, and Retreat from, Reciprocity." Qualitative Sociology 23(3):294-317.

Newman, Katherine S. and Rebekah P. Massengill. 2006. "The Texture of Hardship: Qualitative Sociology of Poverty, 1995-2005." Annual Review of Sociology 32(1):423-446.

O'Connell, James, S. Mattison, C. M. Judge, J. S. Allen and H. K. Kohn. 2005. "A public health approach to reducing morbity and mortality among homeless people in Boston." Journal of Public Health Management Practice 11(4):311-316.

Olorunnipa, Toluse. 2012. "Getting an Unemployment Check in Florida is Frustrating Ordeal for Many

Read More here: Http://www.Miamiherald.com/2012/08/21/2962090_p2/getting-anUnemployment-Check.html\#storylink=cpy." Miami Herald, Aug 21, 2012, . Retrieved 9/15/2012 http://www.miamiherald.com/2012/08/21/2962090_p2/gettingan-unemployment-check.html.

Opurum, Chinonso and Emily Eisenhauer. 2009. Does Florida's Labor Market Create Opportunity for All? Historical Labor Force Statistics by Race and Ethnicity, 19782008. Miami, FL: Florida International University, Center for Labor and Research Studies.

O'Toole, T. P., A. Conde-Martel, J. L. Gibbon, B. H. Hanusa, P. J. Freyder and M. J. Fine. 2007. "Where do people go when they first become homeless? " Health and Social Care in the Community 15:446-453.

Padgett, Tim. 2006. "Letter from Miami: There's Trouble - Lot's of it - in Paradise." Time Magazine, Nov 19, 2006, . 
Penucci, Annie. 2009. General Assistance Programs for Unemployable Adults. Olympia, WA: Washington State Institute for Public Policy.

Pippert, Timothy D. 2007. Road Dogs and Loners: Family Relationships Among Homeless Men. Lanham, MD: Lexington Boks.

Portes, Alejandro. 1998. "Social capital: Its origins and applications in modern sociology." Annual Review of Sociology 24(1):1-24.

Portes, Alejandro and Alex Stepick. 1993. City on the Edge: The Transformation of Miami. Berkeley and Los Angeles, CA: University of California Press.

Portes, Alejandro and Min Zhou. 1992. "Gaining the upper hand: Economic mobility among immigrant and domestic minorities." Ethnic and Racial Studies 15(4):491523.

Prosser, Jon and Dona Scwartz. 1998. "Photographs within the Sociological Research Process." Pp. 121-130 in Image-Based Research: A Sourcebook for Qualitative Researchers, edited by J. Prosser. London, United Kingdom: Falmer Press.

Putnam, Robert A. 2000. Bowling Alone: The Collapse and Revival of American Community. New York, NY: Simon \& Schuster.

Ravenhill, Megan. 2008. The Culture of Homelessness. Burlington, VT: Ashgate Publishing Company.

Roschelle, Anne. 1997. No More Kin: Exploring Race, Class, and Gender in Family Networks. Thousand Oaks, CA: Sage Publications.

Rosenheck, Robert A., Ellen L. Bassuk and Amy Salomon. 1998. "Special Populations of Homeless Americans." Proceedings of the National Symposium on Homelessness Research.

Rosenheck, Robert, Joseph Morrissey, Julie Lam, Michael Calloway, Marilyn Stolar, Matthew Johnsen, Frances Randolph, Margaret Blasinsky and Howard Goldman. 2001. "Service delivery and community: Social capital, service systems integration, and outcomes among homeless persons with severe mental illness." Health Services Research 36(4):691.

Rossi, Peter. 1989. Down and Out in America: The Origins of Homelessness. Chicago, IL: University of Chicago Press.

Roth, Daniel S. 2012. "SOS from Little Havana Residents." Miami Herald, May 30, 2012, Opinion Columnists. 
Ruggles, Steven, Matthew Sobek, Trent Alexander, Catherine Fitch, Ronald Goeken, Patricia K. Hall, Miriam King and Chad Ronnander. 2007. US Census Datal American Communities Survey 2005. Minneapolis, MN: Minnesota Population Center [producer and distributor] Available: Integrated Public Use Microdata Series: Version 3.0. [Machine-readable database].

Saergert, Susan, J. P. Thompson and Mark R. Warren, eds. 2001. Social Capital and Poor Communities. New York, NY: The Russell Sage Foundation.

Sampson, Robert. 2008. "Moving to Inequality: Neighborhood Effects and Experiments Meet Social Structure." American Journal of Sociology 114(1):189-231.

Sassen, Saskia. 2006. Territory, Authority and Rights: From Medieval to Global Assemblages. New Jersey: Princeton University Press.

Sassen, Saskia and Alejandro Portes. 1993. "Miami: A New Global City?" Contemporary Sociology 22(4):471-477.

Severe, LeTania. 2012. Miami-Dade County Annual Point-in-Time Census 2012. Miami, FL: Miami-Dade County Homeless Trust.

Shinn, Marybeth, Jim Baumohl and Kim Hopper. 2001. "The Prevention of Homelessness Revisited." Analysis of Social Issues and Public Policy 1(1):95-127.

Shinn, Marybeth, James Knickman and Beth C. Weitzman. 1991. "Social relationships and vulnerability to becoming homeless among poor families." American Psychologist 46(11):1180-1187.

Sklair, Leslie. 2001. The Transnational Capitalist Class. Malden, MA: Blackwell Publishing.

Skocpol, Theda. 2003. Diminishing Democracy: From Membership to Management in American Civic Life. University of Oklahoma Press.

Small, Mario L. 2009. Unanticipated Gains: Origins of Network Inequality in Everyday Life. New York, NY: Oxford University Press.

Small, Mario L., Erin M. Jacobs and Rebekah P. Massengill. 2008. "Why organizational ties matter for neighborhood effects: Resource access through childcare centers." Social Forces 87(1):387-414.

Smith, Neil. 1996. The New Urban Frontier: Gentrification and the Revanchist City. New York: Routledge. 
Smith, Sandra S. 2007. Lone Pursuit: Distrust and Defensive Individualism Among the Black Poor. New York, NY: Russell Sage Foundation.

------. 2005. "Don't put my name on it: Social Capital activation and job-finding assistance among the black urban poor." American Journal of Sociology 111(1):1-57.

Snow, David A. and Leon Anderson. 1993. Down On Their Luck: A Study of Homeless Street People. Berkeley and Los Angeles, CA: University of California Press.

------. 1987. "Identity work among the homeless: The verbal construction and avowal of personal identities." American Journal of Sociology 92(6):1336-1371.

Social Security Administration. 2012a. Hearing Office Average Processing Time Ranking Report FY 2012. Washington DC: Social Security Online. Retrieved October 1, 2012 http://www.ssa.gov/appeals/DataSets/05 Average Processing Time Report.ht $\underline{\mathrm{ml}}$.

------. 2012b. Understanding Supplemental Security Income SSI Benefits. Washington DC: Social Security Online. Retrieved August 1, 2012 http://www.socialsecurity.gov/ssi/text-benefits-ussi.htm.

Sosin, Michael, Paul Colson and Susan Grossman. 1988. Homelessness in Chicago: Poverty and pathology, social institutions and social change. Chicago, IL: Chicago University - Chicago Community Trust.

Sosin, Michael and Susan Grossman. 2003. "The individual and beyond: A socio-rational choice model of service participation among homeless adults with substance abuse problems." Substance use \& Misuse 38(3-6):503-549.

SSDFacts. 2012. Social Security Disability Facts: Florida Determinations for Period 9/24/11 - 7/27/12.SSDFacts.com.

Stack, Carol. 1974. All Our Kin. BasicBooks.

Stainbrook, Kristin and John Hornik. 2006. "Similarities in the characteristics and needs of women with children in homeless family and domestic violence shelters." Families in Society: The Journal of Contemporary Social Services 87(1):53-62.

Stepick, Alex, Grenier Guillermo, Max Castro and Marvin Dunn. 2003. This Land is Our Land: Immigrants and Power in Miami. Los Angeles, CA: University of California Press.

Substance Abuse and Mental Health Services Administration. 2012. "SSI/SSDI Outreach, Access and Recovery for People Who are Homeless." Bethesda, MD: SAMHSA 
SOAR Technical Assistance Center, Retrieved 09/02, 2012

(http://www.prainc.com/soar/).

Susser, Ida. 1996. "The Construction of Poverty and Homelessness in US Cities." Annual Review of Anthropology 25:411-435.

Timmer, Doug, D., Stanley Eitzen and Kathryn Talley. 1994. Paths to Homelessness: Extreme Poverty and the Urban Housing Crisis. Boulder, CO: Westview Press.

Toohey, Siobhan M., Marybeth Shinn and Beth C. Weitzman. 2004. "Social networks and homelessness among women heads of household." 33(1-2):7-20.

Tsemberis, Sam, Leyla Gulcur and Maria Nakae. 2004. "Housing First, consumer choice, and harm reduction for homeless individuals with a dual diagnosis." American Journal of Public Health 94(4):651-656.

Tyler, Kimberly A. and Katherine A. Johnson. 2006. "Pathways In and Out of Substance Use among Homeless-Emerging Adults." Journal of Adolescent Research 21(2):133157.

US Census Bureau. 2012. American Community Survey 2010 Miami, FL Quick Facts. Washington, DC: US Dept of Commerce.

Wacquant, Loïc J. D. 2009. Punishing the Poor: The Neoliberal Government of Social Insecurity. English language ed. Durham, NC: Duke University Press.

------. 2008. Urban Outcasts: A Comparative Sociology of Advanced Marginality. Malden, MA: Polity Press.

Wacquant, Loïc J. D. and William J. Wilson. 1989. "The Cost of Racial and Class Exclusion in the Inner City." Annals of the American Academy of Political and Social Science 501(Special Issue, The Ghetto Underclass: Social Science Perspectives):8-25.

Wakin, Michele. 2008. "Using Vehicles to Challenge Antisleeping Ordinances." City \& Community 7(4):309-329.

Wall, Daniel. 2010. Miami-Dade County Criminal Justice, Mental Health and Substance Abuse Reinvestment Grant Project. Miami, FL: Miami-Dade County Corrections and Rehabilitation Department and the Eleventh Judicial Circuit of Florida.

Wang, Caroline and Mary A. Burris. 1994. "Empowerment through Photo Novella: Portraits of Participation ." Health Education and Behavior 21(2):171-186.

Wilson, William J. 1996. When Work Disappears. New York, NY: Alfred A. Knopf, Inc. 
Wolch, Jennifer and Michael Dear. 1993. Malign Neglect: Homelessness in an American City. San Francisco, CA: Jossey-Boss.

Wood, David, R. B. Valdez, Toshi Hayashi and Albert Shen. 1990. "Homeless and housed families in Los Angeles: a study comparing demographic, economic, and family function characteristics." American Journal of Public Health 80(9):1049-1052.

Woolcock, Michael. 2001. "The place of social capital in understanding social and economic outcomes." ISUMA Canadian Journal of Policy Research 2(1):11-17.

Wright, James D. 2009. Address Unknown: The Homeless In America. Transaction Edition ed. New Brunswick, NJ: Transaction Publishers.

-----. 1990. "Poor people, poor health: The health status of the homeless." Journal of Social Issues 46(4):49-64.

Wright, James D. and Joel A. Devine. 1993. The Greatest of Evils: Urban Poverty and the American Underclass. Aldine Transaction.

Wright, James D., Beth A. Rubin and Joel A. Devine. 1998. Beside the Golden Door: Policy, Politics, and the Homeless. New York: Walter de Gruyter, Inc.

Wright, Talmadge. 1997. Out of Place: Homeless Mobilizations, Subcities, and Contested Landscapes. Albany, NY: State University of New York Press.

Wright, Susan E. 1993. "Presidential Address: Blaming the victim, blaming society or blaming the discipline: Fixing responsibility for poverty and homelessness." The Sociological Quarterly 34(1):1-16.

Zlotnick, Cheryl, Tammy Tam and Marjorie J. Robertson. 2003. "Disaffiliation, Substance Use, and Exiting Homelessness." Substance use \& Misuse 38(3-6):577599.

Zlotnick, Cheryl and Suzanne Zerger. 2008. "Survey findings on characteristics and health status of clients treated by the federally funded (US) Health Care for the Homeless Programs." Health and Social Care in the Community 17(1):18-26.

Zugazaga, Carole B. 2008. "Understanding social support of the homeless: A comparison of single men, single women, and women with children." Families in Society: The Journal of Contemporary Social Services 89(3):447-455. 


\section{APPENDICES}

1. Semi-Structured Interview Instrument 


\section{SEMI-STRUCTURED INTERVIEW FORM}

Tell me a little bit about your life right now?

What kinds of things do you do during a normal day?

What kinds of things do you need to do to make end meets?

When did your life change? When did you leave home?

What was your childhood like?

What do you think is the most difficult thing in your life right now?

What do you think is different about your life than people on the "outside," who have more money and less problems, think about your life?

What is it like for you trying to get a good job?

What is like for you trying to find good housing?

What do you think causes homelessness?

What do you think could prevent homelessness?

Do believe there is any difference between blacks and Hispanics when it comes to becoming homeless? What about resources for leaving homelessness?

RACE AND ETHNICITY (ANSWER ALL THREE)

Race $\square$ Asian $\square$ Black $\square$ White/Caucasian $\square$ Other:

Ethnicity/Hispanic: $\quad \square$ Hispanic $\square$ NonHispanic

Country of Origin: $\quad \square$ USA $\square$ Cuba $\square$ Haiti $\square$ Other:

\section{LIVING SITUATION}

Current Zip Code/Neighborhood (if not homeless)

Last Zip Code/ Neighborhood (if homeless):

Where do you currently live? $\square \square$ Homeless $\square$ Program $\square \square$ Own place $\quad \square$ Friend/Family

\section{DURATION OF HOMELESSNESS}

If CURRENTLY homeless (living on the street or in an emergency shelter): .

1. How long have you been continually homeless during this current episode?

$\square 1$ mos or less $\square 1 \mathrm{mos}-1$ yr $\quad \square 1 \mathrm{yr}$ or more (indicate \# of yrs: 
2. How many times have you been homeless in the past three years?

If NOT HOMELESS, but living in a treatment, transitional, or permanent program:

3. How long were you homeless (street/in shelter) BEFORE you entered this program?

4. How long have you been in this program?

If PREVIOUSLY HOMELESS, but no longer in any program:

5. How long were you homeless and living on the street?

6. How did you exit homelessness?

\section{DIFFICULTIES IN BACKGROUND}

$\square$ Veteran

Discharge status:

$\square$ Been in Foster Care

$\square$ Victim of partner or domestic violence

$\square \quad$ Criminal History

\section{DISABILITIES}

Ever had a substance abuse problem?

Ever been diagnosed with a mental illness?

Any physical or medical disabilities?

\section{EDUCATION}

Highest level completed:

Where:

\section{GENERL SOCIAL CONTACT}

With whom do you spend most of your free time?

$\square$ Family $\square$ Friends $\square$ Alone $\square$ Other:

Do you wish this were different?

FAMILY

\begin{tabular}{|l|l|l|l|l|l|l|}
\hline Member & $\begin{array}{l}\text { Long, } \\
\text { close rel }\end{array}$ & $\begin{array}{l}\text { Last 30 } \\
\text { days }\end{array}$ & $\begin{array}{l}\text { How } \\
\text { often see }\end{array}$ & Income & Alcohol/ Drugs & Problems? \\
\hline Mother & & & & & & \\
\hline Father & & & & & & \\
\hline Sibling & & & & & & \\
\hline Partner & & & & & & \\
\hline Children & & & & & & \\
\hline Other & & & & & & \\
\hline
\end{tabular}


If no to above, why not?

\section{SUPPORT FROM FAMILY}

\begin{tabular}{|l|l|l|l|l|}
\hline Type & Ever & Last 30 & Scale 1-10, could ask now? & Why not? \\
\hline Cash & & & & \\
\hline Place to stay & & & & \\
\hline Food & & & & \\
\hline Emotional & & & & \\
\hline
\end{tabular}

FRIENDS

How many friends would say have who are:

$\square$ Close friends \#:

$\square$ Acquaintances: \#

What is their situation like:

Where do they live?

Drug/alcohol problems?

Income?

\section{SUPPORT FROM FRIENDS}

\begin{tabular}{|l|l|l|l|l|}
\hline Type & Ever & Last 30 & Scale 1-10, could ask? & Why not? \\
\hline Cash & & & & \\
\hline Place to stay & & & & \\
\hline Food & & & & \\
\hline Emotional & & & & \\
\hline Other & & & & \\
\hline
\end{tabular}

OTHER PRIVATE ASSISTANCE

Have you ever received help from:

$\square$ Faith/based organization/ Church:

$\square$ Non-profit organization:

Direct assistance (food, clothing, temporary cash assistance)

Enrollment in a program: Type

How long:

If no, have you ever tried?

If yes, on scale of 1-10, how helpful was it?

Did you have a relationship with a staff member?

On scale of 1-10, how helpful was that relationship? Why?

\section{EARNED INCOME}

Do you receive any earned income from:

$\square$ Job: $\quad \mathrm{F} / \mathrm{T}$ or $\mathrm{P} / \mathrm{T}$ :

Wage:

$\square$ Pension

. Underground work: 
VITA

KAREN M. MAHAR

Born, Rochester, New York

1988-1991

B.S.C., Motion Picture Production

Magna Cum Laude; Departmental Honors

University of Miami

Miami, Florida

1994-2007

Communications Manager; Grants Manager; Director of

Planning

Camillus House, Inc.

Miami, Florida

$2001-2003$

Fellow with Miami Fellows Initiative

John S. \& James L. Knight Foundation

Miami, Florida

2007-present

Chief Operating Officer, Institute of Homelessness Studies Camillus House, Inc.

Miami, Florida

2006-2008

M.A., Comparative Sociology

Florida International University

Miami, Florida

2008-present

Vice President of Strategy Management

Camillus House, Inc.

Miami, Florida

2009

Accredited Professional

Leadership in Energy \& Environmental Design

U.S. Green Building Council

$2011-2012$

Doctoral Candidate

Florida International University

Miami, Florida

\section{PUBLICATIONS AND PRESENTATIONS}

Mahar, Karen. 2011 "Financial barriers drive key design improvements for Miami Center’s New Campus.” May 26, 2011, Behavioral Healthcare Magazine. 
Mahar, Karen. 2009. "I just need help: The impact of public policy on surviving extreme poverty." Paper presented at the Society for Study of Social Problems Annual Meeting, August 2009, San Francisco, CA.

Mahar, Karen. 2009. "At the margins: Avoiding homelessness in Miami-Dade.” Paper presentation at American Sociological Association (ASA) Annual Meeting, August 2009, San Francisco, CA.

Mahar, Karen. 2009. "I just need some help: Discourses of extreme poverty." Paper and documentary project presented at Lumpen-City: Discourse of Marginality Conference at York University, March 2009, Toronto, Canada.

Mahar, Karen. 2008. "Not just a paycheck away: Race, ethnicity, and the role of social capital in poverty and homelessness in Miami." Paper presented at Race, Ethnicity and Place IV Conference at University of Miami, November 2008, Miami, FL.

Mahar, Karen. 2008. "Homelessness, poverty, and race." Paper presented at Society for the Study of Social Problems National Conference, July 2008, Boston, MA.

Mahar, Karen. 2008. "The intersection of race, homelessness, and poverty." Paper presented at Camillus House $2^{\text {nd }}$ Annual Institute of Homeless Studies Symposium, February 2008, Miami, FL.

Mahar, Karen. 2007. "Homelessness in Miami: A manifestation of racial/ethnic disparities." Paper presented at American Anthropological Association Annual Meeting, December 2007, Washington, DC.

Mahar, Karen. 2005. "Before you write: A guide to designing programs that grant makers want to fund." Workshop presentation at University of Miami, Center for Nonprofit Management, September 2005, Coral Gables, FL.

Mahar, Karen. 2003. "Men's health: Exploring the inequalities." Paper presentation at W.K. Kellogg Foundation's Community Voices Conference, April 2003, Kiawah Island, SC. 